WOLFGANG MEIXNER

\title{
ZUR ENTSTEHUNG DES
}

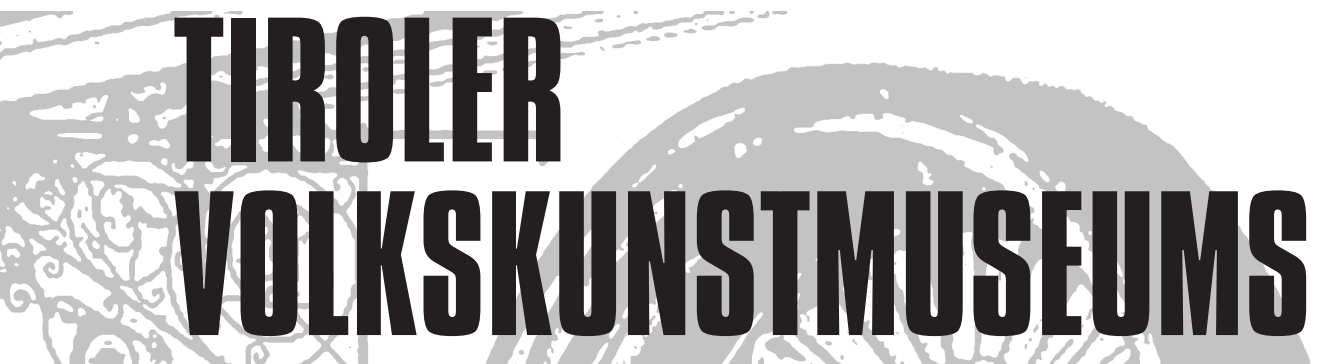

ININMSBRULEK

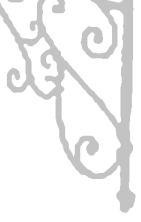

TIROLER

YOLKSKUNST MUSEUM
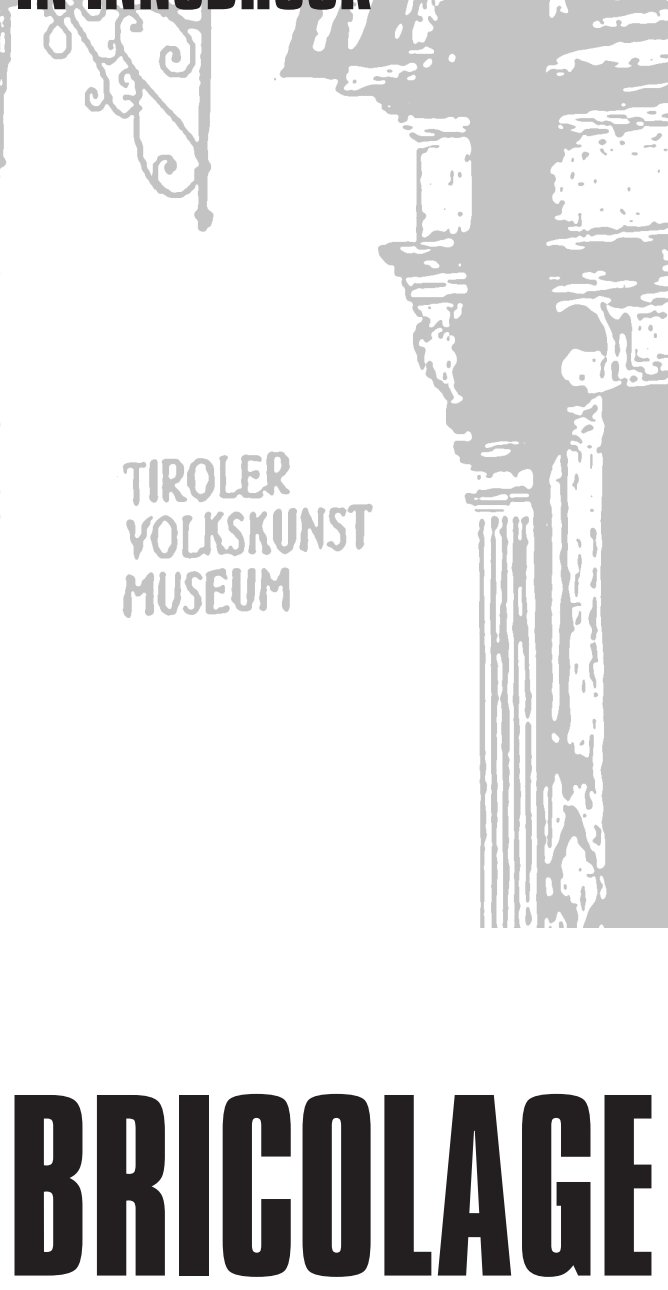


\section{SERIES}

bricolage monografien

Innsbrucker Studien zur Europäischen Ethnologie

Herausgegeben von Timo Heimerdinger, Jan Hinrichsen, Konrad J. Kuhn, Silke Meyer, Oliwia Murawska, Stephanie Schmidt und Ingo Schneider

Band 4 


\section{Wolfgang Meixner}

Institut für Geschichtswissenschaften und Europäische Ethnologie

Diese Publikation wurde mit finanzieller Unterstützung des Vizerektorats für Forschung der Universität Innsbruck, des Dekanats der Historisch-Philosophischen Fakultät der Universität Innsbruck, des Vereins „Freundeskreis des Tiroler Volkskunstmuseums" und des Forschungsprojekts "Tiroler Trachtenpraxis im 20. und 21. Jahrhundert" (Land Tirol, Abteilung Kultur) gedruckt.

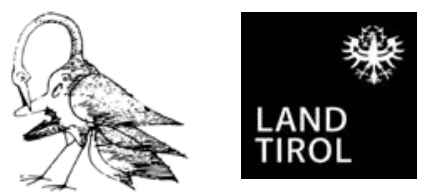

(C) innsbruck university press, 2020

Universität Innsbruck

1. Auflage

Alle Rechte vorbehalten.

Layout: Carmen Drolshagen

www.uibk.ac.at

ISBN 978-3-99106-018-5 


\title{
bricolage monografien
}

Innsbrucker Studien zur Europäischen Ethnologie

\author{
Band 4
}

Wolfgang Meixner

\section{Zur Entstehung des \\ Tiroler Volkskunstmuseums in Innsbruck}

Herausgegeben von

Karl C. Berger, Reinhard Bodner und Timo Heimerdinger 



\section{Inhalt}

7

Geleitworte

Herlinde Keuschnigg

9

Editorische Notiz

Reinhard Bodner und Timo Heimerdinger

13 Vorbemerkungen. „Zur Entstehung des ,Tiroler Volkskunstmuseums in Innsbruck aus gewerbe- und fremdenverkehrsfördernden sowie heimatschützerischen Intentionen “- 1989/2020 Wolfgang Meixner

31

Zur Entstehung des „Tiroler Volkskunstmuseums“ aus gewerbeund fremdenverkehrsfördernden sowie heimatschützerischen Intentionen (1989)

Wolfgang Meixner

251

Anhang Abbildungen

263 Neu aufstellen. Über das Volkskunstmuseum seit 2008

Karl C. Berger 



\section{Geleitworte}

1989 hat Wolfgang Meixner seine Diplomarbeit „Zur Entstehung des ,Tiroler Volkskunstmuseums' in Innsbruck aus gewerbe- und fremdenverkehrsfördernden sowie heimatschützerischen Intentionen" fertig gestellt. Seine akribische Arbeit berücksichtigte die Frühphase des Museums: 1888, anlässlich des 40-jährigen Regierungsjubiläums von Kaiser Franz Josef I., beschloss der Tiroler Gewerbeverein ein Gewerbemuseum zur „Hebung und Förderung des Gewerbewesens in Tirol“ zu gründen. In diesem Museum sollten mustergültige Erzeugnisse aus alter und neuer Zeit präsentiert werden. Weil Tirol schon im 19. Jahrhundert zu einem wichtigen Land des Antiquitätenhandels geworden war, wurde die Sammlung um Objekte des „alttirolischen Kunstgewerbes“ erweitert. 1903 ging das „Museum für Volkskunst und Gewerbe“ in das Eigentum der Handelskammer über. Besondere Verdienste um das Museum erwarb sich der Handelskammersekretär Anton Kofler (1855-1943). Kofler gründete auch den Landesverband für Fremdenverkehr, den Vorläufer der Tirol-Werbung, und wollte das Museum mit dem Fremdenverkehr verbunden wissen. 1926 übernahm das Land Tirol das Museum, 1929 wurde es als Tiroler Volkskunstmuseum im großzügig umgebauten „Theresianum“ in der Innsbrucker Universitätsstraße schließlich eröffnet. Damit war das Museum die erste kulturelle Institution, die im Eigentum des Landes stand. Es ist deshalb nicht verwunderlich, dass seine Eröffnung auch eine politische Willensbekundung war: Im Volkskunstmuseum sollte - zehn Jahre, nachdem der südliche Landesteil zu Italien gekommen war - ein noch ungeteiltes Tirol gezeigt werden. Zehn Jahre später etablierte sich im Museum die NS-Frauenschaft mit der „Mittelstelle Deutsche Tracht“. Nach der Wiedereröffnung 1948 wurde das Museum als „Schatzkammer des Tiroler Volkes“ neuerlich zu einem Ort der Identität Tirols.

Im Laufe seiner Geschichte hat das Tiroler Volkskunstmuseum ganz unterschiedliche, manchmal sogar widersprüchliche und auch problematische Aufgaben zu erfüllen gehabt. Manche dieser Entwicklungen wirken bis heute nach, wie das Projekt „Tiroler Trachtenpraxis im 20. und 21. Jahrhundert“ im Hinblick auf den Nationalsozialismus zeigt. Es ist deshalb für den Verein „Freundeskreis Tiroler Volkskunstmuseum" eine besondere Freude, dass die Veröffentlichung der überarbeiteten Diplomarbeit von Wolfgang Meixner finanziell gefördert werden kann.

Seit seiner Gründung 1990 hat der Verein „Freundeskreis Tiroler Volkskunstmuseum“ stets die Belange des Museums unterstützt. Es wurden nicht nur zahlreiche Objekte für das Museum erworben, sondern auch die ersten museumspädagogischen Aktionen finanziert - zu einer Zeit, als manche Museen noch glaubten, ohne dem auskommen zu können. 1998 wurde die Ausstellung „Der Vogel Selbsterkenntnis. Aktuelle Künstlerpositionen und Volkskunst“ mit und 
über den Freundeskreis organisiert und finanziert. Diese Ausstellung war etwas Besonderes, hat viel Neues und viel frischen Wind in das Museum gebracht. Das Museum wurde zu einem kulturellen Begegnungsraum, zu einem Ort der Diskussion und des Gesprächs.

Das vorliegende Werk kann anlässlich der 30-Jahr-Feier des Vereins „Freundeskreis Tiroler Volkskunstmuseum " präsentiert werden. Ich danke dem Autor Wolfgang Meixner und den Herausgebern Reinhard Bodner und Timo Heimerdinger, die die Verbindung zu unserem Verein geknüpft haben, für diese Möglichkeit. Ein Dank gilt auch dem Leiter des Tiroler Volkskunstmuseums, Karl C. Berger, sowie seinem Team. Ein besonderer Dank gilt meinen Kolleginnen und Kollegen im Vorstand sowie den Beiräten, die den Beschluss für die finanzielle Unterstützung dieser Publikation einstimmig gefasst haben.

Innsbruck, im Juni 2020

Herlinde Keuschnigg, Obfrau Freundeskreis Tiroler Volkskunstmuseum 


\section{Editorische Notiz}

Als Band vier der Reihe „bricolage monografien“ erscheint 2020 die Diplomarbeit „Zur Entstehung des 'Tiroler Volkskunstmuseums' in Innsbruck aus gewerbeund fremdenverkehrsfördernden sowie heimatschützerischen Intentionen " von Wolfgang Meixner. 1989 am damaligen Institut für Volkskunde der Universität Innsbruck entstanden, wurde der Text lediglich formal und sprachlich korrigiert, blieb aber inhaltlich im Wesentlichen unverändert. Allerdings verfasste der Autor ein zusätzliches einleitendes Kapitel aus heutiger Perspektive, und Karl C. Berger - seit 2014 Leiter des Museums - steuerte einen das Buch abrundenden Text zur jüngsten Entwicklung des Hauses seit seiner Neuaufstellung 2008 bei.

Der zeitliche Abstand von 30 Jahren zwischen Abfassung der Studie und Druckpublikation ist ungewöhnlich und bedarf daher einer kurzen Erläuterung. Die Idee, die Arbeit, die bis heute den einzigen eingehenden Beitrag zur Museumsgeschichte darstellt, nun durch die Publikation besser zugänglich und sichtbar zu machen, entstand im Kontext der Arbeiten an dem 2014-2019 vom Land Tirol geförderten und in Kooperation zwischen Universität Innsbruck und den Tiroler Landesmuseen, Bereich Tiroler Volkskunstmuseum, durchgeführten Forschungsprojekt „Tiroler Trachtenpraxis im 20. und 21. Jahrhundert“. Angestoßen durch eine Debatte über das Erinnern und Vergessen der Funktionalisierung so genannter Volkskultur in der NS-Zeit setzte sich das Projekt mit der Biografie Gertrud Pesendorfers (1895-1982) und ihrem Wirken in der Trachtenerneuerungsbewegung auseinander. Pesendorfer war in den Jahren 1927-1932 als Sekretärin am Volkskunstmuseum beschäftigt gewesen, das 1929 unter diesem Namen an seinem jetzigen Standort erstmals einer breiteren Öffentlichkeit zugänglich gemacht wurde. Gemeinsam mit Josef Ringler (1893-1973) - der 1928 Karl Moeser (1877-1963) als Museumsleiter ablöste - etablierte Pesendorfer das Museum nach 1929 auch als eine offizielle Trachtenberatungsstelle für Gemeinden Nordund Osttirols und deren Schützenkompanien und Musikkapellen bzw. vereinzelt auch für Trachten- und Schuhplattlervereine. Mitte der 1930er Jahre entwickelten Ringler und Pesendorfer - parallel zu Entwicklungen in anderen österreichischen Bundesländern - „neue Trachten“ für Tirol. An diese Entwürfe knüpfte Pesendorfer nach dem „Anschluss“ Österreichs an Hitlerdeutschland an, nachdem der nunmehrige kommissarische Leiter Moeser sie als Mitarbeiterin ans Museum zurückgeholt hatte. Als sie im September 1939 von Moeser die Geschäfte übernahm, war die ehemals „illegale“ Nationalsozialistin bereits „reichsweit“ in der „Trachtenarbeit“ tätig: Reichsfrauenführerin Gertrud Scholtz-Klink (1902-1999) hatte Pesendorfer Ende 1938 zur „Reichsbeauftragten für Trachtenarbeit“ ernannt und im Weiteren mit der Leitung einer am Volkskunstmuseum einzurichtenden 
„Mittelstelle Deutsche Tracht“ betraut. Deren (weitgehend weibliche) Mitarbeiterinnen führten in diversen Gauen des Deutschen Reichs Bestandsaufnahmen zur Kleidungsüberlieferung durch, um darauf basierend Trachtenerneuerung zu betreiben: ein Vorhaben, das im NS-Staat teils gefördert, teils abgelehnt wurde, in jedem Fall aber trotz einer Fortsetzung der Arbeiten bis ins Frühjahr 1945 Torso blieb.

Wolfgang Meixner legte in seiner Arbeit den Fokus auf die Entstehungsgeschichte des Museums seit 1888 und betont, dass er die Zeit seit den 1930er Jahren lediglich gerafft und chronologisch darstellen könne. Die „Mittelstelle“ sei erst noch eigens zu untersuchen, da dazu weder am Museum noch am Tiroler Landesarchiv einschlägiges Material zu bekommen gewesen sei. Gleichwohl bietet Meixners Kapitel über die Jahre 1938-1945 den bis heute einzigen einschlägigen Überblick auf Basis der damals greifbaren Unterlagen. Im Hinblick auf Pesendorfer, die 1945 wiederum durch Ringler abgelöst wurde, liefert Meixner zudem wichtige Hinweise auf die Fortsetzung ihrer Trachtenerneuerungen in Nachkriegsösterreich und ihre unkritische Rezeption bis in die 1980er Jahre hinein - und teilweise darüber hinaus, wie man aus heutiger Sicht hinzufügen kann. Für das „Trachtenpraxis“Projekt erwies sich Meixners Abschlussarbeit als wichtiges Grundlagenwerk. Die von 2004-2014 amtierende Museumsleiterin Herlinde Menardi, die das Projekt mitinitiiert hatte, wies auch medial auf die Bedeutung der Arbeit hin. Seit 1989 hatte diese freilich nicht nur im Hinblick auf spezifisch Innsbruck betreffende Fragestellungen eine ergiebige Studie dargestellt. Dass sie in einem für eine Diplomarbeit durchaus bemerkenswerten Ausmaß auch über die Stadtgrenzen hinaus rezipiert und zitiert wurde, bezeugen die deutlichen Gebrauchsspuren des in der Tiroler Universitäts- und Landesbibliothek vorhandenen Exemplars, das in den letzten 30 Jahren vielfältige Aus- und Fernleihvorgänge absolviert hat. Die Arbeit liefert so viele Informationen und Einblicke in die Geschichte des Tiroler Volkskunstmuseums, dass es uns ein Anliegen war, ihr durch die Publikation in der Reihe „bricolage monografien“ eine verbesserte Sichtbarkeit und auch künftige Zugänglichkeit zu verschaffen, nicht zuletzt durch die zeitgleich erfolgende Open Access-Bereitstellung des Druck-PDFs im digitalen Repositorium der Universität Innsbruck.

Gleichwohl gab es zunächst im Gespräch mit dem Autor auch ein Nachdenken darüber, ob und inwiefern dies heute tatsächlich der richtige Schritt sei, liegen doch umfangreiche wissenschaftliche, persönliche und auch institutionelle Entwicklungen zwischen dem Abfassungszeitpunkt und heute. Natürlich ist dem Text in Diktion und Ansatz weiterhin sein Entstehungszusammenhang als Studienabschlussarbeit am Ende der 1980er Jahre anzumerken. Wir denken: dies 
soll und kann auch ruhig so bleiben, und wir danken Wolfgang Meixner, dass er diese Auffassung teilt. Eine Aktualisierung oder Überarbeitung des Textes erschien uns weder sinnvoll noch angeraten, auch wenn manche Formulierung aus dem Abstand von rund 30 Jahren möglicherweise ein wenig anders gefasst werden würde. Wir möchten mit dieser Veröffentlichung die Studie als einen wichtigen Referenz- und Bezugspunkt der jüngeren Forschung markieren, sie zugleich für künftige Forschungsarbeiten besser zugänglich machen und nicht zuletzt auch als historisches Dokument würdigen, das eben keiner inhaltlichen Neubearbeitung bedarf.

In diesem Sinne haben wir uns lediglich für folgende editorische Schritte entschieden: Joachim Bürgschwentner hat unter Mitarbeit von Anna Larl das Manuskript durchgesehen, sprachliche und formale Mängel beseitigt sowie inhaltliche Unklarheiten so weit als möglich identifiziert und aufgelöst. Gritta Heimerdinger hat eine aktuelle grafische Umsetzung der Schaubilder besorgt und die neu eingefügten Scans bearbeitet. Auf der Basis dieser Vorarbeiten hat Wolfgang Meixner den Text an einzelnen Stellen korrigiert bzw. angepasst, allerdings ohne die inhaltliche oder argumentative Ausrichtung der Arbeit substanziell zu verändern. Stattdessen rekonstruiert der Autor in einem neuen, der Arbeit vorangestellten Zusatzkapitel die Genese, Methodik und theoretische Ausrichtung des Textes. Dabei geht er nicht nur auf den geringfügig erweiterten Forschungsstand zur Museumsgeschichte seit Ende der 1980er Jahre ein, sondern beschreibt auch das (alpinistisch gesprochen) „Ausapern“ neuer, durchaus umfangreicher Archivmaterialien im Museum im Zuge seiner Neuaufstellung 2008/2009, von dem er im Zuge dieses Publikationsprojekts Kenntnis erhielt. Insbesondere stammen diese Dokumente und Akten aus den 1930er Jahren und geben Einblicke in die Museumsgeschichte vor und nach dem „Anschluss“. Zwar führen diese Dokumente nicht dazu, dass die in Meixners Diplomarbeit skizzierten Entwicklungslinien des Museums korrigiert werden müssten. Weiteren Forschungen bieten sie aber die Möglichkeit, ein stellenweise empirisch dichteres Bild historischer Entwicklungen, Konflikte und Akteur*innen-Netzwerke zu zeichnen. Umso mehr kann die Neuherausgabe dieser Diplomarbeit hoffentlich auch einen Baustein liefern, der künftige Forschungen zur Museums- und Institutionengeschichte bereichert. Das Nachwort von Karl C. Berger gibt interessierten Leser*innen zudem einen Einblick in die Entwicklung des Museums seit seiner Neuaufstellung bzw. in den - wie Berger betont - stets unabgeschlossenen Prozess des „Neu Aufstellens".

Als Herausgeber danken wir Wolfgang Meixner herzlich für die sehr gute und kooperative Zusammenarbeit und Joachim Bürgschwentner und Anna Larl für ihren wesentlichen Beitrag dazu, dass das Buch nun in der jetzigen Form veröffentlicht werden kann. Karl C. Berger sei für seine Unterstützung des Projekts und 
sein informatives Nachwort gedankt. Für die großzügige finanzielle Förderung dieses Vorhabens danken wir dem Land Tirol, dem Vizerektorat für Forschung und der Philosophisch-Historischen Fakultät der Universität Innsbruck sowie dem Freundeskreis des Tiroler Volkskunstmuseums.

Innsbruck, im Juni 2020

Reinhard Bodner und Timo Heimerdinger 


\section{Vorbemerkungen}

\section{„Zur Entstehung des ,Tiroler Volkskunstmuseums” in Innsbruck, aus gewerbe- und fremdenverkehrs- fördernden sowie heimatschützerischen Inten- tionen" - 1989/2020}

Wenn eine Abschlussarbeit nach 30 Jahren inhaltlich nahezu unverändert veröffentlicht wird, so entsteht Erklärungsbedarf. Der Anstoß zur Veröffentlichung ist nicht von mir ausgegangen, obwohl es immer wieder Überlegungen gegeben hat, diese Diplomarbeit gedruckt zu publizieren, ${ }^{1}$ sondern von Proponenten des von Dr. Reinhard Bodner bearbeiteten Forschungsprojektes „Tiroler Trachtenpraxis im 20. und 21. Jahrhundert“ (2014-2019), Projektleiter*innen Univ.-Prof. Dr. Timo Heimerdinger, Institut für Geschichtswissenschaften und Europäische Ethnologie, Universität Innsbruck, Dr. Herlinde Menardi, Tiroler Volkskunstmuseum, Innsbruck, sowie Dr. Karl C. Berger, Leiter des Tiroler Volkskunstmuseums, Innsbruck, gefördert aus Mitteln des „Förderschwerpunkts Erinnerungskultur" der Abteilung Kultur des Landes Tirol. ${ }^{2}$ Herlinde Menardi hatte in einem Interview zur „Mittelstelle Deutsche Tracht“ 2013 auf meine Arbeit zum Tiroler Volkskunstmuseum hingewiesen und dass diese auch die Zeit von 1938 bis 1945 behandeln würde. ${ }^{3}$

Die Arbeit war in der zweiten Hälfte der 1980er Jahre am damaligen Institut für Volkskunde als Abschlussarbeit (Diplomarbeit) meines Diplomstudiums der Volkskunde/Europäische Ethnologie (Nebenfach: gewählte Fächer; Schwer-

1 Ein Aspekt der Diplomarbeit, der des „Heimatschutzes“, wurde veröffentlicht unter: Meixner, Wolfgang: Mythos Tirol. Zur Ethnizitätsbildung und Heimatschutzbewegung im 19. Jahrhundert. In: Geschichte und Region/Storia e regione, 1 (1992), 1, 88-106.

2 Zum Projekt Bodner, Reinhard: Ein tragbares Erbe? Trachtenerneuerung vor, in und nach der NS-Zeit. In: Beirat des Förderschwerpunktes Erinnerungskultur (Hg.): Vom Wert des Erinnerns. Wissenschaftliche Projekte der Förderperiode 2014 bis 2018 (= Veröffentlichungen des Tiroler Landesarchivs, Bd. 22). Innsbruck 2020, 99-134.

3 Sachen sind bekannt. In: Echo. Tirols 1. Nachrichtenillustrierte, 11 (2013), 35. In dem Interview spricht Menardi fälschlich von einer Dissertation und erwähnt nicht, dass etwa im Tiroler Landesarchiv befindliche Quellen zur NS-Zeit für mich damals nicht zugänglich, da gesperrt, waren. Vgl. dazu jetzt Hagen, Nikolaus: Kultur- und Identitätspolitik im Gau Tirol-Vorarlberg 1938-1945. Philosophische Dissertation, Innsbruck 2017. Hagen verwendet in seiner Dissertation meine Diplomarbeit zum Tiroler Volkskunstmuseum nicht und führt diese auch nicht in seiner Literaturliste an. 
punkt im 2. Studienabschnitt Sozial- und Wirtschaftsgeschichte) entstanden. ${ }^{4}$ Das Thema hatte ich gewählt, nachdem ich im Sommer 1984 ein mehrwöchiges Praktikum im Tiroler Volkskunstmuseum absolviert hatte. ${ }^{5}$ Aus den damals geführten Tagebuchaufzeichnungen meiner dortigen Arbeit lässt sich rekonstruieren, wie das Thema Gestalt angenommen hatte. Zunächst war geplant, eine „Magisterarbeit (Dissertation): Untersuchung von Motivationen, Herkunft, Interesse der Museumsbesucher" zu verfassen. Die Anregung dazu gab ein Mitarbeiter des Museums, der damals in der Bibliothek arbeitete und mit dem ich mich immer wieder fachlich austauschte. ${ }^{6}$ Ein Woche später erstellte ich dann ein „Konzept für ein Projekt (in Zusammenarbeit mit dem Tiroler Volkskunstmuseum): ,Erforschung der Besuchermotivation und der Besucherschichten des Museums “". Ich hatte darin vorgeschlagen, das Projekt als Studierendenprojekt auf mehrere Semester durchzuführen und drei zeitversetzte Besucher*innenbefragungen zu starten. Ziel meiner Überlegungen war es, durch die Auswertung der Besucher*innenfragebögen „Verbesserungsvorschläge [für das Volkskunstmuseum] zu erhalten und schlußendlich ein didaktisches Museumskonzept zu erstellen“" ${ }^{8}$ Nach dem Vorbild der „Tübinger Lernausstellungen“ schwebte mir

4 Das Diplomstudium beendete ich im März 1989. Betreuer der Diplomarbeit war o. Univ.-Prof. Dr. Leander Petzoldt (* 1934), ab 1985 bis zu seiner Emeritierung 2002 Nachfolger von o. Univ.-Prof. Dr. Karl Ilg (1913-2000) als Universitätsprofessor für Volkskunde, der auch als Erstprüfer der Diplomarbeit fungierte. Zweitprüfer war o. Univ.-Prof. Dr. Klaus Tenfelde (1944-2011), der von 1985 bis 1990 als Universitätsprofessor für Wirtschafts- und Sozialgeschichte an der Universität Innsbruck wirkte.

5 Die Idee, nach Ende des Praktikums einen Bericht darüber zu verfassen, war mir damals nicht gekommen. 1995 hat der damalige Volkskundestudent Alois Unterkircher seine sehr persönlich, kritisch und fast satirisch gehaltenen Eindrücke eines dreiwöchigen Praktikums im Tiroler Volkskunstmuseum in der „ethno-postille“ publiziert. Vgl. Unterkircher, Alois: Von der Praxis eines Museumspraktikanten. Was dieser praktisch in seinem Praktikum so praktizierte. In: Ethnopostille. Zeitschrift für Studierende am Institut für Europäische Ethnologie/Volkskunde der Universität Innsbruck, 1 (1995/96), 23-24. Die Zeitschrift war von Studierenden des Instituts für Europäische Ethnologie/Volkskunde zwischen 1995 und 2000 mit dem Anspruch, „,gegen die Ignoranz kulturpolitischer Institutionen gegenüber der modernen Volkskunde auf[zu] treten und veraltete Sichtweisen des Fach [sic!] aus[zu]räumen“, herausgegeben worden. Vgl. Elisabeth Kreuzwieser: ethno-postille. Zeitschrift für Studierende am Institut für Europäische Ethnologie/Volkskunde der Universität Innsbruck, Ausgaben 1-5, 1995/96-2000, je zirka 2030 Seiten. In: Arbeitsgruppe Historische Anthropologie. Rezensionen. Online unter http:// www.kulturwissenschaft.at/historische-anthropologie/rezensionen/ethnopostille.html (Stand: 8.1.2020).

6 Gedanken-Heft I. Begonnen 3.1984, unpaginiert [17], Privatbesitz. Die Notizen werden ungegendert wiedergegeben, weil sich mein Sensorium für geschlechtergerechten Sprachgebrauch erst im Laufe des Studiums und beim Verfassen der Diplomarbeit entwickelt hatte.

8 Ebd., [22-23]. 
vor, Universität und Museum theoretisch wie praktisch in einem museumspädagogischen Projekt zusammenzuspannen und daraus zu lernen. ${ }^{9}$ Im Laufe der weiteren Diskussionen entwickelte sich die Überlegung, in der Diplomarbeit die Genese des Museums zu behandeln und den empirischen Teil in eine angedachte Dissertation zu verlagern. Diese Dissertation kam nicht zustande, weil ich fachlich in die Sozial- und Wirtschaftsgeschichte wechselte und mit einer unternehmergeschichtlichen Arbeit am damaligen Institut für Geschichte der Universität Innsbruck promivierte. ${ }^{10}$

Als zunächst problematisch für die Erstellung der Diplomarbeit erwies sich, dass (zumindest damals) nahezu keine Quellen über die Geschichte und Entwicklung des Museums im Museum selbst auffindbar waren. Auch die Sekundärliteratur zum Museum war überschaubar (und ist es bis heute geblieben, woraus der Ruf nach Drucklegung dieser Diplomarbeit entstand). Ich stützte mich daher bei der Erarbeitung der Diplomarbeit auf Zeitungsquellen sowie auf Dokumente, die sich im Tiroler Landesarchiv befanden. Aus dem Museum selbst waren mir nur „einige Ordner mit Kuratoriums- und Jahresberichten von Seiten der Direktion, ferner ein Teil des Schriftverkehrs mit diversen Institutionen, sowie mit internen Aufzeichnungen der Museumsleitung " zugänglich. ${ }^{11}$ Ich war daher kurze Zeit nach Zusage zur Drucklegung bass erstaunt, als ich von Seiten der heutigen Museumsleitung darüber informiert wurde, dass inzwischen umfangreiche interne Archivmaterialien aufgefunden worden seien. ${ }^{12}$ Dankenswerterweise waren diese Materialien durch Sonia Buchroithner im Zuge ihrer Arbeiten zur Provenienzforschung an den Tiroler Landesmuseen bereits gesichtet und inventarisiert worden. Die Museumsleitung stellte mir zum Gegencheck drei Inhaltsverzeichnisse dieser in Schachteln aufbewahrten Dokumente zur Verfügung („Schachtel Unterlagen TVKM 1938-45 (I)“ mit 16 Post; „Schachtel Unterlagen TVKM Museum - Museumsgeschichte (II)“ mit 18 Post; „Schachtel Unterlagen TVKM

9 Ebd., [23]. Vgl. Scharfe, Martin: Die Tübinger Lernausstellungen und ihr Publikum. Konzept - Evaluation - Konsequenzen. In: Bauer, Ingolf u. Gockerell, Nina (Hg.): Museumsdidaktik und Dokumentationspraxis. Zur Typologie von Ausstellungen in kulturhistorischen Museen. Referate der 3. Arbeitstagung des Arbeitskreises ,Kulturhistorische Museen' in der Deutschen Gesellschaft für Volkskunde vom 2. bis 5. Juni 1975 in München (= Veröffentlichungen zur Volkskunde und Kulturgeschichte: Museumsdidaktik und Dokumentationspraxis, Bd. 2). München 1976, 56-126.

10 Meixner, Wolfgang: Aspekte des Sozialprofils österreichischer Unternehmer im 19. Jahrhundert: regionale und soziale Mobilität. Philosophische Dissertation, Innsbruck 2001 [Erstbetreuer: Univ.-Prof. Dr. Franz Mathis (* 1946)].

11 „Einleitung“ unten hier S. 39-40.

12 Diese waren in der so genannten „Ersatzbibliothek“ verwahrt gewesen und 2008 „gefunden“ worden. 
Inventare, Museumsgeschichte (III)“ mit neun Post). ${ }^{13}$ Eine grobe Sichtung dieses Materials ergab, dass durch diese Dokumente und Akten die in den 1980er Jahren dargestellten Entwicklungslinien des Museums keine nennenswerte Neuausrichtung erfahren. Zwar ist der Bestand an Dokumenten vor allem aus der Zeit vor der Eröffnung des Museums 1929 erfreulich dicht, und es lassen sich vor allem die Richtungsstreite zwischen der kunstgewerblichen versus ethnographischen Ausrichtung des Museums besser nachzeichnen, die Grundakzente dazu wurden aber schon in der Diplomarbeit herausgearbeitet. Auch zur für das Museum einschneidenden Umbruchsphase in der Folge des so genannten "Anschlusses“ von Österreich an das Deutsche Reich im März 1938 finden sich zahlreiche Dokumente und Briefe, die vor allem die Motive und Absichten der Protagonisten (Josef Ringler, Karl Moeser sowie Gertrud Pesendorfer) und ihre Einstellung zu den neuen NS-Machthabern, allen voran Gauleiter Hofer deutlicher nachvollziehen lassen. ${ }^{14} \mathrm{Da}$ dazu aber eigene Arbeiten im Rahmen des erwähnten For-

13 In Schachtel I finden sich u.a. Unterlagen „über Verkäufe aus [dem] Museumsbesitz 1939-1945“, diverse Unterlagen des Interimsdirektors Karl Moeser („Finanz 1938/39“, „Eintrittspreise 1939“, „Nazizeit, Gebäude und Einrichtung, Pläne und Skizzen, Voranschläge“); Korrespondenzen der Zeit von 1938 bis 1945, Aufzeichnungen zur Kassaübergabe 1938, zu Personalangelegenheiten 1938-1945 (Krankenkassenmeldungen), Pensionsangelegenheiten 1938-1939 sowie über „Fremde, Besuche, Führungen“ 1939; in Schachtel II finden sich Dokumente zur Eröffnung des Museums 1929, zu „100 Jahre Tiroler Volkskunstmuseum [im] Sommer 1988“, zum Ausstellungsraum des TVKM (Pläne aus dem Jahr 1945), diverse Dokumente aus dem Jahr 1945, die Rechnungsabschlüsse 1935-1938, diverse Suchanfragen nach 1945 zum Verbleib von Objekten, Tiefdruckprospekte (Muster von 1930 und 1957), die Einladungs-Weihnachtsliste 1992, Zeitungsausschnitte aus dem Jahr 1938 und 1939, Lagepläne der Schauräume, Unterlagen zu den „Besprechungen zum Möbelbuch“ von Franz Colleselli, diverse Zeitungsartikel aus dem Jahr 1968, diverse Korrespondenzen zum Buch und Radiobeitrag sowie volkskundliche Veröffentlichungen (1956), Dienstvorschriften aus den 1930er und 1960er Jahren, das Inventar der Werkstatt (1951), die Inventur von 1953 (allgemeine Richtlinien), Korrespondenzen aus dem Jahr 1933, eine Erwerberliste (vermutlich aus dem Jahr 1933), diverse Rechnungen um 1930 und Ansuchen um Förderungen, Unterlagen zur Kassaverwaltung und Geldergebarung 1925-1928 sowie Grafiken von Otto Vogth für Publikation von Franz Colleselli (u.a. Zunftzeichen-Katalog, „Schwarzmander-Zeichnungen“); in Schachtel III finden sich Dokumente zum Inventarstand, Erwerbungen durch Kauf und Tausch, Verkäufe, diverse Belege aus dem Jahr 1938, Inventarvormerkungen, Inventaraufzeichnungen, Dokumente zu den vorhandenen Öfen und Ofenkacheln, zu den Krippenfiguren aus dem Nachlass von Professor Hans von Voltelini, ein Aktenvermerk zur Überprüfung und Neutextierung der Inventarkartei (1953), Dokumente zu den Bauernhaus- und Wagenmodellen, eine Auflistung von Karl Moeser „Erwerbungen von Antiquarin Mathilde Reitmeir“, eine Auflistung von Tauschgeschäften, ein Inventar der Möbel und Dekorationsgegenstände (1919), Dokumente zu Erwerbungen und Verhandlungen mit Josef Rebitsch, Brixlegg, Ortsmuseum Wörgl, Andre Hofer, Wildschönau, Prof. Weber, Schwaz, ein Ordner Erwerbungen von Antiquar Hans Konzert, ein Ordner Erwerbungen Rebitsch, Brixlegg, Dokumente zu Erwerbungen 1938 f.

14 Zu Pesendorfer und zur „Mittelstelle Deutsche Tracht“ hatte sich u.a. die damalige Kustodin Herlinde Menardi in der Diskussion auf einer Tagung der Deutschen Gesellschaft für Volks- 
schungsprojektes geplant sind, wurde von einer Aufnahme dieser Aspekte in diese Arbeit abgesehen.

Ich hatte die Diplomarbeit in der Methodik und theoretischen Ausrichtung der 1980er Jahre verfasst. Sie ist einem sozialhistorischen Ansatz verpflichtet. Die „kulturelle Wende“ in den Sozial- und Geschichtswissenschaften sowie diskursanalytische Ansätze zeichneten sich damals noch nicht so ab, als dass aus diesen ein tragfähiges Theoriegerüst für eine Diplomarbeit hätte erstellt werden können. ${ }^{15}$ Auch die Diskussionen über Gedächtnisräume und „Narrative“ waren erst im Entstehen und nur rudimentär und aus heutiger Sicht sicher unzureichend in dieser Arbeit verhandelt worden. ${ }^{16}$ Von mir nur für die Zeit bis zur Eröffnung des Museums aufgearbeitet wurde der (ver)öffentlich(t)e Blick auf und der Diskurs um das Museum. ${ }^{17}$ Publikationen, die über das Museum generell und seine Aufgaben reflektierten, waren rar bzw. vorwiegend mit einem museumsdidaktischen Ansatz befasst. ${ }^{18}$

kunde geäußert. Vgl. Schmitt, Heinz: Theorie und Praxis der nationalsozialistischen Trachtenpflege. In: Gerndt, Helge (Hg.): Volkskunde und Nationalsozialismus. Referate und Diskussionen einer Tagung der Deutschen Gesellschaft für Volkskunde, München, 23. bis 25. Oktober 1986 (= Münchner Beiträge zur Volkskunde, Bd. 7). München 1987, 205-217; Menardi, Herlinde: Geschichte und Entwicklung der Tracht in Tirol. In: Beitl, Klaus (Hg.): Kleidung - Mode - Tracht. Referate der Österreichischen Volkskundetagung 1986 in Lienz (Osttirol) (= Buchreihe der Österreichischen Zeitschrift für Volkskunde, N.S., Bd. 7). Wien 1987, 245-262. Mit dem Wirken Ringlers und Pesendorfers in der „Kulturkommission Südtirol“ des SS-Ahnenerbes befasste sich 2016 eine Ausstellung im Tiroler Volkskunstmuseum. Vgl. Puchberger, Magdalena: Gareth Kennedy. Die unbequeme Wissenschaft. Volkskunstmuseum. Ausstellung vom 14.10.2016-29.1.2017 in Innsbruck. In: Österreichische Zeitschrift für Volkskunde, 119 (2016), H. 3+4, 336-343. Zu Pesendorfer vgl. auch Bodner, Reinhard: Porträt einer Sekretärin. Ein Beitrag zur frühen Biografie Gertrud Pesendorfers (1895-1982) und zu den Anfängen der Trachtenerneuerung in Tirol. In: Zeitgeschichte, 44 (2017), H. 6, 360-385.

15 Konrad Köstlin hat die Ambivalenz des Tiroler Volkskunstmuseums, einerseits als „Mustersammlung" der formalen Bildung des Handwerks zu dienen, andererseits „fortschrittlich“ zu sein, indem es „der Rede von den ästhetisierten Lebenswelten vorgreift“ knapp, aber treffend formuliert. Vgl. Köstlin, Konrad: „Volkskünste“. Ästhetische Programmatik in Lebensentwürfen der zwanziger Jahre. In: Nikitsch, Herbert u. Tschofen, Bernhard (Hg.): Volkskunst. Referate der Österreichischen Volkskundetagung 1995 in Wien (= Buchreihe der Österreichischen Zeitschrift für Volkskunde, N.S., Bd. 14). Wien 1997, 39-54, hier 42-43.

16 Vgl. etwa die theoretischen Abhandlungen in Fuge, Janina u. a. (Hg.): Gedächtnisräume. Geschichtsbilder und Erinnerungskulturen in Norddeutschland (= Formen der Erinnerung, Bd. 56/Zeit + Geschichte, Bd. 33). Göttingen 2014.

17 Quellen, die sich damit zu beschäftigen, finden sich neben dem Zettelkatalog in der Bibliothek des Ferdinandeums sowie im Katalog des Innsbrucker Stadtarchivs, da hier die einschlägigen Zeitungsartikel und Artikel der „Kulturberichte aus Tirol“ verschlagwortet sind.

18 Ein vergleichender Überblick zu den Paradigmen des Sammelns und Wegwerfens wurde erst Jahre später vorgelegt. Vgl. Ecker, Gisela u. a. (Hg.): Sammeln - Ausstellen - Wegwerfen (= Kulturwissenschaftliche Gender Studies, Bd. 2). Königstein/Taunus 2001. 
Vergleichbare Arbeiten zur Geschichte von Museen lagen nicht vor bzw. waren im Entstehen und konnten daher zur Erarbeitung dieser Diplomarbeit nicht herangezogen werden. ${ }^{19}$ Eine Aufarbeitung des intellektuellen und sozialen Milieus, dem die Protagonisten (es waren überwiegend Männer, daher erübrigt sich hier ein Gendern) entstammten, wurde sechs Jahre nach Vollendung meiner Diplomarbeit von Irmgard Plattner vorgelegt. Dadurch wurden interessante Verbindungen innerhalb der bürgerlichen Vereinskultur in Innsbruck sichtbar, in der sich auch die Proponenten des Tiroler Volkskunstmuseums bewegten. ${ }^{20}$ Mir damals ebenfalls unbekannt und nicht zur Verfügung stehend, waren die persönlichen Aufzeichnungen von Johann Deininger. ${ }^{21}$ Darin äußert sich Deininger wiederholt und prononciert zu den Entwicklungen der Museumswerdung. ${ }^{22}$

Zur 100-Jahrfeier der Gründung des Museums verfasste Hans Gschnitzer, damaliger Direktor des Museums, aus der bekannten Literatur und seiner eigenen Wahrnehmung einen Beitrag zur Geschichte des Museums. ${ }^{23}$ Die damalige Kustodin Herlinde Menardi stellte das Museum, dessen Geschichte und wechselnde Aufstellungsgeschichte der Trachten ebenfalls 1988 in einem Symposium zur Bekleidungsgeschichte in Vorarlberg vor. ${ }^{24}$ Hans Gschnitzer verfasste 1992 für die beiden Prachtbände mit Objekten des Museums eine Einleitung zur Geschichte

19 Vgl. Schlorhaufer, Bettina: Zur Geschichte eines Regionalmuseums der Donaumonarchie im Vormärz. Der Verein des Tiroler Nationalmuseums Ferdinandeum 1823-1848. Philosophische Dissertation, Innsbruck 1988 sowie Schlorhaufer, Bettina: Museumsraum Provinz. Die Gründung des Tiroler Landesmuseums Ferdinandeum und sein gesellschaftspolitisches Umfeld. In: Fliedl, Gottfried (Hg.): Museumsraum - Museumszeit. Zur Geschichte des österreichischen Museums- und Ausstellungswesens. Wien 1992, 31-48.

20 Plattner, Irmgard: Fin de siècle in Tirol. Provinzkultur und Provinzgesellschaft um die Jahrhundertwende. Philosophische Dissertation, Innsbruck 1996, publiziert unter dem gleichen Titel 1999 im Studienverlag Innsbruck/Wien. Ebenso wertvoll: Falch, Ursula: Edgar Meyer (18531925). Künstler, Schlossherr, Agitator. Philosophischen Dissertation, Innsbruck 2004.

21 Arch, Harwick, W. (Hg.): Johann W. Deininger. Architekt, Denkmalpfleger, Gewerbeschuldirektor - Lebenserinnerungen (= Nearchos, Bd. 16). Innsbruck 2007.

22 Ebd.: 1888: „Notwendigkeit der Errichtung eines Gewerbemuseums in Innsbruck“ (133), 87; 1904: Konstituierung des „Kuratorium des Handels- und Gewerbemuseums“ (235), 138; 1910 : Pläne für ein Gewerbemuseum im Haus des „Goldenen Dachls“ (273), 157 sowie Kritik der „wahnwitzige[n] Ideen für den Museumsumbau“ der Handels- und Gewerbekammer bzw. deren Sekretärs Dr. Kofler, da „durch solche Gebarung nutzlos viel Geld und Zeit verschwendet wurde“" (273/274), 157.

23 Gschnitzer, Hans: Das Tiroler Volkskunstmuseum. Werdegang, Bestand, Funktion, Organisation. In: Jahrbuch für Volkskunde und Museologie des Bezirksheimatmuseums Spittal an der Drau, 3 (1989), 39-45.

24 Menardi, Herlinde: Tiroler Volkskunstmuseum. Erfahrungen mit der Trachtensammlung. In: Brückner, Wolfgang (Hg.): Bekleidungsgeschichte und Museum. Symposium in Schloß Hofen 13.-16.10.1988 veranstaltet vom Amt der Vorarlberger Landesregierung. Bregenz 1988, $147-151$. 
des Tiroler Volkskunstmuseums und seiner Sammlung, in der er einzig auf den Aufsatz von Josef Ringler über „Das Tiroler Volkskunstmuseum“von 1962 Bezug nahm..$^{25}$

Die im Rahmen der Veröffentlichung dieser Diplomarbeit von Joachim Bürgschwentner angestellte Literaturrecherche ergab, dass die Literatur zu Geschichte und Veränderungen des Volkskunstmuseums immer noch sehr überschaubar ist. ${ }^{26}$ Zudem ist auffallend, dass das Tiroler Volkskunstmuseum im Inhaltsverzeichnis der Österreichischen Zeitschrift für Volkskunde im Vergleich zu anderen Museen kaum präsent ist. Interessant ist, dass sich in den 1980er und 1990er Jahren vier Diplomarbeiten von Studierenden der Architekturfakultät mit Erweiterungsbauten des Tiroler Volkskunstmuseums auseinandergesetzt haben. ${ }^{27}$

Die Diplomarbeit endet zeitlich mit der Neugestaltung der Schausammlungen durch den damaligen Direktor Franz Colleselli (1922-1979) in den 1960er Jahren. Die weitere Entwicklung des Museums nach dem Tod Collesellis und der Übernahme der Direktion durch Hans Gschnitzer (1938-2013), der das Museum von 1970 bis 2003 leitete, waren nicht Gegenstand der Arbeit und können im Rahmen dieses Vorwortes nur skizziert werden. Nach dem Ausscheiden Gschnitzers übernahm die langjährige Kustodin Herlinde Menardi (* 1949) 2004 die Leitung des Hauses, die sie bis 2014 innehatte. Am Ende der Ära Gschnitzer beschäftigte sich der Landesrechnungshof, der das Museum zuvor 1988 geprüft hatte, neuerlich mit dem Museum und unterbreitete darin unter anderem auch „Vorschläge zur Verwaltungsreform“. ${ }^{28}$ Das Museum verfügte zum Zeitpunkt der Prüfung 2003 über 25 Bedienstete im Personalstand, davon allerdings nur zwei im wissenschaftlichen Bereich. ${ }^{29}$ Vom Landesrechnungshof kritisiert wur-

25 Gschnitzer, Hans: Die Geschichte des Tiroler Volkskunstmuseums und seiner Sammlungen. In: Menardi, Herlinde (Hg.): Schätze des Tiroler Volkskunstmuseums. Fotos von Attilio BoccazziVarotto. Band 1: Volkskunst und Kunsthandwerk in Tirol, im Trentino und in den ladinischen Tälern. Innsbruck 1992, 5-7; Ringler, Josef: Das Tiroler Volkskunstmuseum. In: Grass, Franz (Hg.): Beiträge zur Kultur- und Kunstgeschichte Tirols. Festschrift Landeshauptmannstellvertreter Prof. Dr. Hans Gamper, Bd. 3 (= Schlern-Schriften, Bd. 167). Innsbruck 1962, 67-95. Ein Exemplar meiner Diplomarbeit ist in der Bibliothek des Tiroler Volkskunstmuseums vorhanden, wurde aber nicht zitiert.

26 Vgl. die Literaturliste im Anhang dieser Vorbemerkungen.

27 Unterluggauer, Ernst: Unvoreingenommene Studien für das Volkskunstmuseum. Diplomarbeit (Architektur), Innsbruck 1985; Trebo, Monika C.: Innsbruck - Untersuchung und Erweiterung Tiroler Volkskunstmuseum und Landesmuseum Ferdinandeum. Diplomarbeit (Architektur), Innsbruck 1990; Fischbach, Susanne: Innsbruck - Erweiterung des Museums Ferdinandeum und des Volkskunstmuseums. Diplomarbeit (Architektur), Innsbruck 1990; Simoni-Lang, Judith: Tiroler Volkskunstmuseum Erweiterung. Diplomarbeit (Architektur), Innsbruck 1996.

28 Landesrechnungshof: Tiroler Volkskunstmuseum, Hofkirchenverwaltung und Hofkirche-Erhaltungsfonds. Prüfbericht an den Tiroler Landtag. Innsbruck 2003.

29 Ebd., 10. 
de die vergleichsweise niedrigere Preisgestaltung bei gleichzeitig sinkenden Besucher*innenzahlen. Dies veranlasste die Prüfer*innen zu der Aussage, dass „[n]eue Wege durch ein völlig neues Museumskonzept [...] notwendig sein [werden], um in Zukunft ein interessantes und attraktives Angebot anbieten zu können ". ${ }^{30}$ Diese Aussage war wohl auch der sinkenden Besucher*innenzahl geschuldet, die gegenüber neuen Ausstellungsorten und -formaten, wie den 1995 von André Heller konzipierten Swarovski Kristallwellten in Wattens, deutlich abgefallen waren. ${ }^{31}$ Hatte das Museum am Ende des Darstellungszeitraumes (1970er Jahre) über 111.000 Besucher*innen und verzeichnete es 1984 mit 128.565 Besucher*innen sein Rekordjahr, so hatte sich diese Zahl bis 1994 halbiert und war bis 2002 auf unter 50.000 gesunken. ${ }^{32}$ Zudem wurde die große Anzahl an Freikarten moniert. Abschließend fand der Bericht des Landesrechnungshofes deutliche Worte und kritisierte den Zustand des Museums: „Sowohl im Museum als auch in der Hofkirche spricht der Besucherrückgang eine deutliche Sprache. Der mit dem Besucherrückgang einhergehende steigende Bedarf an öffentlichen Mitteln kann zukünftig so nicht mehr akzeptiert werden. ${ }^{\text {“33 }}$ Der Bericht verwies auf die bereits kritischen Stellungnahmen der Jahre 1988 und 1995 und hielt „dringend Maßnahmen für eine Neukonzeption des Museums (Ausstellungsveränderung, Öffnungszeiten, Medieneinsatz) erforderlich. ,Mehr ausstellen - weniger deponieren' könnte ein Motto sein, um die Attraktivität des Museums zu steigern." ${ }^{34}$ Damit erhielt die reservierte Haltung des damaligen Direktors gegenüber Neuerungen einen Dämpfer, der die Sammlung als „abgeschlossen“ ansah, wo „aus der Gegenwart [...] wohl nichts mehr dazukommen werde“ .35

Bereits 1990 war ein „Freundeskreis des Tiroler Volkskunstmuseums“ ins Leben gerufen worden, als dessen erster Obmann (der ehemalige) EU-Kommissar Dr. Franz Fischler fungierte. ${ }^{36}$ Der Verein hat das Ziel, das Museum in der Bevölkerung Tirols bekannt und attraktiver zu machen und die Museumsarbeit begleitend zu unterstützen. Jährlich werden Ausstellungen unterstützt und Veranstaltungen (z.B. ein Sommerfest) abgehalten.

\footnotetext{
$30 \quad$ Ebd., 16.

31 Siehe https://kristallwelten.swarovski.com/Content.Node/wattens/index.de.html (Stand: 10.7.2019).

32 Landesrechnungshof: Tiroler Volkskunstmuseum, Hofkirchenverwaltung und Hofkirche-Erhaltungsfonds. Prüfbericht an den Tiroler Landtag. Innsbruck 2003, 27-29.

33 Ebd., 69.

34 Ebd.

35 Das Zitat Gschnitzers, das ich während meines Praktikums auch immer wieder so gehört hatte, findet sich bei Köstlin: „Volkskünste“, hier 43.

36 Siehe http://www.freundeskreis-volkskunstmuseum.com/ (Stand: 10.7.2019). Derzeitige Obfrau ist Herlinde Keuschnigg.
} 
Kurz nach der Jahrtausendwende erreichten Fragen der „Arisierung“ jüdischen Vermögens und dessen Restitution auch die offiziellen Stellen des Landes Tirol. ${ }^{37}$ Im Ferdinandeum wurde die Kustodin Dr. Claudia Sporer-Heis damit beauftragt, die Erwerbungen der Museen in der Zeit zwischen 1938 und 1945 auf „arisierte" Gegenstände zu durchforsten, die gegebenenfalls an Nachfahren der einstigen Besitzer*innen restituiert werden sollen. ${ }^{38}$ Der Autor war in dieser Zeit einmal zu einer internen Sitzung der Kulturabteilung des Landes Tirol geladen, wo es um die Frage ging, welches Quellenmaterial zur Klärung der Provenienz von Gegenständen, die zwischen 1938 und 1945 in das Tiroler Volkskunstmuseum gelangt sind, zur Verfügung steht. Der damalige Tenor war, dass die Erwerbskataloge des Tiroler Volkskunstmuseums dazu wenig hergeben würden. Das war zu dieser Zeit plausibel, weil, wie geschildert, der Archivbestand des Tiroler Volkskunstmuseums erst 2008 wiederentdeckt worden war. Dieses Material enthält umfangreiche Korrespondenzen mit den „Hauptlieferanten“ (Antiquariaten, Privatsammlern, aber auch Tauschgeschäfte und zugeflossene Sammlungen) des Tiroler Volkskunstmuseum in dieser Zeit. ${ }^{39}$ Ob die Korrespondenz zu den Erwerbungen eine lückenlose Provenienz der Museumsbestände rekonstruieren lässt, obliegt einer künftigen Untersuchung.

Die von Landesseite vorgeschlagenen Neuerungen wurden 2007 mit der $\mathrm{Zu}$ sammenführung des Tiroler Landesmuseums Ferdinandeum mit dem Zeughaus, dem Tiroler Volkskunstmuseum, der Hofkirche, dem Kaiserschützenmuseum

37 Vgl. Meixner, Wolfgang: Österreichs (ver-)späte(te) Bemühungen um Entschädigung von NSOpfern: Entstehung und Zukunft von „Versöhnungs-“ und „Restitutionsfonds“. In: Geschichte und Region/Storia e regione, 11 (2002), 1, 193-204. Zur Provenienzforschung und Rückstellung „arisierten“ Kulturguts vgl. Anderl, Gabriele: ... wesentlich mehr Fälle als angenommen. 10 Jahre Kommission für Provenienzforschung (= Schriftenreihe der Kommission für Provenienzforschung, Bd. 1). Wien 2009; Reininghaus, Alexandra (Hg.): Recollecting - Raub und Restitution, diese Publikation erscheint anlässlich der Ausstellung im MAK Wien, 03.12.2008 - 15.02.2009. Wien 2009 sowie die einschlägigen Bände der Veröffentlichungen der Österreichischen Historikerkommission, siehe http://www.boehlau-verlag.com/histkom/ (Stand: 10.7.2019).

38 Sporer-Heis, Claudia: „... sind dem Ferdinandeum Auslagen erwachsen, auf deren Ersatz es Anspruch erheben zu können glaubt ...“. Zur Frage der Restitution jüdischen Eigentums am Tiroler Landesmuseum Ferdinandeum. In: Veröffentlichungen des Tiroler Landesmuseums Ferdinandeum, 82 (2002), 2, 7-36 sowie Sporer-Heis, Claudia u. Gürtler, Eleonore: Restitutionsfälle am Tiroler Landesmuseum Ferdinandeum im Überblick. In: Veröffentlichungen des Tiroler Landesmuseums Ferdinandeum, 82 (2002), 2, 37-168.

39 Eine Seite auf der Homepage der Tiroler Landesmuseen gibt Auskunft über rückgestellte Gegenstände. Der Umfang der pdf-Datei, die anscheinend laufend ergänzt wird, von sechs Seiten und die dortige Erwähnung des Tiroler Volkskunstmuseums mit gerade mal einem restituierten Objekt, erweckt den Anschein, dass diese Arbeit noch nicht abgeschlossen ist. Siehe http:// www.tiroler-landesmuseen.at/page.cfm?vpath=tiroler-landesmuseen/forschung/provenienz/restitution (Stand: 10.7.2019). 
und dem Volksliedarchiv zur Tiroler Landesmuseen-Betriebsgesellschaft m.b.H. organisatorisch begonnen, zu der seit 2011 auch das „Tirol Panorama“ mit dem Kaiserjägermuseum gehört. ${ }^{40}$

Inhaltlich wurde das Tiroler Volkskunstmuseum komplett umgestaltet und am 18. Mai 2009 im 80. Jahr seines Bestehens wiedereröffnet. ${ }^{41}$

In der ab 2011 in Tirol begonnenen Debatte um den Umgang mit dem „Erbe“ der NS-Volkskultur, insbesondere dem Tiroler Musikleben in der NSZeit, ${ }^{42}$ spielte das Tiroler Volkskunstmuseum nur am Rande und zwar über die dort angesiedelte „Mittelstelle Deutsche Tracht“ eine Rolle. Das eingangs erwähnte Forschungsprojekt zur Tiroler Trachtenpraxis wurde aus Mitteln des „Förderschwerpunktes Erinnerungskultur" von der Abteilung Kultur des Landes Tirol im Rahmen von Forschungsprojekten zu „Volkskultur und Nationalsozialismus“ unterstützt. ${ }^{43}$

40 Siehe https:/www.tiroler-landesmuseen.at/page.cfm?vpath=tiroler-landesmuseen/aktuelles/ ueber-uns (Stand: 10.7.2019). Vgl. dazu Tschofen, Bernhard: Modo panoramico? Das Tirol Panorama am Innsbrucker Bergisel - Mutmaßungen über die Medienimmanenz des Affirmativen. In: Österreichische Zeitschrift für Volkskunde, 117 (2014), 3+4, 237-254 sowie Bonz, Jochen: Im Medium des Panoramas verliert sich der ,lange Blick' in Sehlust. Symposium „Vom Zankapfel zum Publikumsmagnet? Drei Jahre Tirol Panorama mit Kaiserjägermuseum“, am 11. März 2014, Tirol Panorama, Innsbruck. In: Österreichische Zeitschrift für Volkskunde 117 (2014), 3+4, 229-236. Zur Volksmusik im 20. Jahrhundert in Tirol vgl. Nußbaumer, Thomas: Volksmusik in Tirol und Südtirol seit 1900. Von „echten“ Tirolerliedern, landschaftlichen Musizierstilen, „gepflegter" Volksmusik, Folklore und anderen Erscheinungen der Volkskultur. Innsbruck-Wien-Bozen 2008, bes. 108-122.

41 Vgl. die aus diesem Anlass gehaltene Festansprache von Scharfe Martin: Eine Lanze für Luzifer! In: Österreichische Zeitschrift für Volkskunde, 112 (2009), 3, 324-329, sowie Menardi, Herlinde/Berger, Karl C.: Luzifer und das Materielle. In: Braun, Karl u. a. (Hg.): Materialisierung von Kultur. Diskurse, Dinge, Praktiken. Würzburg 2015, 340-350. Kritisch zur Neugestaltung „seines“ Museums Gschnitzer, Hans: Lebt hier Tirol? Das neue Volkskunstmuseum. In: Tiroler Heimatblätter. Zeitschrift für Heimatpflege in Nord- und Osttirol, 84 (2009), 2, 81-92. Weiters: Berger, Karl C.: Musealisierte Sorgen. Ein Werkbericht. In: Kreissl, Eva (Hg.): Kulturtechnik Aberglaube. Zwischen Aufklärung und Spiritualität. Strategien zur Rationalisierung des Zufalls (= Edition Kulturwissenschaft, Bd. 19). Bielefeld 2013, 487-504.

42 Vgl. Drexel, Kurt: Klingendes Bekenntnis zu Führer und Reich. Musik und Identität im Reichsgau Tirol-Vorarlberg 1938-1945. Innsbruck 2014.

43 Zum Förderschwerpunkt „Erinnerungskultur“ siehe die Dokumentation auf der Homepage der Tiroler Kulturinitiativen https://www.tki.at/kulturpolitik/tirol/gutachten-zur-tiroler-volkskultur-in-der-ns-zeit-veroeffentlicht.html (Stand: 28.6.2019) sowie Beirat (wie Anm. 2). Im dem Schwerpunkt vorausgegangen und von der Kulturabteilung des Landes Tirol in Auftrag gegebenen Gutachten des Wiener Historikers Michael Wedekind wird meine Diplomarbeit im „Schrifttumsnachweis“ nicht angeführt, obwohl im Gutachten auf das Tiroler Volkskunstmuseum mehrfach Bezug genommen wird. Das Gutachten findet sich nicht mehr auf der Homepage der Tiroler Kulturinitiativen, ist aber auf der Homepage der Kulturabteilung des Landes Tirol in der Rubrik „Stipendien, Wettbewerbe, Diverses“ abrufbar (in zwei Teilen). Vgl. https://www. tirol.gv.at//kunst-kultur/wettbewerbe/\#c56959 (Stand: 28.1.2020). Zum „Erinnerungsfonds“ 
Daher bin ich froh, im Jahr nach der 90. Wiederkehr der offiziellen Eröffnung des Tiroler Volkskunstmuseums, meine Diplomarbeit zur Vorgeschichte und Geschichte des Museums einer hoffentlich interessierten Öffentlichkeit vorlegen zu können und danke allen, die dazu beigetragen haben: Karl C. Berger, Reinhard Bodner, Timo Heimerdinger, Joachim Bürgschwentner und Anna Larl (für die Literaturrecherchen und Korrekturvorschläge), dem Verlag innsbruck university press (iup), dort insb. Carmen Drolshagen und Birgit Holzner (für die verlegerische Betreuung), und den Geldgebern (Freundeskreis des Tiroler Volkskunstmuseums, Land Tirol, Universität Innsbruck) für die Drucklegung.

Wolfgang Meixner, im Februar 2020

vgl. Bodner, Reinhard u. Heimerdinger, Timo: Ein Erinnerungsfonds für die ,Tiroler Volkskultur? Die Ploner-Debatte (2011-2014) als Anstoß und Hemmnis eines Forschungsprojektes über Trachten in Tirol. In: Österreichische Zeitschrift für Geschichtswissenschaften, 27 (2016), 2, 168-208. 


\section{Relevante Literatur}

(erschienen seit der Erstveröffentlichung der Diplomarbeit 1989)

Arch, Harwick W. (Hg.): Johann W. Deininger. Architekt, Denkmalpfleger, Gewerbeschuldirektor - Lebenserinnerungen $(=$ Nearchos, Bd. 16). Innsbruck 2007.

Berger, Karl C.: Musealisierte Sorgen. Ein Werkbericht. In: Eva Kreissl (Hg.): Kulturtechnik Aberglaube. Zwischen Aufklärung und Spiritualität. Strategien zur Rationalisierung des Zufalls (= Edition Kulturwissenschaft, Bd. 19). Bielefeld 2013, 487-504.

Berger, Karl C. u. a.: Gabe und Gegengabe. Eine Festschrift für Herlinde Menardi. In: Karl C. Berger u. a. (Hg.): Gegengabe. Festschrift für Herlinde Menardi. Bozen 2014, 11-16.

Berger, Karl C.: Geschenke und Präsente. Ein Rückblick auf die Museumsgeschichte. In: Wolfgang Meighörner (Hg.): Geschenke und Präsente. Tiroler Volkskundemuseum, 11. Dezember 2015 - 21. Februar 2016 (= Studiohefte, Bd. 27). Innsbruck 2015, 9-16.

Bodner, Reinhard u. Heimerdinger, Timo: Ein Erinnerungsfonds für die ,Tiroler Volkskultur? Die Ploner-Debatte (2011-2014) als Anstoß und Hemmnis eines Forschungsprojektes über Trachten in Tirol. In: Österreichische Zeitschrift für Geschichtswissenschaften, 27 (2016), H. 2, 168-208.

Bodner, Reinhard: Porträt einer Sekretärin. Ein Beitrag zur frühen Biografie Gertrud Pesendorfers (1895-1982) und zu den Anfängen der Trachtenerneuerung in Tirol. In: Zeitgeschichte, 44 (2017), H. 6, 360-385.

Bodner Reinhard: „Lebendige Tracht in Tirol“. Ein Buch als Beispiel volkskundlicher Wissensproduktion nach 1945 und Gegenstand aktueller Debatten. In: Eggmann, Sabine u. a. (Hg.): Orientieren \& Positionieren, Anknüpfen \& Weitermachen: Wissensgeschichte der Volkskunde/Kulturwissenschaft in Europa nach 1945 (= Schweizer Beiträge zur Kulturwissenschaft, Bd. 9). Münster u. New York 2019, 171-204.

Bodner, Reinhard: Ein tragbares Erbe? Trachtenerneuerung vor, in und nach der NS-Zeit. In: Beirat des Förderschwerpunktes Erinnerungskultur (Hg.): Vom Wert des Erinnerns. Wissenschaftliche Projekte der Förderperiode 2014 bis 2018 (= Veröffentlichungen des Tiroler Landesarchivs, Bd. 22). Innsbruck 2020, 99-134.

Bonz, Jochen: Im Medium des Panoramas verliert sich der ,lange Blick' in Sehlust. Symposium „Vom Zankapfel zum Publikumsmagnet? Drei Jahre Tirol Panorama mit Kaiserjägermuseum“, am 11. März 2014, Tirol Panorama, Innsbruck. In: Österreichische Zeitschrift für Volkskunde, 117 (2014), H. 3+4, 229-236. 
Braun, Karl u. a. (Hg.): Materialisierung von Kultur. Diskurse, Dinge, Praktiken. Würzburg 2015.

Drexel, Kurt: Klingendes Bekenntnis zu Führer und Reich. Musik und Identität im Reichsgau Tirol-Vorarlberg 1938-1945. Innsbruck 2014.

Falch, Ursula: Edgar Meyer (1853-1925). Künstler, Schlossherr, Agitator. Philosophische Dissertation, Innsbruck 2004.

Fischbach, Susanne: Innsbruck - Erweiterung des Museums Ferdinandeum und des Volkskunstmuseums. Diplomarbeit (Architektur), Innsbruck 1990.

Gschnitzer, Hans, Das Tiroler Volkskunstmuseum. Werdegang, Bestand, Funktion, Organisation. In: Jahrbuch für Volkskunde und Museologie des Bezirksheimatmuseums Spittal an der Drau, 3 (1989), 39-46.

Gschnitzer Hans: Die Geschichte des Tiroler Volkskunstmuseums und seiner Sammlungen. In: Herlinde Menardi (Hg.): Schätze des Tiroler Volkskunstmuseums. Fotos von Attilio Boccazzi-Varotto. Band 1: Volkskunst und Kunsthandwerk in Tirol, im Trentino und in den ladinischen Tälern. Innsbruck 1992, 5-7.

Gschnitzer, Hans: Hausmodelle im Tiroler Volkskunstmuseum. Das Schicksal ihrer Vorbilder. In: Tiroler Heimatblätter. Zeitschrift für Heimatpflege in Nordund Osttirol, 77 (2002), H. 4, 119-121.

Gschnitzer, Hans: Bemerkungen zur Sammlung bäuerlicher Geräte im Tiroler Volkskunstmuseum. In: Merlin, Friedrich Walter u. Hubatschek, Erika (Hg.): Bergwelt im Wandel. Festschrift Erika Hubatschek zum 90. Geburtstag. Klagenfurt 2007, 250.

Gschnitzer, Hans: Drei Museen der Tiroler Volkskultur im Vergleich. Tiroler Volkskunstmuseum in Innsbruck - Südtiroler Volkskundemuseum in Dietenheim - Museum Tiroler Bauernhöfe in Kramsach. In: Der Schlern. Monatszeitschrift für Südtiroler Landeskunde, 82 (2008), 20-29.

Gschnitzer, Hans: Lebt hier Tirol? Das neue Tiroler Volkskunstmuseum. In: Tiroler Heimatblätter. Zeitschrift für Heimatpflege in Nord- und Osttirol, 84 (2009), H. 2, 81-82.

Gurschler, Susanne: NS-Gerecht geschnürt. In: Echo. Tirols 1. Nachrichtenillustrierte, 2013, Nr. 11, 33-37.

Hagen, Nikolaus: Kultur- und Identitätspolitik im Gau Tirol-Vorarlberg 19381945. Philosophische Dissertation, Innsbruck 2017.

Ilg, Karl: Die Geschichte der tirolischen Volkskunde von den Anfängen bis 1980. In: Tiroler Heimat. Zeitschrift für Regional- und Kulturgeschichte, Nord-, Ost- und Südtirols, 59 (1995), 177-244.

Köstlin, Konrad: „Volkskünste“. Ästhetische Programmatik in Lebensentwürfen der zwanziger Jahre. In: Herbert Nikitsch u. Bernhard Tschofen (Hg.): Volkskunst. Referate der Österreichischen Volkskundetagung 1995 in Wien 
(= Buchreihe der Österreichischen Zeitschrift für Volkskunde, N.S. 14). Wien 1997, 39-54.

Landesrechnungshof: Tiroler Volkskunstmuseum, Hofkirchenverwaltung und Hofkirche-Erhaltungsfonds. Prüfbericht an den Tiroler Landtag. Innsbruck 2003.

Meighörner, Wolfgang: Aus den Waffenbeständen des Tiroler Volkskunstmuseums. Der geschätzten Kollegin Herlinde Menardi anlässlich ihrer Pensionierung gewidmet. In: Berger, Karl C. u. a. (Hg.): Gegengabe. Festschrift für Herlinde Menardi. Bozen 2014, 153-162.

Meighörner, Wolfgang (Hg.): Geschenke und Präsente. Tiroler Volkskundemuseum, 11. Dezember 2015 - 21. Februar 2016 (= Studiohefte, H. 27). Innsbruck 2015.

Meighörner, Wolfgang (Hg.): Über die Jahre. Die Tiroler Landesmuseen 20072019. Innsbruck 2019.

Meixner, Wolfgang: Mythos Tirol. Zur Ethnizitätsbildung und Heimatschutzbewegung im 19. Jahrhundert. In: Geschichte und Region/Storia e regione 1 (1992), H. 1, 88-105.

Menardi, Herlinde: Geschichte und Entwicklung der Tracht in Tirol. In: Beitl, Klaus (Hg.): Kleidung - Mode - Tracht. Referate der Österreichischen Volkskundetagung 1986 in Lienz (Osttirol) (= Buchreihe der Österreichischen Zeitschrift für Volkskunde, N.S. 7). Wien 1987, 245-262.

Menardi, Herlinde: Tiroler Volkskunstmuseum. Erfahrungen mit der Trachtensammlung. In: Wolfgang Brückner (Hg.): Bekleidungsgeschichte und Museum. Symposium in Schloß Hofen 13.-16.10.1988 veranstaltet vom Amt der Vorarlberger Landesregierung. Bregenz 1988, 147-151.

Menardi, Herlinde: Die Ausstellung „Der Vogel Selbsterkenntnis“ im Tiroler Volkskunstmuseum - ein gelungenes Experiment. Erfahrungen im Hause - Besucherreaktionen. In: Österreichische Zeitschrift für Volkskunde, 101 (1998), 472-476.

Menardi, Herlinde: Tiroler Volkskunstmuseum. Ein Begleiter. Innsbruck 2006.

Menardi, Herlinde u. a.: Tiroler Volkskunstmuseum. Kurzführer. Innsbruck 2010. Menardi, Herlinde: Das „neue“ Tiroler Volkskunstmuseum. In: Kaindl, Heimo u. Traxler, Stefan (Hg.): Museen schaffen Identität(en). 20. Österreichischer Museumstag Linz 2009 (= Österreichische Museumstage, Bd. 1). Wien 2011, 51-55.

Menardi, Herlinde u. Berger, Karl C.: Luzifer und das Materielle. In: Braun, Karl u. a. (Hg.): Materialisierung von Kultur. Diskurse, Dinge, Praktiken. Würzburg 2015, 340-350.

Neuner-Schatz, Nadja: Wissen Macht Tracht im Ötztal (= Bricolage Monografien, Bd. 2). Innsbruck 2018. 
Nußbaumer, Thomas: Volksmusik in Tirol und Südtirol seit 1900. Von „echten“ Tirolerliedern, landschaftlichen Musizierstilen, „gepflegter" Volksmusik, Folklore und anderen Erscheinungen der Volkskultur. Innsbruck-Wien-Bozen 2008.

Plattner, Irmgard: Fin de siècle in Tirol. Provinzkultur und Provinzgesellschaft um die Jahrhundertwende. Philosophische Dissertation, Innsbruck 1996, publiziert unter dem gleichen Titel 1999 im Studienverlag Innsbruck-Wien.

Plessen, Marie-Louise von: Der Vogel Selbsterkenntnis. Idiosynkrasien im Volkskunstmuseum. Zur Ausstellung im Tiroler Volkskunstmuseum Innsbruck, 27. Juni bis 26. Oktober 1998. In: Österreichische Zeitschrift für Volkskunde, 101 (1998), 465-471.

Puchberger, Magdalena: Gareth Kennedy. Die unbequeme Wissenschaft. Volkskunstmuseum. Ausstellung vom 14.10.2016 - 29.1.2017 in Innsbruck. In: Österreichische Zeitschrift für Volkskunde, 119 (2016), H. 3+4, 336-343.

Sachen sind bekannt. In: Echo. Tirols 1. Nachrichtenillustrierte, 2013, Nr. 11, 35. Scharfe, Martin: Eine Lanze für Luzifer!. In: Österreichische Zeitschrift für Volkskunde, 112 (2009), 323-329.

Schlorhaufer, Bettina: Zur Geschichte eines Regionalmuseums der Donaumonarchie im Vormärz. Der Verein des Tiroler Nationalmuseums Ferdinandeum 1823-1848. Philosophische Dissertation, Innsbruck 1988.

Schlorhaufer, Bettina: Museumsraum Provinz. Die Gründung des Tiroler Landesmuseums Ferdinandeum und sein gesellschaftspolitisches Umfeld. In: Fliedl, Gottfried (Hg.): Museumsraum - Museumszeit. Zur Geschichte des österreichischen Museums- und Ausstellungswesens. Wien 1992, 31-48.

Schlorhaufer, Bettina u. a. (Hg.): Architektur wird Region. Die Regionalisierung von Architektur in Südtirol von circa 1880 bis in die Zwischenkriegszeit. Basel 2017.

Schmitt, Heinz: Theorie und Praxis der nationalsozialistischen Trachtenpflege. In: Gerndt, Helge (Hg.): Volkskunde und Nationalsozialismus. Referate und Diskussionen einer Tagung der Deutschen Gesellschaft für Volkskunde München, 23. bis 25. Oktober 1986 (= Münchner Beiträge zur Volkskunde, Bd. 7). München 1987, 205-217.

Simoni-Lang, Judith: Tiroler Volkskunstmuseum Erweiterung. Diplomarbeit (Architektur), Innsbruck 1996.

Sporer-Heis, Claudia: „... sind dem Ferdinandeum Auslagen erwachsen, auf deren Ersatz es Anspruch erheben zu können glaubt ...". Zur Frage der Restitution jüdischen Eigentums am Tiroler Landesmuseum Ferdinandeum. In: Veröffentlichungen des Tiroler Landesmuseums Ferdinandeum, 82 (2002), H. 2, 7-36. 
Sporer-Heis, Claudia u. Gürtler, Eleonore: Restitutionsfälle am Tiroler Landesmuseum Ferdinandeum im Überblick. In: Veröffentlichungen des Tiroler Landesmuseums Ferdinandeum, 82 (2002), H. 2, 37-168.

Trebo, Monika C.: Innsbruck - Untersuchung und Erweiterung Tiroler Volkskunstmuseum und Landesmuseum Ferdinandeum. Diplomarbeit (Architektur), Innsbruck 1990.

Tschofen, Bernhard: Modo panoramico? Das Tirol Panorama am Innsbrucker Bergisel - Mutmaßungen über die Medienimmanenz des Affirmativen. In: Österreichische Zeitschrift für Volkskunde, 117 (2014), H. 3+4, 237-254.

Unterkircher, Alois: Von der Praxis eines Museumspraktikanten. Was dieser praktisch in seinem Praktikum so praktizierte. In: Ethnopostille. Zeitschrift für Studierende am Institut für Europäische Ethnologie/Volkskunde der Universität Innsbruck, 1 (1995/96), 23-24.

Unterluggauer, Ernst: Unvoreingenommene Studien für das Volkskunstmuseum. Diplomarbeit (Architektur), Innsbruck 1985.

Wedekind, Michael: „Gutachten“. Wien 2013, 81 Seiten (Seite 1 doppelt gezählt) [I. Stellungnahme zu den vom Verein ,Institut für Tiroler Musikforschung (Rum bei Innsbruck) vorgelegten Publikationen zu den Musikschaffenden der ,Arbeitsgemeinschaft Tiroler Komponisten' (1934-1938), 1-29, Wien, 20.6.2013; II. Stellungnahme zum Stand der historischen und sonstigen wissenschaftlichen Forschung über die Entwicklung der organisierten Tiroler Volkskultur in ihrem historischen und institutionellen Umfeld mit besonderem Fokus auf die Entwicklung im Nationalsozialismus, Wien, 30.9.2013, 2965; Schrifttumsnachweis, 66-78; Anhang: Standortnachweis zu Forschungsergebnissen und Schriftwechsel der Kulturkommission Südtirol des SS-Ahnenerbes (1940-1943/45) in Archiven, Bibliotheken und Instituten Österreichs, Italiens und Deutschlands, Wien, 39.9.2013, 79-81]. Abrufbar unter https:// www.tirol.gv.at/fileadmin/themen/kunst-kultur/abteilung/Sonstiges/Gutachten_Wedekind_S._1-40.pdf sowie https://www.tirol.gv.at/fileadmin/themen/ kunst-kultur/abteilung/Sonstiges/Gutachten_Wedekind_S._41-81_Dez15. pdf (Stand: 26.6.2019).

Weiermair, Peter (Hg.): Der Vogel Selbsterkenntnis. Aktuelle Künstlerpositionen und Volkskunst. Tiroler Volkskunstmuseum Innsbruck 27. Juni bis 26. Oktober 1998. Zürich-New York 1998.

Wieser, Heinz: Das Erfolgsgeheimnis Tirols im Geiste Europas. Brixen 2014 [darin „Tiroler Volkskunstmuseum“, 183]. 
"Wie man es erzählen kann, so ist es nicht gewesen.

Wenn man es aber erzählen kann, wie es war,

dann ist man nicht dabeigewesen,

oder die Geschichte ist lange her,

so daß einem Unbefangenheit leichtfallt.

Allein daß man trennen muß und hintereinanderreihen, um es erzählbar zu machen,

was in Wirklichkeit miteinander vermischt ist

bis zur Unlösbarkeit ..."

(Christa Wolf, Nachdenken über Christa T.) 
Mein Dank gilt all denen, die es mir ermöglicht haben, diese Arbeit fertigzustellen. 


\section{Inhalt}

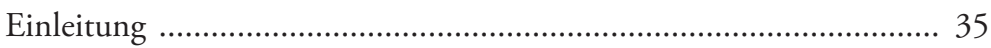

1. Wirtschaftlich-soziale Situation in Österreich ab 1860 .................... 43

1.1. Unterschiedlich Entwicklung der Wirtschaft innerhalb

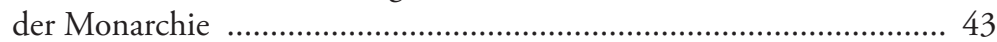

1.2. Wirtschaftlich-soziale Situation in Tirol ab 1860 ............................. 45

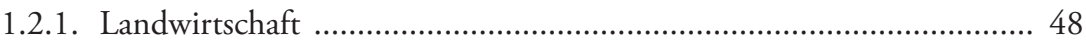

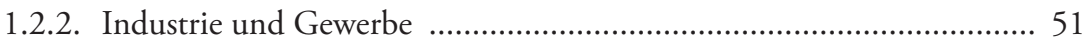

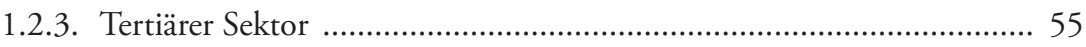

2. Politisch-kulturelle Situation in Tirol ab der

2. Hälfte des 19. Jahrhunderts ........................................................... 61

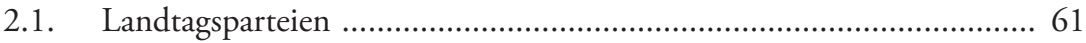

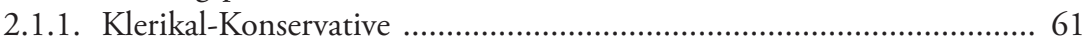

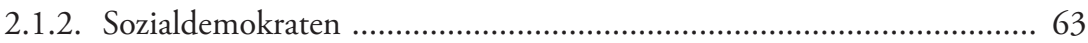

2.1.3. Liberale .............................................................................................. 63

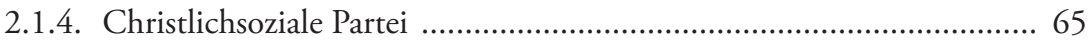

2.2. Kulturelle Landeseinheit und nationalistische Strömungen ..................66 66

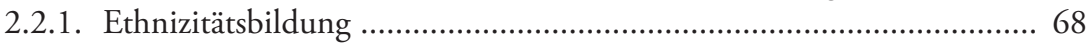

3. Vom Denkmal- zum Heimatschutz ……....................................... 75

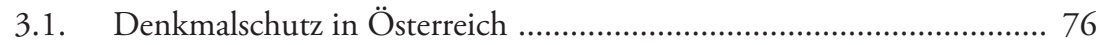

3.2. Denkmal- und Altertumsschutz in Tirol ......................................... 77

3.2.1. Zur Entdeckung der Volkskultur im 19. Jahrhundert ......................... 79

3.2.2. Sammeln und Retten als Aneignungsformen von Volkskunst ............. 80

3.2.3. Verschleppung tirolischer Altertümer ins Ausland .............................. 81

3.3. Zum „Tiroler Heimatschutzverein “ .................................................. 84

4. Zum „Tiroler Gewerbeverein“ .......................................................... 91

4.1. Gewerbevereine und Handelskammern in der Monarchie .................. 91

4.1.1. Gewerbevereine ....................................................................... 91

4.1.2. Handelskammern .................................................................... 93 


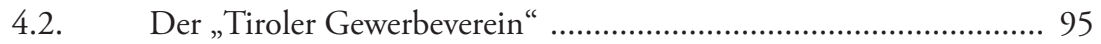

4.2.1. Vereinsgründung .................................................................... 96

4.2.2. Vereinsstatuten ......................................................................... 97

4.2.3. Liberale Ausrichtung des Gewerbevereines .................................... 98

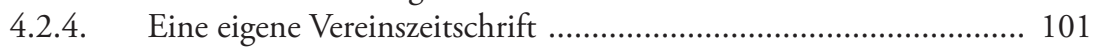

4.2.5. Der Vorstand des „Gewerbevereines“ ........................................ 108

4.2.6. Vereinsausrichtung: Gewerbe oder Kunstgewerbe? ...................... 109

4.2.7. Der Mitgliederstand des Vereins ............................................... 110

4.2.8. Aktivitäten des Gewerbevereins .................................................. 111

Exkurs 1: Über die Weltausstellungen und die dortige Art,

Tirol zu präsentieren ............................................................... 113

4.2.9. Stilfrage .............................................................................. 117

4.2.10. Dominierendes Kunstgewerbe ................................................. 118

4.2.11. Eigenes Ausstellungswesen ...................................................... 119

4.3. Gewerbemuseen ................................................................. 125

5. Vom „Tiroler (Handels- und) Gewerbemuseum“ zum „Tiroler Volkskunstmuseum“ “.................................................. 129

5.1. Frühe Bestrebungen zur Museumsgründung ............................. 131

5.1.1. Statuten für ein „tirolisches Gewerbemuseum “ ........................... 135

5.2. Neuerlicher Anlauf zur Museumserrichtung .............................. 138

5.2.1. Die Handels- und Gewerbekammer als neuer Träger

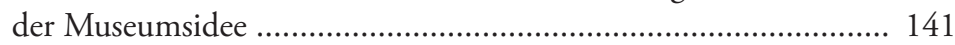

5.2.2. Erste Museumspläne der Kammer .............................................. 144

5.3. Der Weg zum „Museum für Volkskunst und Gewerbe“ .............. 149

5.3.1. Bestrebungen zur Errichtung eines eigenen Museumsgebäudes .... 156

5.3.2. Die Stellung des Landes zur Museumserrichtung ......................... 168

5.3.3. Die Sammlungsobjekte des „Museum für

Volkskunst- und Gewerbe“ ..................................................... 172

Exkurs 2: Gewandeltes Sammelinteresse .................................................... 180

5.4. Die Entwicklung des Museums nach dem Ersten Weltkrieg ........ 186

5.4.1. Neuerlicher Versuch der Vereinigung mit dem Ferdinandeum ..... 186

5.4.2. Die Übernahme des Museums durch das Land Tirol ................... 189

5.4.3. Vorkehrungen zur Museumseröffnung ....................................... 194

5.4.4. Museumseröffnung ................................................................... 202 
6. Kurzgefaßte Museumsgeschichte seit der Wiedereröffnung 1948 bis in die späten 60er Jahre 211

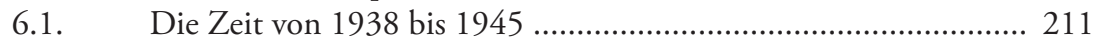

6.2. Das Volkskunstmuseum nach 1945 ........................................... 215

6.2.1. Wiedereröffnung ................................................................ 215

6.2.2. Neue Aufgaben .................................................................. 216

Exkurs 3: Zum „Tiroler Heimatwerk“ ...................................................... 218

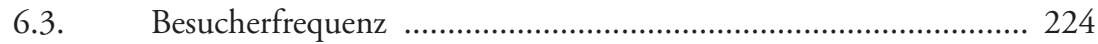

6.4. Die Neugestaltung der Schausammlungen ................................ 230

7. Bibliographie ................................................................... 241

7.1. a) Zeitungen, gedruckte und ungedruckte Quellen .................... 241

7.2. b) Selbständig und unselbständig erschienene Schriften .............. 241 



\section{Einleitung}

Das Museum für Volkskunst in Innsbruck gilt weithin als das Bekannteste und Bedeutendste seiner Art.

Wie im Namen ausgedrückt, liegt der Schwerpunkt dieser Institution bei der Sammlung und Präsentation von Volkskunst.

Das Museum hat aber keineswegs eine reibungs- und bruchlose Geschichte aufzuweisen. Neben allen Schwierigkeiten, die der Begriff Volkskunst für die Museumsarbeit mit sich bringt - nicht zu allen Zeiten wurde das gleiche darunter verstanden - lag die ursprüngliche Intention der Museumsbegründer auf anderem Gebiet. Ihnen schwebte nicht so sehr eine rein ästhetisch-künstlerisch ausgerichtete Sammlung vor als vielmehr eine Musterkollektion, die Vorbild- und Nachahmungscharakter haben sollte, wenn auch hierbei der Geschmacksbildung eine wichtige Rolle zukam.

In der 100jährigen Geschichte des Museums (das erst 1929 offiziell eröffnet worden war) haben sich dessen Intentionen, Pläne und Ziele mehrmals gewandelt.

Diese Arbeit soll nicht so sehr eine Chronik der Museumsentwicklung als vielmehr der Versuch sein, das Werden dieser Institution, vor dem Hintergrund der jeweiligen Zeit, aufzuzeigen.

Museen, wie wir sie heute kennen, gehören seit rund 200 Jahren zum Kulturgut des Bürgertums. Sie sind öffentliche Einrichtungen, das heißt, sie sind für die Bürger OFFEN - dies im Gegensatz zu ihren mittelbaren Vorläufern, den Wunder- und Raritätenkammern der Fürsten und Könige, die nur für diese bestimmt waren.

Das Museum ist in gewisser Hinsicht Mittel und Ausdruck der erfolgreichen Emanzipation des Bürgertums; nicht so sehr aufgrund der mehr oder weniger freien Zutrittsmöglichkeit, vielmehr wegen der ihm zugedachten Aufgaben.

Museale Einrichtungen sind nicht mehr bloß reine Erbauungs- und Prunkräume, mittels derer die Herrscher vor ihresgleichen glänzen konnten, jetzt lag ihre Funktion in der Vermittlung von Bildung und der Hebung des bürgerlichen Bewußtseins.

Museen wurden auch zur Stätte der Hebung nationalen Selbstwertes, und das Gründungsjahr vieler Museen (vor allem der zahlreichen Landes- und Nationalmuseen) fällt nicht zufällig in die Zeit des Aufkommens des bürgerlichen Nationalismus. 
Auch in Tirol entstand bereits 1823 solch ein Nationalmuseum: das Ferdinandeum, dessen Aufgabe es sein sollte, Objekte der Geschichte, Kunst, Naturkunde und des Gewerbes zu sammeln und auszustellen. ${ }^{1}$

In der, das Bildungswesen des 19. Jahrhunderts weitgehend bestimmenden, Vorstellung des veredelnden und erzieherischen Charakters beispielhafter Objekte ${ }^{2}$, erhielten museale Sammlungen und Ausstellungen ihre Bedeutung.

Die durch die industrie-kapitalistische Entwicklung in der zweiten Hälfte des 19. Jahrhunderts erfolgten Veränderungen in Handwerk und Gewerbe (hin zur Massenproduktion, Konzentration und Verlegung von Produktionsstätten, ...) riefen eine konservative Gegenstrategie hervor. Diese ging von den, in ihrer Existenz bedrohten, Handwerkern und Gewerbetreibenden aus.

Die Anlegung von Vorbild- und Mustersammlungen sollte das notwendige Rüstzeug liefern, um der industriellen Konkurrenz widerstehen zu können.

Die Betonung heimischer, traditioneller Produkte sollte den Gegenpol zur vermeintlichen Vermassung und Heimatlosigkeit der maschinell gefertigten Produkte liefern.

Vor dem Hintergrund dieser sozio-ökonomischen Veränderungen werden die ersten Schritte zur Gründung des späteren Volkskunstmuseums verständlich, das, in der Tradition der Gewerbemuseen stehend, eine Vorbild- und Mustersammlung werden sollte.

Nicht nur auf der materiellen Seite, auch auf ideell-geistigem Gebiet, führte die Industrialisierung zu konservativen Gegenbewegungen.

1 Nach Bruckmüller entwickelten „erwachendes und wachsendes Selbstbewußtsein [...] schon im Vormärz eine über die adeligen Trägerschichten frühen Nationalstolzes hinausweisende Dynamik. In Lese- und Gewerbevereinen gewann das wachsende bürgerliche, zunächst das bildungs-, erst sekundär auch das wirtschaftsbürgerliche, Element zunehmend an Gewicht." (1985, S. 344) Auch an der Entstehung des Ferdinandeums waren diese neuen Trägerschichten beteiligt: die Initiative zur Museumsgründung ging nicht zuletzt vom Landesgouverneur Karl Chotek aus; der erste Museumsprotektor war Erzherzog Ferdinand, nach dem die Institution auch benannt wurde. Vgl. Egg, „Chronik des Ferdinandeums 1823-1973“, 1973, S. 5 ff.

2 Vgl. Mundt 1974, S. 13; die in diesem Zusammenhang auf die Vorlagehefte verweist, die die Handwerker zum Nachahmen animieren sollten. Das Konzept der mustergültigen Vorbilder scheiterte aber am mangelnden Kontakt zwischen Entwerfern und Ausführenden (ebd., S. 13 f.). 
In der Entdeckung der traditionellen Kunst als Volkskunst ${ }^{3}$, sowie im Heimatschutz (= Erhaltung des Überkommenen), glaubten (klein)bürgerliche Kreise, ein Mittel zum Einhalt der industriellen Umwälzung gefunden zu haben.

Die Strömung zur Rettung heimischer Altertümer - besonders vor ihrer Verschleppung ins Ausland - bildete einen weiteren Ansatzpunkt zur Museumsgründung, galt es doch, eine Heimstätte für diese geretteten Objekte zu finden!

Dabei entsprang das Interesse an Volkskunst eher der Identitätssuche eines durch die gesellschaftlichen Entwicklungen verunsicherten Bürgertums, als dem Selbstverständnis des VOLKES ${ }^{4}$, dem die ihm angeblich genuine Volkskultur nur allzuoft erst beigebracht werden mußte.

Damit verbunden ist auch das Problem des Rücklaufes, daß, wie Hermann Bausinger vermerkt, „die proklamierte Volkskultur [...] auf die tatsächliche Volkskultur zurück[wirkte]".

Durch die Schaffung eines Kanons echter volkskultureller Äußerungen, mittels „bürgerliche[r] Modifikation bäuerlicher Kulturmotive“6, erhielt eine Institution

3 „Der romantische Entwurf der Wiederentdeckung eines in versunkenen Vorzeiten beheimateten nationalen Volksgeistes [...] war [...] ein Denkstil, in dem die zur Herrschaft gelangte Klassenkultur die ihr anverwandelbaren Traditionselemente so auswählte, uminterpretierte und ihren eigenen Vorstellungen gemäß neu zusammensetzte, wie sie ihrem politisch-kulturellen Selbstverständnis und ihrem geschichtlichen Legitimationsbedürfnis entsprachen." (Schindler 1984 , S. 28 f.)

4 Im „Deutschen Wörterbuch“ heißt es beim Begriff „Volk“: „[...] eine besonders bedeutsame Wandlung tritt in der zweiten Hälfte des 18. Jahrhunderts und in der ersten des 19. Jahrhunderts ein. Die ästhetisch-philosophische Bewegung veredelt den Begriff des VOLKES als des Ursprungs des wertvollsten poetischen Gutes, [...]“" (Grimm 12. Bd., 1951, Sp. 454) Bert Brecht macht in den „Flüchtlingsgesprächen“ auf die beiden unterschiedlichen Gebrauchsweisen des Wortes VOLK aufmerksam, wenn er Kalle sagen läßt: „Das Wort ,Volk‘ ist ein eigentümliches Wort [...] Es hat eine ganz andere Bedeutung nach außen als nach innen. Nach außen, nach den anderen Völkern hin, gehören die Großindustriellen, Junker, höheren Beamten, Generäle, Bischöfe usw. natürlich zum deutschen Volk, zu keinem andern. Aber nach innen hin, wo es sich also um die Herrschaft handelt, werden sie diese Herrn immer vom Volk reden hören als von ,der Masse 'oder ,den kleinen Leuten' usw.; sie selber gehören nicht dazu. [...]“ (1984, S. 135 f.)

5 Hermann Bausinger sieht in der Entdeckung der Volkskultur - um 1800 - einen Fortschritt, da sie das Ende der bislang erfolgten „Ausblendung und Distanzierung“ des „Popularen“ bedeutete. Er betont aber, daß „diese neuentdeckte Volkskultur von Anfang an funktionalisiert wurde, ja sie im Grunde weniger um ihrer selbst willen als zum Zweck der Blutauffrischung der matt gewordenen Hochkultur überhaupt entdeckt wurde“ (1987, S. 35); und gelangt zum Schluß, daß „das Interesse am Volk gar nicht in erster Linie auf dieses Volk zielt, sondern auf mögliche Erneuerungsschübe in der Kultur der Gebildeten“! (Ebd.)

6 Bausinger weist in diesem Zusammenhang darauf hin, daß „hinter der Propagierung einer einheitlichen Volkskultur [...] die sozialen Gegensätze zu verschwinden“ schienen (1987, S. 39 f.). Dies wird vor allem an der "Ständestaat"- und NS-Ideologie offensichtlich, wo 
wie das Volkskunstmuseum Gelegenheit, der Allgemeinheit diesen Fundus zu präsentieren; daneben war das Museum aber auch, gleichsam als Spiegel richtigen Volkskunstschaffens, Wertmaßstab für die der Erhaltung und Erneuerung der Volkskultur verpflichteten Vereine und Personen.

Es verwundert nicht, daß bei der Propagierung der wiederentdeckten Volkskultur schon von Anfang an enge Beziehungen zum Fremdenverkehr geknüpft wurden. Das danach erschaffene Bild diente als hervorragendes Verkaufs- und Werbemittel, und der Tiroler Bauer in Lederhosen wurde nicht nur zum Sinnbild der eigenen Tradition, sondern auch zum Klischee für willkommene Touristen.

Der Sammelbewegung, die der Gründung des Museums vorausging, ist ein guter Teil der Arbeit gewidmet, bestimmten doch diese Sammler und Retter, was, als sanktionierte Kulturobjekte, in Zukunft als Tirolische Volkskultur zu gelten hatte. Dabei wurde ihre Intention vor allem durch ästhetische und nationalistische Kriterien bestimmt; keinesfalls lag es ihnen nahe, Alltagskultur des Volkes zu sammeln! Die des Aufbewahrens für Wert befundenen Objekte wurden somit ihren einstigen „Gebrauchszusammenhängen entrissen und zu Relikten degradiert" ${ }^{\text {"7 }}$.

Die meisten volkskundlichen Sammlungen geben daher - querschnittartig Zeugnis über eine bestimmte Epoche und stellen den sich heute damit beschäftigenden Wissenschaftler vor Probleme der zeitlichen Datierung und Herkunftsbestimmung, da die Objekte vielfach über Händler und Antiquare ins Museum kamen und so genaue Angaben zu ihrem Ursprung fehlen. ${ }^{8}$

Volkstumsveranstaltungen (Trachtenumzüge, Brauchtumsfeste, ...), die den Volkskörper, das Volksganze betonen sollten, zum Repertoire beider Regime gehörten!

7 Schindler 1984, S. 30; ihm zufolge bestimmten in dieser Sammelbewegung „Museen, Geschichts- und Altertumsvereine, zahlreiche der ,Kulturpflege' gewidmete Institutionen und eben auch die Gründerväter der Volkskunde [...] darüber, welche Bestandteile aus dem großen Reservoir der Volkskultur erhaltenswert und d.h. auf gut deutsch ,volkstümlich` waren und welche nicht." (ebd., S. 28)

8 So berichtet Leopold Schmidt, daß Michael Haberlandt vor 1900 in Südtirol „kistenweise verrostetes Alteisen angekauft" habe, das dann die längste Zeit als unscheinbares Depotmaterial im Wiener Museum gelegen hätte (1963, S. 250).

Auch Wolfgang Gürtler weist in seiner Arbeit zur „Österreichischen Volkskundlichen Museologie“ darauf hin, daß zu Sammelbeginn (letztes Drittel des 19. Jahrhunderts) einerseits von einer "naiv-romantischen Fehlhaltung“, die Volk mit Bauern gleichsetzte, ausgegangen, andererseits versucht worden war, "möglichst alte, zum Sammlungszeitpunkt bereits nicht mehr in Verwendung stehende oder für die - vorwiegend aus bürgerlich-städtischem Milieu stammenden - Sammler fremdartige Stücke“ zu sammeln, und er befindet, daß dadurch eine „Anhäufung von Objekten aus verschiedenen Lebensbereichen, Landschaften und sozialen Schichten zustande [kam], die nichts aussagte." (1976, S. 7 f.) 
Die Reliquienhaftigkeit der ausgestellten Objekte, sowie das ästhetisierende Ambiente, in dem sie präsentiert werden, gibt einen Geschichtsschein vor, der jegliche Authentizität verbannt.

Verstärkt wird diese Art der Darstellung noch durch das Fehlen jeglicher Hintergrundinformation, sodaß es dem Betrachter unmöglich ist, den Zusammenhang, aus dem die Gegenstände gerissen wurden, wiederzuerkennen.

Museen gelten nur allzu oft als neutrale Vermittler zwischen Kunst und dem Menschen; dies sind sie jedoch auf keinen Fall, verwirklicht doch im Museum "der Teil unserer Gesellschaft seine kulturellen Interessen, der heute die Normen bestimmt", wie Dieter Hacker in einem Beitrag über "Unsere Nationalgalerie“ feststellt. ${ }^{?}$

In den Volkskundemuseen, die meist noch immer so tun, als ob die Mehrzahl der Leute auf dem Lande leben würde, herrschen monumentale Gerätesammlungen vor, die jedoch nichts über die Arbeit auszusagen vermögen.

$$
\begin{aligned}
& \text { "Überall werden nur die Objekte gesammelt, aber kaum irgendwo stellt } \\
& \text { sich der Mensch als Erfinder, Verfertiger und Benutzer dieser Objekte } \\
& \text { ein. }{ }^{10}
\end{aligned}
$$

Ein besonderes Problem dieser Diplomarbeit stellte die Quellenlage dar.

Obwohl das Museum, wie oben schon erwähnt, zu den bekanntesten und bedeutendsten seiner Art zählt, gibt es dazu nahezu keine Arbeiten.

Einzig um das Jahr 1929 waren ein paar Aufsätze erschienen, die - zusammen mit dem bislang umfangreichsten Beitrag zur Museumsgeschichte, verfaßt vom

9 Wiedergegeben in „Kunst - Gesellschaft - Museum“ (hg. H. Kurnitzky). Notizbuch 3 (1980), S. $123 \mathrm{f}$.

10 So Janos Frecot im Beitrag „Museum, Trödel, Kinderzimmer“ ebenfalls im Notizbuch 3, S. 157 ff.; Hier wäre eine Kritik an der heute so beliebten Zauberformel des Alltags angebracht. Es nützt nichts in dem Moment, wo der Alltag in Mode gekommen zu sein scheint, einfach anstelle der früheren Begriffe Alltagskultur zu setzen, um dann wieder zur Tagesordnung überzugehen. Dann holt einen der Schein des Alltags schneller wieder ein, als einem lieb sein könnte. So in einem Beitrag der Tiroler Tageszeitung zum 100-Jahr-Jubiläum des Tiroler Volkskunstmuseums, wo es, betreff der von der jetzigen Museumsführung angestrebten Einbeziehung der Alltagskultur, heißt: „Aber auch heute wollen die Tiroler in ihrem Volkskunstmuseum ein Schmuckkästchen sehen, und nicht das Zeugnis funktional ausgerichteten, harten Alltags." (Nr. 158 vom 9./10.7.1988) Einmal möchte ich bezweifeln, ob angesichts der überwiegend ausländischen Museumsbesucher (Touristen) überhaupt so eine starke Beziehung der Tiroler (und wohl auch der TirolerINNEN!) zu ,ihrem“ Museum besteht, zum anderen wird hier deutlich, daß Alltag, losgelöst von den gesellschaftlichen Bezügen der Produktion und Reproduktion, allemal wieder einen „affirmativen Charakter“ (Marcuse) gewinnt! 
ehemaligen Direktor Josef Ringler - den ganzen Grundstock an Veröffentlichungen bilden. ${ }^{11}$

So war ich großteils auf Zeitungs- und Primärquellen (Akten, Briefe und Schriftstücke) angewiesen.

Im Archiv des Tiroler Volkskunstmuseums (im weiteren zitiert als TVM) befinden sich einige Ordner mit Kuratoriums- und Jahresberichten von seiten der Direktion, ferner ein Teil des Schriftverkehrs mit diversen Institutionen, sowie mit internen Aufzeichnungen der Museumsleitung.

Im Tiroler Landesarchiv (im folgenden zitiert als TLA) fand sich Material über das Volkskunstmuseum in den Aktenbeständen der Präsidialabteilung der Tiroler Landesregierung, sowie in der späteren Abteilung III (Kunst).

Daneben habe ich die zur damaligen Zeit im Tiroler Raum vorherrschenden Zeitungen auf Artikel und Beiträge zum Volkskunstmuseum und seinen Vorläufereinrichtungen („Gewerbemuseum“, „Museum für Tirolische Volkskunst und Gewerbe") durchgesehen.

Schlußendlich enthielten auch die Sitzungsprotokolle des Tiroler Landtages, sowie der Innsbrucker Handels- und Gewerbekammer Einschlägiges zur Thematik Volkskunstmuseum. ${ }^{12}$

Für die Darlegung der Entstehung der Museumsidee, die ich hier vor allem anhand des „Tiroler Gewerbevereines“ und des Denkmal-/Heimatschutzes abhandle, habe ich dieselben Quellengattungen eingesehen; dazu zusätzlich die jeweiligen Vereinsmitteilungen („Gewerbeblatt“, „Tiroler Heimatblätter“).

Bei all dieser Arbeit galt es stets zu berücksichtigen, was Jörg Mauthe zum Umgang mit Protokollen und ähnlichen Quellen, in Bezug auf die Übertragung der Ministerratsprotokolle, - literarisch - festgehalten hat:

„[...] denn natürlich war hier nicht einfach eine stenographische Niederschrift in allgemein lesbare Schreibmaschinzeilen zu transponieren, sondern in der Tat eine wahre Übersetzung vorzunehmen, indem man das Protokoll von allen Zufälligkeiten, Subjektivitäten und Aktualitätsbezügen aufs gründlichste reinigte und das übrigbleibende so lange einem veredelnden Abstraktionsprozeß unterzog, daß es am Ende, von allen menschlichen Schlacken gereinigt, unbesorgt veröffentlicht beziehungs-

11 Hier wären die Aufsätze von Kofler 1929, Paulin 1929, Ringler 1928, sowie Stifter 1930 zu nennen; der erwähnte Beitrag von Ringler erschien 1959 in der „Gamperfestschrift“. Ein weiterer Bericht zum Volkskunstmuseum erschien, verfaßt vom ehemaligen Handelskammersekretär Friedrich Mader, zu dessen 25. Jubiläum in der Tiroler Tageszeitung Nr. 71 vom 27.3.1954, S. 7.

12 Vgl. den Teil a) der Bibliographie: „Zeitungen, gedruckte und ungedruckte Quellen“! 
weise im Haus-, Hof- und Staatsarchiv zum Nutzen späterer Geschichtsschreibung abgelegt werden konnte. "13

Immer gilt es dabei zu berücksichtigen, daß Dokumente nicht für sich selbst sprechen, „nicht selbst ihre eigene Geschichte erzählen“; genauso wie eine historische Wissenschaft, „die sich auf die bewußten Handlungen von Menschen konzentriert, nicht ausreicht; menschliches Verhalten kann nur verstanden werden in dem Rahmen von Strukturen, innerhalb deren dieses Verhalten stattfindet. ${ }^{\text {"14 }}$

14 Iggers 1978, S. 20. 



\section{Wirtschaftlich-soziale Situation in Österreich ab 1860}

Allzu oft wird die Entstehungsgeschichte kultureller Institutionen, wie Museen, Schulen etc., losgelöst von ihren gesellschaftlichen Entwicklungsbedingungen untersucht und beschrieben. Meist sind es dann die großen Männer mit ihren großen Ideen, die solche Institutionen emporgebracht hätten. Wenn es oft die rechte Person zur rechten Zeit benötigt, um von einem Plan zur Verwirklichung einer Idee zu gelangen, können diese Betreiber doch nicht losgelöst von ihrem sozio-ökonomischen Umfeld aus agieren; ja auch die Ideen, deren Realisierung sie anstreben, sind nicht losgelöst vom gesellschaftlichen Kontext entstanden, sondern Produkt desselben.

Deshalb versuche ich in den ersten beiden Kapiteln, einen gerafften Überblick der ökonomischen, politischen und kulturellen Bedingungen der Entstehungszeit des Museums zu geben.

Da aber die Tiroler Situation nur eingebunden in die Gesamtentwicklung der Monarchie zu verstehen ist, stelle ich die wichtigsten ökonomischen Veränderungen im Habsburgerreich seit der Mitte des vorigen Jahrhunderts voran.

\subsection{Unterschiedliche Entwicklung der Wirtschaft innerhalb der Monarchie}

Die sozio-ökonomische Entwicklung des Habsburgerreiches in der zweiten Hälfte des 19. Jahrhunderts - spätestens seit der Auflösung der feudalen Gesellschaftsverfassung durch die bürgerliche Revolution 1848 und dem Beginn des modernen Parlamentarismus ${ }^{15}$ - ist durch zunehmende Industrialisierung, vor allem in den östlichen, deutschsprachigen Ländern der Monarchie, gekennzeichnet, verlief aber gegenüber anderen europäischen Staaten zeitlich verzögert und gebremst.

15 Das sogenannte Februarpatent (1862) verlegte die Gesetzgebung in den Reichsrat, der von den Landtagen beschickt wurde. Diese waren aufgrund der neu erlassenen Landesverfassungen nicht mehr ständisch zusammengesetzt, sondern wurden mittels eines Kurien-Wablsystemes gewählt. Das Stimmrecht war an eine Mindeststeuerleistung („Zensus“) gebunden, die für jede Kurie eigens festgelegt wurde. Außerdem konnten nicht alle Abgeordnete direkt gewählt werden; Kirche, Großgrundbesitzer, Handelskammern und die Innsbrucker Universität entsandten ihre Vertreter unmittelbar in den Landtag (vgl. Forcher 1986, S. 22 f.). 
1869 lebten ca. 20,4 Mill. Menschen im damaligen Österreich ${ }^{16}$, in dem die Agrarbevölkerung - mit einem Anteil von 67,2 \% aller Beschäftigten (1890 62,4 \%, 1900 58,2 \% und 1910 53,1 \%) - den sozialen Unterbau stellte.

Die Zahl der Beschäftigten in Industrie und Gewerbe stieg dagegen im gleichen Zeitraum nur allmählich von 19,7 \% (1869) auf $24 \%$ (1910). ${ }^{17}$

Allerdings geben diese Daten ein verzerrtes Bild des Industrialisierungsprozesses wieder; denn dieser war durch starke räumliche Differenzierungen gekennzeichnet, da verschiedene Umstände einer ausgeglichenen Modernisierung entgegenstanden:

- so die natürlichen Gegebenheiten der Länder [die für die wirtschaftliche Entwicklung ungünstigen Geländeverhältnisse (Alpen, Karpaten, ...), das Fehlen günstig gelegener Wasserwege, vor allem eine effiziente W-O-Verbindung und die ungleiche regionale Verbreitung der Bodenschätze].

- ferner wirkte das Nationalitätenproblem „wegen der grundsätzlichen Unvereinbarkeit der politischen und wirtschaftlichen Ziele hemmend" ${ }^{\text {"18 }}$.

So betrug der Anteil der Beschäftigten an Land- und Forstwirtschaft 1869 in den „Karpatenländern“ $87,1 \%$, in den „Sudetenländern“ hingegen $56,4 \%$, in den „Alpenländern“ 60,0 \%.

In Industrie und Gewerbe lag der Anteil im gleichen Jahr in den „Karpatenländern“ bei 5,2\%, in den "Sudetenländern“ bei 30,1\% und in den „Alpenländern" bei $23,3 \%$. $^{19}$

Die insgesamt steigende Bevölkerungszahl (von 20,6 Mill. im Jahre 1870 auf 28,6 Mill. 1910) zeigt ebenfalls die unterschiedliche Entwicklungsdynamik in der Monarchie auf.

Die Alpen- und Sudetenländer verzeichneten ein eher geringes Wachstum gegenüber den Gebieten der Bukowina und Galizien.

Durchschnittlich betrug das jährliche Bevölkerungswachstum zwischen 1857 und 1910 in den „Alpenländern “ 0,82 \%; in den beiden „Karpatenländern“ aber $1,03 \%$.

16 Dies waren die im „Reichsrat vertretenen Königreiche und Länder“: die „Alpenländer“ Niederösterreich, Oberösterreich, Salzburg, Kärnten, Krain, Vorarlberg, Tirol und Steiermark, die „Sudetenländer“ Böhmen, Mähren und Schlesien, die „Karpatenländer“ Galizien und Bukowina, sowie die „Küstenländer“ Görz und Gradiska, Triest, Istrien und Dalmatien (vgl. Helczmanovszki 1973, S. 114), die seit dem Ausgleich mit Ungarn (1867) auch als Cisleithanien bezeichnet wurden (vgl. Matis 1985, S. 479).

17 Matis 1985, S. 480 u. 484.

18 Ebd., S. 479.

19 Ebd., S. 484. 
Die Bevölkerungsdichte stieg zwischen 1869 und 1910 von 68 auf 95 Einwohner $/ \mathrm{m}^{2}$, erreichte aber in manchen Teilen von Böhmen, Mähren und Schlesien sowie in Galizien über 120 Einwohner $/ \mathrm{m}^{2} .{ }^{20}$

Eng mit der Industrialisierung verbundenen schritt die Urbanisierung in der zweiten Hälfte des 19. Jahrhunderts fort.

1870 waren nur die Städte Wien und Prag Großstädte mit über 100.000 Einwohnern, 1900 gab es schon 7 solcher Städte, in denen 10,8 \% der Monarchiebevölkerung lebten.

Neben dem Geburtenüberschuß beruhte dieses städtische Wachstum vor allem auf Einwanderung und Zuzug. So wuchs Wien im Zeitraum von 1870 bis 1910 von 880.000 auf 2,03 Mill. Einwohner an. Der Wanderungsgewinn in diesem Zeitraum betrug 665.000 Personen. $^{21}$

\subsection{Wirtschaftlich-soziale Situation in Tirol ab 1860}

Die gesamtgesellschaftliche Entwicklung der Monarchie wirkte sich auch aufTirol aus, jedoch verliefen diese sozio-ökonomischen Veränderungen hier gemächlicher. 1869 lebten innerhalb des Kronlandes Tirol 783.055 Menschen, wobei die Gesamtfläche $26.700 \mathrm{~km}^{2}$ umfaßte (incl. der südlich des Brenners gelegenen Landesteile mit $\left.14.100 \mathrm{~km}^{2}\right) .{ }^{22}$ Bis 1910 stieg die Bevölkerung auf 946.613 Personen an. ${ }^{23}$

Wie in anderen Alpenländern war im Kronland Tirol die Agrarbevölkerung noch lange sozialer Unterbau der Gesellschaft.

Erst gegen Ende des vorigen Jahrhunderts begann sich die gesellschaftliche Struktur des Landes zu wandeln.

Außerhalb des Agrarsektors weitgehend fehlende Arbeitsmöglichkeiten zwangen schon seit langem einen ungleich größeren Teil der Erwerbstätigen ins benachbarte Ausland abzuwandern (meist saisonal), als Arbeitssuchende ins Land kamen - zwischen 1869 und 1900 ist daher die positive Wanderungsbilanz Tirols eher gering. Da sich auch die Geburtenbilanz innerhalb von 1869 bis 1890 nur in einem bescheidenen Maße bewegte, war die gesamte Bevölkerungsentwicklung

20 Ebd., S. $480 \mathrm{ff}$.

21 Ebd., S. 482; 1900 zählte Cisleithanien 41 Städte mit mehr als 25.000 Einwohnern/Stadt, in denen ca. 14 \% der Reichsbevölkerung lebten.

22 Riedmann 1983, S. 966.

23 Bolognese-Leuchtenmüller 1978, S. 144 f. (Tab.52) 
in diesem Zeitraum, mit einer Zunahme von insgesamt 13.100 Personen, eher unbedeutend.

Erst ab den 1890er Jahren kam stärkere Bewegung in die Bevölkerungsentwicklung, erreichte doch die Geburtenbilanz ab diesem Zeitpunkt weit höhere Werte; die Wanderungsbilanz verzeichnete zwischen 1900-1910 ein Plus von 13.100 Personen, sodaß sich für Tirol in den zwei Jahrzehnten von 1890 bis 1910 eine Bevölkerungszunahme von 54.700 Personen ergab.

Die folgende Tabelle zeigt die Entwicklung detailliert; als Vergleichszahlen sind die Werte der heutigen Bundesländer Salzburg und Wien beigegeben.

Bevölkerungsentwicklung der österreichischen Bundesländer Tirol, Salzburg und Wien (in 1.000): ${ }^{24}$

\begin{tabular}{lcccccc}
\hline & & $1869-$ & $1880-$ & $1890-$ & $1900-$ & $1910-$ \\
& & 1880 & 1890 & 1900 & 1910 & 1923 \\
\hline \multirow{4}{*}{ Tirol } & G & 2,9 & 1,4 & 12,5 & 25,2 & 5,7 \\
& W & 4,9 & 3,9 & 3,9 & 13,1 & 3,5 \\
& Z & 7,8 & 5,3 & 16,4 & 38,3 & 9,2 \\
\hline \multirow{4}{*}{ Salzburg } & G & 3,9 & 4,7 & 9,5 & 17,1 & 3,9 \\
& W & 6,5 & 5,2 & 9,8 & 4,8 & 4,2 \\
& Z & 10,4 & 9,9 & 19,3 & 21,9 & 8,1 \\
\hline \multirow{4}{*}{ Wien } & G & 88,4 & 102,6 & 165,5 & 162,8 & $-103,9$ \\
& W & 175,7 & 164,5 & 173,4 & 151,7 & $-61,0$ \\
& Z & 264,1 & 267,1 & 338,9 & 314,5 & $-164,9$ \\
\hline
\end{tabular}

$\mathrm{G}=$ Geburtenbilanz; $\mathrm{W}=$ Wanderungsbilanz; $\mathrm{Z}=$ Zusammen (Gesamtveränderung)

24 Nach Helczmanovszki 1973, S. 122; die Zahlenangaben beziehen sich auf die Länder im Gebietsstand der Zweiten Republik!

Eigentlich müßte es, anstatt des hier von Helczmanovszki verwendeten Ausdruckes Geburtenbilanz, Geborenenbilanz heißen, da mit Geburten die Zahl der Geburtsvorgänge, mit Geborenen die Zahl der Auf-die-Welt-gekommenen verstanden wird; bei Mehrlingsgeburten ist die Zahl der Geburten dann nicht gleich der Zahl der Geborenen. Der Vergleichbarkeit mit H. wegen, bleibe ich aber hier bei seiner Benennung! 
Bis 1910 konnte Wien bevölkerungsmäßig von seiner Metropolstellung im Habsburgerreich profitieren; sowohl die hohe Geburten- wie die Wanderungsbilanz sind Folge der überragenden Bedeutung der Hauptstadt, die wirtschaftlich stark dominierend und ein Machtzentrum war.

Erst nach dem Ende des Ersten Weltkrieges verringerte sich diese Wiener Vormachtstellung; die Provinzländer (u.a. Tirol und Salzburg) konnten vom Funktionsverlust der Metropole gewinnen, und ihr kontinuierlicher Aufwärtstrend in der Bevölkerungsentwicklung verstärkte sich noch durch die ökonomischen Veränderungen seit der Jahrhundertwende (beginnende Industrialisierung, Fremdenverkehr, ...).

Waren 1869153.298 Menschen in der Statistik als Erwerbstätige geführt, so sind es 1890157.241 und 1910 170.810; ihnen standen 186991.702 Personen, 189098.195 und 1910140.189 als sogenannte „Nichtbeschäftigte“ gegenüber.

Damit verringerte sich die Anzahl der „Erwerbstätigen“ an der Gesamtbevölkerung Tirols von 1869 mit 62,6 \% auf 54,9\% für 1910.

Mit 50,5\% standen 1934 gar mehr „Nichterwerbstätige“ den „Erwerbstätigen" gegenüber. ${ }^{25}$

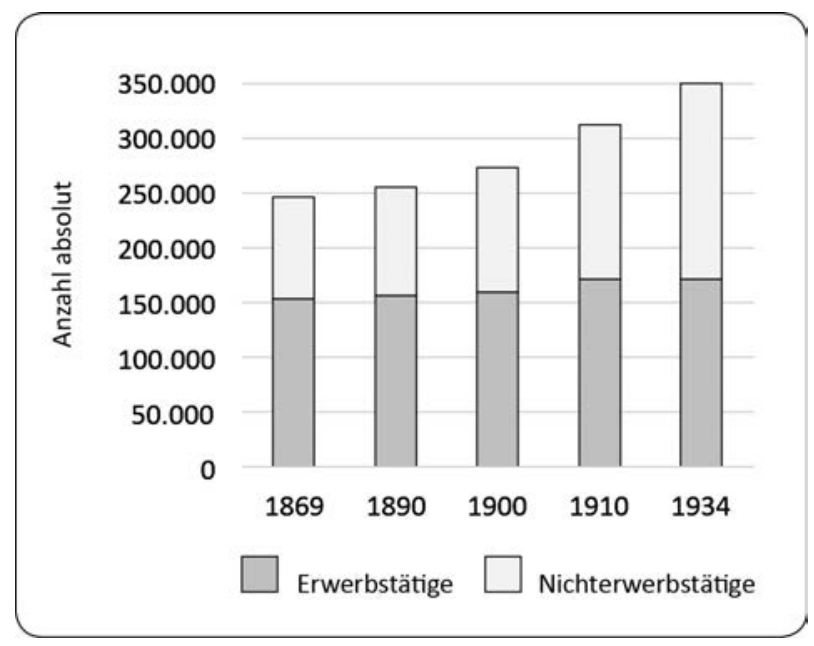

Graphik 1: Tiroler Wohnbevölkerung nach Erwerbstätigen und Nichterwerbstätigen

25 Errechnet nach den Angaben bei Otruba 1975; die Zahlenangaben beziehen sich auf Tirol im Gebietsstand der Zweiten Republik!

Auf die eigene Problematik der Begriffe „Erwerbstätige“ und „Nichterwerbstätige“, hinter letzterem meist Frauen- und/oder Hausarbeit als Nicht-Arbeit versteckt wird, kann ich hier nicht eingehen. 


\subsubsection{Landwirtschaft}

In der Land- und Forstwirtschaft waren 1869 67,3 \% aller Berufstätigen Tirols beschäftigt (= 314.129 Personen); 1910 waren es 60,6 \% (= 318.151 Personen). ${ }^{26}$

Doch dieser Agrarsektor war kein statisches Gebilde, sondern ebenfalls dem ökonomischen Wandel unterworfen.

Otto Bauer, der führende sozialdemokratische Politiker der Ersten Republik, beschreibt diese, durch die kapitalistische Entwicklung veränderte Lage der österreichischen Landwirtschaft:

„Mit dem Ausbau der Eisenbahnen, mit der Industrialisierung des Landes, mit der Verdichtung des Handelsverkehrs wurde die alte bäuerliche Naturalwirtschaft zersetzt. Der Bauer ging dazu über, Bedürfnisse, die er von alters her aus der eigenen Wirtschaft gedeckt hatte, durch Warenkauf zu decken. Vordem ließ der Gebirgsbauer die aus der eigenen Wirtschaft gewonnene Bockshaut vom Gerber im Lohnwerk gerben und sich aus der gegerbten Haut vom Schneider auf der Stör seine Hose anfertigen; nun zog er es vor, sich beim Krämer des nächsten Marktes eine Tuchhose zu kaufen. [...] Wollte der Bauer aber jetzt auf dem Markt kaufen, was er sich vordem selbst erzeugt hatte, so mußte er auch mehr verkaufen. “27

Dabei entfielen aber dem Bauern Geldeinkünfte, die er aus Fuhrwerksdienst gehabt hatte. Nachdem die Eisenbahnen gebaut worden waren, verödeten die Straßen, die Bauern konnten mit ihren altgewohnten Nebengeschäften keine Einnahmen mehr erzielen.

Daneben verloren die Bauern und Kleinhäusler bedeutende finanzielle Einnahmen aus der hausindustriellen Produktion, denn die Hausspinnerei und -weberei wurden von der Fabrikskonkurrenz verdrängt. Umso mehr mußten die Bauern darauf bedacht sein, aus dem Verkauf von Getreide, Vieh und Milch größere Geldeinnahmen zu gewinnen.

„So wurden denn die bäuerliche Landwirtschaft und Viehzucht immer mehr von der Produktion für den Eigenbedarf auf die Produktion für den Markt umgestellt." ${ }^{28}$

26 Bolognese-Leuchtenmüller 1978, S. 144 f. (Tab.52)

27 So 1925 in seiner Schrift „Der Kampf um Wald und Weide“ in: Bauer 1976, S. $144 \mathrm{f}$.

28 Ebd., S. 145. 
Die Bauern des Alpenraumes mußten aber zur Erlangung dieses Zieles andere Wege gehen als die Flachlandbauern; konnten sie doch nicht ihre Almen und Weiden in Äcker und Wiesen verwandeln, sondern sie nur besser als vorher zu nützen versuchen.

Höherer Viehbestand aber braucht höhere Futtermengen im Winter. So wurde der Futteranbau auf Kosten des Getreideanbaues ausgedehnt.

„Lag vorher auch in den Alpengebieten der Schwerpunkt der bäuerlichen Wirtschaft im Getreideanbau, [...] so trieb der Alpenbauer nunmehr erwerbsmäßig Viehzucht, er schränkte seinen Getreidebau wesentlich ein und begann, Getreide für seinen Eigenbedarf zuzukaufen, aber dafür erzeugte er Zucht- und Nutzvieh, Milch, Butter und Käse für den Markt. ${ }^{\text {“29 }}$

Obwohl der agrarische Bereich in Tirol bestimmend war, war dessen wirtschaftliche Situation nicht besonders gut.

Der Großteil der bäuerlichen Anwesen waren Kleinbetriebe mit nicht mehr als 10 ha Betriebsgröße (1902 waren in Tirol 45,1 \% Kleinbauern; dabei hatten $51,95 \%$ überhaupt nur bis zu 2 ha Betriebsfläche), ${ }^{30}$ die gerade noch vom Ertrag ihrer Grundstücke leben konnten ohne fremde Lohnarbeit nebenher annehmen zu müssen.

In der Regel hatten diese Betriebe keine fremden Dienstboten. Den Großteil der anfallenden bäuerlichen Arbeit besorgten eigene Familienangehörige (der Anteil an „mithelfenden Familienmitgliedern“ in der Land- und Forstwirtschaft betrug in Tirol 1910 41,6 \%, davon waren 70 \% Frauen). ${ }^{31}$

Im ersten Drittel des 20. Jahrhunderts war die landwirtschaftliche Gesamtfläche Tirols (1,111.478 ha) zu fast einem Viertel unproduktiv (22,0 \%), 35,2 \% wurden forstwirtschaftlich und $42,8 \%$ landwirtschaftlich genutzt.

Davon gehörten $74 \%$ rund 1.000 Großbetrieben mit jeweils über 100 ha Betriebsfläche.

In Nordtirol gehörte ihnen über $57 \%$ des rein landwirtschaftlich genutzten Bodens (zum Großteil Grünland: davon gut $30 \%$ Wiesen und Weiden und fast $70 \%$ Almen).

29 Ebd., S. 145 f.

30 Krammer 1976, S. 40 u. 43; dort nähere Bestimmungsmerkmale zur Kategorie „Kleinbauer“ (S. 39 f.)

31 Nach Berufsstatistik 1910, Heft 7, Hauptergebnisse für Tirol und Vorarlberg, 1915, S. 2 u. 6. 
Die große Masse der kleinen Betriebe verfügte nur über knapp $3 \%$ der Gesamtbetriebsfläche! ${ }^{32}$

Die landwirtschaftliche Entwicklung, insbesondere die Umstellung des Agrarsektors von Natural- auf Geldwirtschaft, brachte für Tirol große Probleme.

Seit dem Eisenbahnbau war das Land für internationale Märkte erschlossen, es kamen Waren zu einem günstigeren Preis auf den Markt als sie von heimischen Produzenten hergestellt werden konnten. So fiel im Zeitraum von 1894-1896, wegen billigeren amerikanischen und ungarischen Importen, der Preisindex für Weizen von 14,3 auf $7,9 .{ }^{33}$

Seit Mitte des 19. Jahrhunderts stiegen die Bodenpreise rasch in die Höhe. Mit jedem Erbgang mußte der erbende Bauer seinen weichenden Geschwistern hohe Abfindungen zahlen, bei jedem Besitzwechsel wurde der Besitz mit hohen „Kaufschillingresten " belastet. $^{34}$

Die Folge davon war ein hoher Verschuldungsgrad der bäuerlichen Güter und eine steigende Zahl von Versteigerungen und Exekutionen.

Jedem Gulden Katastral-Reinertrag stand in Tirol eine Schuldlast von 55 Gulden gegenüber.

Zwischen 1868 und 1892 wurden in Tirol 28.052 Bauerngüter zwangsweise versteigert (1895 waren es 1.400)..$^{35}$

Wie andere Alpenregionen war auch Tirol ein Auswanderungsgebiet. Mangelnde Arbeitsmöglichkeiten im Land zwangen seit langem viele Menschen, besonders aus den westlichen und südlichen Landesteilen, zur saisonalen Abwanderung ins benachbarte Ausland [als Handwerker, Maurer, im bäuerlichen Dienst als Mägde, Knechte, Hüterkinder („Schwabenkinder“) etc.]; im letzten Drittel des vorigen Jahrhunderts mußten, aufgrund der wirtschaftlichen Veränderungen, Klein- und Mittelbauern mitsamt ihren Familien abwandern. ${ }^{36}$

32 Günther 1951, S. 27 ff. Großbetriebsbesitzer waren in der Forstwirtschaft vor allem Ärar/Staat, Länder und Gemeinden; auch die Kirche hatte großen landwirtschaftlichen Besitz.

33 Vgl. Krammer 1976, S. 35.

34 Bauer 1976, S. 146 und Krammer 1976, S. 33 f.

35 Erhard 1981, S. 47.

36 Ebd., S. 48; nach Johann Jakob Staffler sind 1836 insgesamt 33.600 Menschen zeitweise aus Tirol ausgewandert (dies entspräche rund $4 \%$ der damaligen Gesamtbevölkerung!). Größte Abwanderungsgebiete waren die Kreise Trient mit 9.600 Personen, Rovereto 7.400, Oberinntal 6.200 und Unterinntal mit 3.500 Personen (Zillertal!). Seinen Angaben zufolge ist damit die Zahl der Auswanderer aus Tirol seit 1828 um 12.000 Personen angestiegen (1839, S. 370 und S. 374). 


\subsubsection{Industrie und Gewerbe}

Der gering entwickelte sekundäre Sektor des Landes bot kein ausreichendes Arbeitsplatzangebot für die aus der Landwirtschaft abwandernden Menschen.

Zwischen 1891 und 1900 verringerte sich die Zahl der unselbständig Beschäftigten in der Tiroler Land- und Forstwirtschaft um 63.949 Personen (= -22,9\% des Anfangsstandes von 1891); in Industrie und Gewerbe hat sie sich im selben Zeitraum zwar fast verdoppelt $(+47,8 \%)$, dies waren aber absolut bloß 22.663 Personen.

Die Abnahme der unselbständig Beschäftigten im primären Sektor war damit in Tirol deutlich stärker als im österreichischen Durchschnitt (-8,6 \%); die Zunahme im sekundären Sektor lag ca. $10 \%$ über dem Monarchiedurchschnitt von $37,1 \% .^{37}$

Beschäftigte des sekundären Sektors bezogen auf den Gebietsstand der heutigen Republik (in \%): ${ }^{38}$

\begin{tabular}{lccccc}
\hline & Tirol & Wien & Salzburg & Vorarlberg & Österreich \\
\hline 1869 & 17,3 & 46,7 & 16,2 & 31,5 & 24,8 \\
1890 & 18,5 & 54,5 & 20,8 & 40,3 & 30,9 \\
1900 & 20,8 & 52,0 & 23,2 & 45,1 & 32,7 \\
1910 & 22,1 & 48,2 & 22,5 & 45,8 & 32,4 \\
1934 & 25,0 & 47,2 & 24,7 & 40,1 & 34,0 \\
\hline
\end{tabular}

Um 1900 gab es auf dem Gebiet des heutigen Bundeslandes Tirol ca. 10.000 gewerbliche Einzelbetriebe (ohne Handelsgewerbe) mit durchschnittlich 3,5 Personen/Betrieb.

Vor allem die kleingewerbliche Struktur dominierte. So hatten nur 76 Industriebetriebe mehr als 50 Beschäftigte und waren somit als Großbetriebe zu

37 Vgl. Berufsstatistik 1910, Heft 1 Hauptübersicht und Besprechung der Ergebnisse, 1916, S. 39. (In der dort wiedergegebenen Übersicht 22 dürfte es sich bei der jeweils ersten Zählungsjahrzehntangabe „1891-1910“ [sic!] um einen Schreibfehler handeln, und es muß wohl lauten „1891-1900“!). Wie weiter unten noch gezeigt wird, hat der tertiäre Sektor in Tirol in diesem Zeitraum Zuwachsraten von über $100 \%$ zu verzeichnen!

38 Otruba 1975, S. 61; die Angaben für Österreich beziehen sich auf die Republik ohne das Bundesland Burgenland! 
bezeichnen; 627 waren Mittelbetriebe mit 6-50 Beschäftigten; der Rest waren Kleinbetriebe mit maximal 5 Beschäftigten. ${ }^{39}$

Traditionelle Produktionszweige waren vor allem die Grundstoffindustrien zur Woll-, Eisen- und Baustofferzeugung.

Seit 1768 war die Strelesche Wollstrumpf-Fabrik in Telfs in Betrieb, die allerdings 1822 eingestellt wurde.

Erst im frühen 19. Jahrhundert entstanden wollverarbeitende Fabriken in Innsbruck (1814) und in Mühlau die Firma „Weyrer“ (1817).

Um 1840 gab es erst 6-7, um 191111 Wollfabriken. Die industrielle Erzeugung von Strick- und Wirkwaren erfolgte in Tirol erst ab 1918.

Die Standorte der Eisenindustrie waren überwiegend im Nordtiroler Unterland und im Trentino.

Ab 1850 erfolgte die Sensenerzeugung, die vorher gewerblich betrieben wurde, industriell (z.B. Jenbach).

Die Stubaier Kleineisenwerke waren ab 1850 in ihrer Existenz bedroht; ihre Lage konnte sich erst zum Ende des Jahrhunderts hin verbessern (ab 1897 Gründung einer Werksgenossenschaft, Errichtung einer Fachschule).

Die „leonische Zierdrahtfabrik“ in Stans bei Schwaz war ab 1814 zu einem Großbetrieb geworden, der vor allem HeimarbeiterInnen beschäftigte (zeitweise mehrere hundert Personen).

Obwohl die Holzindustrie ein beträchtlicher Erwerbszweig für Tirol war, gab es im 19. Jahrhundert kein großes Sägewerk.

Um 1890 bestanden in Nordtirol 8 Zementfabriken; eine der bedeutendsten war das Perlmoser Zementwerk in Kirchbichl.

1895 wurde in Wattens die Glasindustrie der Firma Swarovski gegründet. Dieser böhmische Unternehmer siedelte seinen Betrieb in einer aufgelassenen Lodenfabrik an und produzierte schon früh mittels elektrischer Energie.

Georg Zwanowetz schreibt abschließend in seiner vergleichenden Betrachtung über die Industrialisierung Tirol und Vorarlbergs:

39 Zwanowetz 1972, S. 155 ff.; die folgende Aufzählung der Produktionszweige folgt seinem Beitrag. 
„In Tirol, und zwar mehr im $\mathrm{N}$ als im $\mathrm{S}$ des Landes, wirkte sich die durch die Technisierung ausgelöste Dynamik der Wirtschaftsentwicklung erst jetzt - im späten 19. und frühen 20. Jahrhundert - stärker aus. [...] die chemische Industrie begann sich um die Jahrhundertwende recht merklich zu entwickeln, die Ausnutzung der Wasserkräfte und der damit zusammenhängende Bau von Elektrizitätswerken machte bedeutende Fortschritte.

Daß die Wirtschaftsstruktur Tirols am Vorabend des 1. Weltkrieges trotzdem noch wesentlich weniger durch die Industrialisierung bestimmt war als jene Vorarlbergs, sei [...] in folgender Weise angedeutet: Im Jahre 1910 verhielt sich die Zahl der innerhalb Deutschtirols in Industrie und Gewerbe Beschäftigten zur Zahl der in Land- und Forstwirtschaft Erwerbstätigen ungefähr wie $1 \mathrm{zu}$ 2,3; in Vorarlberg hingegen war das entsprechende Zahlenverhältnis damals annähernd 1,3:1.“40

Soziale Schichtung der Berufstätigen im Jahre 1910 (in \%): ${ }^{41}$

\begin{tabular}{lccc}
\hline & Tirol & $\begin{array}{c}\text { NÖ } \\
(+ \text { Wien })\end{array}$ & Österreich \\
\hline Selbständige & 30,6 & 23,5 & 27,7 \\
Angestellte & 1,7 & 6,8 & 2,2 \\
Arbeiter, Lehrlinge u. Taglöhner & 35,5 & 58,3 & 39,8 \\
& $>67,7$ & $>69,7$ & $>70,1$ \\
mithelf. Familienangehörige & 32,2 & 11,4 & 30,3 \\
\hline
\end{tabular}

Aus diesen Zahlen wird der in Tirol, im Vergleich zu Niederösterreich/Wien und zum österreichischen Mittel, höherliegende Anteil der Selbständigen ersichtlich.

Zurückzuführen ist dies auf die höhere Agrarquote und die kleingewerbliche Struktur der Tiroler Wirtschaft. Unterstrichen wird dies durch den geringen Angestelltenanteil.

Gut zwei Drittel der Beschäftigten Tirols können als Arbeiter bezeichnet werden, wobei 216.786 Personen (davon 142.588 als mithelfende Familienangehörige) im primären und nur 70.814 im sekundären Sektor tätig waren. ${ }^{42}$

40 Ebd., S. 167.

41 Nach Berufsstatistik 1910, Heft 1 ... 1916, S. 38.

42 Nach Berufsstatistik 1910, Heft 7 ... 1915, S. 88. 
Ursache für die wirtschaftliche Rückständigkeit Tirols im 19. Jahrhundert war die ungleiche ökonomische Entwicklung der Habsburgermonarchie. Im Zuge der industriellen Revolution konzentrierte sich die Produktion auf wenige Zentren und Metropolen (Wien, ...), andere Regionen wurden zu reinen Zuliefergebieten von Rohstoffen und Arbeitskräften.

Damit wurden dem Land ständig Ressourcen entzogen, die noch verbleibende Bevölkerung war gezwungen, ihr Überleben durch verstärkte eigene Ausbeutung zu sichern (Heimarbeit, familiär betriebene Landwirtschaft).

„Die Lösung der Produktion von ihren traditionellen Fesseln technischer und politischer Art führte im Laufe von einem knappen Jahrhundert zu einer nie dagewesenen Konzentration gesellschaftlicher Ressourcen in einer oder in wenigen Regionen: Unterschiedliche natürliche und gesellschaftliche Voraussetzungen der Produktion in verschiedenen Regionen, die im Kontext der feudalen Produktionsweise nur begrenzte Unterschiede regionaler ökonomischer Entwicklung entstehen ließen, wurden unter völlig veränderten politischen und ökonomischen Bedingungen zu entscheidenden Voraussetzungen regionaler Differenzierung. “43

Die Errichtung großer Industrien führte zur Konzentration der Produktion an einem Standort. Damit verlagerten sich nahezu alle politischen und wirtschaftlichen Entscheidungsprozesse in die Zentren. Wien wurde zur dominierenden Metropole der Monarchie, von wo aus „die Provinz [...] durch Eingliederung in ein System von Abhängigkeiten von den wirtschaftlichen Zentren“ erschlossen wurde. ${ }^{44}$

Die Veränderung der Produktions- (Maschineneinsatz) und der Transporttechnologie (Eisenbahn) hatte für Tirol schwerwiegende Folgen, war doch der fabrikmäßige Maschineneinsatz nur ab einer gewissen Produktionsgröße rentabel und setzte voraus, daß nicht nur für den lokalen Markt produziert wurde. Größere Fabriksansiedlungen scheiterten aber zunächst an der dafür wenig geeigneten geographischen Situation und an der modernisierungsfeindlichen Haltung der regierenden Konservativen. ${ }^{45}$

Die Bahn als neues Transportsystem ermöglichte die Vernetzung verstreut liegender Produktionsstätten und wurde zur Voraussetzung regionaler Arbeitstei-

43 Hein 1978, S. 63.

44 Ebd., S. 64.

45 Erst der Einsatz von Wasserkraft, um die Jahrhundertwende, vermehrte Betriebsansiedlungen, begünstigt durch die Machtübernahme der Christlichsozialen, die nicht so industrialierungsfeindlich waren (vgl. das 2. Kapitel!). 
lung. Für Tirol bedeutete dies den Niedergang des traditionellen Transportwesens (Fuhrwerke etc.), wodurch die mittelbar daran beteiligten Gewerbe (Wagner, Sattler, ...) ihre Absatzmöglichkeiten verloren.

Die Einführung der neuen Gewerbeordnung (1859) gefährdete das gesamte Gewerbe. Die Gewerbefreiheit sprengte zwar endgültig die Fesseln des überlebten Zunftzwanges, verschärfte aber durch die Möglichkeit von Gewerbebetriebsneugründungen die innergewerbliche Situation zunehmend. Daneben war die Lage durch die industrielle Konkurrenz angespannt.

„Viele Gewerbetreibende, die früher als ehrsame Handwerker mit dem Betriebe eines Gewerbes ihr Leben fristeten, sind zu Grunde gegangen und müssen jetzt ihr Brod als Hilfsarbeiter in Fabriken dienen."

Die Gründe dafür waren einerseits die Erfindung der Dampfmaschine, andererseits die Arbeitsteilung, was dazu führte, daß die Fabriken in "großen Mengen und billiger" produzierten. ${ }^{46}$

Diese Situation verbesserte sich erst gegen Ende des 19. Jahrhunderts, als ein völlig neuer Wirtschaftszweig zu dominieren begann.

\subsubsection{Tertiärer Sektor}

Ernst Hanisch hat am Beispiel des Landes Salzburg aufgezeigt, daß es bei der Regionalentwicklung Gebiete gab, „die den Industrialisierungsprozeß gleichsam übersprangen und das Wirtschaftswachstum zum großen Teil über den tertiären Sektor der Dienstleistungen bewerkstelligten: über den Fremdenverkehr ${ }^{\text {“4 } 77}$.

Er hat darauf hingewiesen, daß für rückständige Regionen diese fremdenverkehrswirtschaftliche Chance nur zum Tragen kommt, wenn

- ein geglückter Industrialisierungsprozeß, mit ausreichendem Wirtschaftswachstum und gesicherter Freizeit, in den Zentren erfolgt ist; und

- in der Region selbst attraktive Anreize, wie Naturschönheiten, geeignetes kulturelles Angebot, für eventuelle Urlaubsgäste vorhanden sind. ${ }^{48}$

46 So der damalige Innsbrucker Handelskammer-Sekretär Carl Payr in der Beantwortung einer Enquete des Handelsministers zur Lage des Kleingewerbes (1872, S. 6). Als Rettungsmittel schlug er die bessere Ausbildung der Gewerbetreibenden vor, nicht ohne einen Seitenhieb auf die regierenden Konservativen zu machen, die sich gegen die Durchführung der neuen Schulgesetze wehrten (S. 13).

$47 \quad 1985$, S. 817.

48 Ebd.; vgl. insgesamt diesen Aufsatz mit dem Titel „Wirtschaftswachstum ohne Industrialisierung“. 
Dies gilt nicht nur für Salzburg. Ab 1910 hatte auch in Tirol der tertiäre Sektor den sekundären zahlenmäßig überholt und beschäftigte 24,1 \% aller Erwerbstätigen. 1934 waren über ein Viertel aller arbeitenden Personen in seinen Branchen tätig $(28,1 \%)^{49}$

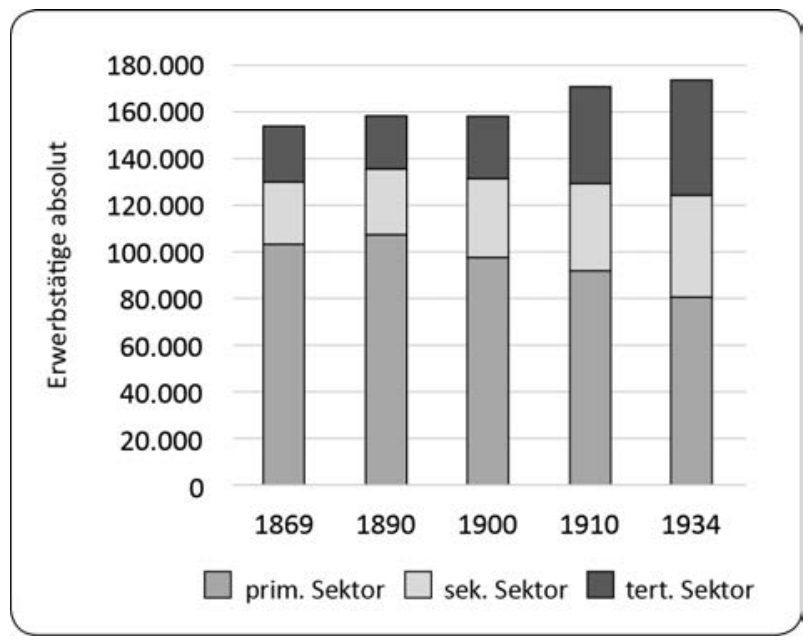

Graphik 2: Tiroler Erwerbstätige nach Sektoren

Absolut fanden hier 191041.177 und 1934 48.624 Personen ihre Beschäftigung, der Großteil davon im Schank- und Gastgewerbe und im Warenhandel. ${ }^{50}$

Deutlich wird dies, wenn für das Jahr 1869 der Anteil der Erwerbstätigen im tertiären Sektor auf $100 \%$ gesetzt und seine Entwicklung mit dem österreichischen Durchschnitt verglichen wird.

49 S. Otruba 1975, S. 61; Tirol lag damit, prozentuell, in diesem Sektor hinter Wien und Salzburg an dritter Stelle! Die Angaben beziehen sich auf die Fläche des heutigen Bundeslandes Tirol. Auch die Graphik wurde nach diesen Zahlenangaben erstellt!

50 Ebd., S. 57 f.; sowie Berufsstatistik 1910, Heft 7 ... 1915, S. 24 u. 29; Allein im Handelskammerbezirk Innsbruck wurden 1910 im Warenhandel 5.633 und im Schank- und Gastgewerbe 5.780 Personen gezählt (der Großteil davon Frauen).

Damit die Gesamtzahl des tertiären Sektors besser interpretiert werden kann, müßte eigentlich die Zahl der Militärs abgezogen werden (für 1910: 4.389; für 1934: 793 Männer). 


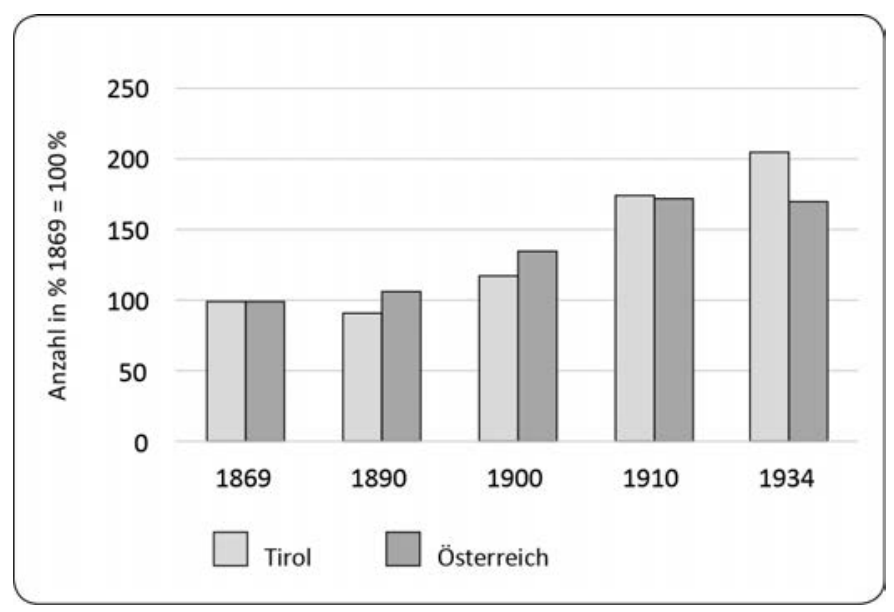

Graphik 3: Tiroler und österr. Erwerbstätige im tert. Sektor im Vergleich $-1869=100 \%$

Der Anteil der im primären Sektor Erwerbstätigen sank sowohl in Tirol - hier zwar langsamer - als auch bundesweit bis 1934 auf ca. 78 \% des Ausgangswertes von 1869; der sekundäre und vor allem der tertiäre Sektor zeigten aber stark unterschiedliche Entwicklungstendenzen.

Eine deutliche Steigerung der Erwerbstätigen in Industrie und Gewerbe erfolgte in Tirol erst ab 1900, und erst in der Zeit der Ersten Republik war der Zuwachs seit 1869 im Land etwa gleich der des österreichischen Durchschnittes.

In der Erwerbstätigenzunahme im tertiären Sektor hatte Tirol bereits ab 1910 das cisleithanische Mittel übertroffen und bis 1934 die Ausgangsrate von 1869 mehr als verdoppelt. 
Tiroler und österreichische Erwerbstätige nach Sektoren - $1869=100 \%::^{51}$

\begin{tabular}{|c|c|c|c|c|c|c|}
\hline \multirow{2}{*}{ (in \%) } & \multicolumn{2}{|c|}{ primärer Sektor } & \multicolumn{2}{|c|}{ sekundäre Sektor } & \multicolumn{2}{|c|}{ tertiäre Sektor } \\
\hline & Tirol & Österr. & Tirol & Österr. & Tirol & Österr. \\
\hline 1869 & 100 & 100 & 100 & 100 & 100 & 100 \\
\hline 1890 & 103,5 & 97,2 & 109,9 & 135,1 & 90,5 & 105,2 \\
\hline 1900 & 94,7 & 90,3 & 124,6 & 150,8 & 116,1 & 133,6 \\
\hline 1910 & 89,2 & 89,1 & 142,4 & 163 & 173,8 & 163 \\
\hline 1934 & 78,4 & 77,4 & 163,4 & 161,4 & 205,2 & 169,5 \\
\hline
\end{tabular}

Vor allem der aufkommende Fremdenverkehr trug zu dieser Entwicklung bei.

Ab 1840 nahm die Anziehungskraft einzelner Kurorte, besonders in Südtirol (Meran, ...), größere Ausmaße an.

Daneben erfolgte durch den zunehmenden Alpinismus ein weiterer touristischer Aufschwung. Dies insbesondere seit der Gründung diverser alpiner Organisationen:

1862 wurde der Österreichische Alpenverein (ÖAV) gegründet; der sich zuerst vornehmlich wissenschaftlichen Zwecken widmete.

1869 wurde der mehr auf Geselligkeit ausgerichtete Österreichische Touristenclub (ÖTC) ins Leben gerufen, der mit dem Schutzhüttenbau begann.

Fremdenverkehrsfördernd wirkte die neue sektorale Gliederung des DeutschÖsterreichischen Alpenvereins (DÖAV), der 1873/74 aus der Vereinigung des 1869 in München gegründeten Deutschen Alpenvereins (DAV) mit dem ÖAV hervorgegangen war. ${ }^{52}$

51 Die Werte sind nach den Daten bei Otruba 1975 berechnet und beziehen sich auf die Fläche des heutigen Bundeslandes Tirol und der Republik Österreich in den Grenzen nach 1918. Die obige Graphik wurde ebenfalls aufgrund der Angaben bei Otruba erstellt!

52 „Von innen her, durch die Alpenvereinssektionen allein, kann Nützliches geschaffen werden, um die Bereisung der Alpen zu erleichtern und dadurch einen dem Lande gewinnbringenden Fremdenverkehr zu ermöglichen“, hieß es in der geplanten Statutenänderung (vgl. Kramer 1983, S. 27). Daneben entstanden weitere Bergsteiger- und Schivereine; so 1893 der „Akademische Alpenclub“, 1904 folgten die „Karwendler“, 1911 die „Gipfelstürmer“. 1901 war der „Schiklub Arlberg“ gegründet worden, 1905 folgte der „Österreichische Schiverband“ mit seinem Sitz zuerst in München, ab 1908 in Innsbruck, dem 1912 bereits 17 Verbandsvereine angehörten. (vgl. Dapra 1948, S. 176 ff.) 
Laut eines Berichtes der Statthalterei an das Ministerium für Inneres aus dem Jahr 1888 hatte der DÖAV 188734 Sektionen im Lande, der ÖTC 10 Sektionen; insgesamt gab es bis dahin bereits 91 Schutzhütten.

Laut gleichem Schreiben hatten Tirol 1885 188.359, 1886 204.318, 1887 217.374 Fremde besucht. ${ }^{53}$

1910 wurde, mit der Errichtung des „Landesverkehrsrates“, eine gesetzliche Regelung für den Fremdenverkehr erlassen.

$\mathrm{Zu}$ den Aufgaben dieses Rates gehörte die Erarbeitung von Gutachten, die Unterstützung der Gemeinden und Vereine zur Förderung des Fremdenverkehrs, Propaganda- und Reklameaufgaben, Erstellung von einschlägigen Statistiken und der „Heimatschutz“.

Zur effizienten Arbeit wurden in allen Bezirken „Bezirksverkehrsräte“ eingerichtet. $^{54}$

Bereits 1890 war - allerdings auf Vereinsbasis - der „Landesverband der vereinigten Kur- und Fremdenverkehrsvereine von Tirol“ aufgrund des „Ruf[es] nach Koalition, nach engerem Zusammenschlusse zum Zwecke energischer Wahrung gemeinsamer Interessen" als zentrales Koordinationsorgan der lokalen Fremdenverkehrsvereine des Landes gegründet worden.

Dieser Verband unterhielt ein eigenes Büro und seine Arbeit bestand vor allem „in der Durchführung der Propaganda für das Land und in der Verbesserung der Verkehrsverhältnisse“.

Daneben war der Verband, der seit dem Jahre 1902 zusammen mit den Staatsund Südbahnen ein „Stadtbureau der k. k. Staatsbahnen“ unterhielt, Auskunftsund Vermittlungsstelle für diverse touristische Belange.

Weiters sah diese Vereinigung - von im Fremdenverkehr führend engagierten Personen (Hoteliers, Vertreter der Handelskammern etc.) - ihre Aufgabe in der Begutachtertätigkeit einschlägiger Gesetze und im Unternehmen „unter allen Umständen, die Gründung einer Kommission mit gewissen Machtverhältnissen von der Regierung zu erlangen“55.

Anläßlich des 20jährigen Bestandes dieses Verbandes betonte dessen Sekretär Dr. Heinrich Rohn den „allgemeinen wirtschaftlichen Aufschwung [...], der sich

53 Tiroler Landesarchiv; Statthalterei 1888, Zl. 24536; Das Schreiben war für die Gewerbeausstellung in Wien, anläßlich des 40jährigen Regierungsjubiläums des Kaisers, erstellt worden.

54 Dapra 1948, S. 167 f. Das Gesetz wurde am 5.7.1911 beschlossen; vgl. Landesgesetzblatt (LGBl.) Nr. 20/1911. 1920 (LGBl. Nr. 16/1921) wurde dieser Verkehrsrat in ein „Landesverkehrsamt“ umgewandelt.

55 S. die Denkschrift zur Feier des 20jährigen Bestandes des Landesverbandes für Fremdenverkehr in Tirol 1910; die drei Zitate finden sich dort auf den S. 8, 12 u. 10. 
in Tirol unter der Einwirkung des Fremdenverkehres in diesen letzten zwanzig Jahren vollzogen hat" ${ }^{\text {"56. }}$.

Zwischen 1890 und 1909 stieg die Fremdenfrequenz in Tirol von ca. 210.000 auf gut 820.000 Meldungen an - seit 1896 erhöhte sich der Gesamtverkehr um 146,8 \%; davon waren gut die Hälfte ausländische Touristen (vor allem aus Deutschland).

1890 gab es 1.101 Hotels und Gasthöfe mit 20.909 Betten, 1909 waren es schon 2.504 mit 54.252 Betten.

Die Zahl der Privatzimmerbetten nahm im gleichen Zeitraum von 6.090 auf 18.882 zu. $^{57}$

Die Einnahmen aus dem Fremdenverkehr betrugen 1899 wohl 12 Mill. Gulden, erreichten in der Schweiz aber im selben Jahr den Betrag von 140-150 Mill. Franken. ${ }^{58}$

58 So der Bozner Handelskammer-Sekretär Johann Angerer in seiner Schrift „Vergleichende Betrachtungen über den Fremdenverkehr in Tirol und in der Schweiz" 1899; vgl. Kramer 1962, S. 324 u. dort Anm. 13. 


\title{
2. Politisch-kulturelle Situation in Tirol ab der 2. Hälfte des 19. Jahrhunderts
}

\begin{abstract}
„Freilich ist Tirol ein Agrarland geblieben, der Bauer wird da noch auf lange hinaus die entscheidende Bevölkerungsschicht bilden und seine Denkweise einen erheblichen Teil sogar des industriellen Proletariats beeinflussen, denn die Zahl der Zwischenschichten zwischen Bauern und Proletariern ist groß - Zwergbauern, die Lohnarbeit leisten. Dank dieser Zwischenschichten behaupten sich auch in manchen Schichten des eigentlichen Lohnproletariats lange klerikale und konservative Tendenzen."
\end{abstract}

Mit diesen Worten kennzeichnet der sozialistische Theoretiker Karl KAUTSKY die ökonomisch-gesellschaftliche Situation des Landes am Ende des letzten Jahrhunderts.

Besonders die „konservative Bevölkerung [in den] abgelegenen Gebirgstälern, die zäh an alten Sitten, Trachten, Denkgewohnheiten hängt und Neues nur schwer annimmt", sah er als ein Haupthindernis für die mangelnde Aufstiegsmöglichkeit des Sozialismus in Tirol. ${ }^{59}$

In der Tat kann die politische Lage des Landes als Spiegel seiner wirtschaftlichen und sozialen Verhältnisse angesehen werden.

\subsection{Landtagsparteien}

\subsubsection{Klerikal-Konservative}

Im Landtag hatten die klerikal-konservativen Politiker seit 1861 eine absolute, meist sogar eine Zweidrittelmehrheit und bekämpften energisch jegliche Neuerungen.

59 So in seinen „Erinnerungen und Gedanken aus Tirol II“, erschienen in der Volkszeitung Nr. 221, 31. Jhg., vom 28.9.1923. 
Sie stützten sich dabei nicht nur auf das sie begünstigende Wahlrecht ${ }^{60}$, sondern konnten - mittels ihrer kirchlichen Gefolgsleute - nahezu die gesamte Bevölkerung Tirols in ihrem Sinne beeinflussen. ${ }^{61}$

Durch die katholische Restauration des 17. und 18. Jahrhunderts war Tirol geistig und kulturell von der Außenwelt nahezu abgekapselt und eingeschlossen worden.

Um die Mitte des 19. Jahrhunderts erreichte diese Absonderung einen neuerlichen Höhepunkt in den Fragen der Glaubenseinheit und Schulgesetzgebung.

Wegen des von der Wiener Zentralregierung 1861 erlassenen Gesetzes über die Gleichstellung des evangelischen mit dem katholischen Religionsbekenntnis sahen die Tiroler Konservativen die Glaubenseinheit des Landes bedroht.

Als 1875 in Innsbruck und Meran den Protestanten erlaubt wurde, eigene Gemeinden zu bilden, brach in Tirol ein Sturm der Entrüstung los; in Bozen erneuerten 17.000 Menschen den Bund mit dem Herzen Jesu. ${ }^{62}$

Ab 1867 weigerten sich die Tiroler Konservativen, die von der liberalen Zentralregierung erlassenen Schulgesetze zu beschließen, da damit der Verlust der klerikalen Schulaufsicht verbunden gewesen wäre.

Erst 1892 war die konservative Landesregierung bereit, die entsprechenden Landesschulgesetze zu erlassen; damit endete formell der Kulturkampf in Tirol, der mehr als drei Jahrzehnte das Land gelähmt hatte.

60 Diese Konservativen vertraten vor allem den Adel, bürgerliche Grundbesitzer, kleinstädtische Bürger, den gesamten Klerus und die Bauern. Vor allem die erstgenannten Gruppen delegierten ihre Vertreter unmittelbar in den Landtag. Der Rest der Abgeordneten konnte indirekt gewählt werden, das Wahlrecht war allerdings an Besitz oder eine bestimmte Steuerleistung gebunden; Nichtbesitzende, Dienstboten, Tagelöhner und Arbeiter waren dadurch vom Wahlrecht ausgeschlossen (vgl. Hartungen/Pallaver 1986, S. 13 f.).

61 „Vielfach war der Ortsgeistliche der einzige Studierte im Dorf, verfügte über Verbindungen mit der Welt draußen und wurde dadurch auch politisch und nicht nur moralisch-religiös zu einer unbestrittenen Autorität." (ebd., S. 12) Zentralen Stellenwert in der vermittelten konservativen Ideologie hatten die Begriffe Glaube, Heimat und Kaisertreue.

S. Fontana 1978, S. $414 \mathrm{ff}$.

Zum „Herz-Jesu-Bund“ und dessen besonderer Bedeutung für Tirol s. Juen/Nussbaumer 1983, bes. S. 192 ff.; „Innenpolitisch bietet er [der „Herz-Jesu-Bund“; W.M.] nicht nur die Möglichkeit der nationalen Identifikation aller Gruppierungen, sondern er ist auch Machthebel der Klerikal-Konservativen im Kampf gegen jede Art von Veränderung." (S. 196) Allgemein zur „Kirche in Tirol“" s. Pallaver 1984, S. 39 ff. 
„Der Kulturkampf in Tirol war aber nicht nur ein vergeblicher Kampf, er war auch ein schädlicher Kampf. Durch die jahrzehntelangen ideologischen Auseinandersetzungen wurden wichtige wirtschaftliche und soziale Fragen in den Hintergrund gedrängt. Im geistigen Leben Tirols trat eine Stagnation ein."63

Dabei hätte nur ein Blick über die Landesgrenzen genügt, um die Sinnlosigkeit und Unsachlichkeit der „vielfach überholten Positionen und Werte“, die die Kirche - und damit die konservative Landesmehrheit - vertrat, zu erkennen. ${ }^{64}$

Weder die Sozialdemokraten noch die Liberalen konnten ein politisches Gegengewicht zur klerikal-konservativen Landtagsmehrheit bilden.

\subsubsection{Sozialdemokraten}

Anläßlich der letzten Landtagswahlen vor dem Ersten Weltkrieg (1914) konnten die Sozialdemokraten erstmals zwei Mandate erringen. Ihr Einflußbereich blieb lange nur auf Städte und Industrieansiedlungen beschränkt, wo sozialistische Arbeitervereine bestanden. ${ }^{65}$

Erst im ersten Drittel des 20. Jahrhunderts konnten sie auf dem Land, mittels ihrer Vorfeldorganisationen (vor allem der Freizeit- und Turnvereine), größere Verbreitung und damit Wählerschaft gewinnen.

\subsubsection{Liberale}

Obwohl die Liberalen in Tirol nur eine kleine Gruppe bildeten, war ihr Einflußbereich ungleich größer.

Vor allem in den Handelskammern und in den größeren Städten hatten sie ihre politischen Zentren (so stellten die Liberalen ab 1867 den Bürgermeister von Innsbruck; ferner waren die Handelskammerpräsidenten durchwegs dem

63 Fontana 1978, S. 418.

64 Ebd., S. 419 f., sowie Forcher 1986, S. 24 f.

65 Da viele Arbeiter, vor allem Eisenbahner, aus dem O und S der Monarchie zugewandert waren, war es für die konservative Ideologie leicht, die Sozialdemokratie als fremdartig und untirolerisch abzutun (vgl. Hartungen/Pallaver 1986, S. 13). 
liberalen Lager zuzurechnen) ${ }^{66}$ Es fehlte ihnen einzig an einer zentralen Organisationsstruktur.

Hauptanliegen der Liberalen waren vor allem wirtschaftliche und kulturelle Modernisierung; so traten sie entschieden für Eisenbahnbau und Fremdenverkehr ein und bekannten sich zur Wiener Schul- und Wahlgesetzgebung.

Auch in Tirol wurde im letzten Drittel des 19. Jahrhunderts das liberale Gedankengut vom nationalen abgelöst, denn seit dem Niedergang des Liberalismus als führende Kraft der Monarchie wurde dessen deutsche Ausrichtung immer stärker. ${ }^{67}$

1888 wandelte der „Constitutionelle Verein“ seinen Namen in „Deutsch-liberaler Verein für Tirol" um.

Hatte der Verein 1872 rund 600 Mitglieder, so trat ab 1890 bereits das politische Ermatten ein und 1901, bei der Auflösung des Vereines waren es nur noch $80 .^{68}$

Bekenntnis zum Deutschtum und Antisemitismus waren fortan Grundlagen national-liberaler Gesinnung; letztere Einstellung war ebenso bei den Christlichsozialen zu finden (hier als religiös begründeter Antisemitismus).

„In Tirol, wo die Kirche, der konservative Adel und das alte, traditionsgebundene Bauerntum den Ton angaben, fanden die neuen Ideen schwer Eingang. Liberal waren hier die Intellektuellen, das Bürgertum in den Städten und größeren Orten sowie Teile des Adels. Ihre akademische Diktion kam gegen die massive Wortführung der Klerikalen nicht auf. Die kirchlich konservative Propaganda verstand es, religiöse Anliegen mit landespolitischen Argumenten zu verknüpfen, und das Ganze als Identifikations- und Existenzproblem hochzuspielen. Entweder, so der Grundgedanke der Überlegungen, bleibt Tirol wie es ist, oder es ist nicht mehr Tirol.“69

66 Vgl. Fischnaler Bd. IV 1930, S. 12 ff.; dort wird mit Dr. Johann Tschurtschenthaler erstmals ein Liberaler als Bürgermeister genannt. Allerdings war bereits von 1861-64 der Kaufmann Karl Adam erster konstitutioneller Bürgermeister der Stadt. Ein Verzeichnis aller Präsidenten der Tiroler Handelskammer findet sich im 2. Band der Handelskammer-Festschrift „Tiroler Wirtschaft in Vergangenheit und Gegenwart" 1951, S. 267 f.

671879 gelangten die Feudalkonservativen unter Taaffe an die Regierung und lösten damit den Wirtschaftsliberalismus ab (vgl. Matis 1985, S. 509 f.).

68 Payr 1902; Ursache für die Spaltung und nachfolgende Vereinsauflösung war, nach Payr, die unterschiedliche Einstellung der Mitglieder zum Antisemitismus. Den, 1898 abgespaltenen, „Deutschen Volksverein in Tirol“ bezeichnet er als „verbesserte Auflage des ,Deutschliberalen Vereins" mit nationalem Einschlag und volksthümlicher Vordure" (S. 13). So Josef Fontana am Beginn seiner Arbeit über den „Kulturkampf in Tirol“ (1978, S. 10). 
In den 90er Jahren des letzten Jahrhunderts geriet Bewegung in die politische Landschaft Tirols; bezeichnenderweise aus dem eigenen Lager der Konservativen.

\subsubsection{Christlichsoziale Partei}

Zunehmende ökonomische Schwierigkeiten und damit verbunden die Behandlung der sozialen Frage, hatten Gegner im eigenen Lager hervorgebracht, die nicht mehr auf bedingungsloses Festhalten an allem Althergebrachten bestanden.

Diese schärfere Tonart, wie sie sich zu Beginn bezeichnete, hatte ihr Sprachrohr vor allem in der aufkommenden Massenpresse und im Umstand, daß führende Männer dieser Bewegung im Brixner Priesterseminar tätig waren. ${ }^{70}$

So wird verständlich, daß sich vor allem der junge Klerus dieser neuen politischen Strömung zugewandt fühlte.

Die „Christlichsozialen“, wie sie sich bald nannten, nahmen sich vor allem des darniederliegenden Bauernstandes an, waren aber industriellen Neuerungen nicht so sehr abgeneigt wie die Klerikal-Konservativen und setzten vor allem auf den zunehmenden Fremdenverkehr.

Trotz der anfänglichen Anfeindung durch die Konservativen waren die Christlichsozialen auf ihrem Weg zur führenden Kraft des Landes nicht mehr aufzuhalten.

„Ihre Vermischung von Altem und Neuem, von traditionellen und fortschrittlichen Anschauungen, von Religion, sozialen und nationalen Ideen, von Bestätigung alter Vorurteile und dem Aufbruch zu neuen Lebens- und Wirtschaftsformen hatte für breite Bevölkerungsschichten [...] etwas Faszinierendes. Diese Ideologie verlangte von ihnen nicht den radikalen Bruch mit der Vergangenheit, wie bei den Sozialdemokraten notwendig. “71

70 Der Brixner Theologieprofessor und Publizist Dr. Aemilian Schöpfer war nicht nur ein geistiger Vater der christlichsozialen Bewegung in Tirol, sondern zeitweise auch Chefredakteur der Brixner Chronik, einem der ersten Publikationsorgane christlichsozialer Ideen, die ebenso im „Tyrolia/Athesia-Verlag“ erschien, wie der Tiroler Volksbote und zahlreiche konservative Kalender (vgl. Erhard 1981, S. 37 ff.; zum Zeitungswesen auch Weissensteiner 1979).

71 Hartungen/Pallaver 1986, S. 16 f. 
Vor allem Antisemitismus und bedingungslose Ablehnung der Sozialdemokratie zeichneten die Artikel der Publizisten der schärferen Tonart aus, die sich oft einer, alles andere als christlich zu bezeichnenden, Sprache bedienten. ${ }^{72}$

Seit Beginn unseres Jahrhunderts waren die Bauern die mächtigste Gruppe innerhalb der Christlichsozialen geworden, was sich ab 1904 durch die Gründung des Tiroler Bauernbundes noch verstärkt hatte. ${ }^{73}$

Nach 1918 vereinigten sich die Christlichsozialen mit den Konservativen zur „Tiroler Volkspartei“, die sich nach der Teilung des Landes in einen Tiroler und Südtiroler Flügel trennte. ${ }^{74}$

\subsection{Kulturelle Landeseinheit und nationalistische Strömungen}

Durch die Niederlage im Krieg von 1866 verlor Tirol Venetien und sah sich damit endgültig vom feindlich gesinnten Italien bedroht.

Die Debatte um die seit 1848 immer wieder geforderte Loslösung des Trentino von Tirol flammte nun in einer heftig geführten separatistischen Bewegung wieder auf. Der deutsche Landesteil reagierte gereizt darauf, und die Frage der hochheiligen Landeseinheit wurde zu einem zentralen Thema der Landtagspolitik.

Auf beiden Seiten wurde der Nationalismus zum bestimmenden Moment politischer Äußerungen und Handlungen. ${ }^{75}$

Bereits 1809 waren in Tirol Patriotismus und Religiosität als gemeinsamer Nenner für die kulturelle und geistige Einheit des Landes bemüht worden.

72 Zwei Beispiele des beliebten Schreibers Sebastian Rieger, bekannt als „Reimmichl“, aus dem Tiroler Volksbote sollen dies - stellvertretend für viele - belegen: „Die Sozi schwören ja auf die ,freie Liebe'. Die Sozi wüten Hand in Hand mit den Juden gegen jene Gesetze, durch welche die Sittlichkeit des Volkes geschützt werden soll“. (Nr. 22/1904) „Die Soziführer sind nebenbei die Schmarotzer der Kapitalisten und große Geldsäcke, die sie angeblich bekämpfen [...] Arbeiter! [...] betrachtet doch einmal eure Verführer die sogenannten Obergenossen, wie sie im Genusse schwelgen und wie Blutegel an euren Gewissen [...] zehren." (Nr. 12/1902) Schuld an allem und jedem hatten die Juden und die Sozialdemokraten. Da beide Gruppen in Tirol nur gering vertreten waren, boten sie ideale Feindbilder und konnten einfach als untirolerisch abgetan werden (s. Weissensteiner 1979, S. 45; sowie die Beiträge in den sturzflügen Nr. 15/16 1986 „Die Geschichte der Juden in Tirol“).

73 Erhard 1981, S. $89 \mathrm{ff}$.

74 Hartungen/Pallaver 1986, S. 17.

75 Ebd., S. 17 ff.; auch Forcher 1986, S. 19 ff. 
Schon seit 1790 bezeichnete der Ausdruck „tyrolische Nation“ die „höchste Steigerung des tirolischen Selbstwertgefühls“, wurde aber nicht losgelöst von der Gesamtnation gebraucht, eher „als ein besonders gearteter Teil derselben “76.

Nicht zuletzt durch den Eisenbahnbau war das Land ab der Mitte des 19. Jahrhunderts vermehrt Ziel von Reisenden; diese neue Infrastruktur begünstigte eine Öffnung nach Außen, vermehrte die Kenntnisse über andere.

Das Bild des Tirolers wurde nicht zuletzt im Ausland geprägt, wo sich die Beschäftigung mit dem Land - besonders in England - zuerst aufgrund der 1809-Ereignisse, in Heldenverehrung, dann durch den zunehmenden Tourismus, in romantisierenden Exotismus erstreckte, der die ökonomische Rückständigkeit Tirols als heile Welt ansah. ${ }^{77}$

In Tirol selbst wurden diese, teilweise von außen herangetragenen, Stereotype aufgenommen und bildeten den Grundstock des eigenen Nationalgefühls. Mangelnde Modernität, Rückständigkeit und Anderssein waren nicht mehr Makel, sondern wurden zur Eigen- und Besonderheit des Landes erklärt.

Für die Tiroler Kultur blieb „einzig die Provinzialität als Entwicklungsraum offen “78, ökonomische Rückständigkeit wurde ästhetisch kompensiert:

„Die Regionen, so wie sie sich heute vor allem auch in ihren Kulturstilen darbieten, sind nicht nur die territorialen Restformen vorindustrieller Strukturen, sondern vor allem neue Produkte ungleicher industrie-kapitalistischer und nationalstaatlicher Entwicklung. Zu den natürlich-geogra-

76 S. Dörrer 1948, S. 280; er bezieht sich hier auf Otto Stolz, der darauf hingewiesen hatte, daß dieser Ausdruck das Volk von Tirol, gemäß der alten Landesverfassung (= 4 Stände), als eigenen politischen Körper, bezeichnete. (1932, S. 273) Daß diese Formulierung gerade in einer Zeit äußerer (und innerer) Bedrängnis entstand, mag die These stützen, daß über Nationalismus Kompensation und Integration bestehender Gegensätze versucht wird, was vor allem in Krisenzeiten notwendig für die Herrschaftserhaltung erscheint. „Im Prinzip wird Nationsbildung des 19. Jahrhunderts begriffen als ein Vorgang, in welchem Menschen eines Gebietes oder (und das jetzt primär) einer Sprache immer stärker von dem Gefühl durchdrungen werden, einer (eben ihrer) Nation anzugehören, wobei dieser Zugehörigkeit für die eigene Identität immer größere Bedeutung zugemessen wird.“ (Bruckmüller 1985, S. 416)

77 Vgl. die zahlreich im 19. Jahrhundert entstandene Reiseliteratur über Tirol (s. die Bibliographie von Hannes Obermair 1983, S. 223 ff.). Bereits 1835 berichtet der deutsche Literat und Reisende August Lewald über den beginnenden Fremdenverkehr: „Nach und nach fangen die Engländer schon an, die stillen Theile Tyrols aufzusuchen, da sie die Schweiz ganz und gar kennen“ und verurteilt deren übermäßige Wünsche und Ansprüche (1. Bd., S. 36 f.), da er an Tirol die „Naivität dieser Thalbewohner", schätzt, sie mit amerikanischen Ureinwohnern vergleicht und froh ist, daß „diese lieben Naturmenschen unsere Landsleute sind und Deutschland an seiner Gränze noch so holde Schönheiten bietet“. (2. Bd., S. 244)

78 Gürtler 1986, S. 177. 
phischen Unterschieden kommen im Laufe des 19. Jahrhunderts zunehmend auch ökonomisch-historische Ursachen, die zur Provinzialisierung einer Region führen [...]." ${ }^{\text {"79 }}$

Mit Hilfe folkloristischer ${ }^{80}$ Rückgriffe auf für Tirol typisch scheinende, kulturelle Muster „soll ,wettgemacht` werden, was der Landbevölkerung im Verlauf der kapitalistischen Industrieentwicklung genommen wurde" ${ }^{\text {" }}$. Regionalismus ersetzte die vorhandene Regionalkultur. Durch die Herstellung unverwechselbarer Symbole und Abzeichen wurde ein unverwechselbares Image geschaffen, oft unter Verwendung kultureller Elemente der Vergangenheit.

\subsubsection{Ethnizitätsbildung}

Markus Barnay wies in seiner Arbeit über die „Erfindung des Vorarlbergers“ darauf hin, daß die Entstehung des Glaubens an eine gemeinsame Volkszugehörigkeit - die Ethnizitätsbildung - Ergebnis eines politischen Prozesses und nicht von „zeitewigem“ Charakter sei. Landesbewußtsein wäre nicht einfach ,von unten

79 Korff 1980, S. 44; vgl. auch Jeggle/Korff 1974 in ihrem Aufsatz über das Zillertal. Bereits in den 50er Jahren hatte auf diesen Umstand Theodor W. Adorno aufmerksam gemacht, wenn er in Bezug auf den Gebrauch volkstümlicher Musik meint, daß hier ein „Zustand, der in den realen ökonomischen Bedingungen gründet, durch ästhetischen Gemeinschaftswillen zu beseitigen“ versucht wird (1958, S. 63).

80 Folklorismus wird hier nicht als ,verfälschende [...] unechte Aneignung der kulturellen Traditionsmasse“ verstanden, da „die Kategorien falsch und unecht [...] immer dann nicht aus[reichen], wenn es um bewußte Rückgriffe, um Selektionsleistungen geht, die von aktuellen Lagedeutungen gelenkt und gesteuert sind.“ Denn: „was angeeignet wird, bestimmt sich nicht nur durch die Qualität des Überlieferungsgutes, sondern bemißt sich an der Brauchbarkeit fürs Hier und Jetzt." (Korff 1980, S. 40). Analog zu den Überlegungen von Hermann Bausinger sollte auch hier von einem „Folklorismus für die Oberschicht“, zumindest bis zum Monarchieende, gesprochen werden. Dieser, ältere, ,funktioniert nur dann ganz, wenn es den Folklorismus für das Volk noch nicht gibt, wenn also die Oberschicht mit einigermaßen gutem Gewissen die Worte ,echt', ,ursprünglich` und ,natürlich` als Etikette auf die Volkskultur aufkleben kann.“ (1966, S. 69)

81 Korff 1980, S.43; er weist darauf hin, daß diese „Bereitschaft, spezifische Züge aus dem kulturellen Repertoire zu folklorisieren“ (S. 42) nicht durch den Tourismus neu entsteht, sondern der Fremdenverkehr lediglich „verstärkend“ wirkt und „kräftigende Impulse“ gibt (ebd.). Fremdenverkehr, der letztendlich wirtschaftlichen Aufschwung bringt (vgl. oben), wirkt somit als Transmissionsriemen kultureller Veränderung, auch deshalb, weil über die Touristen aus den Metropolen (Wien, München, ...) gegenwärtige Kultur aus diesen hereinkommt. Diesem Umstand wird in der Provinz eine eigene, endogen verstandene Kultur gegenüberzustellen versucht, die nicht selten durch „Überkompensation“ gekennzeichnet ist (Trachten- und Brauchtumserhaltungsvereine, ...) (vgl. Köstlin 1982a, S. 144 f.; sowie Hanisch 1981, S. 68 u. $91 \mathrm{ff}$.$) .$ 
gewachsen", sondern durch ganz bestimmte politische und ökonomische Voraussetzungen geschaffen worden. ${ }^{82}$

Ethnizitätsbildung stand in engem Zusammenhang mit der politischen Zentralisierung und ökonomischen Verdichtung in den letzten 200 Jahren und kann somit als „Zwillingsschwester der Nationenbildung" in der Phase der Industrialisierung angesehen werden. ${ }^{83}$ Kennzeichnend für diesen Prozeß ist der ZentrumPeripherie-Konflikt und damit verbunden die Herausbildung einer „räumlichen Arbeitsteilung" (Konzentration der wirtschaftlichen und politischen Mächte in wenige Zentren und damit verbunden die einseitige Ausbeutung der Provinzen). Daneben bot sich den zurückfallenden Regionen in der Ethnizitätsbildung die Möglichkeit des Widerstandes gegen die metropolische Ausbeutung, indem versucht wurde, durch den Aufbau einer eigenen Identität ökonomische Rückständigkeit kulturell zu kompensieren.

Seit dem Beginn des 19. Jahrhunderts fand in Tirol eine Frühform der Ethnizitätsbildung statt, die nicht zuletzt durch den Widerstand gegen Napoleon und die bayerische Herrschaft ausgelöst worden war. Einigendes Element sollte der Tiroler Freiheitswille, die seit alters her bestehende Unabhängigkeit und Eigenständigkeit des Landes Tirol sein; vor allem in der tragischen Figur des Tiroler Freiheitskämpfers Andreas Hofer verdichteten sich diese mythischen Elemente. Daß diese - damals beschworene - Eigenständigkeit Tirols nur Trugbild war, zeigte sich spätestens nach der Niederlage Napoleons und dem Abzug der Bayern. Das restaurative Österreich belohnte die - habsburgertreu gebliebenen - Tiroler Freiheitskämpfer mit noch stärkerer Anbindung an die Zentralgewalt. ${ }^{84}$

82 1988; zusammenfassend S. 483 ff., bes. S. 489 f. Leider fehlt bis jetzt eine in dieser Richtung vergleichbare Arbeit über Tirol, die nicht zuletzt deshalb interessant wäre, da ein Moment der Konstituierung Vorarlberger Besonderheit die Abgrenzung von Tirol war! (ebd., S. 160 ff. und S. 173 f.)

83 Ebd., S. 489; vgl. den guten Überblick über verschiedene Theorien der Nations- und Ethnizitätsbildung bei Blaschke 1985 !

84 Zur Konstituierung dieser Mythen, vgl. die einschlägigen Landesgeschichtsschreibungen von Stolz, Egger, Hirn, ... Kritisch dazu diverse Artikel in den Zeitschriften „sturzflüge“ [Nr. 7 (1984) Thema: „Diroll 1809“] und „erziehung heute“ [Heft 1/2 (1984) Thema: „helden“], die anläßlich des 175-Jahr-Gedenkens an 1809 erschienen sind. So Christoph Hartungen in einer Analyse der Rückkehr Tirols zu Österreich: „Das Land wurde nun einfach mit den anderen Provinzen des Reiches gleichgeschalten. [...] Die Steuern wurden keinesfalls gesenkt [...] die Wehrpflicht [...] verschärft; [...] Die Landstände wurden zwar wieder eingeführt, aber sie hatten nur mehr das Recht angehört zu werden, oder Bittschriften an den Kaiser zu senden - etwas Eigenständiges zu sagen oder gar zu beschließen, war ihnen vollends untersagt." [eh Nr. 1/2 (1984), S. 10 f.] 
In der 2. Hälfte des 19. Jahrhunderts gewann die Proklamierung der tirolischen kulturellen Einheit eine neue Ausrichtung, kann sie doch als einigender Versuch angesehen werden, Gegensätze der modernen, durch Industrialisierung gekennzeichneten, Gesellschaft zu verdecken. Der Feind wurde, angeblich nur von Außen kommend, in der Modernisierung, Industrialisierung, den zuwandernden Arbeitskräften u.ä. gesichtet und mit seiner Bekämpfung sollte von inneren, tirolischen Problemen abgelenkt werden (z.B. dem verschärften ökonomischen Druck auf Bauern und Gewerbestand, da durch die gesamtgesellschaftliche Entwicklung industriemäßig erzeugte Produkte billiger ins Land kamen, als sie hier produziert werden konnten).

Nicht so sehr die bäuerliche Schicht, als vielmehr das Kleinbürgertum, wurde zum Träger dieser nationalen Ideen.

Otto Bauer hat auf die besondere Lage des Bürgertums der Alpenländer hingewiesen, das weit weniger differenziert war als in den städtischen Ballungszentren.

„Im allgemeinen droht doch dem aufrechten Bürgertum der Alpenländer weder von fremden Minderheiten noch von den Arbeitern der eigenen Nation gleiche Gefahr wie den deutschen Kleinbürgern der Sudetenländer."

Und er betonte, daß dieses Bürgertum nicht so sehr ökonomische, als vielmehr ideologische Gegensätze vom klerikal konservativ eingestellten Bauerntum trennen würde. Einzig an den Sprachgrenzen, wie zum Beispiel in Südtirol, wo Menschen verschiedener Sprachen aufeinandertreffen würden, gäbe es „nationalen $\mathrm{Ha} \Re^{\prime 85}$.

Die Symbole dieser kulturellen Einheit und Besonderheit wurden dem Fundus der Vergangenheit entnommen. Die Besinnung auf das gesunde Bauerntum und dessen kulturelle Manifestationen, wie dessen Kleidung (Tracht), musikalische und verbale Äußerungen, Bräuche, Volkskunst, ... wurde zum Motor ästhetischer Kom-

85 So in Bauers umfangreicher theoretischer Arbeit zum Nationalismusproblem „Die Nationalitätenfrage und die Sozialdemokratie“ (entstanden 1906/07), jetzt in Bd. 1, 1975, S. 444 f. Er sah die Nation als „relative Charaktergemeinschaft“ an, die er nur geschichtlich verstanden wissen wollte und die, seiner Ansicht nach, vor allem auf gemeinsamen Verkehr und Beziehungen beruhte. Damit lehnte er jede mechanistische und natürliche Bestimmung des Nationenbegriffs ab und sah diese stets im Zusammenhang mit Kultur, unter Einbeziehung von deren klassenspezifischen Ausformungen. Dadurch wurde er zum Vorläufer einer soziologischen Nationalismustheorie und zum Vorläufer derjenigen, die Nationalismus als Vehikel einer sozialen Emanzipation ansahen (Eine kritische Auseinandersetzung mit Bauers Nationalismustheorie liefert Blaschke 1985, S. 76 ff.). 
pensation ökonomischer Rückständigkeit. Ehemals für bestimmte Zwecke (religiöse Handlungen, Standessymbole, ...) dienende kunsthandwerkliche Objekte der bäuerlichen Welt wurden von bürgerlichen Schichten übernommen, um, folkloristisch verwandelt, den Bezug auf eine räumlich orientierte Tradition zu symbolisieren. Damit wurden Artefakte der bäuerlichen Welt zum Symbol für die ganze Nation, indem sie vermeintliche (Volks-)Einheit vorzugeben hatten. ${ }^{86}$

Zum einen wurde so die Schaffung eines nationalen Marktes ermöglicht, indem Gegensätze verwischt wurden und Stabilität erlangt wurde, zum anderen bot die vorgegebene Volkseinheit Identitätsstiftung, die - gerade in dieser sozioökonomischen Umbruchsphase - etwaige Brüche zu verdecken half.

Die zur ethnischen Identität gehörenden Symbole bestimmter gesellschaftlicher Gruppen sind allerdings keine natürlichen Konstanten, sie sind auswechselbar und können sich wandeln. ${ }^{87}$ Diese Symbole waren aber keinesfalls nur ideelles Gut, sondern unterlagen einer gewissen ökonomischen Verwertbarkeit, wie sich an einem 1909 von der Bozner und der Innsbrucker Handelskammer abgehaltenen „Preisausschreiben für Fremdenartikel“ zeigen läßt:

\begin{abstract}
„Als Fremdenartikel in diesem Sinne sind jene Waren kunstgewerblichen Charakters anzusehen, die in Form und Ausstattung in einer Beziehung zum Lande Tirol [...] stehen, deswegen als Erinnerungszeichen seitens der Fremden angekauft werden und sich hierfür durch ihre handliche Form und ihren Kaufpreis, der einen größeren Absatz ermöglicht, besonders eignen. "88
\end{abstract}

Bereits 17 Jahre zuvor war Johann DEININGER, Innsbrucker GewerbeschulDirektor und Obmann des Tiroler Gewerbevereins, anläßlich eines Vortrages über den Fremdenverkehr, auf dessen kunsthandwerkliche Bedeutung eingegangen:

„Fremde bringen den charakteristischen Eigenthümlichkeiten der von ihnen besuchten Orte ein gewisses Interesse entgegen, [dieses ist] in den meisten Fällen [davon] bestimmt, daselbst einen oder mehrere Gegenstände anzukaufen, um sie als Andenken in ihre Heimath mitzunehmen.

86 S. Blaschke 1985, S. 187 f.; vgl. Greverus 1978, die diesen Wandel von bäuerlicher Kultur zur Volkskultur beschreibt: „Der Marginalisierung der bäuerlichen Bevölkerung und ihrem dadurch mitbedingten kulturellen Identitätsverlust in einer sich verstädternden und industrialisierenden Welt wurde durch das nationale Kulturideal eine neue - die nationale - Identifikation angeboten“. (S. 174) Zur „Nationalisierung der Volkskultur“ ebd., S. 178 ff.!

87 Blaschke 1985, S. 186.

88 Tiroler Gewerbeblatt Nr. 6/1909, S. 5. 
[Viele würden, weil] etwas Seltenes und Originelles anzukaufen in einem bestimmten Orte geboten wird, gerade deshalb diesen Ort besuchen. " ${ }^{\text {"9 }}$

Die in Tirol, vor allem in den letzten Jahren des 19. Jahrhunderts, stark zugenommene Besinnung auf Heimat, Vergangenheit und Tradition hat darin ihren Ausgang, neben dem Hand in Hand gehenden modernisierungsfeindlichen Element. $^{90}$

Doch nicht realer Umgang mit Heimat und Vergangenheit stand im Mittelpunkt, sondern die Tatbestände wurden dem eigenen, vorgestellten Bild nach zurechtgebogen..$^{91}$

Werner Gürtler hat in seinem Aufsatz „Über die kulturelle Einheit Tirols“ auf den dahinterliegenden Zirkelschluß aufmerksam gemacht, daß als Voraussetzung angenommen wird, was erst bewiesen werden soll.

„Ausschließlich diejenigen Erzeugnisse des kulturellen Lebens werden als
tirolisch identifiziert, gelten als ,echt' tirolisch, die die Merkmale ,patrio-
tisch' und ,religiös' aufweisen und somit dem, Wesen' des Landes entspre-

89 Mittheilungen des Tiroler Gewerbevereins 1/2 (1892), S. 43. Auch er ist für den Verkauf von Gegenständen mit „,harakteristische[m] Gepräge“, meint aber, „selten wird die Hauptform eines solchen älteren Erzeugnisses zur Nachbildung für einen modernen Gebrauchsgegenstand direkt verwendet werden können, fast immer aber deren Verzierungsweise." (S. 44) Neuschöpfungen solch alttirolischer Hausindustrie, waren dann auf den verschiedensten Ausstellungen zu bewundern! Zur „Entdeckung der Volkskunst für das Kunstgewerbe“ s. die Arbeiten von Bernward Deneke 1964 u. 1980.

90 Beispiele von Heimat- und Erhaltungsvereinen in Tirol: der „I. Tiroler Volkstrachten Erhaltungs- und Schuhplattlerverein“, aber vor allem der „Heimatschutzverein“, der 1908 gegründet wurde. (Vgl. Kap. 3.3!)

$91 \mathrm{Da}$ dies auch nach dem Zweiten Weltkrieg noch bestimmendes Moment in der offiziellen Selbstdarstellung Tiroler Kultur war/ist, zeigt eine Rede des ehemaligen Landesrates und Kulturreferenten von Tirol, Dr. Hans Gamper, die er zur Eröffnung der Ausstellung „Gotik in Tirol“ 1950 hielt. Darin heißt es in Bezug auf Tiroler Selbstbewußtsein: „In dieser zweitausendjährigen Kulturentwicklung ist Tirols Selbstbewußtsein gewachsen, hat der genius loci seine Eigenwilligkeit und seine Eigenständigkeit erworben. Wenn auch diese Eigenwilligkeit höheren Ortes [...] nicht immer gern gesehen wird, so müssen wir sie trotzdem bewahren und dafür kämpfen, weil diese Eigenwilligkeit der Urquell ist für die Schaffensfreude des Volkes und für seinen schöpferischen Geist“. (S. 2) Bereits in der Zwischenkriegszeit hatte Gamper die Besonderheit Tirols und der Tiroler hervorzuheben versucht. 1925 veröffentlichte er sein Buch „Wohin steuern wir?“, in welchem er den Gegensatz Tirol-Wien besonders herauszustreichen versuchte. „Diesem fremden, internationalen Wien stehen wir Alpendeutsche gegenüber, stehen die Tiroler gegenüber, mißtrauisch und ablehnend; [...] Die Tiroler sind ein eigener Menschenschlag. [...] Und in dieser Bevölkerung ist ein Geist lebendig, der dem Wiener Geist völlig entgegengesetzt ist: hart und unbeugsam, gläubig und heimattreu, grüblerisch und versonnen." (S. 20 f.) 
chen, das wie es ja aus den Tiroler kulturellen Erzeugnissen hervorgehe, als patriotisch und religiös zu charakterisieren sei. ${ }^{\text {"9 } 2}$

Nach der Jahrhundertwende nahmen die nationalistischen Züge in Tirol teilweise chauvinistischen Charakter an, die auf Deutsch-Tiroler Seite 1905 in der Gründung des „Tiroler Volksbundes“ mündeten.

Diese Vereinigung baute ihren Nationsbegriff vor allem auf Sprache und Abstammung auf. Ein Umstand, der sich im Leitspruch: „Tirol den Tirolern - ungeteilt von Kufstein bis zur Berner Klause, die deutsche Heimatscholle deutsch für immer" zeigte. ${ }^{93}$ Der Bund versammelte in seinen 320 Ortsgruppen ca. 26.000 Mitglieder und erlangte damit einen nicht unbedeutenden Einfluß auf die öffentliche Meinung. ${ }^{94}$

92 1986, S. 179; er vermerkt weiters in seiner Arbeit: Für Tirol hatte „die sogenannte kulturelle Einheit [...] für die Machtträger im Lande den Gebrauchswert der Legimitation und Motivation für den Export von soviel Konflikten wie nur irgend möglich jenseits der realen Grenzen des Landes und jenseits der fiktiven Grenzen des Volkes. Für die überwiegende Mehrheit der Tiroler Bevölkerung dagegen hat die genannte Vorstellung den Gebrauchswert der Identitätsstiftung“. (S. 198.) Bleibt die Frage, ob im Falle der „Tyroler Nation“ überhaupt von einem eigenständigen Nationalismus gesprochen werden kann, oder ob sie nicht bloß eine Variante des Bekenntnisses zum Deutschtum darstellt.

93 Zit. bei Kunzenmann 1971, S. 110.

94 Stolz 1955, S. 665 f.; der „Andreas-Hofer-Bund“ bildete ab 1919 für Nordtirol die Fortsetzung des Volksbundes (ebd.). 



\section{Vom Denkmal- zum Heimatschutz}

Die Entstehungsgeschichte des „Tiroler Volkskunstmuseums“ wird nur verständlich, wenn sie eingebettet in die kulturelle Entwicklung gesehen wird. Diese machte es sich ab der Mitte des vorigen Jahrhunderts einerseits zur Aufgabe, das, im Zuge der industrie-kapitalistischen Entwicklung in Bedrängnis gekommene Gewerbe mittels Belehrung und Anlegung von Vorbildsammlungen zu fördern. Andererseits kam ungefähr zum gleichen Zeitpunkt, ebenfalls durch die Industrialisierung ausgelöst, der Gedanke auf, vom Verfall und Ausverkauf bedrohte Kulturgüter zu schützen.

Ich versuche in diesem Kapitel diese Entwicklung für Tirol abzuhandeln, während im folgenden Kapitel die besondere Art der Gewerbeförderung, am Beispiel des „Tiroler Gewerbevereins“, dargestellt wird.

Dem Umstand, daß beide Richtungen - Gewerbeförderung mittels Bereitstellung von vorbildhaften Mustersammlungen und der Schutz des heimischen Kulturgutes - durchaus zusammenlaufen können, verdankt nicht zuletzt das „Tiroler Volkskunstmuseum“ seine - lange Zeit nur theoretisch gedachte - Entstehung.

Als um 1912 der Landesverkehrsrat den Auftrag erteilte, den Heimatschutz auf gesetzliche Grundlagen zu stellen, hatte dieser damit nicht nur einen ersten Höhepunkt in Tirol erreicht, vielmehr wurde damit festgestellt, „welch inniger Zusammenhang zwischen beiden [Heimatschutz und Fremdenverkehr; W.M.] bestand" ${ }^{\text {"95. }}$.

Wie der Sekretär des Landesverkehrsrates, Dr. Heinrich Rohn, in seinem Gutachten über die „rechtlichen Grundlagen des Heimatschutzes“ ausführte, wurde mit

„Heimatschutz das Streben verstanden [...], das Schöne und Eigenartige, das besteht, zu erhalten, das neu Entstandene schön und eigenartig zu gestalten und Verunstaltungen zu verhüten, dann ist es für jene, die den Fremdenverkehr fördern helfen, nicht nur eine mit dem Gemüte erfaßte kulturelle Aufgabe, sondern es bedeutet für sie zugleich auch die Pflege und Förderung eines wirtschaftlichen Gutes ersten Ranges. ${ }^{\text {"“96 }}$

95 Rohn 1912, S. 3.

96 Ebd.; Rohn berichtete dem Rat am 14.12.1912 in einer Sitzung über das Ergebnis seines Gutachtens. 
Er wies auch darauf hin, daß „ausgeschlossen [...] werden [müsse], der Bevölkerung mit gesetzlichen Zwangsmitteln ästhetische Anschauungen [...] aufnötigen zu wollen, zu denen sie sich auf gütlichem Wege nicht bekehren läßt."

Ein gesetzlicher Rahmen sollte jedoch ,jene Fälle grober Verletzung des Heimatschutzempfindens, die, wie man bei uns zu sagen pflegt, geradezu strafbar sind“, erfassen. Als solche erachtete er grobe „Verletzungen des Heimatgefühls und des guten Geschmackes, die von der Allgemeinheit als solche empfunden werden" ${ }^{\text {"97? }}$.

Nicht gesetzlicher Zwang, sondern, gemäß liberaler Grundsätze, die Einsicht sollte Grundlage des Heimatschutzgedankens in der Tiroler Bevölkerung sein. Da diese Einsicht nur durch Erziehung und Belehrung zu erzielen sei, waren Lehrer und andere pädagogisch tätige Personen (vor allem Geistliche) Hauptansprechpartner für den Heimatschutzgedanken. ${ }^{98}$

\subsection{Denkmalschutz in Österreich}

In etwas anderer Form bestand der Schutzgedanke für materielle Kulturgüter in Österreich schon seit der Mitte des 19. Jahrhunderts.

1854 wurde in Wien eine Denkmalpflegestelle gegründet, die „Zentralkommission für Erfassung und Erhaltung der Baudenkmale"; sie sah ihre Aufgabe vornehmlich in der Rettung von Großbauten, besonders von Kirchen und Burgen.

Damit lag die Obsorge des Denkmalschutzes beim Staat, denn die Zentralkommission unterstand zuerst dem Handels-, ab 1861 dem Unterrichtsministerium.

Ab 1873 wurde sie in „Zentralkommission zur Erfassung und Erhaltung der Kunst- und historischen Baudenkmale" umbenannt, blieb beim Cultus(Unterrichts)ministerium und war in drei Sektionen gegliedert. ${ }^{99}$

97 Ebd., S. 5; Auch an anderer Stelle betont er seine Abneigung gegen gesetzliche Maßnahmen und plädiert für die Stärkung der Wertschätzung des Heimatschutzgedankens: Es wäre fatal, „wenn man mit rechtlichen Zwangsmitteln den Widerstrebenden dazu verhalten wollte, pietätvoll zu bewahren, was er für einen wertlosen Plunder hält." (S. 4)

„Wo guter Geschmack und Kulturempfinden fehlen, lassen sie sich nicht durch Gesetze dekretieren, sondern müssen durch Belehrung, Erziehung und Propaganda geweckt werden." (Ebd., S. 16.)

99 Hocke 1975, S. 15 ff; diese Sektionen umfaßten verschiedene Zielsetzungen und Zeitspannen: Objekte der prähistorischen und antiken Zeit; Architektur, Plastik, Malerei und zeichnende Künste des Mittelalters bis zum 18. Jahrhundert sowie historische Denkmäler verschiedener Art von der ältesten Zeit bis zum Ende des 18. Jahrhunderts. (S. 18) Zur Arbeit der Zentralkommission in Tirol vgl. das Kapitel „Denkmalpflege und Heimatschutz“ in Fontana 1987, S. $401 \mathrm{ff} . !$ 
Für jedes Kronland gab es einen „Landeskonservator“, daneben noch korrespondierende Mitglieder, die vor allem die Aufgabe hatten, denkmalschutzwürdige Bauten zu benennen.

Seit der Jahrhundertwende verstärkten sich die staatlichen Bemühungen. So war das Unterrichtsministerium in einem Erlaß von 1907 an die Lehrer herangetreten, sich am Schutze der Denkmäler zu beteiligen. Schon bei den „Schulkindern [sollten sie] ein lebhaftes Gefühl für die heimatlichen Denkmäler erwecken und alle Bevölkerungsschichten heranziehen "100.

\subsection{Denkmal- und Altertumsschutz in Tirol}

In einem daraufhin vom Landesschulrat von Tirol herausgegebenen Zirkular an alle Bezirks- und Stadtschulräte betreff des „Schutz[es] des Bestandes von Altertümern" hieß es an die Lehrer gerichtet, es sollte „in den verschiedenen Kreisen der Bevölkerung dem angestrebten Ziele [Schutz der Altertümer; W.M.] ein lebhaftes Interesse entgegengebracht werden "101.

Bereits ein Jahr zuvor war ein Zirkularerlaß zum „Schutz alter Friedhöfe und Grabdenkmäler" an alle Bezirksämter Tirols ergangen. Darin hieß es, daß die:

„Beseitigung oder Vernachläßigung der alten, oft künstlerisch oder kunst-
gewerblich hochinteressanten Grabdenkmale einerseits einen unwider-
bringlichen Verlust an heimischen Kunstgute, andererseits häufig auch
einen Mangel an Pietät für die Grabstätten von Menschen bedeutet, die
der Heimat in der einen oder anderen Richtung zur Ehre und zum Nutzen
gereichten. ${ }^{102}$

All diese Bemühungen waren jedoch weniger Ausdruck einer weitsichtigen Denkmalschutzpolitik, als vielmehr verzweifeltes Reagieren auf die reale Lage: denn in

100 Tiroler Landesarchiv (TLA), Statthalterei/Kunst Nr. 22918/232 1907; Erlaß des Ministeriums für Cultus- und Unterricht vom 14.4.1907, Zl. 47119 ex 1906.

101 Ebd.; Zirkular des Landesschulrates von Tirol Nr. 2288 vom 10.5.1907; dieses Schreiben war analog zu dem des Kärntner Landesschulrates aus dem Jahre 1906 verfaßt worden.

102 TLA, Statth./Kunst Nr. 45299/259 1905/6; Zirkularerlaß der Statthalterei vom 30.8.1906 Nr. 45299; diesem vorangegangen war ein Brief des Ministeriums für Cultus und Unterricht vom 6.9.1905, Zl. 34081, mit der Bitte um Berichterstattung aus allen Bezirken des Landes, betreff des „Friedhofschutzes“. 
der zweiten Hälfte des 19. Jahrhunderts waren „Alterthümer“ zu einem lukrativen Handels- und Spekulationsobjekt geworden. ${ }^{103}$

In einem Zirkular zum „Verbote des Verkaufes von heimischen Alterthümern ins Ausland" mußte der damalige Landeshauptmann von Tirol, Theodor Freiherr von Kathrein, eingestehen, daß „kostbare Objekte durch Verkauf ins Ausland“ gingen. Das dagegen gerichtete Bemühen der Behörden wäre oft vergeblich und erst dann von Erfolg gekrönt, wenn „die ganze Bevölkerung des Landes an der Erhaltung der Kunstwerke und Alterthümer mit Eifer und Interesse sich beteiligt, wenn sie sich bewußt wird, daß Alterthümer und Kunstwerke auch mit zum Wesen der tiroler Heimat gehören.“ Weiters hob er die „Pflicht sie [die Altertümer; W.M.] zu vererben“ hervor, es läge „nunmehr an der Bevölkerung des Landes darüber zu wachen, daß den noch herrschenden Mißständen entschieden begegnet" werde.

Als schützenswert wurden in diesem Schreiben sakrale wie profane Bauwerke, bewegliche Sachen wie Hausgeräte, Getäfel, Einrichtungsstücke, alte Trachten, Schmuck, ... angesehen. ${ }^{104}$

Auch zahlreiche Künstler und Intellektuelle hatten, in mehr oder weniger schwärmerischer Weise, auf den Ausverkauf Tiroler Kunst und Kultur hingewiesen. So bereits 1884 Fridolin Plant in seinem Aufsatz über „Alttirolische Bauernhöfe“:

„Schreine oder Truhen [...] sind schön geschnitzt und eingelegt und leider ein vielgesuchtes Object der Alterthumssammler semitischer und nicht

103 Wie die Statthalterei der Kammer schon 1886 zur Kenntnis brachte, scheiterte das Vorhaben, diesen Ausverkauf über strengere Gewerbeauflagen in den Griff zu bekommen, auch am Einspruch des Handelsministeriums, welches in einem Erlaß von 6.7.1886 feststellte, „dass das Ansuchen der Trödler um die Einreihung des Antiquitätenhandels unter die concessionierten Gewerbe abgewiesen" wurde. Siehe Protokolle der ordentlichen Sitzungen der Handelsund Gewerbekammer Innsbruck vom 15.10. 1886, wo die Circular-Verordnung der Tiroler Statthalterei (Zl. 14609 vom 19.7.1886), die auf den Ministeriums-Erlaß (Zl.19890) bezugnimmt, verhandelt wurde.

104 TLA, Präsidiale Nr. 884/1906; Zirkular des Tiroler Landesausschusses Nr. 25347 ex 1904 vom 7.12.; darin hieß es weiter: „Der Magistrat (die Gemeindevorstehung) wird daher beauftragt, auf die Angehörigen der Gemeinde dahin einzuwirken, daß sie beabsichtigte Verkäufe von Kunstgegenständen und Alterthümern, sowie die wahrgenommene Gefährdung von solchen der k.k. Bezirkshauptmannschaft" melden und anzeigen. Neben dieser eher appellativen Maßnahme wurde vorgeschlagen, daß sich das Museum Ferdinandeum durch Ankauf, sowie die „Zentralkommission“ mittels ihrer Konservatoren verstärkt „tirolischen Kunstwerken und Altertümern" annehmen sollten. Abschließend wurde nochmals auf die seit 1827 vorgeschriebene „Anzeigepflicht bei Verkauf von Gegenständen von historischem Wert“ hingewiesen und der Wunsch des Landesausschusses ausgesprochen, daß die „Sicherung [...] erreicht und der Verschleppung [...] Einhalt getan werde." 
semitischer Abstammung, was auch von dem übrigen alten Hausrathe gilt, wodurch ein gutes Stück Poesie aus dem Hause kommt. Es ist bald kein alter Nagel an der Wand mehr sicher!“105

\subsubsection{Zur Entdeckung der Volkskultur im 19. Jahrhundert}

Der Ausverkauf heimischen Kulturgutes war jedoch nicht so sehr dem Unvermögen der Tiroler Bevölkerung anzulasten, vielmehr zeigte sich hier die Kehrseite der bürgerlichen Volks- und Natur-Romantik.

Peter Burke verwies darauf, daß im 19. Jahrhundert die Hinwendung zum Volk und zu dessen Kultur - oder vielmehr, was dafür angesehen wurde - ästhetische, intellektuelle und politische Gründe hatte. ${ }^{106}$

Die „Entdeckung der Volkskultur“ war nicht nur eng verknüpft mit der „Ausbreitung des Nationalismus“ und eine „Reaktion auf die Aufklärung“; sie war auch eine ästhetische Bewegung, die aufgrund ihrer kulturpessimistischen Einstellung in der Gegenwartskunst keine Erfüllung mehr finden konnte und die Erlösung in der „Volkskunst und -kultur" suchte, deren „Primitivität“ und „Exotik“ besonders anziehend wirkte. ${ }^{107}$

„Musealität wird zur Aneignungsform par excellence, mit deren Hilfe die
bürgerliche Kultur von anderen Kulturen Besitz ergreift [...] Geradezu
besessen von ihr, entwickeln die Protagonisten des Musealen ein Stellver-
treterdenken, einen, konservatorischen Blick', der ihre ungehemmte Sam-
melleidenschaft, d.h. die Vereinnahmung fremder Kulturgüter für eigene
Zwecke rechtfertigt, indem er sie zu pflegen und an einem sicheren Ort
zu verwahren vorgibt. Ihren Gebrauchszusammenhängen entrissen und zu

105 Plant 1884, S. 8 f.; diese romantisierende Arbeit erschien in der „Chronik des österreichischen Touristenclubs“. Plant vermag diesem Ausverkauf auch eine positive Seite abzugewinnen, da so doch „diese oder jene gemüthliche alte Stube vom Bauern, der selbe in einer Anwandlung von Renovierungssucht dem Feuertode überliefert hätte, in ein städtisches Haus wandelt, und dort ihren gesunden Segen walten läßt, der den Menschen dort oft nothwendiger und wohlthätiger ist, als droben im Gebirge, wo sonst alles von Poesie und Gesundheit erfüllt ist." (Ebd.)

106 Burke 1981, S. $22 \mathrm{ff}$.

107 Ebd.; vgl. Fischer 1985, der betont, daß bereits ,in ihrer Suche nach einer verlorengegangenen Einheit, nach einer Synthese von Persönlichkeit und Kollektiv, in ihrem Protest gegen kapitalistische Entfremdung [...] die Romantiker das Volkslied [...], die Volkskunst, die Folklore [entdeckt hatten] und [...] das Evangelium des ,organisch' gewachsenen, des ,homogenen 'Volkes verkündet[en]. [...] Volkskunst wurde als das, Gewordene` dem, Gewollten ' jeder anderen Kunst entgegengesetzt, und man hielt sie in ihrer ,Anonymität‘ für die spontane Schöpfung eines mystifizierten Kollektivs, unabhängig von Individualität und Bewußtsein“. (S. 71) 
Relikten degradiert, fristen die konservierten Gegenstände in den Wandelhallen des bürgerlichen Sammeleifers eine Schattenexistenz, Trophäen der herrschenden Kultur und ihres überlegenen Zugriffs weit mehr als Zeugnisse der kolonisierten Lebenswelten, für die sie nicht mehr zu sprechen vermögen. " ${ }^{108}$

\title{
3.2.2. Sammeln und Retten als Aneignungsformen von Volkskunst
}

Sammeln und Retten alter Volkskunst war nicht nur Sache des städtischen Bürgertums, sondern wurde auch im Namen der Wissenschaft betrieben, für die vor allem der Alpenraum ein bevorzugtes Sammelgebiet war.

Leider finden sich keine detaillierten Angaben darüber, wie groß die Anzahl der außer Landes gebrachten Güter war; jedoch hieß es bereits 1888 in einem Bericht der „Mittheilungen der k. k. Central Commission zur Erforschung und Erhaltung der Kunst- und historischen Denkmale“:

\begin{abstract}
„Wahr ists, daß vor 30 Jahren Wagenladungen, man könnte sagen, in ununterbrochenem Zuge, über die Gränze von Tyrol gingen, und daß man im benachbarten Deutschland und besonders in Bayern lebhaftes Verständnis den Kunstschätzen der stammverwandten Tyroler entgegen brachte und mit Freuden diese Wagenladungen, die mit Kunstsachen bepackt ein unpatriotischer Geist aus Tyrols Alpenland ziehen ließ, aufnahm. " ${ }^{109}$
\end{abstract}

Als Ursache galt dem Autor „Mangel an eigenem Kunstsinn, Gleichgiltigkeit, ungenügender Patriotismus“, was „das Überdiegränzewandern unserer Kunstsachen begünstigen“ würde; ferner würden der „Mangel an Sammelstätten, öffentlichen Museen und Privat-Sammlungen“ das „Unheil“ befördern. ${ }^{110}$

108 Schindler 1984, S. 29 f.

109 Tappeiner 1888, S. 199. Der Autor nimmt in seinen Ausführungen Bezug auf einen Artikel von Hans Eduard von Berlepsch-Valendas, „Gothisches aus Tyrol“, der 1888 im „Kunstgewerbeblatt“ erschienen war und führt zur Bekräftigung an: „Eine Wanderung durch das National-Museum in München und durch die weitläufigen Anlagen des germanischen Museums wird dies bestätigen." (Ebd.)

110 Ebd., S. 200; Tappeiner bedauerte das Herabsinken der gesammelten Stücke zu „Schaustücke[n]“, die, „nicht der ersten Bestimmung gemäß verwendet, ihren ursprünglichen Zweck ganz verloren" hätten (ebd.). 
1906 veranlaßte eine Anfrage aus der Kanzlei Erzherzog Franz Ferdinands ein strengeres Vorgehen gegen diesen Kunsthandel. In diesem Brief wurde erwähnt, daß dem Erzherzog anläßlich eines Museumsbesuches in Dresden, ein „gotisches Zimmer mit Tiroler Einrichtung“ aufgefallen wäre, welches ein „Dresdener Antiquar geliefert“, der „die Einrichtungsstücke gelegentlich einer Reise im Vintschgau, allerdings aus Privat- (zum großen Teil bäuerlichen) Besitz“, erworben hätte.

Der Erzherzog forderte nun, da „im Vintschgau [...] keine gesetzliche Handhabe gegen [den] Ausverkauf" bestünde und das Tal durch den Bahnbau erschlossen wäre, ein Eingreifen der Behörden, indem sie aufklärerisch wirken, die „Bevölkerung belehren, und vom Verkauf abzuhalten " versuchen sollten. ${ }^{11}$

\subsubsection{Verschleppung tirolischer Altertümer ins Ausland}

In der Folge richtete die Statthalterei in Innsbruck ein Schreiben an alle Bezirkshauptmannschaften in Tirol und Vorarlberg, worin sie beklagte, daß ,in letzter Zeit wertvolle Objekte des alttirolischen Kunstgewerbes aus kirchlichem wie aus privatem Besitz in das Ausland gewandert" wären, wies auf das "gotische Zimmer aus dem Vintschgau“ hin und bedauerte, daß die Bezirksstellen "noch immer nicht gegen die Verschleppung kunsthistorisch interessanter Altertümer vorgehen" würden. ${ }^{112}$

Die Antwortschreiben der einzelnen Bezirksbehörden verwiesen darauf, daß die einschlägigen Erläße in den Amtsblättern veröffentlicht worden wären.

Die Bezirkshauptmannschaft Meran berichtete, daß an die Gendarmerie „Weisungen wegen strengster Invilierung der Antiquitätenhändler und Anzeigeerstattung von Verkäufen von Kunstgegenständen ergangen" seien. Die Erhebung wegen der "gotischen Einrichtung aus dem Vintschgau" wäre aber noch nicht abgeschlossen. ${ }^{13}$

Die Bezirkshauptmannschaft Schlanders ging in ihrem Antwortbrief vor allem auf den Antiquitätenhandel ein und wies darauf hin, daß in Schlanders selbst keine solchen Händler anwesend, sondern „nur Meraner Antiquitätenhändler“ tätig wären. ${ }^{114}$

111 TLA, Präs. Nr. 884/1906; dieser Brief vom 15.2.1906 ging im Namen des Erzherzogs an die Statthalterei von Tirol und war von seinem Flügeladjutanten, Hauptmann Alexander Brosch, unterzeichnet worden. Das Antwortschreiben vom 26.2.1906 bedauerte die Vorfälle und versprach eine Untersuchung (ebd. Nr. 10802).

112 Ebd. Statth./Kunst Nr. 10802/65 ex 1906. Auch in diesem Schreiben, vom 26.2.1906, wird „als Gegenmittel“ die „Belehrung der Bevölkerung“ vorgeschlagen.

113 Ebd. Nr. 14239/89 ex 1906; der Brief stammt vom 9.3.1906.

114 Ebd. Nr. 18692/105 ex 1906, Schreiben mit der Zl. 3441 vom 3.4.1906. 
In seinem Gutachten für das Meraner Museum, vom 24.9.1906, über drei Vinschgauer Getäfel, befaßte sich der Korrespondent der Zentralkommission für Kunstdenkmale Dir. Alois Menghin ebenfalls mit den Praktiken eines Meraner Antiquars.

Sein streng auf kunsthistorischen Wertvorstellungen basierender Bericht maß zwei der drei Vertäfelungen nur geringen Kunstwert bei und sah allein in der Burgeiser Löwenwirtshaus Wandtäfelung ein „schützenswertes Denkmal heimischen Kunstgewerbes“, „das aber kaum irgendwo besser hinpaßt, als wo es sich eben befindet". Menghin vermerkte auch, daß sich ein Meraner Antiquar für zwei Täfelungen interessieren würde, aber „in der Wertschätzung der Objekte geirrt“ hätte. ${ }^{115}$

Bereits 1904 hatte die Statthalterei die Antiquitätenhändler und Trödler darauf aufmerksam gemacht, daß der „Verkauf von Kunstgegenständen und Altertümern ins Ausland ohne vorherige Anzeige bei der Verwaltungsbehörde I. Instanz verboten" wäre.

Weiters wurden die Bezirkshauptmannschaften angewiesen, der Statthalterei in Innsbruck zu melden, welche Antiquitätenhändler als „legitimiert “ gälten. ${ }^{116}$

Davor hatten sich die Beschwerden gehäuft, daß diese Händler „in voller Kenntnis der ihrem Handel entgegenstehenden Bestimmungen und im richtigen Verständnis für den Kunstwert der anzukaufenden Gegenstände, die Geistlichkeit durch Überredung zu den Verkäufen derselben zu bewegen wissen“.

Daher, so das Ministerium für Cultus und Unterricht in einem Brief an den Statthalter in Innsbruck, ,ersuche [ich] Eure Exzellenz [...] behufs Konstatierung eines Exempels mit allen zu Gebote stehenden Mitteln alle hiebei schuldtragenden Persönlichkeiten zur Verantwortung zu ziehen" ${ }^{117}$.

115 Kopie des Gutachtens im TLA, Statth./Kunst Nr. 60165/370 ad 6315; dieses war zustandegekommen, nachdem in zwei weiteren Briefen an die Statthalterei der Bezirkshauptmann von Schlanders von „alten Plafonden“, die im Bezirk vorhanden wären und die ein „Fachmann“ betrachten sollte, berichtete. (Schreiben vom 22.6.1906, Zl. 5040, TLA Statth./ Kunst Nr. 34479/191 und vom 23.8., Zl. 9334, Nr. 45298/ 253 sub. 18692).

Die daraufhin im September 1906 von der Statthalterei (TLA, Statth./Kunst, Nr. 45298/253 eingeschaltenen Museen in Bozen (Brief vom 16.9.1906, TLA, Statth./Kunst Nr. 48965/281) und Meran (Brief vom 16.11.1906, TLA, Statth./Kunst Nr. 60165/370) erklärten sich bereit, jeweils einen Sachverständigen nach Schlanders und Burgeis zu entsenden, das Ferdinandeum sah sich außerstande, „diese zeitraubende Besichtigung vorzunehmen“ (so Dir. Wieser in seinem Antwortschreiben vom 12.9.1906, TLA, Statth./ Kunst Nr. 48445/275).

116 TLA, Präs. Nr. 884 ex 1906; dieses Schreiben vom 13.3.1905 (Zl. 12874) ist eine Erinnerung der Befolgung des Zirkulars vom 13.4.1904 (Zl. 4015).

117 Brief vom 23.9.1904 (Zl. 1477) worin von einem „ausländischen Antiquar“ berichtet wird, der „periodische Raubzüge in den Kirchen Vorarlbergs anstelle“. (TLA, Statth./Kunst Nr. 45111/213 ex 1904) 
Erst 1918 kam es zu einem staatlichen Ausfuhrverbot für „Gegenstände von geschichtlicher, künstlerischer oder kultureller Bedeutung "118. Inwieweit dies eingehalten und kontrolliert wurde, war leider nicht in Erfahrung zu bringen.

Schon zehn Jahre vorher hatten die Innsbrucker Nachrichten ein Urteil des Obersten Gerichtshofes über die Kunstveräußerung wiedergegeben. In diesem war festgestellt worden, daß es von seiten eines privaten Käufers keine Verpflichtung gäbe, gekaufte Kunstwerke dem Staat zu überlassen, für die dieser „nationales Interesse“ bekunde.

Ganz im Sinne der zunehmenden tirolbezogenen, nationalen Gesinnung wurde vermerkt, daß für Tirol ein Sonderstandpunkt gelten müsse, denn „unsere Interessen heischen nicht ein staatliches Ausfuhrverbot, sondern ein solches für die engeren Grenzen des Landes“.

„Es ist ziemlich gleichbedeutend für Tirol“, hieß es in den Innsbrucker Nachrichten weiter,

„ob seine Kunstschätze zu den Großantiquaren nach Wien wandern, oder in die Jagdschlösser böhmischer Magnaten, die Bedeutung liegt darin, daß sie vor allem dem Lande und in diesem der Heimat, der Gegend, deren Zubehör sie nach der Idee des Schöpfers und nach der Tradition der Bewahrer geworden sind, erhalten bleiben."

Weiters wurde der fortschreitende kulturelle Ausverkauf der Heimat beklagt, der das „letzte schmiedeiserne Grabkreuz und [den] letzte[n] gothische[n] Kirchenleuchter" verschwinden läßt, wenn er noch zehn Jahre so fortschreite.

Der Artikel endete mit der Forderung nach einem

„Verbot der Ausfuhr aus dem Lande. Und wir appellieren an den neuen Landtag, daß er in der Herbstsession ein Gesetz berate, das in seiner Tendenz laute: Das Verbringen von Kunstwerken aus ihrer Heimat ist verboten. ${ }^{" 119}$

118 S. Hocke 1975, S. 125 ff., der dieses Gesetz „Betreffend das Verbot der Ausfuhr und Veräußerung von Gegenständen ..." (Staatsgesetzblatt Nr. 90/1918) zitiert.

11 Nr. 180 vom 7. August 1908, S. 1 f.; (Hervorhebung von W.M.) Der Artikel trug die Überschrift „In Tirol wird der Ruf nach Heimatschutz immer stärker“! Zu einer „Verordnung zum Schutze der heimischen Kulturgüter“, die die Reichsstatthalter ermächtigte, Verordnungen zu erlassen, mit denen sichergestellt werden sollte, daß der „heimische Besitz an [...] bodenständiger alter Kultur [nicht] durch Ankäufe in einem Maße bedroht wird, daß er in seinem Bestande gefährdet" ist, kam es unter der Besetzung Österreichs durch Nazi-Deutschland (Verordnung vom 23.3.1944 (!) Reichsgesetzblatt Nr. 13, Ausgabetag 25.3.1944). 


\subsection{Zum „Tiroler Heimatschutzverein“}

Es war kein Zufall, daß es kurz nach der Jahrhundertwende zur Gründung des Tiroler Heimatschutzvereines kam (1908).

$\mathrm{Da}$ als Hauptursache des Ausverkaufes heimischer Kulturgüter mangelndes Bewußtsein der anwesenden Bevölkerung angesehen wurde, sah der Verein seine vordringlichste Aufgabe darin, den Wert dieser Güter hervorzuheben.

„In Tirol selbst aber war, abgesehen von einigen Sammlern, das Verständnis für die Schönheit und den Wert unserer alten Kunst verlorengegangen, es war, als ob nicht mehr dasselbe Volk das Land bewohnt hätte [...] bar jedes Interesses, verschleuderten die Leute den alten Hausrat, rissen die Vertäfelungen aus den Stuben“,

meinte der Gründer des Heimatschutzvereines, Kunibert Zimmeter. ${ }^{120}$ Angeregt durch einen Bericht über die deutsche Heimatschutzbewegung ging er daran, den „Heimatschutz auch nach Tirol zu verpflanzen“, denn „ich sah immer mehr ein, daß es höchste Zeit war, gegen die zunehmende Verschandelung unseres schönen Landes einzugreifen" ${ }^{2121}$.

Es gelang dem Verein, der prominente Mitglieder in seinen Reihen vereinigte (Vorstand war Gotthard Graf Trapp), nach und nach Einfluß auf die Politiker des Landes und der Stadt Innsbruck zu gewinnen.

Mittels verschiedener Aufklärungsmaßnahmen, zum Beispiel der „Heimatschutzausstellung" von 1913, der Tagung des bayerischen und tirolischen Heimatschutzvereines in Innsbruck 1923 (anläßlich derer ein Trachtenfestzug stattfand $^{122}$ ), diverser Flugschriften (die sich vor allem an Lehrer richteten) oder der seit 1917 herausgegebenen „Mitteilungen“, die ab 1923 von den „Tiroler Heimatblättern" abgelöst wurden, versuchte der Verein in seinem Sinne zu werben. ${ }^{123}$

120 1910/11, S. 201; Zimmeter wurde 1872 in Tramin geboren und starb 1952 in Innsbruck. Bis 1908 war er Beamter der Landes-Brandschadenversicherung und ist danach als Direktor und Mitbesitzer in die Tiroler Glasmalerei- und Mosaikanstalt in Innsbruck eingetreten. Ab 1912 war er auch Obmann der Ortsgruppe Innsbruck des Tiroler Gewerbebundes. 1944 erhielt er durch Rektor Klebelsberg die Ehrenmitgliedschaft der Innsbrucker Universität! (vgl. Zimmeters Erinnerungen aus dem Jahre 1947)

121 Ebd. 1947, S. 55; vgl. den Beitrag von Norbert Mumelter (1969) zum 60jährigen Bestandsjubiläum des Vereines, der auf die Vereinsgeschichte und die Gründungsväter eingeht.

122 Zimmeter 1947, S. 87; Zimmeter betonte, daß „nur echte Trachten zugelassen“ waren und sprach von einem „Volksfest im echten Sinne des Wortes, alle Gesellschaftsschichten nahmen daran teil." (ebd.)

123 Ab 1921 finden sich in der Zeitschrift „Der Schlern“ (gegr. 1920) in regelmäßigen Abständen Berichte über die Vereinstätigkeiten. Diese mußten allerdings aufgrund der faschistischen 
1908 schrieb Zimmeter in seinem Aufruf zur Vereinsgründung:

„Es ist die Aufgabe dieser Schrift, den kulturellen Niedergang, die zerstörende Wirkung des Zeitalters der Maschine auf unser Kulturgut und auf die Schönheit unseres Landes aufzudecken."

Er sah das Wirken des Vereines jedoch nicht in „Äußerlichkeiten“, sondern in der „Reorganisation von innen heraus“, in der „Rückkehr zur Einfachheit und Wahrheit", in der „Bekämpfung des Scheins und der Großmannssucht", denn Zimmeter galt die „Schönheit unseres Landes [als] das letzte Kapital [...], das uns noch geblieben ist, worauf sich die einzige bedeutende Industrie Tirols, der Fremdenverkehr", aufbauen würde.

Nicht „geistloses Kopieren alter Bauten, gewerblicher Erzeugnisse“, das Beibehalten von „Sitten und Gebräuchen [...] die in die heutigen Verhältnisse nicht mehr passen“ sollte Ziel des Heimatschutzgedankens sein, sondern der „Verwilderung des Geschmackes, [der] Zerstörung der Schönheiten unserer Heimat, [der] innerlichen Verödung des Lebens" entgegenzuwirken. ${ }^{124}$

„Der Heimatschutz strebt die Erhaltung des charakteristischen Bildes der Heimat in Landschaft, Natur, Bauweise und Volkstum an. Dieses Ziel ist aber nicht so einfach zu erreichen, denn der unaufhaltsame Strom der Entwicklung tritt diesem Bestreben vielfach in den Weg. ${ }^{\text {"125 }}$

Waren diese Bestrebungen anfangs vor allem auf die städtische Architektur beschränkt, so versuchte der Heimatschutzverein mit der Zeit im ländlichen Bereich Fuß zu fassen.

Helfen sollten dabei grundlegende Äußerungen zu Denkmälern und Altertümern.

Im Aufsatz „Was Denkmäler sind und was man von ihnen halten soll“ unterschied der Autor „Natur- und Kulturdenkmäler“ und letztere wiederum, in solche von „profaner“ oder „kirchlicher“, sowie von „,vor- und frühgeschichtlicher“ Provenienz.

Machtübernahme in Italien ab 1923 wieder eingestellt werden. „Der Schlern“ konnte aber noch bis 1926 den Untertitel „Zeitschrift des Vereins für Heimatschutz “ führen! (vgl. Mumelter 1969, S. 5)

124 Zimmeter 1923, S. III u. S. 2 ff.

125 Zimmeter 1947, S. 100. 
In Bezug auf Altertümer betonte er besonders deren hohen materiellen Wert für „Wissenschaft und Kunst, [sowie auch] für Liebhaber, die solcherlei sammeln und gut bezahlen“" und daß daher viele „Agent[en von] Altertumshändler[n]“ solche billig aufzukaufen versuchen würden.

Zwar könne er verstehen, daß aus „Not der eine oder der andere dazu gezwungen sei, Gegenstände aus dem eigenen Besitz zu veräußern “, doch sollte dies nicht unter dem Preis und wenn möglich, unter Ausschaltung des Zwischenhandels, direkt an ein Museum geschehen, denn dort wären die Gegenstände Objekte des Studiums der "Heimat- und Ortsgeschichte“ und somit „lebendige“ Zeugen der Vergangenheit. Daher, so sein Resümee, würden sich in letzter Zeit zahlreiche „Vereine oder einzelne Männer“ der Übermittlung solcher Erkenntnisse an die Mitbürger widmen. ${ }^{126}$

Die 1926 vorgenommene Änderung der Tiroler Bauordnung gab dem Heimatschutzverein quasi halbamtliche Stellung, waren doch nun die Bezirkshauptmannschaften aufgefordert, die Baupläne auf die Berücksichtigung der Heimatschutzinteressen hin zu überprüfen, indem Gutachten des Heimatschutzvereines einzuholen waren. Eine zwei Jahre später erfolgte Novelle der Bauordnung räumte dem Schutz der heimischen Bauweise noch mehr Platz ein. ${ }^{127}$

Ab 1931 übernahm der Heimatschutzverein auch Aufgaben des Naturschutzes, nachdem die Tiroler Landesgruppe des Österreichischen Naturschutzbundes aufgelöst worden war.

Anläßlich des Jubiläums der 25jährigen Vereinsgründung wurden 1933 mit Befriedigung die Erfolge der Vereinsarbeit aufgezählt:

126 Dieser Aufsatz von Georg Wehr (übernommen aus der deutschen „Dürerbundeskorrespondenz“) erschien nicht zufällig im Tiroler Gewerbeblatt, 23. Jhg. Nr. 12 (1910), S. 1 ff., war doch seit 1906 Kunibert Zimmeter „Schriftleiter“ dieser Zeitschrift! (vgl. Kap. 4.2) In Bezug auf die jetzt überall tätigen „Heimatschutzvereine“ schrieb der Verfasser: „Wenn du davon, lieber Leser, in deiner Heimat noch nichts gehört haben solltest, so mache dich einmal an den Pfarrer oder den Lehrer heran." (ebd., S. 2)

127 Vgl. Stenographische Berichte des Tiroler Landtages, II. Periode, 4. Tagung, 12. u. 13. Sitzung vom 16.12.1926. Der liberale Abgeordnete Zösmayr hatte in dieser Sitzung darauf aufmerksam gemacht, daß „die Bauführung in vielen Orten nicht immer unserem heimatlichen Boden und Charakter entsprochen hat" und „sehr viel Fremdartiges in unsere Bauten hereingekommen“ sei und schlug deshalb eine Angleichung der Gesetzgebung an die strengeren bayerischen Verhältnisse vor (S. 348). Der Abgeordnete der Tiroler Volkspartei, Gebhart, stellte eine Entschließung zum Gesetzesentwurf, in der er forderte, „daß für die Überprüfung der Baupläne hauptsächlich der Heimatschutzverein herangezogen wird“, weil dort die Fachleute und „Leute mit Liebe zur Heimat" wären. (S. 349) Siehe auch Seberiny 1933. 
„Die zahlreichen Trachtenfeste und die immer häufiger werdende Uniformierung von Schützenkapellen sind Zeugen dafür. Ja sogar alte Bräuche leben unter dem Einflusse der Propaganda der ,Heimatblätter ${ }^{`}$ wieder auf." 128

Einige Jahre vorher, 1929, richtete ein anderer Autor der „Tiroler Heimatblätter“ noch einen eindringlichen Appell an die Bauern im Land, sich der Heimatschutzanliegen anzunehmen und forderte deshalb die Bauernbundvertreter auf, mehr dahingehend zu wirken. Nach dem Bekenntnis zum Bauerntum als „Wurzel unserer Volkskraft" meinte der Verfasser, eher dem eigenen Wunsche folgend als der Realität entsprechend:

„Wir brauchen die Aufgaben eines Heimatpflegers in der Gemeinde nicht vorzuschreiben, der Bauer findet sie selbst und die Mitarbeit der Bauern ist für uns wenigstens ebenso wertvoll, wie die der sogenannten Intelligenzler. "129

Auch außerhalb des unmittelbaren Einflußkreises des Heimatschutzverbandes und seiner Publikationsorgane galt die Erreichung eines Kulturschutzes als erstrebenswert.

Adolf GÜNTHER, Innsbrucker Professor für Soziologie und Politische Ökonomie, meinte in seinem Werk über „Die Alpenländische Gesellschaft“:

„Die Erhaltung oder Wiederherstellung der Volkstracht, die Konservierung eigentümlicher Siedlungsformen; die Sorge für Mundart, für sonstige Ausdrucksformen der Kultur: das alles würde insoweit, als es den Ansprü-

128 Seberiny 1933, S. 12; als Beispiele solcher Brauchbelebungen führt er den Leonhardsritt bei Kufstein, das Schellenschlagen in Matrei und das Grasausleuten in einigen Unterinntaler Gemeinden an. (ebd.)

129 Weitlaner 1929, S. 392 f.; Ende der 20er und in den 30er Jahren schien der Tiroler Heimatschutzverein verstärkt ins Fahrwasser der Volkstumsideologie geraten zu sein. Die Pflege eines gesunden Bauernstandes wurde zum Mittelpunkt vieler Themen. Bereits im ersten Heft der Tiroler Heimatblätter beklagte Gg. Opperer in einem Aufsatz den „land- und volksfremden Einfluß“ seit Ende des Ersten Weltkrieges. Ihm schien es fast schon zu spät, den Ruf „Zurück zur Scholle“ zu befolgen, denn der ,soziale Fortschritt hat [das] patriarchalische Verhältnis Bauer - Ehehalter, Meister - Gesellen zerstört“ und nun stünden sich „Arbeitgeber und Arbeitnehmer gegenüber.“ (1923, S. 1) Der Obmann des Tiroler Heimatschutzvereines Graf Trapp sowie der Schriftleiter der Tiroler Heimatblätter Dr. Hans Hochenegg waren u.a. geistige Väter des Tiroler Erbhöfegesetzes von 1931. (Vgl. Erhard 1981, S. 167 f.) Inwieweit dies in Tirol den Weg zur späteren nationalen Blut und Boden-Ideologie vorbereitete, ist leider bislang noch nicht näher untersucht worden. Auch über das Tiroler Heimatschutzwesens im „Ständestaat“ gibt es kaum Arbeiten (vgl. Natter 1984). 
chen der Wirtschaftlichkeit nicht entgegen wäre, Anspruch auf Schutz haben."

Allerdings stellte er sich diesen Schutz nicht als gesetzlichen oder „polizeilichen“ vor, sondern plädierte dafür, den „Wille[n] des Einzelnen und der Gruppen zu beeinflussen“, denn „ein Gutteil der Aufgabe, alpenländische Kultur zu erhalten, liegt auf erzieherischem Gebiet" ${ }^{\text {130 }}$.

Die Tiroler Heimatschutzbewegung kann somit als „Kompensations- [und] Kontrastprogramm" angesehen werden, indem sie Heimat als Gegenbild zur gegenwärtigen, modernisierten Welt entwirft. ${ }^{131}$

Industrie- und (zum Teil auch) Fremdenverkehrsfeindlichkeit zeichnen dieses Programm aus, denn in beiden wird ein „gefährlicher Allesgleichmacher" gesehen, der „Volkstum und Volkskunst in erschreckender Weise [zu] verschling[en]“ drohe. ${ }^{132}$

Das dabei verwendete Bild von Volkstum, Volkskultur und Volkskunst war stark mit dem Bauerntum verknüpft, von dessen Kultur vielfach Heil und Besserung erhofft wurde. Doch dabei saßen die Protagonisten unbedacht und nicht hinterfragt einem Klischee auf: Nicht die realen Lebensumstände, die vielfache bäuerliche Not und der gesellschaftliche Wandel waren Ausgangspunkt, sondern Versatzstücke davon, in denen Teile für das Ganze standen (wie das Tragen von Trachten oder das Beharren auf längst überholten Bräuchen). Dadurch wurde ein einseitiges Bild von Heimat propagiert, und die Heimatschutzbewegung Teil einer Ideologie ${ }^{133}$ der Verherrlichung des Bauerntums, gerade zu dem Zeitpunkt, wo wirtschaftliche Schwierigkeiten diesen Stand bedrängten. Doch nicht die Bekämpfung dieser Not stand im Zentrum dieser Ideologie, sondern der Versuch, mittels kultureller Fixierung Modernisierung zu verhindern. Es wurde versucht, ökonomische Rückständigkeit kulturell zu kompensieren, indem kulturelle Versatzstücke, wie Trachten, Bräuche etc. zur Eigenheit, zur Andersartigkeit und somit zum Besonderen stilisiert worden waren. So gelang es, eine als eigen gedachte Kultur herauszustreichen. ${ }^{134}$

130 Günther 1930, S. 553 f.

131 Vgl. Bausinger 1980, bes. S. 13 f.; die folgenden Gedanken beziehen sich auf diesen Aufsatz.

132 Siber 1910/11, S. 75 f.

133 Ich verwende den Begriff hier im Sinne Wolfgang Emmerichs: „Ideologie ist eine aus ökonomischen und machtpolitischen Interessen entspringende Verhüllung und Rechtfertigung von Herrschaftsverhältnissen." (1971, S. 15)

134 S. Köstlin 1980, bes. S. 33 und die bereits oben zur Rückständigkeitsthese angegebene Literatur von Jeggle/Korff 1974, Korff 1980 u. Köstlin 1982a. 
Auch an der Mitgliederliste des Heimatschutzvereines zeigt sich, daß dies eher durch die gesellschaftliche Elite und dem vom sozialen Abstieg bedrohten Kleinbürgertum geschah, denn dem Verein gehörten vor allem Lehrer, Beamte, kleine Wirtschaftstreibende und Adelige an.

Heimat wurde in diesen Bestrebungen letztendlich zur Kulisse und erlangte so besonders für den Fremdenverkehr Bedeutung. 



\section{Zum „Tiroler Gewerbeverein“"}

\subsection{Gewerbevereine und Handelskammern in der Monarchie}

\subsubsection{Gewerbevereine}

Ein Kennzeichen des modernen bürgerlichen Staates ist sein ausgeprägtes Vereinswesen.

Vereine sind nicht nur Stätten der Geselligkeit, sie erfüllen auch wichtige gesellschaftliche Integrationsfunktionen.

Bereits im Merkantilismus des 18. Jahrhunderts wurden verschiedene Vereinigungen gegründet, die der Interessensvertretung ihrer Mitglieder dienten. So nahm sich die „Patriotisch-ökonomische Gesellschaft“ in Graz (1767) - ganz im Sinne des Physiokratismus - eine Intensivierung der Landwirtschaft vor. Noch vor der bürgerlichen Revolution von 1848 entstanden die ersten gewerblichen Vereine, die aber bald wieder aufgelöst werden mußten. Als erster moderner Industrieverein der Habsburgermonarchie kann der „Verein zur Ermunterung des Gewerbegeistes in Böhmen " bezeichnet werden, der sich 1829 gründete und 1833 konstituiert wurde. Ab 1828 veranstaltete diese Vereinigung in Prag bereits Gewerbeausstellungen.

Kurze Zeit später entstanden ähnliche Vereine in der westlichen Reichshälfte. So trug die Wiener Gewerbeausstellung von 1835 maßgeblich zur Gründung des „Österreichischen Gewerbevereins“ bei, der 1838 entstand, sich ab 1839 „Niederösterreichischer Gewerbeverein“ nannte (mit 1.000 Mitgliedern) und sich 1840 konstituierte.

In der kaiserlichen Entschließung vom 6.2.1838 werden die Gewerbevereine als Privatvereine bezeichnet, die auf dem Prinzip der Freiwilligkeit beruhten, allen Branchen zugänglich seien und keine offizielle Vertretungsvollmacht gegenüber der Regierung haben sollten. Als Vereinszwecke wurden namentlich genannt:

- die Hebung des Standes,

- die Veranstaltung permanenter Ausstellungen,

- die Verbreitung von einschlägigen Zeitschriften

- und Musterprämierungen. 
Ausdrücklich wurde darauf hingewiesen, daß diese Vereinigungen keine Korporationen in der Art der Zünfte wären und daher den Nichtmitgliedern keine Nachteile erwachsen dürften. ${ }^{135}$

Allen diesen Vereinigungen war gemein, daß ein Hauptanliegen die Hebung des eigenen Standes war. Dies versuchten sie, getreu liberal-bürgerlicher Ansichten, über die Hebung der Bildung zu erreichen. Deshalb richteten sie bald Fachbibliotheken ein, veranstalteten Kurse, Vorträge und Ausstellungen. Im Gegensatz zum patriotisch-ökonomischen Charakter der "Gesellschaften" des 18. Jahrhunderts stand für die Gewerbevereine nicht mehr obrigkeitliche Förderungsintention im Mittelpunkt, sondern in erster Linie die Bekundung ihrer gemeinsamen Interessen. Sie sind somit „Ausdruck eines neuen Gruppenbewußtseins einer neuen Unternehmerschicht ${ }^{\text {" }}{ }^{136}$.

War diese Ausrichtung anfängliche für alle Mitglieder noch einigend gewesen, so stellten sich im Laufe der Zeit deutlich zwei Gruppen heraus: die Gewerbetreibenden und die Industriellen, die keineswegs die gleichen Ziele verfolgten.

Die Gewerbeordnung - mit ihrer Einführung der Gewerbefreiheit und der dadurch entstandenen vermehrten Konkurrenz - zusammen mit der liberalen Zollpolitik bewirkten, daß sich im letzten Drittel des 19. Jahrhunderts eigene, mehr fachbezogene Interessensvertretungen für beide Gruppierungen bildeten. ${ }^{137}$

Die industriellen Vereinigungen verlagerten ihre Ambitionen hauptsächlich auf ein koordiniertes Vorgehen zur Erlangung größtmöglichen Einflusses auf die staatliche Wirtschaftspolitik (so war der Kampf gegen den Freihandel anfangs einigendes Moment für einige Großindustrielle, sich im „Industriellen Klub“ zusammenzuschließen).

Die Vertreter des Gewerbes sahen sich durch den Niedergang ihrer kleingewerblichen Produktionsweise gefährdet und suchten Heil in einer Protesthaltung, die zur gewerbepolitischen Bewegung führte.

135 Geissler 1949, S. 52 f.; dort weitere Angaben zum frühen Gewerbevereinswesen. Eine weitere solche Vereinsgründung war der von Erzherzog Johann angeregte „Innerösterreichische Gewerbeverein" (1837), der vor allem in der Steiermark, in Kärnten und in der Krain tätig war, 1846 bereits 2.600 Mitglieder zählte und seit 1839 eine eigene Zeitschrift herausgab (vgl. Bruckmüller 1985, S. 338).

136 Bruckmüller 1985, S. 339.

137 In den 70er Jahren des 19. Jahrhunderts entstanden zahlreiche industrielle Fachverbände: 1872 der „Verein der Österreichisch-ungarischen Papierfabriken“ und der „Verein der Baumwollspinner“, 1873 der „Verein der Montan-, Eisen- und Maschinenindustriellen“. (Vgl. Fischer 1978, S. 9.) 
Schließlich wurde dieses Auseinandergehen durch die 1883 erfolgte Novelle der Gewerbeordnung besiegelt, die für Industriebetriebe die Beitrittspflicht zu den Gewerbegenossenschaften aufhob. ${ }^{138}$

\subsubsection{Handelskammern}

Durch die kaiserliche Entschließung von 1838 war den Gewerbevereinen eine direkte Einflußnahme auf staatliche Entscheidungen nicht zugestanden worden, doch bildete ihre Tätigkeit wichtige Vorarbeit zur Gründung eigener, gesetzlich anerkannter Interessensvertretungen mit politischen Entscheidungsmöglichkeiten, den Handelskammern.

Diese entsprangen dem bürgerlichen Bedürfnis nach Mitbestimmung, sowie Wahrung seiner politischen und wirtschaftlichen Rechte. Allerdings waren dafür Bildung und Vermögen wichtige Voraussetzungen.

In Österreich war die Errichtung der Kammern auch ein Akt des Umganges mit dem Nationalitätenproblem. Denn im Gegensatz zu anderen Ländern, wo die Nationalstaatsgründungen vor allem auf eine gemeinsame Sprache und Kultur bauen konnte (Frankreich, Deutschland), mußte in der Habsburgermonarchie ein einheitliches Moment für die geforderte Mitbestimmung gefunden werden, ohne daß damit das Reich dem Zerfall preisgegeben wurde. Das Handelskammergesetz von 1850 wurde somit auch zum Versuch, der Vielzahl der sich entwickelnden, nationalen Individualitäten und deren, aus gesteigertem Selbstbewußtsein resultierenden Autonomiebestrebungen entgegenzuwirken. ${ }^{139}$

Vor allem aus dem liberalen Kreise der wirtschafts- und gewerbetreibenden Bürger, der Industriellen und Handelsleute rekrutierten sich die Betreiber des Versuches einer Handelskammergründung, der nach der Märzrevolution von Erfolg gekrönt war. Am 15.1.1849 kam es in Wien zur Konstituierung der ersten, provisorischen österreichischen Handelskammer, wobei die, auch heute noch gültigen, Grundlagen festgelegt wurden:

- obligatorische Mitgliedschaft

- Recht auf Begutachtung von Gesetzen und Verordnungen

- finanzielle Unabhängigkeit

- öffentlich-rechtlicher Charakter

138 Ebd., S. 9 f. u. S. 15 f.

139 Vgl. Geissler 1974, S. 5 f. 
- die Möglichkeit unter den Kammern zur Konsultation, Beratung und Vorbereitung einheitlicher Stellungnahmen. ${ }^{140}$

1850 entstand, trotz der inzwischen erfolgten neoabsolutistischen Restauration, eine gesamtösterreichische Handelskammer-Organisation, die auf der Einteilung des Staatsgebiets in Kammerbezirke und der fachlichen Untergliederung in eine Gewerbe- und Handelssektion beruhte.

$1868 \mathrm{kam}$ es, infolge einer neuerlichen Gesetzesnovelle, unter anderem zum Ausbau des Begutachterwesens, zu umfangreichen politischen Rechten (die Kammern bildeten fortan eine der vier Wählerklassen für die Landtage und das Abgeordnetenhaus im Reichsrat!), sowie zur Ausweitung der Mitgliederzahl durch Senkung des Minimalsteuerzensus. ${ }^{141}$

Als sich 1873 die Lage der Gewerbetreibenden, nach dem Börsenkrach und der Wirtschaftskrise, drastisch verschlechtert hatte, wurde deren Wunsch laut, eine eigene Gewerbekammer zu errichten. Die Debatte darüber zog sich bis in die 90er Jahre des letzten Jahrhunderts; schließlich verhinderte das in der Kammer dominierende Großbürgertum eine Spaltung. ${ }^{142}$

Mit dem Handelskammergesetz von 1850 war das Kronland Tirol in drei Handelskammerbezirke, mit Sitz in Innsbruck, Bozen und Rovereto, eingeteilt worden. Am 13. Januar 1851 kam es zur Gründung der Innsbrucker Handels- und Gewerbekammer. $^{143}$

Durch die Errichtung der Handelskammern war den Gewerbevereinen eine Konkurrenz erwachsen, der sie nicht gewachsen sein konnten. Aber nicht so sehr Konkurrenzverhalten bestimmte die Beziehung zwischen beiden - dazu war die

140 Näheres ebd., S. 10 f.

141 Ebd., S. 13 ff. und Ucakar 1982, S. 404 f.

142 Ucakar 1982, S. 405; ab 1918 teilte sich die Kammer in drei Sektionen (Handel, Gewerbe und Industrie). Im Ständestaat wurde 1937 ein eigenes Kammergesetz erlassen, das auch nach 1938 im wesentlichen für die Gauwirtschaftskammern Gültigkeit hatte. In der Zweiten Republik kam es 1946 zu einer Neuorganisierung im Handelkammergesetz von 1946. Die „Kammer der gewerblichen Wirtschaft" gliedert sich in sechs Sektionen: Handel, Industrie, Gewerbe, Geld-, Kredit- und Versicherungswesen, Verkehr, sowie Fremdenverkehr. Sowohl die inhaltlichen Kompetenzen (Begutachterwesen, ...) wie die formale Struktur (Pflichtmitgliedschaft, Organisation in Bezirken, sowie in Branchen und Fachgruppen) waren beibehalten worden (ebd., S. 406).

143 Zur Geschichte der Tiroler Handelskammer, von der Gründung bis 1900, vgl. Marek 1951, S. $129 \mathrm{ff}$.! 
Zahl der Gewerbevereinsmitglieder, die sich aktiv für die Errichtung der Kammern eingesetzt hatten, zu groß - sondern eine Art Aufgabenverteilung.

Während die Kammern offizielle, öffentlich-rechtliche Interessensvertretungen der gewerblichen Wirtschaft wurden, begannen die Gewerbevereine Gebiete abzudecken, die nicht unmittelbare Kammeragenden waren: vor allem Förderungs- und Bildungsaufgaben in der "technischen Vervollkommnung der Industrie, Pflege des technischen Nachwuchses, des technischen Fortschrittes usw. ${ }^{\text {"144 }}$.

Auch andere gewerbliche Tätigkeiten erhielten Anstoß durch diese Vereine. So gingen die Errichtung der Technischen Hochschule und die Gründung des Technologischen Museums in Wien auf Aktivitäten des „Österreichischen Gewerbevereines“ zurück. Weiters regte dieser Verein die Verleihung von Auszeichnungen und Stipendien für gewerbliche Aktivitäten, sowie die Einrichtung des Volksbildungsinstitutes „Urania“ an. ${ }^{145}$

Seitdem 1867 in Österreich die Vereinsfreiheit erklärt worden war, stieg die Zahl der gewerblichen Vereine an. 1867 war nur ein gewerblicher Fachverein in Cisleithanien registriert, 1880 waren es bereits 170.1867 wurden 28 Vereine „zur Beförderung von Gewerbe und Handel“ gezählt, 1880 schon 135. All diese Vereine waren ausschließlich Vereinigungen von Selbständigen: gegründet zur Erweiterung ihrer fachlichen Bildung, sowie zur gegenseitigen Information und Interessensvertretung. ${ }^{146}$

\subsection{Der „Tiroler Gewerbeverein“}

Als es 1872, vom Handelsministerium veranstaltet, zu einer Enquete über das Kleingewerbe kam, mußte der Innsbrucker Handelskammer-Sekretär Carl Payr nicht nur den argen Zustand dieses Gewerbes beklagen, sondern er bedauerte in seiner Beantwortung den „Mangel eines gewerblichen Vereins- und Genossenschaftswesens “, das er zur Hebung des Standes für unerläßlich hielt. Ausdrücklich stellte er fest, daß bis dato „in Nordtirol [...] ein Gewerbeverein nicht“ bestehe. ${ }^{147}$

144 Geissler 1974, S. 8.

145 Vgl. Wenger/Seidel 1966, S. 605.

146 Bruckmüller 1985, S. 404; Vorbild für die Vereinsgründungen war das englische und französische Gewerbe-Förderungswesen von 1754, bzw. 1792. In Deutschland folgten 1815 in München der „Polytechnische Verein für Bayern“, der auch das „Bayerische Gewerbeblatt“ herausgab, sowie 1821 der „Verein zur Beförderung des Gewerbefleißes in Preußen“. Vorbild dafür war das Pariser „Conservatoire des arts et métiers“. (Vgl. Mundt 1974, S. 27 ff.)

147 Payr 1872, S. 23 und S. 58; Payr hielt die gewerbliche Weiterbildung für notwendig, weil nur so die „wachsende Tüchtigkeit der Arbeitsleitung, andererseits [...] gegenseitige billige 
Wie er weiters ausführte, könnte nur die staatliche Förderung und Unterstützung des „Mittelstandes“, der „doch die Grundlage und Macht, sowie die Hauptsteuer des Staates“ repräsentiere, diesen vor dem Herabsinken zum „Proletariat“ retten.

Geeignete Mittel erschienen ihm dafür „zweckmäßig organisierte Gewerbeschulen, leichtfaßliche Fachschriften, populäre Vorträge, technologische Sammlungen, Bibliotheken, sowie Ausstellungen neuer Werkzeuge, Hilfsmaschinen, Betriebseinrichtungen, dann aber auch preiswürdiger Leistungen aus den Werkstätten des Kleingewerbes".

Nur eine „allmälige Ausbildung der Produktiv-Gewerbe [...] zum Kunstgewerbe“ könnte, seiner Meinung nach, der Industrie Konkurrenz bieten, denn ,auf dieses Feld wird die Maschine, wie sehr sie auch vervollkommnet werden mag, nicht folgen können; da werden immer die Intelligenz, der Geschmack, verbunden mit der Geschicklichkeit der Hand dominieren“. ${ }^{148}$

\subsubsection{Vereinsgründung}

Einige Jahre später gingen aus den Kreisen der Innsbrucker Handelskammerkonkrete Bestrebungen hervor, die gewerbliche Fortbildung in Tirol voranzutreiben.

Nachdem der 1863 an die Innsbrucker Oberrealschule angegliederte Zeichenund Modellierkurs für Handwerker ab 1874 nicht mehr weitergeführt worden war, kam es im Herbst 1877 in Innsbruck, aktiviert durch das Ministerium für Cultus und Unterricht, zur Gründung der ,allgemeinen gewerblichen Zeichenund Modellierschule“. Eine kaiserliche Entschließung erlaubte dieser viersemestrigen Schule 1884 den Namen „K.K. Staatsgewerbeschule“ zu führen. ${ }^{149}$

Beurtheilung der Arbeits- und Lohn-Verhältnisse seitens der Meister von den Gesellen “ möglich wäre. (S. 26) Für ihn war eine Konkurrenz mit der Industrie nur möglich, wenn es für die Gesellen zur bedingungslosen Trennung der Arbeitsstätte von der Kost/Logie kommen würde, da nur so Konflikte, die sich aus mangelnder Disziplin und der hierarchischen Struktur der Gewerbebetriebe ergaben, überwunden werden könnten (S. 25 f.).

148 Ebd., S. 20 f. und 53; weiters vertrat er die Ansicht, daß diesen „Artikel[n] einer tüchtigen Handarbeit, ihrer größeren Solidität wegen, sogar der Vorzug vor der Maschinenarbeit eingeräumt [werde], und daß man sich dieses Vorzuges wegen [...] höhere Preise gefallen" ließe (S. 53).

149 Marek 1951, S. 148 f. Erster Direktor dieser Einrichtung war der Architekt und Regierungsrat Johann Deininger (1849-1931), der auch die kunstgewerbliche Abteilung der Schule leitete und besonderes Augenmerk der heimischen Bauweise und der Erforschung und Erhaltung der Kunst- und historischen Denkmale des Landes widmete. Deininger war lange Zeit im Vorstand des Tiroler Gewerbevereins (vgl. Kap. 4.2.5), Mitglied und Vorstand des „Tiroler Kunstvereins“, sowie Verfasser einschlägiger Werke zur Tiroler Volkskunst, wie „Das Bauernhaus in Tirol und Vorarlberg“ (1894-95), oder „Tiroler Volkskunst“ (1910). Er hat, besonders in 
Bereits 1878 wurde in Innsbruck die erste Kunstgewerbe-Ausstellung eröffnet, die vom Wiener „Museum für Kunst und Industrie“ Unterstützung erhalten hatte.

1880 beschlossen 32 Gewerbetreibende in Innsbruck die Gründung des „Tiroler Gewerbevereines“. Dem vorbereitenden Comité zur Vereinsgründung gehörten unter anderem der Architekt und Gewerbeschul-Direktor Johann Deininger, sowie der Innsbrucker Handelskammer-Sekretär Carl Payr an.

Am 25. Oktober 1880 fand, unter der provisorischen Leitung Carl Payrs, die konstituierende Versammlung statt, an der 82 zukünftige Mitglieder teilnahmen; darunter auch Anton von Schumacher, Vizepräsident der Tiroler Handels- und Gewerbekammer, sowie Besitzer der Wagner'schen Buchdruckerei.

\subsubsection{Vereinsstatuten}

Bereits am 11. November desselben Jahres wurden die, von Johann Deininger ausgearbeiteten, Statuten von der Statthalterei genehmigt. ${ }^{150}$

Im Paragraph 2 der Statuten wird der Zweck des Vereins folgendermaßen festgelegt:

„Dieser ist: Die Hebung und Förderung des Gewerbewesens in Tirol, deren Erreichung durch gegenseitige Belehrung und thatkräftiges $\mathrm{Zu}-$ sammenwirken der Mitglieder mit Ausschluß jeder religiös-politischen Tendenz angestrebt wird.“

Innsbruck, zahlreiche künstlerische Arbeiten (z.B.: den Aussichtspavillon am Bergisel, den Leopoldsbrunnen beim Landestheater, oder die Kapelle am Tummelplatz bei Amras) und Restaurierungen durchgeführt (zu seiner Person vgl. auch Fischnaler Bd. IV 1930, S. 255 u. Bd. V 1934, S. 63 f.).

150 Vgl. den „I. Bericht über die Thätigkeit des Tiroler Gewerbevereines“, Innsbruck 1882. Diese Rechenschaftsablegung über die Periode November 1880 bis Februar 1882 war die einzige solch einer Art. Spätere Darstellungen wurden nur mehr im eigenen Mitteilungsblatt veröffentlicht. Erster Vorstand wurde der „Leiter der gewerblichen Zeichen- und Modellierschule in Innsbuck“, Architekt Johann Deininger, Vorstandsstellvertreter war der „Sekretär der Handels- und Gewerbekammer in Innsbruck“, Carl Payr, die wichtigsten Ausschußmitglieder waren Anton von Schumacher, „Vizebürgermeister der Stadt Innsbruck“, Heinrich Fuß, „Bildhauer und Lehrer an der gewerblichen Zeichen- und Modellierschule in Innsbruck“, der Tischlermeister Michael Konzert, Baumeister Franz Mayer und der Tapezierermeister Josef Melzer (TLA bei Präs. Nr. 3923 9/11/1880 (Geschz. 9028 Polizei). 
Als Mittel zur Erreichung dieses Zieles gibt das Vereinsstatut an $(\$ 3):{ }^{151}$

- Versammlungen zu Vorträgen und Besprechungen in gewerblichen Angelegenheiten,

- Periodische Ausstellungen gewerblicher und kunstgewerblicher Erzeugnisse,

- Schaffung und Erhaltung eines geeigneten permanenten Ausstellungslokales in Innsbruck,

- Verkehr mit Vereinen und Anstalten, welche gleiche oder verwandte Zwecke verfolgen,

- Schaffung einer Vereinsbibliothek mit gewerblichen Fachschriften und kunstgewerblichen Publikationen,

- „Veranlassung von Nachbildungen mustergiltiger gewerblicher und kunstgewerblicher Erzeugnisse zur Veröffentlichung in periodisch erscheinenden Vereinspublikationen",

- „Verleihung gewerblicher Prämien oder öffentlicher Anerkennungen für ausgezeichnete Leistungen auf gewerblichem oder kunstgewerblichem Gebiete, sowohl in Bezug auf Erfindung als auch exakter Ausführung",

- Erteilung von Gutachten.

\subsubsection{Liberale Ausrichtung des Gewerbevereines}

Mit dieser Zielrichtung stand der „Tiroler Gewerbeverein“ ganz in der Tradition des bildungsmäßigen, gewerbefördernden Liberalismus. Dies ist nicht verwunderlich, war der Verein, trotz vereinsgesetzmäßig aufgenommenen Verbotes jedweder direkten politischen Tätigkeit ${ }^{152}$ ein Hort für liberal gesinnte Gewerbetreibende aller Prägungen (von altliberal bis deutsch-national).

Viele seiner zukünftigen Mitglieder, besonders aus dem Kreis des Ausschusses und Vorstandes, waren im Innsbrucker Gemeinderat oder im Tiroler Landtag als liberale Gemeinderäte oder Abgeordnete tätig.

So der langjährige Vereinsvorstand und Handelskammer-Sekretär Dr. Anton Kofler (1855-1943), der als Vertreter der deutsch-freiheitlichen Partei von 1888-

151 Vgl. das Vereinsstatut des „Tiroler Gewerbevereines“, TLA bei Präs. Nr. 3923 9/11/1880 (Geschz. 9028 Polizei).

152 Das Vereinsgesetz vom 15.11 .1867 (veröffentlicht im Reichsgesetzblatt (RGBl.) Nr. 134/1867) bildete die Grundlage aller nicht auf Gewinn ausgerichter Vereine. Ihnen wurde auferlegt, sich bei der politischen Landesstelle erfassen zu lassen und bei ihrer schriftlichen Anmeldung die Vereinsstatuten in fünffacher Ausfertigung zu hinterlegen. Wenn nach vier Wochen keine Untersagung von seiten der Behörde erfolgte, war die rechtliche Existenz dieser „idealistischen“ Vereine begründet und sie konnten ihre Tätigkeit aufnehmen. Für Vereine mit „öffentlichen oder gemeinnützigen Zwecken“ galt bereits das Vereinspatent von 1852 (RGBl. Nr. 253/1852)! 
1901 im Innsbrucker Gemeinderat, von 1902-1919 im Tiroler Landtag und von 1911-1918 im Österreichischen Reichsrat war. ${ }^{153}$

Carl Payr (1835-1907), Koflers Vorgänger als Handelskammersekretär, war ebenfalls als Vertreter der Altliberalen (Deutsch-liberaler Verein) im Innsbrucker Gemeinderat tätig (von 1869-84 und 1887-90) und für die Kammer von 18831902 im Tiroler Landtag, zuletzt als Mitglied des Landesausschusses.

Der Innsbrucker Textilkaufmann und Besitzer der Wattener Papierfabrik, Karl Kapferer (1853-1934), war ebenfalls seit 1882 im Innsbrucker Gemeinderat tätig (von 1888 bis 1923 war er Obmann des Finanzreferates der Stadt!).

Der Inhaber der Wagner'schen Universitätsbuchhandlung, Vorstand der Innsbrucker Sparkasse und Handelskammerpräsident (von 1886-1902; davor von 1881-86 Vizepräsident), Anton von Schumacher, war langjähriger Innsbrucker Vizebürgermeister.

Der liberale Abgeordnete der Stadt Innsbruck im Tiroler Landtag (1914-18), der Schlossermeister Bernhard Zösmayr (1863-1942), war ebenfalls langjähriger Gemeinderat der Stadt und von 1914 bis 1918 liberaler Landtags-Abgeordneter. In der Ersten Republik war er von 1921 bis 1929 Abgeordneter der Großdeutschen Volkspartei im Tiroler Landtag, in der Periode von 1925-29 sogar Landesrat.

Hans Hörtnagl (1864-1944), Großkaufmann, Metzgermeister und privater Heimatforscher, war Mitglied des Gewerbevereines und ab 1919 im Verwaltungsausschuß des Museums Ferdinandeum tätig; ihm wurde für die Verdienste um die Stadt Innsbruck die Ehrenbürgerschaft verliehen. ${ }^{154}$

Ein Bericht der konservativen Neue Tiroler Stimmen über die Versammlung des „Tiroler Gewerbevereines“ aus dem Jahr 1887 zeigt, daß diese liberale Vereins-

153 Die Antwort auf ein Telegramm des Handelsministers vom 28.10.1908 zeigt, daß der Tiroler Statthalterei die politische Gesinnung Koflers suspekt war. Dieses Schreiben bezieht sich darauf, ob sich Kofler, nebst anderen Personen aus dem Kreis der Handelskammer, wie deren Präsident Walter, für eine Auszeichnung, anläßlich des Kaisergeburtstages von 1908, eignen würden. Die Ehrung Walters wurde von seiten der Statthalterei befürwortet. Im Falle Koflers stellte sie ein negatives Gutachten, denn dieser gehöre der „deutsch-freiheitlichen Partei“ an, deren „äußersten radikalen Flügel er bildet“; daher sei eine Auszeichnung wegen seiner Parteizugehörigkeit und aktiven politischen Tätigkeit abzulehnen! (Antwortschreiben Zl. 548/08 präs.; TLA, Präs. Nr. 6947 ex 1908)

154 Weitere biographische Angaben zu den genannten Personen finden sich bei Pfaundler 1983 (zu Hörtnagl S. 139 f.; zu Kapferer S. 181; zu Kofler S. 202; zu Payr S. 296 - bei seinem Sohn Erwin Payr; zu Schumacher S. 384), bei Schober 1984 (zu Zösmayr S. 585), sowie im Österreichischen Biographischen Lexikon (zu Kapferer Bd. 3, S. 220; zu Kofler Bd. 4, S. 55; zu Payr Bd. 7, S. 377 f.). Zu Kofler und Hörtnagl auch Paulin 1953, S. 231 ff. und 236 ff. Generell zu den Handelskammer-Sekretären Payr und Kofler, Marek 1951, S. 129 ff. 
ausrichtung zu Spannungen führte und von Außen her angegriffen wurde. Der Verfasser mokierte sich nicht nur über die geringe Teilnehmerzahl von 15 oder 19 Personen, sondern ging kritisch auf die Art der Mitgliederwerbung des Vereines ein, der über Wanderversammlungen versuche, Mitglieder zu gewinnen. Überhaupt wäre, seit die Konservativen aus dem Verein ausgeschieden seien, die Sachlage dort verändert. Abschließend befaßte sich der Autor noch mit der Postenverflechtung von Gewerbevereinsmitgliedern mit der Handelskammer und spielte besonders auf die Person Carl Payrs an, der als Liberaler im Vorstand saß, obwohl Johann Deininger betont hätte, keine Parteileute im Vorstand zu dulden. ${ }^{155}$

Im Zusammenhang mit den Handelskammerwahlen kam es meist zu Anfeindungen gegenüber dem Gewerbeverein, die sich nicht zuletzt auf die, gegenüber dem politischen Vereinsflügel, anscheinend eher schwache Position des Vorstands Johann Deininger bezogen.

Dieser hatte bereits 1885 auf einer Versammlung des Gewerbevereines, bei der es zu einer Resolution gegen Parteiagitationen anläßlich der Handelskammerwahlen kam, die unpolitische Ausrichtung des Vereines hervorgehoben:

„Diejenigen, welche das Heil des Gewerbestandes im Kolportieren der leider vielfach beliebten modern-politischen Schlagworte suchen wollen, denen Parteigehetze und agitatorische Umtriebe zum Lebens-Elemente geworden sind, sie mögen unserem Verein ferne bleiben, denn sie haben entweder den wichtigen Zwecke desselben verkannt oder absichtlich nicht erkennen wollen.

Die Männer, welche sich um die Fahne des tirolischen Gewerbevereines scharen, sollen denselben als eine Institution betrachten, welcher die Seele wahren Patriotismus innewohnt. Ihr Ehrgeiz sei nur auf die Förderung reeller Arbeit gerichtet [...] die Ehre des tiroler Gewerbestandes zu heben und ihn zu wappnen gegen den drohenden Feind der ausländischen Konkurrenz. [...] Wir wollen sein ein einig Volk der Arbeit!"156

155 Nr. 143 vom 27.6.1887; im Zuge der Mißbilligung der Wanderversammlungen heißt es dort: „Mißbräuche werden dabei nicht vorkommen (weil liberal-jüdische Parteibestrebungen eben nicht als Mißbrauch betrachtet werden)“!

156 Mittheilungen des Tiroler Gewerbevereins 2. Jhg. Nr. 12 (1885), S. 52; Bereits in der ersten Nummer dieses Blattes (1884) wurden Agitationen eines Gewerbevereinsmitgliedes zugunsten einer an den Handelskammerwahlen beteiligten Partei mißbilligt, um nicht in den Verdacht zu kommen, der Verein stecke dahinter. Nachdem der deutschfreiheitliche Innsbrucker Gemeinderat und Gewerbetreibende Franz Thurner 1887 die Redaktion des Tiroler Gewerbeblattes übernommen hatte, häuften sich im Blatt parteipolitisch, nationalistisch gefärbte Artikel. Besonders der „Österreichischen Gewerbepartei“ und deren Eintreten für die deutschen Gewerbetreibenden waren einige Berichte gewidmet. 1901 wurden im Tiroler Gewerbeblatt 
Trotz seiner, zumindest in Tirol, nicht unumstrittenen politischen Position gelang es dem Verein, sich unter das Protektorat eines Mitgliedes der kaiserlichen Familie zu stellen. Bereits am 25. November 1880 konnte der Vorstand in der ersten ordentlichen Vereinsversammlung die Übernahme des Protektorates durch Erzherzog Heinrich bekanntgeben. Nach dessen Tod am 30.11.1891 übernahm mit April 1894 Erzherzog Karl Ludwig das verwaiste Protektorat. ${ }^{157}$

\subsubsection{Eine eigene Vereinszeitschrift}

Obwohl im ursprünglichen Vereinsstatut von 1880 die Herausgabe eines eigenen Mitteilungsorganes nicht ausdrücklich vorgesehen war, entschloß sich die Vereinsleitung ein eigenes Informationsblatt aufzulegen.

In der Gewerbevereinsversammlung vom 30. November 1883 wurde dieses Vorhaben in die Realität umgesetzt und mit Beginn des Jahres 1884 erschien die erste reguläre Nummer der neugeschaffenen Mittheilungen des Tiroler Gewerbevereins. ${ }^{158}$

Erster Redakteur wurde der Vereinsvorstand und Gewerbeschuldirektor Johann Deininger, der das Blatt im Sinne des Vereinsstatutes als Zeitschrift zur „Förderung gewerblicher Interessen durch gegenseitige Belehrung und Anregung“ betreute. So erschienen nun laufend „Artikel, welche technische und wirthschaftliche Fragen gewerblicher Richtung behandelten “, wie er - rückblickend - in seinem Bericht zum 10jährigen Vereinsbestand feststellte. ${ }^{159}$

In diesem (anfangs) vierteljährlich erschienenen Blatt wechselten sich Gewerbevereins- und Fachinformationen, Abdrucke von im Verein gehaltenen Vorträgen ${ }^{160}$ mit grundlegenden Beiträgen zu gewerblichen und kunstgewerblichen Fragen ab.

die Satzungen der „Österreichischen Gewerbepartei“ abgedruckt. Diese wurde als freiwillige Vereinigung der bestehenden deutschen Gewerbegenossenschaftsverbände vorgestellt, deren Ziel es sei, den Gewerbestand zu fördern und politisch zu vertreten (Nr. 3/1901, S. 6).

157 Vgl. Mittheilungen 1. Jhg. Nr. 1 (1884), sowie 8. Jhg. Nr. 1/2 (1891), sowie 10. Jhg. Nr. 1-6 (1893)

158 1. Jhg. Nr. 1 vom Januar 1884; davor war bereits am 22. Dezember 1883 eine Probenummer aufgelegt worden, die Anklang bei den Gewerbetreibenden finden konnte.

159 Siehe Mittheilungen 7. Jhg. Nr. 11/12 (1890), S. 61 f.

160 Ebd., S. 62 f. wo im Rechenschaftsbericht zum 10jährigen Vereinsbestand, von Johann Deininger verfaßt, eine Auflistung der stattgefundenen Vorträge zu finden ist. Von den insgesamt dort angeführten 42 Vorträgen können 16 dem technisch-praktischen Bereich (z.B. „kunstgewerbliche Metalltechniken“ oder „Blitzfotografie“), 15 dem „gewerbepolitischen“ sowie gewerbeinternen (z.B. „Das neue Gewerbegesetz“ oder Referate über Ausstellungen) und 11 dem kunsthistorischen Gebiet (z.B. „Pompeji und Herkulanum“ oder „Meisterwerke tirolischer Holzintarsien der Renaissance") zugeordnet werden. 
Weiters wurden Buchbesprechungen von gewerbe- und kunstgewerbetechnischen Werken aufgenommen, ferner Ankündigungen einschlägiger Veranstaltungen wie Messen, Ausstellungen und Versammlungen anderer Gewerbevereinigungen; und, seit dem 2./3. Jahrgang, auch Werbeeinschaltungen von Vereinsmitgliedern.

Ab dem 5. Jahrgang, 1888, wechselte die Redaktion. Der neue Leiter des Blattes, der Innsbrucker Kunstgeschichteprofessor Dr. Hans Semper, verbesserte mittels Abbildungen die innere Ausstattung.

In einem Grundsatzartikel definierte er die neue Ausrichtung des Blattes:

„Hauptzweck [...] ist die Anregung, Förderung und Hebung des Tiroler Gewerbes durch Mittheilungen nützlicher Kenntnisse und Vorbilder, technischer Fortschritte und Neuerungen, sowie Bekanntmachung hervorragender neuerer Leistungen der Kunstindustrie und des Gewerbes. ${ }^{\text {"161 }}$

Semper war sich aber der Gefahr des Auseinanderstrebens von Gewerbe und Kunstgewerbe bewußt und rief zum gemeinsamen Vorgehen aller Gewerbetreibenden auf, denn es gälte die ,in Tirol zerstreuten gewerblichen Kräfte zu sammeln und zu einen, nicht aber Zwiespalt und Hader unter sie zu säen."

Er wandte sich scharf gegen ,jede tendenziöse Erörterung von Partheigesichtspunkten“, die „mit der Sache selbst, das heißt dem Gedeihen des gewerblichen Lebens in Tirol nichts zu tun haben" und will „die zu Grunde liegenden geistigen Factoren“ nur so weit berühren als sie zur „zwecklichen Erläuterung dienen“.

Es war ihm ein großes Anliegen, der Zeitung „auch nach Außen hin möglichste Verbreitung zu verschaffen", und er erhoffte sich, das Blatt dadurch attraktiver zu machen, indem er "die geeigneten Kräfte zu erhalten und zu gewinnen [versuchte], um gediegene Originalstudien und Aufnahmen nach mustergiltigen älteren und neueren Erzeugnissen des tiroler Kunstgewerbes bringen zu können."

Vor allem Professoren der Kunstgewerbeschule und Mitarbeiter der Glasmalereianstalt gehörten zu den neuen Autoren, wodurch es zu einer Schwerpunktverlagerung in der Blattlinie kam. Dem Kunsthandwerk gehörte das Hauptaugenmerk, trotz des Bekenntnisses zu allen Gewerberichtungen.

161 Ebd., 5. Jhg. Nr. 3/4 (1888), S. 1 ff.; die nunmehr verstärkt vorgenommene kunstgeschichtliche Ausrichtung begann der neue Redakteur mit einem Artikel über die gegenwärtigen Tiroler Kunstströmungen. 
Neben der Förderung und Hebung des gegenwärtigen (Kunst-) Gewerbes ging es Semper auch um die Erhaltung und Rettung älterer Zeugnisse heimischen Kunstschaffens, die er als wichtige Vorbilder ansah. ${ }^{162}$

Zu Beginn des Jahres 1890 teilte die Redaktion ihren Lesern mit, daß das Blatt ab sofort aus Aktualitätsgründen monatlich erscheinen würde. Ferner hatten sich die Herausgeber entschlossen, das beigelegte Anzeigenblatt „neu und wirksamer“ zu gestalten, indem sie verschiedene Einschaltgrößen ermöglichten.

Aus Gründen des „Raumsparens“ und zur Erreichung eines „einheitlicheren Gepräges“ wurden die „Titelköpfe einfacher ausgestaltet“ und jeweils ein „Gesamttitelblatt“ zum Jahresabschluß beigelegt. ${ }^{163}$

1896 legte Hans Semper die Schriftleitung des Blattes zurück; die Zeitung war 1895 nur mehr unregelmäßig erschienen, genauere Gründe dafür - sowie für Sempers Rücktritt - wurden im Blatt nicht genannt.

Albert von Moné, Professor an der Innsbrucker k. k. Staatsgewerbeschule, übernahm die Redaktion; die Zeitung wurde, aufgrund eines Generalversammlungsbeschlusses, wieder als „Vierteljahresschrift“ geführt. ${ }^{164}$

Diese Konstellation währte nicht lange, denn ein Jahr später wurde das Blatt in „Tirolisches Gewerbeblatt - Zeitschrift für Kunstgewerbe, Gewerbe, Handel und Verkehr" umbenannt; ab Juni des Jahres übernahm Franz Thurner die Redaktion, die ehemaligen Herausgeber Johann Deininger und Hans Semper hatten ebenfalls ihre Mitarbeit zugesichert.

Über den politisch engagierten Franz Thurner kamen nun verstärkt parteipolitische Inhalte ins Blatt; so wurden des öfteren Beiträge über die „Österreichische Gewerbepartei“"abgedruckt. Zu Beginn des Jahres 1900 erschien ein Artikel gegen die „christlich-sozialen/klerikalen Gewerbefunktionäre“ in der Wiener Handelsund Gewerbekammer. ${ }^{165}$

162 Ebd., S. 14 f.; Material für solche Vorhaben ortete er „trotz aller schon geschehenen Verschleuderungen und Plünderungen, noch massenhaft in den Ortschaften, Kirchen und Schlössern des Landes [...], sowie theilweise auch im hiesigen Reichsmuseum, dessen Schätze in dieser Richtung noch fast ungehoben sind." (ebd.)

163 Mittheilungen 7. Jhg. Nr. 1/2 (1890), S. 13.

164 Ebd., 10. Jhg. Nr. 9-12 (1894).

165 Die Nummer 1 (1887) dieses neuen Blattes ist zugleich der 1. Jhg.; der Artikel gegen die Kammerfunktionäre findet sich im 10. Jhg. Nr. 2 (1900), S. 30. Franz Thurner war Mitglied der deutsch-freiheitlichen Partei und kandidierte u.a. 1909 für die Ergänzungswahlen zum Innsbrucker Gemeinderat [vgl. Innsbrucker Nachrichten Nr. 112 (1909) vom 18.5., S. 6.]. 
Ab 1901 erschien monatlich eine Literaturbeilage, in der einschlägige Werke der Gewerbetechnik und -kunst besprochen wurden. ${ }^{166}$

Nachdem 1905 Franz Thurner die Redaktion niedergelegt und sich das Blatt, infolge finanzieller und personeller Engpässe, zu einem organisatorisch-technischen Mitteilungsorgan gewandelt hatte, erschien es 1906 in neuer Aufmachung.

Bereits nach der Jahrhundertwende, als die Innsbrucker Handels- und Gewerbekammer ein eigenes „Gewerbeförderungsinstitut " ${ }^{\text {167 }}$ einrichtete, entstand erstmals der Plan, das Gewerbeblatt der Kammer zu übergeben. Der Hintergedanke dabei war, infolge des finanziellen Rückhaltes, das Blatt so besser ausgestalten (eventuell illustrieren) zu können.

Mit 1. Januar 1906 konnte dieses Vorhaben verwirklicht werden. Gleichzeitig übernahm Kunibert Zimmeter die Leitung des Blattes, welches zwar unter dem alten Namen weitererschien, jedoch nun den Zusatz „Organ des Gewerbeförderungsinstitutes der Handels- und Gewerbekammer Innsbruck“ trug.

Völlig neu gestaltet wurde der Titelkopf, der anstelle des bis dahin verwendeten holzschnittartigen Adlermotives - flankiert von Symbolen des Gewerbe- und Kunstgewerbefleißes (div. Werkzeugen, Malpalette, geflügeltes Rad des Verkehrsgewerbes und einer stilisierten Muse) - stark vereinfacht und stilisiert wurde.

166 Gewerbeblatt 14. Jhg. Nr. 5 (1901). Diese Beilage, unter dem Namen „Literatur-Bericht des Tiroler Gewerbeblattes", findet sich erstmals in der Mainummer!

167 Bereits 1900 hatte die Tiroler Handels- und Gewerbekammer die Errichtung eines solchen Institutes beschlossen, das ein Jahr später eingerichtet wurde.

Die Aktivitäten bestanden in den ersten Jahren in der Abhaltung von Kursen (z.B. 1901 der Wanderkurs für Bautischler) und der Durchführung von Ausstellungen (z.B. die Fachausstellung holzverarbeitende Gewerbe mit 95 daran beteiligten Firmen). Weiters wurden regelmäßig Buchhaltungs- und Spezialkurse (z.B für Friseure, Zuckerbäcker und Schlosser) angeboten. 1909 veranstaltete das Institut, zusammen mit der Staatsgewerbeschule, einen Wanderkurs für Zimmerer über heimatliche Bauweise; ein Jahr später war es Mitveranstalter des Preisausschreibens für gute und originelle Fremdenartikel. Ab 1913 wurde eine eigene Beratungsstelle für das Kunstgewerbe eingerichtet. Ein jährlich herausgegebener Tätigkeitsbericht informierte die Öffentlichkeit und das Handelsministerium über die durchgeführten Aktivitäten (vgl. Fischnaler Bd. IV 1930, S. 163 f.). 


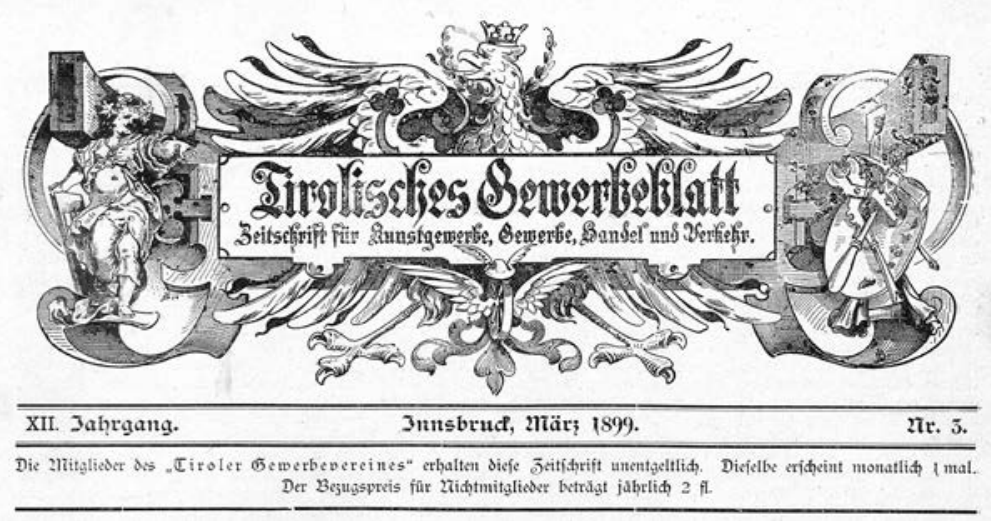

Titelkopf des Tiroler Gewerbeblatt 12. Jhg. Nr. 3 (1899)

Die zarte Pflanzenumrahmung und der einfache Schriftzug wirken fast jugendstilartig; einzig der in der Kopfmitte befindliche kleine Tiroler Adler weist auf die patriotische Gesinnung des Blattes hin.

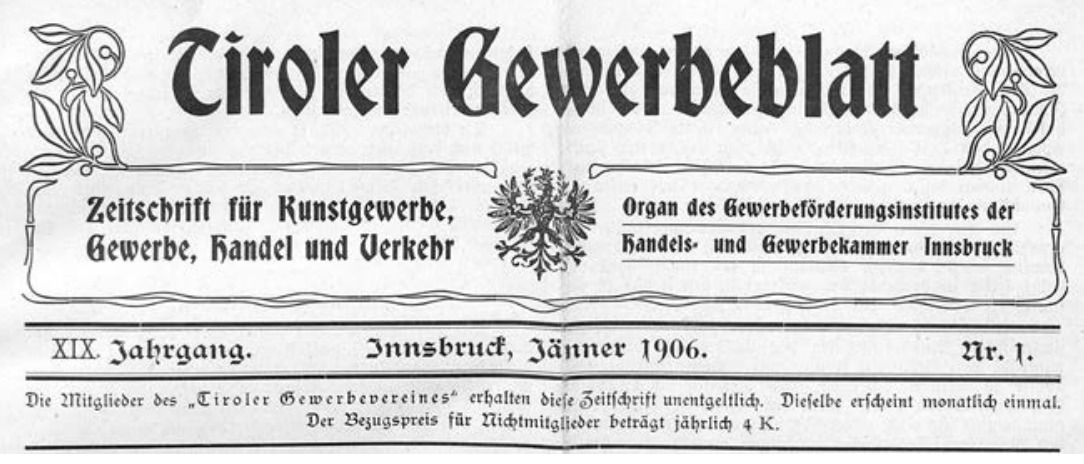

Titelkopf des Tiroler Gewerbeblatt 19. Jhg. Nr. 1 (1906)

Mit Kunibert Zimmeter, der das Blatt zwei Jahre vor der Mitwirkung bei der Heimatvereinsgründung übernahm, wandte sich die Blattlinie wieder kunstgewerblichen Inhalten zu; vor allem heimatschützerische Gedanken wurden aufgegriffen.

In seinem „Geleitwort“ betonte Zimmeter, daß es zahlreiche Gründe gäbe, sich intensiver dem Kunsthandwerk zuzuwenden. Eine allgemeine Übersicht über sämtliche Gewerbebelange sah er als nicht mehr machbar an, betonte aber, daß dazu zahlreiche Fachblätter im Gewerbeförderungsinstitut aufliegen würden. 
Für Zimmeter war es Anliegen und Ziel des Blattes

„Gemeinsames herauszugreifen, wofür doch bei dem Großteil der Gewerbetreibenden und auch einem weiteren Leserkreis auf Interesse zu rechnen ist: das ist nun das Kunstgewerbe oder, moderner gesprochen, die angewandte Kunst. [...] Die Durchdringung von Kunst und Leben wird der Kunst jene hart entbehrte Volkstümlichkeit bringen, die sie zum unentbehrlichen Gute der Nation macht, dem Handwerk aber jene Freude am Schaffen und jenes Ansehen, das für jede gedeihliche Entwicklung not tut."

Dabei lag dem neuen Herausgeber vor allem die Betonung der Bodenständigkeit der angewandten Kunst am Herzen, die das Blatt zu präsentieren und zu fördern hätte, beteuerte aber, daß es nicht um „das sklavische Nachahmen des Alten“ ginge, sondern darum, die „Entwicklung da fort[zu]setzen, wo sie unterbrochen worden sei. Ein den neuen Verhältnissen und Errungenschaften angepaßtes Weiterbauen sei unser Ziel.“

Seinen Vorstellungen nach musste der Anschluß an die moderne Entwicklung der Dinge behalten werden, ohne sich „selbst zu verlieren“ und dem Fehler zu verfallen, ,an Stelle des Alten das Fremde zu kopieren“.

Um diese theoretischen Vorgaben praktisch umsetzen zu können, war Zimmeter darum bemüht, in jede Ausgabe mindestens eine Originalarbeit, „welche das Heimische in erster Linie fördert", aufzunehmen. Weiters sollten sich Beiträge den neuesten, kunsthandwerklichen Strömungen widmen. Hinsichtlich der Illustration des Blattes mußte er die Leserschaft aber enttäuschen, da dies der geringe Verbreitungskreis und die bescheidenen Mittel nicht zuließen. ${ }^{168}$

In der Februarnummer des Jahres 1907 erschien ein großer Artikel über den Heimatschutz (ev. von Zimmeter selbst verfaßt), in dem auf die Untauglichkeit ausschließlich gesetzlicher Maßnahmen hingewiesen und für aufklärerische Maßnahmen - im Sinne einer persönlichen Denkmalpflege - plädiert wird.

In dieser Nummer wurde auch das Referat des Berliner Heimatschützers Oberbaurat Oskar Hossfeld abgedruckt.

Nach dessen Ansichten wäre Tirol ein geradezu prädestiniertes Land für den Heimatschutz, denn nur in Gegenden wo „noch treuer, konservativer Sinn herrscht [...], wo noch Genügsamkeit und selbstbewußter Bauernstolz vorhanden sind“ (z.B. in Gebirgen) finde die Denkmalpflege „noch ein dankbares Feld ihrer Betätigung“. Dort wo „Halbbildung und Neuerungssucht“, sowie „die ganz

168 Gewerbeblatt 19. Jhg. Nr. 1 (1906), S. 1 f. 
klugen Leute sitzen“ und die „Industrie“, die das Land „mit ihren Erfindungen und Surrogaterzeugnissen überschwemmt“, hätte „sie schweren Stand“169.

Weitere Artikel befaßten sich mit der Gründung des „Tiroler Heimatschutzvereines“ (1908), dessen Proponenten und Zielsetzungen, sowie der Frage der „Gesetzlichen Regelung der Denkmalpflege“. Ein 1909 von einem Innsbrucker Gewerbeschulprofessor im Gewerbeverein gehaltener Vortrag über die „Bodenständige Bauweise in Tirol" fand ebenso Eingang in die Zeitschrift, wie ein Beitrag zum „Schutz der heimischen Bauweise“, in dem der Landesgesetzentwurf zur Novellierung der Bauordnung besprochen wurde, der dem Heimatschutzverein ein Mitspracherecht in der Bauplanbegutachtung einräumte.

Auch ein Artikel über das Verbot des „Antiquitätenhandels“ in Hohenzollern zeigt die, seit der Redaktionsübernahme durch Kunibert Zimmeter, deutlich gewordene Ausrichtung auf Heimatschutz und der Rettung heimischer Kunst und Altertümer. In diesem Beitrag wurde bedauert, daß „Aufkäufer von sogenannten Altertümern die hiesige Gegend unsicher" machen würden. Der (unbekannte) Autor endete mit einem Vorwurf an die heimischen Bauern, die sich „schämen sollte[n] [...], Gegenstände der Verehrung oder sei es auch nur [...] des täglichen Gebrauches seiner Vorfahren für ein Lumpengeld zu verschleudern“"170.

Um die Verbreitung des Blattes dürfte es aber schlecht bestellt gewesen sein, da das Gewerbeblatt sein Erscheinen mit der Dezembernummer des Jahres 1910 einstellte, obwohl jedes Vereinsmitglied die Zeitschrift unentgeltlich erhalten hatte.

Der Niedergang des Blattes steht sicherlich im Zusammenhang mit dem Bedeutungsverlust des Gewerbevereines. Seit der Jahrhundertwende war diesem, durch die Eröffnung des handelskammereigenen „Gewerbeförderungsinstitutes“, sowie des allmählichen Eintretens der Landesregierung für Gewerbebelange und der

169 Ebd. 20. Jhg. Nr. 2 (1907), S. 3; ein Jahr später brachte die Zeitschrift einen weiteren Aufsatz zur Heimatschutzproblematik mit dem Titel „Dorfschule und Heimatschutz in den Alpenländern“. Darin meinte der in Berlin lebende Tiroler Architekt Karl Paulmichl, daß „eine Bauernkunst, wie sie in früheren Zeiten in den Alpen so üppige Blüten trieb, [...] heute nicht mehr gedeihen [kann], die Grundbedingungen zu ihrer Entwicklung sind ihr entzogen und können nicht wiedergeschaffen werden“; trotzdem plädierte Paulmichl in diesem, ursprünglich in der deutschen Zeitschrift „Das Schulhaus“ erschienenem Artikel, für eine landschaftsbezogene, auf kunstgewerbliche Traditionen eingehende Bauweise (21. Jhg. Nr. 1 (1908), S. 1 ff.).

170 Die Beiträge erschienen im Gewerbeblatt 21. Jhg. Nr. 9 (1908), S. 5 f.; Nr. 11 (1908), S.1 f.; 22. Jhg. Nr. 11 (1909), S. 1 f.; Nr. 11 eigentlich 12 (1909), S. 6 f. (zum Antiquitätenhandel) und 23. Jhg. Nr. 4 (1910), S. 7 f. 
Übernahme der Museumsideen durch die Handels- und Gewerbekammer, die Vereinsgrundlage entzogen worden.

In einem abschließenden Artikel „An unsere Leser“ führte die Redaktion die Gründe an, die Zeitschrift aufzulassen:

\begin{abstract}
„Allein ebenso wie die Fachvorträge des Gewerbevereines wegen Mangel an Teilnahme aufgelassen werden mußten - es erschienen zwei bis drei Gewerbetreibende -, so fand auch das Organ des Gewerbevereines wenig Teilnahme. In den vier Jahren, welche die Redaktion das Blatt leitete, kam ihr aus den Kreisen der Gewerbetreibenden trotz immer wiederholter Einladung nicht ein einziger Beitrag zu. ${ }{ }^{171}$
\end{abstract}

\title{
4.2.5. Der Vorstand des „Gewerbevereines“
}

Obwohl die Zielsetzung des Vereines eindeutig durch die Statuten definiert war - Hebung und Förderung des Gewerbewesens in Tirol - und vor allem Gewerbetreibende Mitglieder wurden, blieben sie von der Vereinsführung weitgehend ausgeschlossen.

Zwar war im achtköpfigen Ausschuß stets eine Anzahl von Gewerbetreibenden vertreten - einige behielten diese Position über Jahre hinaus - in den Vorstand wurden aber durchwegs Männer aus der Staatsgewerbeschule, der Tiroler Handelskammer oder politische Mandatare gewählt. ${ }^{172}$

Seit der Vereinsgründung bis 1888 stand der Gewerbeschul-Direktor Johann Deininger dem Verein vor; Stellvertreter waren zwar 1885 ein Tischler- und 1886 ein Tapezierermeister, aber ab 1887 dann der Handelskammer-Sekretär Carl Payr.

Mit Frühjahr 1888 übernahm Dr. Anton Kofler, Payrs Nachfolger als Handelskammer-Sekretär, den Vorsitz des Gewerbevereines und behielt ihn bis 1910; Stellvertreter waren der Kunsthistoriker Prof. Hans Semper (1888-1885/86), sowie der Direktor der Staatsgewerbeschule Anton Hellmessen (1906-1909/10).

Zwischen 1886 und 1905 war Bernhard Zösmayr, Schlossermeister und deutsch-liberaler Gemeinderat in Innsbruck, Stellvertreter des Vereinsvorstandes. ${ }^{173}$

171 Gewerbeblatt 23. Jhg. Nr. 12 (1910), S. 1.

172 Bei den Innsbrucker Handels- und Gewerbekammerwahlen von 1902 kandidierten (und wurden gewählt!) einige Mitglieder des Gewerbevereins: so in der Sektion II u.a. der Mühlenbesitzer J. Rauch, in der Sektion III u.a. Leopold Lindner und der Drechslermeister Gabriel Hammerl. [Vgl. Gewerbeblatt 15. Jhg. Nr. 2 u. 3 (1902), S. 5.]

173 Leider waren keine vollständigen Ergebnisse der Vorstandswahlen auffindbar. Daher stützen sich die Angaben nur auf die Anführungen der Jahreshauptversammlungen, die in den Mitthei- 
Die letzten Vorstandswahlen verliefen allem Anschein nach in angespannter Atmosphäre. So konnten die Neuwahlen von 1907 erst nach „längerer Debatte“ durchgeführt werden. Anton Kofler erhielt schließlich 28 von 50 Stimmen und drückte nach Bekanntgabe des Wahlergebnisses den Wunsch aus, „die Einigung zugunsten des gemeinsamen Zieles des Vereines zu wahren“.

An der von Dir. Hellmessen geleiteten Generalversammlung des 6. Mai 1908 nahm Kofler nicht teil, wurde aber, trotz seiner Abwesenheit, zum Vorstand wiedergewählt.

Die Wahl von 1909 mußte zweimal durchgeführt werden, weil im ersten Wahlgang keine absolute Mehrheit für Anton Kofler zustande gekommen war. ${ }^{174}$

\subsubsection{Vereinsausrichtung: Gewerbe oder Kunstgewerbe?}

Die Zweiteilung der Vereinsmitglieder in Theoretiker und Praktiker brachte - zumindest zu Beginn - Probleme in den Verein.

Als vom Verein 1884 ein Preis für Lehrlingsarbeiten in der Holzindustrie ausgeschrieben werden sollte, entbrannte in einer Mitgliederversammlung eine grundsätzliche Debatte über die Vereinsausrichtung. Vertreter verschiedenster Gewerbe beklagten, daß der Verein für alle Gewerbe des Landes da zu sein hätte, nicht bloß für Kunstgewerbetreibende.

An der grundsätzlichen Hebung und Veredelung des Standes hatten die kritisierenden Mitglieder allerdings nichts auszusetzen, und es begrüßten alle die durch den Verein vorgenommene Vertretung des Gewerbestandes und die Wahrung der Interessen nach Außen. ${ }^{175}$

lungen und ab 1897 im Gewerbeblatt - leider unvollständig - erschienen sind. Seit der 1910 erfolgten Einstellung des Gewerbeblattes fehlen Vereinsangaben völlig, sodaß über die Zeit danach keine Angaben gemacht werden können! Im Tiroler Landesarchiv finden sich, bis auf die Statutenhinterlegung von 1880 und die Statutenänderung von 1894 keine weiteren Akten zum Gewerbeverein. Im Archiv der Tiroler Handelskammer befinden sich keine Vereinsunterlagen, wie ich nach eigenen Recherchen im Katalog und durch mündliche Auskunft der Bibliothekarin feststellen konnte!

174 Vgl. Gewerbeblatt 20. Jhg Nr. 5 (1907), S. 2; 21. Jhg. Nr. 5 (1908) und 22. Jhg. Nr. 5 (1909), S. 5 f. Von der Hauptversammlung des Jahres 1910 hieß es lediglich, sie hätte gut besucht im Hotel Greif stattgefunden und Kofler hätte krankheitshalber nicht teilnehmen können; ein Wahlergebnis wurde nicht veröffentlicht! [Ebd. 23. Jhg. Nr. 5 (1910), S. 5 f.]

175 Mittheilungen 1. Jhg. Nr. 6 (1884), S. 26; die Versammlung des Gewerbevereines fand am 18.7.1884 statt. 
Am 10jährigen Stiftungsfest des Vereines, am 20.11.1890, ging der Kunsthistoriker Hans Semper nochmals auf die engere Bedeutung des Vereines ein und grenzte in seiner Rede die Beziehung Gewerbe-Kunstgewerbe ab.

Seiner Auffassung nach hätte der „Tiroler Gewerbeverein“ „eine große Mission, namentlich zur ästhetischen Bildung des Volkes beizutragen, denn die kunstgewerbliche Thätigkeit [sei] jener Zweig, der am leichtesten in das Volk dringt " ${ }^{\text {"176 }}$.

Dem Verein käme, so Semper weiter, „ein großer Verdienst für die Wiederanregung der Kunstthätigkeit in Tirol“ zu, denn solange es an Kunstsinn mangelte, würde eine Hauptquelle des Wohlstandes fehlen.

Damit war das Primat der kunstgewerblichen Ausrichtung innerhalb des Vereines nochmals bekräftigt worden, denn nur diese könnte, wie der Tischlermeister und Gewerbevereinsmitglied Michael Konzert auf dem Stiftungsfest betonte, die „wirthschaftlichen Interessen des Volkes" heben und fördern.

\subsubsection{Der Mitgliederstand des Vereins}

Da, wie schon erwähnt, die Aktenlage zum „Tiroler Gewerbeverein“ sehr dürftig ist, sind keine genauen Angaben zum Mitgliederstand möglich.

In den Jahreshauptversammlungsberichten wurden die Namen und Berufe der Ausschuß- und Vorstandsmitglieder angeführt, doch sind diese nicht vollständig; detaillierte Mitgliederlisten wiederum sind nur zu Beginn der Vereinstätigkeit in den einschlägigen Publikationsorganen erschienen.

Im Gründungsjahr wird die Mitgliederzahl mit 82 bezeichnet, 1881, ein Jahr später, waren es 108 .

Eine Aufzählung des Mitgliederstandes von $\mathbf{1 8 8 4}$ nennt 559 Personen, davon der Großteil (166) aus Innsbruck, 70 aus Bozen, 44 aus Fulpmes, 35 aus Brunneck, 31 aus Schwaz, 21 aus Hall, 29 aus Lienz und 25 aus Reutte.

Ein Jahr später wird die Zahl der Mitglieder mit 365 angegeben, wovon 141 aus Innsbruck stammten.

1886 waren von den 271 Mitgliedern 160 Innsbrucker.

1888 betrug der Mitgliederstand 213, davon 166 aus Innsbruck.

1889 hatte der Verein 219 Mitglieder, davon 177 Innsbrucker.

176 Ebd. 7. Jhg. Nr. 11/12 (1890), S. 68 f.; Semper gab seinem Bedauern Ausdruck, daß „die Theilnahme der wohlhabenden Bürgerkreise im Ganzen heute noch eine zu geringe [sei] und nur zu hoffen [wäre], daß der einstige ausgesprochene Kunstsinn Tirols wieder allgemeiner erwache." (S. 69) 
1891 waren es 213 Mitglieder - Angaben über die Herkunft fehlen allerdings. Der Akt der Vereinspolizei, der anläßlich der Statutenänderung von 1894 angelegt wurde, vermerkte für 1891 die Zahl von 205 Mitgliedern, für 1892203.

1907, drei Jahre vor der Einstellung des Gewerbeblattes, verzeichnete der Verein 236 Mitglieder, um 31 mehr als ein Jahr zuvor. 1908 waren es 229 Personen, die anläßlich der Jahreshauptversammlung als Mitglieder geführt wurden. ${ }^{177}$

Wenn die Zahl der am Verein beteiligten Personen (im Durchschnitt 200) nicht überwältigend erscheint, darf daraus keinesfalls auf eine Bedeutungslosigkeit der Vereinigung geschlossen werden. Dagegen spricht einerseits das Naheverhältnis zur Handelskammer und zur Staatsgewerbeschule, andererseits die politische Tätigkeit mancher Vereinsmitglieder, die teils über Jahrzehnte als Mandatare im Landtag, Reichs- oder Gemeinderat aktiv waren. All diese Gruppen waren opinion leaders und hatten Einfluß auf einen Teil der Tiroler Öffentlichkeit. ${ }^{178}$

\subsubsection{Aktivitäten des Gewerbevereins}

Die meisten Aktivitäten des „Tiroler Gewerbevereines“ blieben zwar auf den Innsbrucker Raum beschränkt, über die Wanderveranstaltungen wurden seine Gedanken und Ansichten aber im gesamten Kronland verbreitet. So wird verständlich, $\mathrm{da} ß$ es in anderen Tiroler Orten ähnliche Bestrebungen gab, die den Kontakt mit dem „Tiroler Gewerbeverein“ in Innsbruck suchten, aber nie dessen Bedeutung erlangten.

Besonders bei Gewerbeausstellungen zogen gleichgesinnte Gewerbetreibende Mitglieder des „Tiroler Gewerbevereines“ als Berater und Begutachter heran.

1885 hatten Genossenschaftsobmänner aus Südtirol beschlossen, eine Gewerbeausstellung abzuhalten, die dann zwei Jahre später unter dem Protektorat von Erzherzog Heinrich stattfand. Sowohl der Obmann des „Tiroler Gewerbevereines“, Johann Deininger, als auch der Leiter der permanenten Kunstgewerbe-Ausstellung des Vereines Constantin Nicolits waren als Fachjuroren tätig. Die Ver-

177 Vgl. TLA, Statth. Verein Zl. 29.730/1984, die anderen Angaben stammen aus den Mittheilungen 1. Jhg. Nr. 1 (1884); 2. Jhg. Nr. 12 (1885); 3. Jhg. Nr. 24 (1886), S. 93 ff.; 4. Jhg. Nr. 35/36 (1887); 6. Jhg. Nr. $1 / 2$ (1889), S. 8 f.; 7. Jhg. Nr. 1/2 (1890), S. 15, sowie dem Tiroler Gewerbeblatt 20. Jhg. Nr. 5 (1907); 21. Jhg. Nr. 5 (1908). Eine Mitgliederliste findet sich in den Mittheilungen 5. Jhg. Nr. $7 / 8$ (1888)!

178 Die größte Innsbrucker Tageszeitung, die Innsbrucker Nachrichten, die im Naheverhältnis zur liberalen politischen Öffentlichkeit stand, war gegenüber dem Gewerbeverein aufgeschlossen und berichtete über Aktivitäten des Vereines (Zu den Versuchen des Vereins ein Gewerbemuseum zu gründen, vgl. Kap. 5.). 
anstaltung wurde von insgesamt 17.000 Menschen besucht und in einem Bericht darüber hieß es, daß „Bozen mit dieser Ausstellung in die Reihe der Fortschrittstädte getreten“ wäre und, als Erfolg davon, ,schöne und gediegene Arbeiten im In- und Auslande bekannt und es [so] an Aufträgen sicher nicht fehlen " werde. ${ }^{179}$

Der Gewerbeverein war über seine Mitglieder an der Veranstaltung diverser Gewerbeausstellungen beteiligt. So wirkten führende Vertreter des Vereines, allen voran Dr. Anton Kofler, an der Entstehung der Tiroler Landesausstellung von 1893 mit.

Diese größte heimische Gewerbeleistungsschau war bereits in den späten 1880er Jahren geplant worden, mußte aber aus Raum- und Finanzgründen in die 90er Jahre verschoben werden.

Die Veranstaltung fand dann im Beisein Kaiser Franz Josefs im Innsbrucker Saggen statt; zwischen der Siebererstraße und den Viaduktbögen war eigens eine Halle errichtet worden.

Inhaltlich war sie ein Sammelsurium aus Gewerbe- und Kunstgewerbeschau, Leistungsausstellung industrieller Maschinen und Produkte, aber nationaler Identifiktationsmuster, wie Tirolischer Altertümer, Gerätschaften und Trachten.

In den vorbereitenden Komitees saßen u.a. der Handelskammerpräsident Anton von Schumacher (als Vizepräsident der Ausstellung), der Handelskammersekretär Dr. Anton Kofler (als ständiger Referent und Geschäftsleiter), sowie im Comité für Kunst und Kunstgewerbe Dir. Johann Deininger und im Comité der historischen Abteilung Dr. Franz von Wieser, seit 1887 Vorstand des Museums Ferdinandeum und Korrespondent der Zentralkommission für Denkmalschutz. ${ }^{180}$

Die Tiroler Gewerbezeitung jubelte in einem Bericht über diese Ausstellung, daß sie eine "glänzende Widerlegung dieser geradezu frivolen Behauptung sei“, daß die Gewerbetreibenden nicht leistungsfähig wären und Gelegenheit biete, „unseren Erzeugnissen neue Absatzgebiete zu eröffnen "181.

179 Näheres im Ausstellungsbericht von Oberkofler/Egger 1899; die Zitate finden sich auf den S. 99 u. 134.

180 Siehe den Katalog der Tiroler Landesausstellung 1893, herausgegeben vom Executiv Comité, sowie die kurze Darstellung (mit zwei Abbildungen der Ausstellungshalle) bei Fischnaler Bd. I 1930, S. $85 \mathrm{ff}$.

181 2. Jhg. Nr. 2 (1893), S. 11. Eine weitere wichtige Vereinsaktivität bestand in der Propagierung von Gewerbegenossenschaften. Der Verein setzte sich, zusammen mit dem 1901 gegründeten „Gewerbeförderungsinstitut“, für den Zusammenschluß von Handwerkern oder Gewerbetreibenden zu Genossenschaften ein. So war Anton Kofler maßgeblich an der Gründung der „Werksgenossenschaft der Stubaier Kleineisenindustrie“ beteiligt, die 1897 ins Leben gerufen wurde. 


\section{Exkurs 1: Über die Weltausstellungen und die dortige Art, Tirol zu präsentieren}

Bereits vorher waren auf den diversen Weltausstellungen (die erste fand 1851 in London statt) mit Erfolg Tiroler Gewerbeprodukte gezeigt worden, wobei in der Folge versucht wurde, über diese Produkte Tiroler Image zu verkaufen.

Waren die verschiedensten Ausstellungsgegenstände zuerst noch nach rein gewerblichen Gesichtspunkten präsentiert worden, so wandelte sich dies - verbunden mit dem zunehmenden Fremdenverkehr im eigenen Lande und den damit aufkommenden Klischeevorstellungen von Tirol und seinen BewohnerInnen zur ästhetisch angelegten Präsentation von Tiroler Kultur.

Bei den folgenden Weltausstellungen (London 1862; Paris 1867, 1878 und 1900; Wien 1873; Chicago 1892; Antwerpen 1894; St. Louis 1904 ...) waren die, von Tiroler Seite aufgestellten, Bauernhäuser und Ansitze Anziehungspunkte. Diese präsentierten sich vor gemalter Kulisse und wurden zur idealen Versinnbildlichung tirolischer Lebensweise. ${ }^{182}$

In seinem Rechenschaftsbericht über die Pariser Weltausstellung von 1900 gab Anton Kofler als Grund der Teilnahme Tirols an: Es könnte dort „zugunsten der Hebung des Reiseverkehrs Reclame“ gemacht werden. Bereits 1895 war durch den Landschaftsmaler M. Zeno Diemer die Skizze eines Alpenpanoramas geschaffen worden, das zusammen mit einem „Tiroler Bauernwirtshaus und einer Tiroler Kapelle“ zur „Propagierung dieses Alpenlandes zum Zwecke der Hebung des Reiseverkehrs" aufgestellt werden sollte. Aus Raum- und Geldmangel war man aber wieder davon abgekommen und beabsichtigte nun einen „Tiroler Edelansitz", der von Johann Deininger nach dem Vorbild des Schlosses Eppan entworfen worden war, aufzurichten. Für das Gewerbeblatt war damit ein "großer moralischer Erfolg“ für das Land entstanden, denn viele Besucher hätten so „Einblick [in] die landschaftlichen Reize und die Kunstfertigkeit der Bewohner" erhalten. Tirol hätte sich, so das Blatt weiter, „durch diese Spezialausstellung einen selbständigen Ruf" geschaffen und viele Prämierungen erreicht. ${ }^{183}$

182 An der Ausstellung in München (1854) und an der Weltexposition in Paris (1855) hatten sich noch wenige Tiroler Gewerbetreibende beteiligt, auf der Pariser Weltausstellung von 1878 war Tirol schon mit zahlreichen Exponaten vertreten (u.a. Glasmalereiwaren, Lederhandschuhe, diverse Fournierarbeiten und Kunstschnitzereien, sowie Kleineisenprodukte, wie Sensen, Sicheln etc.); es gab sogar eine Reisebeihilfe durch den Tiroler Landtag. Schon 1873 waren in Wien 144 Tiroler Aussteller vertreten gewesen, die insgesamt 43 Medaillen und 48 Diplome für ihre Produkte erzielen konnte (s. Marek 1951, S. 134 f. u. 146).

183 14. Jhg. Nr. 10 (1901), S. 1 ff. 
Vier Jahre später war Tirol auf der Weltausstellung in St. Louis vertreten. Das Tiroler Gewerbeblatt zitierte in einem Bericht über „Das Tirolerdorf auf der WeltAusstellung" eine Schweizer Zeitung, die einen ausführlichen Bericht zur Tiroler Weltausstellungspräsenz brachte.

Aus diesem Artikel läßt sich einiges über die Art der Präsentation und Vermarktung des Tirolbildes herauslesen. So kokettierte die Inszenierung bewußt mit einer - wenn auch oberflächlich angelegten - Verwechslung mit der Schweiz, die damals in Amerika bekannter war als Tirol.

"Jedesmal wenn ich im Olive-Tram nach der Ausstellung hinausfahre“, so der Schweizer Kolumnist,

„erregt das Tirolerdorf meine Eifersucht. Die Schweiz hat da eine Gelegenheit verpaßt, die nicht so bald wiederkehren wird. Schon von weitem sieht jeder Besucher der Ausstellung die ragenden Schneeberge; , ah, das ist Switzerland', sagt wohl etwa der eine oder der andere, aber er wird bald darüber aufgeklärt, daß es die Tiroler Alpen seien. ${ }^{\text {"184 }}$

Das Dargestellte glich aber eher einer Anhäufung aller Klischees Tiroler und alpenländischer Besonderheiten.

„Man sieht also, alles ist zusammengesucht worden, um ein Zugstück zu machen, die frommen Tiroler und die bayerischen Königsschlösser, die Oberammergauer und das Zillertal. Dazu hätten noch die berühmten Schweizerberge in die Tiroler Alpen kommen sollen, so war es geplant. ${ }^{\text {185 }}$

Dieser Ästhetizismus wurde nicht nur seiner selbst willen betrieben, sondern diente Werbezwecken und dem beabsichtigten Verkaufserfolg.

„Bewunderungswürdig ist, wie die ganze Anlage zum Geschäfte gestaltet worden ist. Mit Ausnahme der paar Häuser, einem kleinen Platz mit dem

184 17. Jhg. Nr. 8 (1904), S. 4; das Eingangsschild beseitigte aber alle Zweifel der Herkunft, stand doch darauf: „German und Tyrolean Alpes“! (ebd.) Der zitierte Artikel war ursprünglich in der Berner Zeitschrift „Bund“ erschienen. Darüber berichtete sowohl im Verein als auch in den Innsbrucker Nachrichten, das Gewerbevereinsmitglied Andrä Norz, der in St. Louis dabei war [vgl. Tiroler Gewerbeblatt 18. Jhg. Nr. 7 (1905)].

185 Ebd., S. 5; Der Autor erwähnt u.a. eine Kirche, in dem das Oberammergauer Passionsspiel aufgeführt wurde, ein als amerikanische Bar eingerichtetes Haus mit dem Innsbrucker Goldenen Dachl, „Dioramen der bayerischen Königsschlösser Linderhof, Hohenschwangau u.s.w.“, ein Minizillertal mit einer nachgestellten Kirchenprozession und den Dörfern Zell und Mayrhofen. 
Andreas Hoferdenkmal und dem Dioramenzauber in den Felsen ist alles, Platz und Grotten, Schloß und Rathaus, alles Restaurant",

schwärmte der Schweizer Berichtschreiber und betonte, daß es den Tirolern - im Gegensatz zur renommierten Schweiz - gelungen wäre, zentral und für viele Besucher lukrativ, eine ideale Fremdenverkehrspropaganda aufzuziehen.

Abschließend bemerkte er, daß, auch wenn die Darstellung der „Deutschen Tiroleralpen“ eher "nach allen Seiten verflatter[t] “ und „nicht ausschöpfen[d]“ gewesen wäre, sie eine „vorzügliche geschäftliche Mache [...], eine erstklassige Propaganda-Nummer für den Fremdenverkehr und die Hotelindustrie [war]. Man denke nur daran, daß alles davon spricht, daß alle Nationen hier Einkehr" hielten. ${ }^{186}$

Die auf den verschiedensten Weltausstellungen gewonnene, reiche Erfahrung der größtmöglichen Vermarktung heimischer Kulturversatzstücke als Tiroler Volkskultur, der „Nationalkultur" wie sie genannt wurde, zeigte sich besonders auf der Landesausstellung von 1893.

Insgesamt wurden auf dieser Leistungsschau zwei traditionelle Gebäude aufgestellt: ein „Unterinntaler Bauernhaus“, in dessen Innenräumen Tiroler Hausindustriegegenstände ausgestellt wurden, sowie ein „deutschsüdtiroler Torggelhaus“, das im Auftrag des Bozner Weinbaucomités, nach Plänen des Architekten Johann Deininger, gefertigt worden war.

Weiters waren noch ein Anbau für die „Innsbrucker Hütte“ der Sektion Innsbruck/Wilten des österreichischen Touristenclubs und die neue „BettelwurfSchutzhütte" der Sektion Innsbruck des Deutsch-Österreichischen-Alpenvereines zu sehen. ${ }^{187}$

So war diese Schau nicht nur eine Geschmackspräsentation, die anregend wirken sollte, sondern sie demonstrierte die enge Verbundenheit von Fremdenverkehr, Gewerbeförderung und Besinnung auf heimische Kunst. ${ }^{188}$

186 Ebd.; im Artikel werden die Kosten für das „Tirolerdorf“ mit vier Millionen Franken angegeben; dafür gäbe es hier aber das größte Restaurant der Weltausstellung mit 3.000 Sitzplätzen, welches sich lohnen würde, sorgten doch für die Unterhaltung ein 60 Mann-Orchester, Original-Tiroler Konzertsänger, sowie Schuhplattler und Jodler. Sogar Alice, die Tochter des amerikanischen Präsidenten Roosevelt, wäre bei ihrem Ausstellungsbesuch direkt ins Tirolerdorf marschiert, vermerkte der Autor (ebd.).

187 Vgl. die Angaben in den Mittheilungen 10. Jhg. Nr. 1-6 (1893), S. 61.

188 Jedoch war manchem das dort Präsentierte noch zu wenig. Der Kunsthistoriker Hans Semper bedauerte in einem Artikel über „Die historische Abteilung der Tiroler Landesausstellung von 1893“, daß der eigens geplante, bauernhausartige Pavillon mit ,volksthümlichen Kunstprodukten der Vergangenheit" nicht zustande gekommen wäre und vermerkte generell zum Fehlen einiger, nicht ausgestellter Gegenstände: „Was nun das Kunstgewerbe der Vergangenheit Tirols betrifft, 
Hervorgehoben wird dieser Vorbildcharakter auch in einem Aufsatz „Über die Holzindustrie auf der Tiroler Landesausstellung“, der in den Mittheilungen erschienen war. Darin meinte der Autor Franz Rosmael:

„Es wäre nur zu wünschen, daß man auch in Tirol einsähe, daß jedes Land am besten fährt, wenn es [...] vorzugsweise seine eigene Stilart pflegt, weil nur diese in einer wirklich lebendigen Weise geräth. Und Tirol, dieses Land volksthümlicher Kunst, hat diesen Stil; einen Stil, welcher das Ergebnis von Sitten, Gewohnheiten, des Materials und der sonstigen örtlichen Bedingungen ist, in seiner - Gothik."

Jedoch bedauerte der Verfasser, daß in der Ausstellung Renaissanceinterieurs überwogen hätten, allerdings nicht mehr in solch klobigem Stil wie noch vor kurzem, was darauf zurückzuführen wäre, daß die Staatsgewerbeschulen „schon segensreich gewirkt" hätten.

Rosmaels Meinung nach läge die Zukunft für das Tiroler Gewerbe in der Hausindustrie, vor allem in der Spielwarenerzeugung und der Herstellung religiöser Figuren. ${ }^{189}$

so wäre allerdings zu wünschen gewesen, daß die für Tirols volksthümliche Kunstbegabung so bezeichnenden Erzeugnisse des einfacheren bürgerlichen und bäuerlichen Gewerbefleißes [...] in erster Linie ins Treffen geführt worden wären, zumal da sie auch besonders fruchtbare Keime der Fortbildung und Verwertung für eine nationale Kunstbetriebsamkeit enthalten. Aber leider waren gerade solche Erzeugnisse in der kurzen Zeit [schwer] aufzustöbern und herbeizuschaffen." (Mittheilungen 11. Jhg. Nr. 5/6 (1894), S. 25)

189 Mittheilungen 10. Jhg. Nr. 1-6 (1893), S. 63 ff.; in einer Anmerkung meinte allerdings die Redaktion, daß sie in DER Ausschließlichkeit die Reklamierung der Gotik zum „Tiroler Stil“ schlechthin nicht teilen könnte (S. 63). Die Bezugnahme auf die Gotik als den nationaldeutschen Stil, der deshalb besonders für Tirol große Bedeutung hätte, spielte in der späteren Diskussion um das Volkskunstmuseum und die dort ausgestellten Stücke eine wichtige Rolle, und oft wurde dabei auf die besondere Stellung Tirols hingewiesen. Die Frage der Qualität des Tiroler Kunstgewerbes beantwortete der ehemalige Direktor des Tiroler Volkskunstmuseums, Dr. Josef Ringler, folgendermaßen: Sie ruhe „in der geradezu sprichwörtlichen Kunstbegabung des Tiroler Volkes, in seinem handwerklichen Ehrgeiz und seiner Geschicklichkeit, in seiner Aufnahmebereitschaft Anregungen von außen gegenüber und in der tatkräftigen Förderung aller dieser Bestrebungen durch geistliche und weltliche Landesherren." (1948, S. 184) 


\subsubsection{Stilfrage}

Ein Artikel, der 1906 im Gewerbeblatt erschienen war, zeigt, daß auch andere Autoren der Zeitschrift die Gotik als den Tiroler Stil ansahen.

Der Innsbrucker Architekt Hermann Kirchmair meinte in diesem Beitrag, daß die „Gotik, diese[r] tatgewordene [...] Ausdruck germanischen Empfindens [...] unübertroffen [und eine] Eigenkunst" sei.

Nach Kirchmair wäre Tirol in der günstigen Lage, eine „echte Volks- und Heimatkunst“ wiedererstehen zu lassen, die „sozial ausgleichend, allen Ständen gleich erreichbar ist, und alle Geräte des bürgerlichen Lebens in veredelter Form wiedererstehen" ließe.

Seiner Ansicht bedürfte jede Kunst „einer Heimat, eines Wurzelbodens, der ihr das ,örtlich-eigenthümliche" verleiht", daher sollte sich das Land wieder auf seine kunsthandwerklichen Traditionen, z.B. der Gotik, erinnern und so „aller Welt [beweisen], daß die Jungmeister Tirols neuschaffend weitergebaut haben an ,ihrer Väter Werke““.

Er sah den praktischen Nutzen der Besinnung auf traditionelle Stilformen vor allem darin, daß eine Tiroler Heimat- und Volkskunst, „weil typisch als solche erkennbar, die Erläuterung, Gruß aus Tirol' oder ,Gruß aus Innsbruck' nicht mehr bedürfe“"190.

Auf diversen Vereinsversammlungen kam die Stilfrage in der Tiroler Kunst zur Sprache.

Anläßlich einer Diskussion um die Beteiligung des Gewerbevereines an einer modernen Kunstgewerbeausstellung in Innsbruck, zu der das Wiener „Museum für Kunst und Industrie“ Exponate senden wollte, sprach sich Anton Kofler für die „Absicht“ einer Bekanntmachung des heimischen Gewerbes und Publikums mit der „Wiener Richtung in der Kunst und im Kunstgewerbe“ aus.

Daraufhin entbrannte eine Debatte, in der sich der Innsbrucker Gewerbeschulprofessor Josef Tapper „für das Festhalten an der typisch tirolischen Kunst“ aussprach, jedoch betonte, daß dieser "nationale Stil“ nicht mit „Nachahmerei“ verwechselt werden dürfte.

190 19. Jhg. Nr. 3 (1906), S. 4 ff.; seine Darlegungen erschienen unter dem Titel „Die moderne Innenkunst“. Kirchmair war vor allem der Ausverkauf heimischer Kunst ein Dorn im Auge. Er äußerte deshalb die Hoffnung, daß diese „Überreste“ nicht in „Privatsammlungen“ landen, sondern in einem „eigenen Museum nicht zur Nachahmung sondern zur Befruchtung aufgestellt" werden würden (ebd., S. 5). Besonders in den Werken der „Schmiede-, Töpfer- und Holzschnitzer-Kunst“, wäre seiner Ansicht nach, eine solche Besinnung auf der „Väter Werke“ möglich und auch schon zu bemerken. 
Weiters erinnerte Tapper an das „nationale Gepräge der Tiroler Ausstellung des Jahres 1893“, hob den "hohen Wert tirolischer erstklassiger Produkte“ hervor und „warnte vor einem Abgehen von den eingeschlagenen Bahnen des specifisch Tirolischen“, denn die Besucher würden, „im Lande nicht moderne, sondern nationale Kunst suchen und wünschen“, außerdem gäbe es, seiner Ansicht nach, in den Gewerbemuseen der Großstädte ohnehin genug moderne Kunst.

Anton Kofler konnte Tapper in dessen Betonung des Nationalen nur Recht geben, wies aber auf die Notwendigkeit hin, „sich der modernen Richtung anzuschließen“, da ja nicht nur „Fremde, sondern auch Einheimische zu befriedigen seien".

Die Diskussion endete damit, daß sich auch Tapper als Freund der modernen Richtung bezeichnete, aber feststellte, daß „das Nationale oben auf sei und das Moderne mitgehen" müsse. ${ }^{191}$

\subsubsection{Dominierendes Kunstgewerbe}

Die im Jahre 1894 durchgeführte Statutenänderung brachte die verstärkte Ausrichtung des „Tiroler Gewerbevereines“ auf das heimische Kunstgewerbe.

Wichtigste Neuerungen waren die „Erhaltung eines Gewerbemuseums in Innsbruck nebst einer permanenten Ausstellung von modernen Erzeugnissen tirolischer Industrie in Innsbruck und eventuell auch an anderen Orten" (neuer $\$ 3$ ) sowie das Recht der Mitglieder, „ihre gewerblichen und kunstgewerblichen Erzeugnisse in der permanenten Gewerbeausstellung oder durch Vermittlung des Vereines auch anderwärts unter den im Regulativ festgesetzten Bedingungen auszustellen“192.

Bereits zehn Jahre zuvor hatte der Innsbrucker Professor Vinzenz Lychdorff in einem Vortrag für den Gewerbeverein auf die „national-ökonomische Bedeutung des Kunstgewerbes" hingewiesen. ${ }^{193}$ Seiner Meinung nach wäre das Kunsthandwerk ein wichtiger Faktor der Nationalökonomie, denn

191 Gewerbeblatt 15. Jhg. Nr. 2 (1902), S. 1 ff.; in der bereits zuvor entzündeten Debatte, ob sich an der Ausstellung nur Kunstgewerbetreibende oder das gesamte Gewerbe beteiligen dürfe, hatte Kofler für die Teilnahme der „gesamten Industrie“ plädiert! Josef Tapper (1854-1906), ein gebürtiger Niederösterreicher, war in der Gründungsphase des „Tirolischen Museums für Volkskunst und Gewerbe“ - zusammen mit Anton Kofler - eifriger Einkäufer auszustellender Gegenstände. Seine Ansichten über National- und Volkskunst haben die Sammeltätigkeit der ersten Museumsjahre entscheidend beeinflußt! (vgl. Kap. 5.3.3)

192 TLA, Statth. Verein Nr. 28576/4400 und Zl. 29730 ex 1894.

193 Mittheilungen 2. Jhg. Nr. 11 (1885), S. 47 ff.; der Vortrag fand in der Vereinsversammlung am 2.12.1884 statt. 
„in einem Lande, dessen Bodenproduktion nicht hinreicht, die Bedürfnisse der Bevölkerung zu befriedigen, welches außerdem arm an geeigneten Rohstoffen für industrielle Zwecke ist, und diese von auswärts bezogen werden müssen, ergibt sich in noch ausgeprägterer Form die Nothwendigkeit, diese an sich schon theurer zu erwerbenden Rohstoffe durch kunstmäßige Verarbeitung in ihrem Werte [zu] steigern."

Er verwies auf das Beispiel Frankreichs, wo nicht „natürliches Geschick für kunstvolle Arbeiten“, sondern die „seit langem gepflegte gewerbliche und künstlerische Schulung dieses Volkes“ Grund für den hohen kunsthandwerklichen Stand des Landes wären. ${ }^{194}$

Vor allem in einer soliden und kunsthandwerklich hochstehenden Ausführung der Produkte sah er die Zukunft des Kleingewerbes, das so nicht vor den „Fabriksschloten zu zittern" bräuchte. Daher wäre es, seiner Ansicht nach, nötig, geeignete Mustersammlungen zu schaffen, in denen Vorbilder zum Studium und zur Anregung auszustellen wären, da „Erzeugnisse der Kunsthandwerker früherer Zeiten [...] in jeder Hinsicht als nachahmenswerte Beispiele dienen “ könnten. ${ }^{195}$

\subsubsection{Eigenes Ausstellungswesen}

Bereits im Jahr der Vereinsgründung, 1880, war es zur ersten „Weihnachtsausstellung “ gekommen, bei der Mitglieder des Vereines ihre Gewerbeprodukte ausstellen konnten. Diese Ausstellungsart wurde in den folgenden Jahren zu einer Verkaufsausstellung erweitert, die meist unter reger Teilnahme lokaler Prominenz eröffnet wurde. Durchschnittlich besuchten mehrere 100 Personen diese Schau; genaue Zahlen über die Verkaufsergebnisse sind leider nicht mehr vorhanden. ${ }^{196}$

194 Ebd.; In der zweiten Hälfte des 19. Jahrhunderts häufen sich in Deutschland und Österreich Klagen über den kunsthandwerklichen Rückstand gegenüber Frankreich und England. Besonders die Weltausstellungen von 1867 und 1873, als nationale Leistungsschauen, hatten für viele Kunstkritiker den mangelnden Geschmack und geringen kunsthandwerklichen Stand, besonders der deutschen Produkte, aufgezeigt (vgl. das Urteil von Friedrich Pecht über die Kunstindustrie auf der Wiener Weltausstellung, 1873). Reaktion darauf waren Gründungen von Kunstgewerbemuseen in Deutschland und Österreich (Wien 1863, Leipzig 1873, Berlin 1879) und damit der Versuch, die gewerbliche Produktion mittels Muster- und Vorbildsammlungen im qualitativen Wert zu heben (vgl. Mundt 1974, S. 11 ff.).

195 Mittheilungen 2. Jhg. Nr. 11 (1885), S. 49.

196 Für das Jahr 1884 wurde die Besucherzahl mit 772, für 1886 mit 484, für 1887 mit 766 Personen angegeben. Die Zahl der Aussteller belief sich auf jeweils 40 bis 50, der Verkaufserfolg wurde anfangs als eher schwach beurteilt (vgl. die Mittheilungen der betreffenden Jahre). 
In den ersten beiden Vereinsjahren mußte der Versuch, eine permanente Ausstellung (kunst-)gewerblicher Produkte einzurichten, aus finanziellen Gründen fallen gelassen werden.

Ab 1882 konnte dann eine Ausstellung, dank der Eigenleistung des Vereinsmitgliedes Constantin Nicolits, eröffnet werden.

Ab 1886 wurde die Ausstellung vom Verein übernommen, Nicolits hatte noch bis 1888 die Verwaltung der Präsentation inne, danach wurde diese vom Verein allein getragen. ${ }^{197}$

In der Versammlung vom 10. August 1886 wurde ein die permanente Ausstellung betreffendes „Regulativ“ beschlossen, aufgrund dessen „nur gewöhnliche Erzeugnisse tirolischer Provenienz ausgestellt werden und zwar nur von den Erzeugern selbst“"198.

Für die Jahre 1882-84 wurde der Umsatz der permanenten Ausstellung mit 23.788 fl. 45 kr. beziffert, wobei der Verein im gleichen Zeitraum Ausstellungsgebühren und Verkaufsprovisionen in der Höhe von 3.324 fl. 96 kr. eingenommen hätte. Die Besucherzahlen betrugen in diesen Jahren 10.000 bis 12.000 Personen pro Jahr.

Obwohl 1885 über 12.000 Personen die Ausstellung besucht hatten, lehnten der Stadtmagistrat (1885) und der Tiroler Landtag (1887) Subventionsansuchen ab.

Die Stadt Innsbruck gewährte 1887, vorerst für drei Jahre, eine Subvention von $300 \mathrm{fl}$. und ab 1888 konnte der Verein für seine Ausstellung eine Zuwendung der Stadt, des Landes und der Innsbrucker Sparkasse erwirken. ${ }^{199}$

Bereits die ersten Subventionsansuchen und die daraufhin durch die Statthalterei erfolgte Aufforderung an die Handelskammer, ein Gutachten über den Gewerbeverein und seine Ausstellungstätigkeit zu verfassen, nützte die Kammer zur Darstellung der Vereinsziele.

So hieß es in einer 1885 verfertigten Stellungnahme an den Statthalter, daß der Verein, „der nun die Kinderkrankheiten glücklich überwunden [häbe], immer

197 Vgl. die Darlegungen von Johann Deininger anläßlich des „Rückblick auf die 10jährige Thätigkeit des Tiroler Gewerbevereines“ in den Mittheilungen 7. Jhg. Nr. 11/12 (1890), S. 61 ff. Die Eröffnung der ersten permanenten Ausstellung fand am 5.6.1882 in Anwesenheit von Bürgermeister Falk und Statthalter Widmann statt (ebd., S. 62).

198 Mittheilungen 3. Jhg. Nr. 29/30 (1886), S. 105 ff.

199 Vgl. Mittheilungen 2. Jhg. Nr. 12, S. 51 ff. und Nr. 19/20 (1885), S. 2; 4. Jhg. Nr. 35/36 (1887) und 5. Jhg. Nr. 1/2 (1888), S. 3. Das damalige liberale Landtags- und Gewerbevereinsmitglied Carl Payr warf 1886 den Abgeordneten, die sich gegen die Subventionierung wandten, vor, sie würden weder den Verein, dessen Ziele, noch die permanente Ausstellung kennen [s. seine Landtagsrede, abgedruckt in den Mittheilungen 4. Jhg. Nr. 33/34 (1887), S. 113]. 
größeren Aufschwung [nähme] und damit auch seinem Ziel, das Gewerbewesen in Tirol zu heben und zu fördern, unentwegt näher" rücken würde. Zur Einschätzung der permanenten Ausstellung wurde vermerkt:

„Innsbruck, wo Jahr für Jahr Tausende von Fremden ab- und zuströmen, ist für eine solche Ausstellung tirolischen Gewerbefleisses wohl ganz besonders berufen. [...] Die erwähnte Ausstellung hat bereits in verschiedenen Artikeln einen namhaften Absatz erzielt und überdies bedeutende Bestellungen vermittelt“.

Weiters würde es, laut diesem Schreiben, den Mitgliedern ermöglicht, „die aus ihrer Hand hervorgegangenen, durch edle Form, sichere Technik, Zweckmäßigkeit und Preiswürdigkeit ausgezeichneten Arbeiten zur allgemeinen Beurtheilung zu bringen" 200 .

Für die Jahre 1891-93, 1894-96 und 1897-99 gewährte der Tiroler Landtag dem Verein für seine Ausstellungsaktivitäten einen jährlichen Zuschuß von 100 fl. ${ }^{201}$

Somit war der Bestand der permanenten Ausstellung gesichert. Die jährliche „Weihnachtsausstellung“, die mit Prämierungen von ausstellenden Lehrlingen, Gesellen und Meistern verknüpft worden war, wurde im selben Lokal eingerichtet.

In den Innsbrucker Nachrichten findet sich im Dezember 1905, unter dem Titel „Heimischer Gewerbefleiß“, ein Beitrag zur „Weihnachtsausstellung“ des Gewerbevereines.

„Man denke nicht, diese Verkaufshalle sei eigentlich für die Fremden da, welche dort ihre Brandmalereien, Ansichtskarten und anderen Andenkenplunder erwerben; diese Verkaufshalle ist ein Vereinigungspunkt der Erzeugnisse unserer tüchtigen heimischen Gewerbetreibenden, und ermöglicht den Bewohnern der Stadt und den zureisenden Weihnachts-

200 Vgl. die Prot. d. o. Sitz. d. Handels- und Gewerbekammer Innsbruck vom 22.6. 1885, S. 15 ff. Daneben trug die Kammer einen finanziellen Beitrag zur Erhaltung der permanenten Ausstellung. 1888 nahm sie einen Antrag der "Gewerbesection“ (Zl. 1323), dem Tiroler Gewerbeverein für 1889 eine Subvention von 100 fl. zu gewähren, einstimmig an (Prot. d. o. Sitz. d. HGK Innsbruck vom 6.10.1888, S. 189 f.).

201 Vgl. Stenographische Berichte des Tiroler Landtages 8. Sitzung 2. Session VII. Periode vom 10.11.1890, S. 91 u. Beilage 38 (Nr. 12474/47); 15. Sitz. 4. Sess. VII. Per. vom 15.5.1893, S. 167, sowie 10. Sitz. 2. Sess. VIII. Per. vom 23.2.1897, S. 128. 
einkäufern aus Nah und Fern, ihrem Heim eine Zier, ihren Lieben eine Gabe zu erwerben, die tirolischen Arbeitshänden entstammt, und in tirolischem Geist erdacht ist."

Besonders hervorgehoben wurde die „Solidät [sic!] und Ehrlichkeit der Ausführung heimischer Erzeugnisse" ${ }^{\text {"202 }}$.

Eine Ankündigung in den Mittheilungen des Jahres 1888 zeigt, daß die Ausstellungsbetreiber manchen neuen Techniken nicht verschlossen waren. So wurde auf fünf Gruppenbilder des Innsbrucker Fotografen Gratl verwiesen, der „Aufnahmen von Objecten der Weihnachtsausstellung" gemacht hatte, die, wie weiters betont wurde, „als Erinnerungsblätter nur ja zu empfehlen sind“203.

Eine eigene Werbeeinschaltung im Mitteilungsblatt des Vereines versuchte, auf die Ausstellung aufmerksam zu machen.

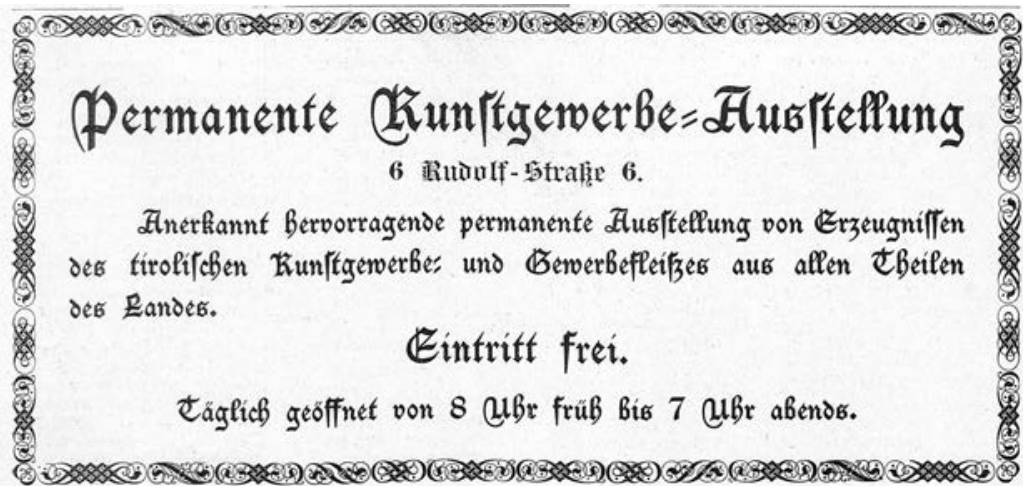

aus Tiroler Gewerbeblatt 12. Jhg. Nr. 3 (1899), S. 7

Auch in anderen Zeitungen finden sich Beiträge zur Ausstellungstätigkeit des Vereines. 1885 berichtete das Innsbrucker Tagblatt von der „Weihnachtsausstellung" und wies auf die veränderte Situation im lokalen Gewerbebereich hin:

„Eine jährlich wiederkehrende Ausstellung von hiesigen Gewerbsleuten: Handwerkern und Kunsthandwerkern zusammen genommen, wäre vor

202 Zitiert im Gewerbeblatt 18. Jhg. Nr. 12 (1905), S. 1.

203 5. Jhg. Nr. 11/12 (1888), S. 68. 
etlichen Jahren noch eine bare Unmöglichkeit gewesen, einfach deshalb, weil auf einer Ausstellung dasjenige, was jedem Menschen völlig bekannt ist und als alltäglich erscheint, weder für den Erzeuger, noch für den Beschauer einen Reiz hat."

Dem Blatt zufolge hätte sich aber in Tirol mittlerweile die Produktion der alltäglichen Güter geändert und nicht zuletzt sei dieser Fortschritt den Bemühungen der Gewerbeschulen und der durchgeführten Ausstellungen zu verdanken.

Der Bericht verdeutlicht die Absicht der ästhetischen Geschmacksbildung mittels der Präsentation diverser Gebrauchsgegenstände; der Autor hob auch, neben der bloßen Aufzählung ausgestellter Erzeugnisse, das, seiner Meinung nach, gelungene Arrangement und die Inszenierung hervor:

„[Ein] kleines altdeutsches Bauernzimmer von Hammerl und Konzert gemeinschaftlich hergestellt mit vollständig gedecktem Tisch [...] ein großer Christbaum, als Dekorationsstück und um der Weihnachtsausstellung ihr eigenes Gepräge zu geben, zeigt natürlichen Gebirgsuntergrund und ist mit frischem ,Schnee' bedeckt, wogegen das unnatürliche Behängen mit Back- und Zuckerwerk vermieden ist. ${ }^{\text {"204 }}$

Somit wirkte diese Art der Ausstellungsinszenierung nicht nur auf die verschiedensten Gewerbetreibenden, sondern auch auf die Betrachter gestalterisch und geschmacksbildend.

Das Gewerbevereinsmitglied Heinrich Fuß, zugleich Lehrer an der Staatsgewerbeschule, kritisierte 1889 die Art der Präsentation der vom Verein durchgeführten Ausstellungen, die allzu sehr einem „Bazar“ gleiche. Stattdessen schlug er vor, im Interesse eines „schöne[n] vornehme[n] Bild[es] der Gesamtleistung“ die Gegenstände öfters zu wechseln und „weniger aber nur vorzügliche Objecte, nicht ganz vollgestopfte, im Wege stehende Vitrinen, keine überfüllten Stellagen“" auszustellen. ${ }^{205}$

204 Der Artikel findet sich in den Mittheilungen 2. Jhg. Nr. 22 (1885) auf S. 84 ff. nachgedruckt. Bei den beiden erwähnten Tischlermeistern handelte es sich um Mitglieder des Gewerbevereines.

205 Mittheilungen 6. Jhg. Nr. 1/2 (1889), S. 7. Obwohl bei dieser Weihnachtsausstellung Gegenstände aus dem Wiener Kunstgewerbemuseum ausgestellt worden waren, wurde die Veranstaltung durch das heimische Publikum anscheinend nur schwach besucht, das, Fuß zufolge, allzuoft die Ausrede: „Man sieht ja immer da dasselbe“ gebraucht hätte. (Ebd.) 
Erst 1907 kam es zu einer Neugestaltung der permanenten Ausstellung. Die Exponate wurden nun auf Schautische konzentriert und nach Sachgruppen präsentiert. Mit dieser Umstellung der Objekte hofften die Betreiber dem Bazarcharakter entgegenzuwirken. ${ }^{206}$

Ziel der „permanenten Ausstellung“" war es, mittels der Präsentation von Gegenständen aus handwerklicher Erzeugung, wie Bauernstuben, Schlosserwaren, sakraler Holzkunst etc. geschmacksbildend zu wirken. Ferner beabsichtigten die Betreiber ein Musterlager anzulegen, das Grundstock für ein, noch zu gründendes, Gewerbemuseum sein sollte.

In seinem Bericht über die von ihm geleistete Arbeit hob Constantin Nicolits, damaliger Leiter dieser Institution, die Hebung und Förderung des (Kunst-)Gewerbes in Tirol sowie weitere Ausstellungsabsichten hervor. Seiner Auffassung nach wäre es Aufgabe der Einrichtung,

„den guten Geschmack zu veredeln und zu verfeinern, kurz, damit im Sinne und als Ersatz eines Gewerbemuseums eine Stätte der Belehrung und Bildung auf artistischem Gebiete zu schaffen und endlich dadurch, daß die exponierten Gegenstände zugleich verkäuflich, den direkten Contakt zwischen Produzenten und Consumenten herzustellen. ${ }^{{ }^{2} 207}$

Auf der Gewerbevereins-Generalversammlung von 1904 berichtete Anton Kofler nicht nur über den Erfolg Tiroler Erzeugnisse auf der Weltausstellung in St. Louis sondern auch über die permanente Ausstellung. Dabei erwähnte er, daß sich solche „Gegenstände, welche mit der heimischen (nationalen) Eigenheit zusammenhängen, [...] beim Verkauf als besonders gangbar" erwiesen hätten. Weiters plädierte er für Filialen der permanenten Ausstellung, eventuell in Verbindung mit Fremdenverkehrsbüros und trug den Plan vor, aus dieser Ausstellung ein „Exportmuseum“ zu errichten. ${ }^{208}$

206 Gewerbeblatt 20. Jhg. Nr. 12 (1907), S. 4; der Beitrag trug den Titel „Unsere Gewerbeausstellung“.

207 Mittheilungen 5. Jhg. Nr. 1/2 (1888), S. 3 f.; Hervorhebung von W.M.! Wie Nicolits feststellte, war die Präsentation im Moment noch defizitär und keine „lukrative, geschäftliche Unternehmung". (Ebd.)

208 Gewerbeblatt 17. Jhg. Nr. 4 (1904), S. 1 ff. 


\subsection{Gewerbemuseen}

Zu Beginn war der Gedanke der Gewerbeförderung noch von den Vorstellungen merkantilistischer Politik des 17. und 18. Jahrhunderts geleitet; sie sollte zentrale Hilfsmaßnahme für Handwerker und gewerbliche Produzenten sein, die in der Phase der frühen Industrialisierung durch sich auflösende Zunftbindungen, der zunehmenden Gewerbefreiheit und des sich verstärkenden Konkurrenzdruckes (auch aus dem Ausland) mit ernsthaften existenziellen Problemen konfrontiert waren. Diese Förderung sollte einerseits durch fortbildenden Spezialunterricht und soziale und wirtschaftliche Sofortmaßnahmen erreicht werden, andererseits durch das Anlegen von Mustersammlungen und Sammlungen einschlägiger technischer Geräte mit angeschlossenen Auskunftsbüros, Fachbibliotheken etc. ${ }^{209}$

In dieser Intention stehend kam es zu Beginn des 19. Jahrhunderts zur Errichtung des „Polytechnikum“ und der „Akademie der bildenden Künste“, die beide die Aufgabe hatten, das Gewerbe, insbesondere das Kunsthandwerk, zu fördern.

1835 hieß es in einer Kundmachung für das „Polytechnische Institut“: Es sei „eine fast ausschließlich der technischen Vervollkommnung der heimischen Industrie gewidmete Einrichtung und auch als Standort für die Ausstellung von gewerblichen Erzeugnissen und technischen Neuerungen gedacht ${ }^{\text {“210. }}$.

Seine Errichtung erfolgte aufgrund eines kaiserlichen Handschreibens von 1807, in der die Errichtung eines eigenen Kabinetts zur Aufstellung sämtlicher inländischer Fabriks- und Manufakturprodukte in Wien angeordnet wurde.

Ab 1818 besaß dieses „Fabriksproduktenkabinett“ eine Sammlung von 20.000 Musterstücken, die von zahlreichen Wiener Fabrikanten und Großhändlern gestiftet worden waren.

Durch die 1840 erfolgte Vereinigung mit dem „technischen Kabinett“ Kaiser Ferdinands gewann das „Fabriksproduktenkabinett“ den Charakter einer permanenten Industrieausstellung.

Eine Verbesserung erfolgte 1850 durch die Schaffung einer „Realakademie“, die nicht nur fertige Produkte präsentierte, sondern fortan als „Vorbereitungskabinett“, zusammen mit der Ausstellung, als zentrale Bildungsanstalt für Handel und Gewerbe fungierte.

209 Mundt 1974, S. 12.

210 Geissler 1949, S. 56; dort weitere Angaben zur Entwicklung der gewerbefördernden Institutionen. 
Grundlage all dieser Bestrebungen war der „Glaube in den veredelnden und erzieherischen Charakter beispielhafter Objekte“, der das Bildungswesen des 19. Jahrhunderts prägte.

In Sammlungen und Ausstellungen, weiters durch die Herausgabe einschlägiger Vorlagehefte, in denen Muster und Vorbilder gesammelt und zur Nachahmung bereitgestellt wurden, offenbarte sich die Intention dieser Bestrebungen:

„Die Handwerker sollten nicht selber komponieren sondern nachahmen." ${ }^{211}$

Im Jahre 1863 kam es in Wien zur Gründung des „Österreichischen Museums für Kunst und Industrie“, und vier Jahre später folgte eine daran angegliederte Kunstgewerbeschule. Ebenfalls in der Reichshauptstadt entstand 1879 das „Technologische Gewerbemuseum", in dem, ein Jahr später, diverse technische Versuchsanstalten eröffnet wurden. Diese wurden zum Vorbild zahlreicher ähnlicher Institutionen in ganz Europa (so 1872 für das Bayerische Gewerbemuseum in Nürnberg, 1883 für das Budapester Technologische Gewerbemuseum, 1885 für das „Central Institute in South Kensington“). ${ }^{212}$

Ziel dieser Einrichtungen war es nicht nur zu sammeln, zu konservieren, sondern als Bildungsinstitution „auf das aktuelle Geschehen von Handwerk und Industrie ein[zu]wirken, bei gestalterischen, technischen und wirtschaftlichen Fragen [zu] helfen, [sie] sollten lehren und forschen "213. Da diese Museen in ihrer Vielseitigkeit und Praxisnähe von anderen musealen Einrichtungen vernachlässigte Gebiete und Bevölkerungsschichten ansprachen, wurden diese Geschmackssammlungen mustergültiger Industrie- und Gewerbeprodukte in Wanderausstellungen durch das Land geschickt.

211 Mundt 1974, S. 13 f.

212 Ebd., S. 15.

213 Ebd., S. 11; Mundt nennt vier Mittel, dieses Ziel zu erreichen: a) die Schaffung von Lehrabteilungen und didaktische Aktionen, b) die Errichtung von Schauabteilungen und -veranstaltungen, c) die Erhaltung von Forschungsabteilungen, wie Labors, Bibliotheken,... und d) Einrichtungen zur direkten Wirtschaftshilfe, wie Auskunftsstellen für technische, wirtschaftliche und künstlerische Fragen (ebd.). 
So bemühte sich die Tiroler Handelskammer recht bald nach der Gründung des „Museums für Kunst- und Industrie“ um die Wanderausstellung dieser Bildungsinstitution, doch erst 1878 gelang es, diese nach Innsbruck ins Ferdinandeum zu bekommen. ${ }^{214}$ Den Mittheilungen des Tiroler Gewerbevereins zufolge war damit

„ein Mittel geboten, die mannigfaltigsten Erzeugnisse des Landes aus alter und neuer Zeit auf kunstgewerblichem Gebiete in der Landeshauptstadt zu vereinigen, als ein vorzügliches Studienmaterial zur leichteren und sicheren Erkenntnis dessen was Nothtut. ${ }^{\text {2215 }}$

Langfristiges Ziel des „Tiroler Gewerbevereins“ war es, ein eigenes Gewerbemuseum in Innsbruck errichten zu können.

Bereits anläßlich des ersten Subventionsansuchens für den Verein und dessen Ausstellung hatte der liberale Abgeordnete Carl Payr in seiner Landtagsrede festgestellt, daß die permanente Ausstellung durch die „Vorführung mustergiltiger Erzeugnisse [...] instruktiv und anregend zugleich" wirke, und diese Ausstellung „schon heute im engeren Rahmen eine Art Gewerbemuseum“, eine „vortreffliche Vorschule [...] für die endliche Errichtung und Angliederung eines im größeren Stile eingerichteten Gewerbemuseums an der hiesigen k.k. Staats-Gewerbeschule“ sei.

Mit dieser Museumserrichtung verband er nicht nur ideelle Zielsetzungen sondern auch praktischen Nutzen, wären doch durch die permanente Ausstellung bereits „neue Industrien geschaffen“ (Schwazer Majolika-Fabrik) und „alte, völlig verloren gegangene Techniken wieder einer besseren Kultivierung" zugeführt worden. $^{216}$

214 Gezeigt wurden vielfältige Gegenstände und Erzeugnisse der textilen Kunst, Email- und Goldschmiedewaren, Waren aus unedlen Metallen wie Bronze und Zinn, Keramik, Glas, Buchbinderei- und Lederarbeiten, Holzschnitzereien u.a., sowie Lehrmittel für den Unterricht im Freihandzeichnen. Schon 1869 war es erstmals zu einer „kleine[n] Ausstellung von Gegenständen der Metalltechnik [gekommen], welche auf Wunsch der dortigen Handels- und Gewerbekammer aus den Sammlungen des, Österreichischen Museums für Kunst und Industrie ausgewählt und nach Innsbruck gesandt wurden [und] erfreute sich zahlreichen Besuches der Fachleute." [Mittheilungen 5. Jhg. Nr. 51 (1869), Beilage S. 62]

215 1. Jhg. Nr. 1 (1884), S. 4; weiter heißt es dort, daß aufgrund der Rückständigkeit der Tiroler Kunstindustrie „nichts mehr einem blind fortschreitenden Werdeprozess überlassen bleiben darf, sondern einiges Handeln nöthig ist in Zweck und zielbewußter Arbeit.“ (ebd.)

216 Mittheilungen 4. Jhg. Nr. 33/34 (1887), S. 113 f.; „Insbesondere für jene Meister [wäre dies] von Bedeutung, welchen die Wohlthat eines fachlichen Unterrichts nicht zu Theil werden konnte“, vermerkte er weiter (ebd.). 
Aber auch in den nächsten Jahren verhinderte die politische Situation im Tiroler Landtag die finanzielle Förderung des Gewerbevereines und damit verbunden eine Museumserrichtung.

In seinem Jahresbericht mußte der damalige Vorstand Johann Deininger zu seinem Leidwesen feststellen, daß die „Majorität des Landtages [...] noch nicht hinreichend über die Zwecke dieser Institution [des TGV; W.M.] und deren bisherige fast sechsjährige ersprießliche Wirksamkeit informiert" wäre und sich deshalb in "Tirol kein Gewerbe-Museum, wie solche in anderen Provinzen schon seit langem mit Unterstützung seitens der maßgebenden Faktoren bestehen" würden, befände. $^{217}$

217 Mittheilungen 4. Jhg. Nr. 35/36 (1887), S. 115; Deiningers Wunsch war eine finanzielle Zuwendung von Landesseite: „Soll deshalb diese Gewerbe-Ausstellung, welche uns in Tirol ein solches Museum ersetzen soll und kann, wirklich nicht die wenigen Mittel für ihre ungeschmälerte Existenz erlangen können?"(ebd.) 


\section{Vom „Tiroler (Handels- und) Gewerbe- museum“ zum „Tiroler Volkskunst- museum"}

Die Entstehungsgeschichte des Museums läßt sich grob in drei zeitliche Abschnitte einteilen:

Die erste Phase reicht vom Aufkommen der ersten Bestrebungen des Tiroler Gewerbevereins zur Museumsgründung bis zur Übernahme und Ausführung dieser Idee durch die Handels- und Gewerbekammer (1888 bis ca. 1900).

Die zweite Phase umfaßt die Versuche der Kammer, die Museumsidee zu verwirklichen. Sie ist gekennzeichnet durch den inhaltlichen Wandel des Museumsprogrammes von einem reinen Handels- und Gewerbemuseum mit der Intention der Gewerbeförderung zu einer in erster Linie nationale Kunst- und Kulturobjekte umfassenden Sammlung, die als Tiroler Volks- und Nationalkunst angesehen wurde. Der Plan, ein Volkskundemuseum zu schaffen, das alle Bereiche der Tiroler Volkskultur enthalten sollte (incl. translozierter Gebäude in einem angeschlossenen Freilichtmuseum), wurde schon um 1910 bzw. 1912 aufgrund finanzieller Überlegungen fallen gelassen. Der Erste Weltkrieg bildete für diese Phase eine Zäsur.

Der dritte Abschnitt erstreckt sich von der Wiederaufnahme des Museumsgedankens (um 1917 bzw. 1919) bis zur Übernahme des Museums - als „Tiroler Volkskunstmuseum" - 1926 durch das Land und dessen offizieller Eröffnung im Jahre 1929.

Damit war die eigentliche Entstehungsgeschichte abgeschlossen. Die räumliche und inhaltliche Ausgestaltung der Sammlungen blieb bis in die späten 60er Jahre unseres Jahrhunderts im Großen und Ganzen so bestehen, wie sie sich seit der Eröffnung dargeboten hatte.

Die Einkäufe und Neuerwerbungen waren seit der Museumsöffnung nicht mehr von dem Ausmaß wie zu Beginn des Jahrhunderts; in den Jahren 1931 und 1956 kam es jedoch zu einem Objektaustausch zwischen dem Volkskunstmuseum und dem Ferdinandeum (überwiegend gingen Gegenstände aus dem Gebiet der religiösen Volkskunde sowie Schnitzereien und Textilien in die Sammlung des Volkskunstmuseums ein, das Tiroler Landesmuseum erhielt dafür vor allem gotische Exponate). 
Der Großteil der Arbeit im Museum selbst wurde für die innere Gestaltung und Bearbeitung der Objekte aufgewendet.

Bis Ende der 60er Jahre konnten beinahe alle Gegenstände registriert und inventarisiert werden; 1967 war die Neuaufstellung, die Anlegung einer Studiensammlung und die Errichtung angemessener Depots weitgehend abgeschlossen.

Die inhaltliche Konzeption, soweit überhaupt von einer solchen gesprochen werden kann, wurde aber unverändert belassen: Das Museum blieb ein Volkskunstmuseum, trotz der Unschärfe dieses Begriffes.

Diese Arbeit beschäftigt sich vorwiegend mit der Entstehungsgeschichte des Museums. Auf die Weiterentwicklung des Museums ab den 30er Jahren wird nur in geraffter, chronikartiger Form eingegangen.

Dies aus mehreren Gründen:

- einerseits hat sich in den darauffolgenden Jahren an der inhaltlichen Konzeption des Museums nicht mehr viel gewandelt; wohl wurden Bereiche ausgebaut oder leicht verändert, das Grundkonzept eines Museums der Tiroler Volkskunst wurde aber belassen;

- andererseits hatten die meisten Museumsvorkommnisse während der nationalsozialistischen Herrschaft in Österreich mit der eigentlichen Museumsarbeit nicht viel zu tun und hingen rein räumlich und personell mit diesem zusammen. So war die damalige Museumsdirektorin, die ehemalige Museumssekretärin Gertrud Pesendorfer, gleichzeitig Leiterin der „Mittelstelle Deutsche Tracht", die im Museum untergebracht war und für die zahlreiche Malerinnen, Zeichnerinnen und Schneiderinnen arbeiteten.

Eine eingehendere Befassung mit diesen Vorgängen hätte aber nicht nur den Umfang dieser Diplomarbeit gesprengt und wäre in diesem Rahmen kaum zu leisten gewesen, sondern erwies sich auch wegen der gegebenen Quellenlage als kaum durchführbar, da sich aus dieser Zeit weder über die eigentlichen Museumsvorgänge noch über die Reichstrachtenstelle und die Schulungstätigkeit der NS-Frauenschaft, die im Museumsgebäude untergebracht war, schriftliche Aufzeichnungen im Museum finden. ${ }^{218}$

218 Leider erwies sich die rigid gehandhabte Datensperre der Tiroler Landesregierung im Tiroler Landesarchiv, die 50 Jahre beträgt und für eine Akteneinsicht in den Zeitraum 1938 bis 1945 ein Sonderansuchen an die Landesregierung verlangt, als hinderlich. So war es mir nicht ohne weiteres möglich, übertragene Akten aus den 20er und 30er Jahren, die sich in Aktenbeständen des Jahres 1938 befinden, einsehen zu dürfen; ein dahingehendes Ansuchen an die Tiroler Landesregierung, gestellt im Frühjahr 1988, blieb lange Zeit unbeantwortet! Für eine genauere Behandlung der Bedeutung und der Wirkung dieser „Mittelstelle Deutsche Tracht“ 
Dieser Bereich wäre - zusammen mit anderen Aktivitäten der Reichstrachtenstelle und des Amtes Rosenberg - eigens zu erforschen und harrt noch einer Bearbeitung.

\subsection{Frühe Bestrebungen zur Museumsgründung}

Auf der Monatsversammlung am 13. April 1888 hielt das Gewerbevereinsmitglied Leopold Lindner einen Vortrag mit dem Titel: „Werth und Nutzen eines tirolischen Gewerbemuseums“. Er erklärte, daß der Verein vom Ferdinandeum aus dem Nachlaß des Herrn Hofrates Ritter von Wieser Objekte zur Aufstellung erhalten habe.

Weiters stellte er den Antrag auf Errichtung eines Gewerbemuseums. Dies wurde einstimmig angenommen und in einer Ergebnisadresse dem Statthalter gesandt.

Lindners Vorstellungen nach hätte das 40. Regierungsjubiläum des Kaisers feierlicher Anlaß der Erklärung der Museumserrichtung sein können.

Bereits in der nächsten Versammlung konstituierte sich ein vorbereitendes Komitee, in das u.a. Johann Deininger, Dr. Anton Kofler, Anton von Schumacher, Bürgermeister Dr. Heinrich Falk, Karl Adam, der Direktor der Glasmalereianstalt

war ebenfalls kein einschlägiges Material zu bekommen. Wie überhaupt die Organisation der „Mittelstellen“ noch wenig untersucht ist (neben der für die Deutsche Tracht bestanden noch weitere „Mittelstellen“, z.B. für den Deutschen Bauernhof, die Spielforschung oder für Fest- und Feiergestaltung). Organisatorisch gehörten sie zur „Arbeitsgemeinschaft für deutsche Volkskunde“, welche zum Jahreswechsel 1936/37 im „Amt Rosenberg“ gegründet worden war. $\mathrm{Ob}$ sie aber dort als eigene Referate bestanden oder frei assoziierte Einrichtungen waren, ist, Lutz 1983, S. 164 f. zufolge, noch nicht endgültig geklärt. Nach Wolfgang Emmerich war diese „Arbeitsgemeinschaft", die unter Leitung von Matthes Ziegler stand, in den Unterabteilungen Wissenschaft, Schrifttum, Schulung und Feiergestaltung sowie in Gauarbeitsgemeinschaften tätig und zeichnete sich vor allem durch eine „propagandistische und auf praktische Verwertbarkeit volkskundlichen Materials im Sinne eines Blut- und Bodenfolklorismus drängende Tendenz“ aus (1971, S. 114). A. Lener gibt in ihrer Dissertation an, daß die „Mittelstelle“ eine Unterorganisation der Abteilung „Volkstum-Brauchtum im Amt Feierabend der NS-Gemeinschaft ,Kraft durch Freude““ (deren Leiter Otto Schmidt war) gewesen sei (1983, S. 122 ff.), ohne aber eine nähere Quellenangabe zu dieser Feststellung zu machen (einzige Quelle scheinen ihr zwei Gewährspersonen aus dieser Zeit gewesen zu sein). Weiters gibt sie an, daß Pesendorfer eigentlich einen Ruf nach Berlin, als Leiterin der „Mittelstelle“, erhalten, diesen aber aus familiären Gründen (sie war mit einem Innsbrucker Rechtsanwalt verheiratet) abgelehnt hätte. Daraufhin wäre dann in Innbruck eine Außenstelle eingerichtet worden, da man, Lener zufolge, auf ihre Mitarbeit nicht hätte verzichten wollen! (Ebd., S. 124 f.) 
Albert Neuhauser sowie der Ferdinandeums-Direktor Dr. Franz von Wieser gewählt wurden. ${ }^{219}$

Zugleich wurde mit der Beschaffung von ersten Ausstellungsgegenständen begonnen, und in einer Vereinsmitteilung zur „Gründung des Kunst- und Gewerbemuseums" hieß es als Spendenaufruf:

„[Es] wäre nur höchst wünschenswerth, wenn die Industriellen des ganzen Landes je ein kleines Musterstück ihrer Erzeugung zur Deponierung gelangen ließen, damit die Vielseitigkeit der tirolischen Industrie beim Beginne und Aufstellen dieses Gewerbemuseums sofort zu würdiger Geltung komme. ${ }^{\text {“220 }}$

Als nächstes versuchte der Verein über öffentliche Propaganda, mittels seiner guten Kontakte zur Kammer, zu diversen politischen Vertretern und zur liberalen Presse, die Idee der Museumserrichtung allgemein bekannt und akzeptiert zu machen.

In der am 15. November 1889 abgehaltenen Monatsversammlung des Tiroler Gewerbevereines hielt Dir. Deininger einen eigenen Vortrag zur Idee der Gründung eines Innsbrucker Gewerbemuseums.

Deininger wies auf die Bedeutung der permanenten Ausstellung für das „heimische Kunstgewerbe" hin und ging dann auf die eigentlichen Beweggründe einer Museumserrichtung ein.

„Fachliche Belehrung und Anregung“, die beide wichtige Faktoren für die „Hebung der einheitlichen Gewerbe" seien, würden in einer bloßen Verkaufsausstellung nicht genügend zur Geltung kommen.

Daher sei es einerseits notwendig, „musterhafte Erzeugnisse [...] in Originalen und guten Reproduktionen, Abbildungen..." auszustellen, andererseits aber auch „mannigfache Rohprodukte und Werkzeuge“ zur Ansicht und Aufstellung zu bringen. Die in einer "technologischen Sammlung“ dargebotenen „Hilfsmittel“ würden zusammen mit dem „Studienmateriale“, nach Deininger, „der Inbegriff eines Gewerbemuseums" sein.

219 Vgl. Mittheilungen 5. Jhg. Nr. 3/4 (1888); der anläßlich der Museumsgründung von Leopold Lindner gehaltene Vortrag findet sich leider nicht in den Mittheilungen abgedruckt.

220 Ebd. Nr. 5/6 (1888), S. 33. 
Eine weitere Aufgabe des zukünftigen Museums, neben der Präsentation von Anschauungsmaterial, wäre die „Abhaltung belehrender Vorträge auf dem Gebiete der Kunst und Technik“, um so zur Vermittlung des Verständnisses der neuartigen Maschinen und Objekte beizutragen. Durch die Anlegung einer guten Bibliothek sollten diese Bestrebungen noch ergänzt werden. ${ }^{221}$

Deiningers Ansichten zum Gewerbemuseum und seine Argumentation zur Errichtung desselben befanden sich damit noch weit in der Tradition der Gewerbemuseumsbewegung. ${ }^{222}$

Seinen Vorstellungen nach war es mit der Anlegung einer rein gelehrigen Kunstsammlung nicht getan, das Museum sollte der Praxis dienen und daher vor allem das „Charakteristische aus der Kunsttechnik“ in sich vereinigen.

Das Museum müsse daher vor allem „instructiv“ wirken, seine gesammelten Objekte - die durchaus auch Leihgaben sein könnten - gewissenhaft auswählen, didaktisch anordnen, um, wie er hervorhob, diese „exponierten Gegenstände in möglichster Ausdehnung dem Studium dienstbar“ zu machen und dadurch „Anschauungsunterricht" zu erteilen. ${ }^{223}$

In seinen Ausführungen verkannte Deininger aber nicht den „eminent patriotischen Zweck" eines solchen Museums, das noch zu schaffen wäre und das vor allem durch die Mithilfe der Bevölkerung Tirols gefördert werden könnte, da das Land „noch immer reich an kunstgewerblichen Musterobjecten alter Zeit" sei.

Er betonte auch, daß vor allem die Stadt Innsbruck, durch das damit verbundene „Aufblühen der heimischen Gewerbe“ und die „Hebung des Fremdenverkehrs“, vom Museum profitieren würde und erhoffte sich daher - von der „hohen Regierung“, dem Land sowie von der Stadt Innsbruck - Subventionen für dessen Errichtung.

Die Befürchtungen, daß dem bereits bestehenden Museum Ferdinandeum dadurch eine Konkurrenz erwachsen würde, teilte er nicht, denn dieses sei ein „his-

221 Ebd., 6. Jhg. Nr. 11/12 (1889), S. 70.

222 Konrad Köstlin zufolge stellen diese Gewerbesammlungen „isolierte Objekte aus [...], um sie als Mustersammlungen einem desorientierten Handwerk als Vorbild anzubieten." Doch seiner Ansicht nach geht es dabei um mehr: „Die ,Mythe Antiquität' mischte mit: anschauliche Qualität, handwerkliche Arbeit, nichtentfremdete Arbeit, gemütliches Holz, Wärme, Stimmungen, solide, wohnlich, materialgerecht, Echtheit, [...]“. (1982b, S. 54 f.)

223 Mittheilungen 6. Jhg. Nr. 11/12 (1889), S. 71. Seine Ansichten sind vor allem von den theoretischen Überlegungen Gottfried Sempers, des geistigen Vaters des Londoner South-KensingtonMuseums, beeinflußt. 
torisches Landesmuseum" und damit von den Interessen eines Gewerbemuseums grundverschieden.

Die im Besitz des Ferdinandeums befindlichen „Reproduktionen kunstgewerblicher Objekte“, welche dort aus Platzgründen nicht aufgestellt werden können, würden, Deiningers Worten zufolge, ein „schätzbares Material“ für das Gewerbemuseum bilden, und der Direktor des Landesmuseums Dr. von Wieser hätte schon einen Teil dieser Sammlung dem Gewerbeverein für die Museumsgründung zur Verfügung gestellt.

Die einzig große ungelöste Frage sei, so der Vorstand abschließend, die Beschaffung geeigneter Räumlichkeiten, um das Museum errichten zu können. ${ }^{24}$

In diesen Ausführungen Deiningers finden sich alle Fragen und Probleme angesprochen, die die Entwicklungsgeschichte dieses Museums in den nächsten Jahren, ja Jahrzehnten, begleiten sollten:

- die Frage der Museumsidentität (Gewerbe- oder Kunstgewerbemuseum, der eventuelle nationale Charakter dieser Institution) und damit verbunden, die schon früh erfolgte Einbeziehung des Fremdenverkehrs;

- die lange Zeit ungelöste Finanzierungsfrage (außer einigen jährlichen Subventionen von seiten der öffentlichen Hand waren der Gewerbeverein und die Handelskammer Hauptfinanziers);

- die Standortfrage und die Suche nach geeigneten Räumlichkeiten

- und damit im Zusammenhang die Frage der Abgrenzung/Zusammenarbeit mit dem Museum Ferdinandeum.

In dieser Monatsversammlung wurde auch über die ersten Aktivitäten des neugegründeten, vorbereitenden Komitees berichtet.

Dieses hatte Deininger, zusammen mit Anton Kofler, beauftragt, ein Programm für die Museumserrichtung zu entwerfen. Im Komitee war man zur Überzeugung gekommen, daß der „Tiroler Gewerbeverein [...] Eigenthümer, Erhalter und Verwalter des Museums sein müsse“. Daneben wurden erste Kontakte mit dem Ferdinandeum aufgenommen, um „technische und gewerbliche Gegenstände" für das neue Gewerbemuseum zu erhalten. In der Standortfrage verhandelte

224 Ebd., S. 72; Deininger zog in seinem Referat eine eventuelle Museumszusammenlegung bei gleichzeitiger inhaltlicher Kompetenzenteilung mit dem Ferdinandeum in Erwägung, verwarf dies aber wieder, da er die Schwierigkeiten eines solchen Vorhabens als zu groß erachtete! 
der Gewerbeverein mit der Stadt und hoffte die unentgeltliche Überlassung eines freiwerdenden, ehemaligen Schulgebäudes zu erlangen. ${ }^{225}$

\subsubsection{Statuten für ein „tirolisches Gewerbemuseum“}

Wichtigster Verhandlungspunkt der Versammlung war aber die Genehmigung der Museumsstatuten, die dann ein Jahr später in den Mittheilungen als „Programm für ein tirolisches Gewerbemuseum in Innsbruck" veröffentlicht wurden.

Aus diesen Statuten geht als Vereinszweck „die Hebung der Concurrenzfähigkeit der technischen und Kunstgewerbe in Tirol“ hervor.

Mittel für diesen Zweck sollten sein: „Vorführung mustergiltiger gewerblicher Erzeugnisse kirchlicher und profaner Richtung aus alter und neuer Zeit, von Apparaturen, Werkzeugen, Modellen und Zeichnungen, Mustern von Rohprodukten mit Angabe der Bezugsquellen, Anlage einer gewerblichen Fachbibliothek“.

Hervorgehoben wurde der „innige Contact mit der k. k. Staatsgewerbeschule in Innsbruck“.

Für die Museumsverwaltung sah das Statut die Einsetzung eines „Curatorium[s] [...], welchem die gesammte artistische und administrative Leitung und Vertretung des Instituts oblieg[en]“ soll, vor. Bestehen sollte dieses Kuratorium aus drei Vertretern des „Tiroler Gewerbevereins“, einem Vertreter der Staatsgewerbeschule und aus je einem Vertreter jener „Gemeinwesen, welche zur Erhaltung des Museums beitragen"; die Funktionsdauer des Kuratoriums sollte drei Jahre betragen.

Weiters war vorgesehen, daß dieses Kuratorium die „Custoden“ und Museumsdiener zu bestellen und alle „rechtlichen und ökonomisch-administrativen Fragen“ zu erledigen hätte. ${ }^{226}$

Das Vereinsstatut unterschied drei Arten der Mitgliedschaft:

- Stifter, die einen Gründungsbeitrag von mindestens 100 fl. zu erlegen oder über vier Jahre einen Jahresbeitrag von $25 \mathrm{fl}$. zu leisten hatten;

225 Nach Anton Kofler erhielt der Gewerbeverein von der Stadt „in der städtischen Turnhalle in der Fallmerayerstraße mehrere Zimmer zur Verfügung" gestellt. Als die Räumlichkeiten zu klein wurden, übersiedelte die Sammlung in die „alte Realschule am Bozner Platz“ (1929, S. 1).

226 Mittheilungen 6. Jhg. Nr. 11/12 (1889), S. 72 u. 7. Jhg. Nr. 1/2 (1890), S. 9 (Statutenabdruck); über die Versammlung vom 15.11.1889, die im Beisein von Gewerbeinspektor Ernst Rziha stattfand und wobei der Gründungsbeschluß gefaßt worden war, berichtete der Bote für Tirol und Vorarlberg 75. Jhg. Nr. 265 v. 18.11.1889, S. 2456. 
- ordentliche Mitglieder, worunter sämtliche Mitglieder des „Tiroler Gewerbevereins" verstanden wurden, sowie

- die außerordentliche Mitgliedschaft durch die Leistung eines Jahresbeitrages von $3 \mathrm{fl}$.

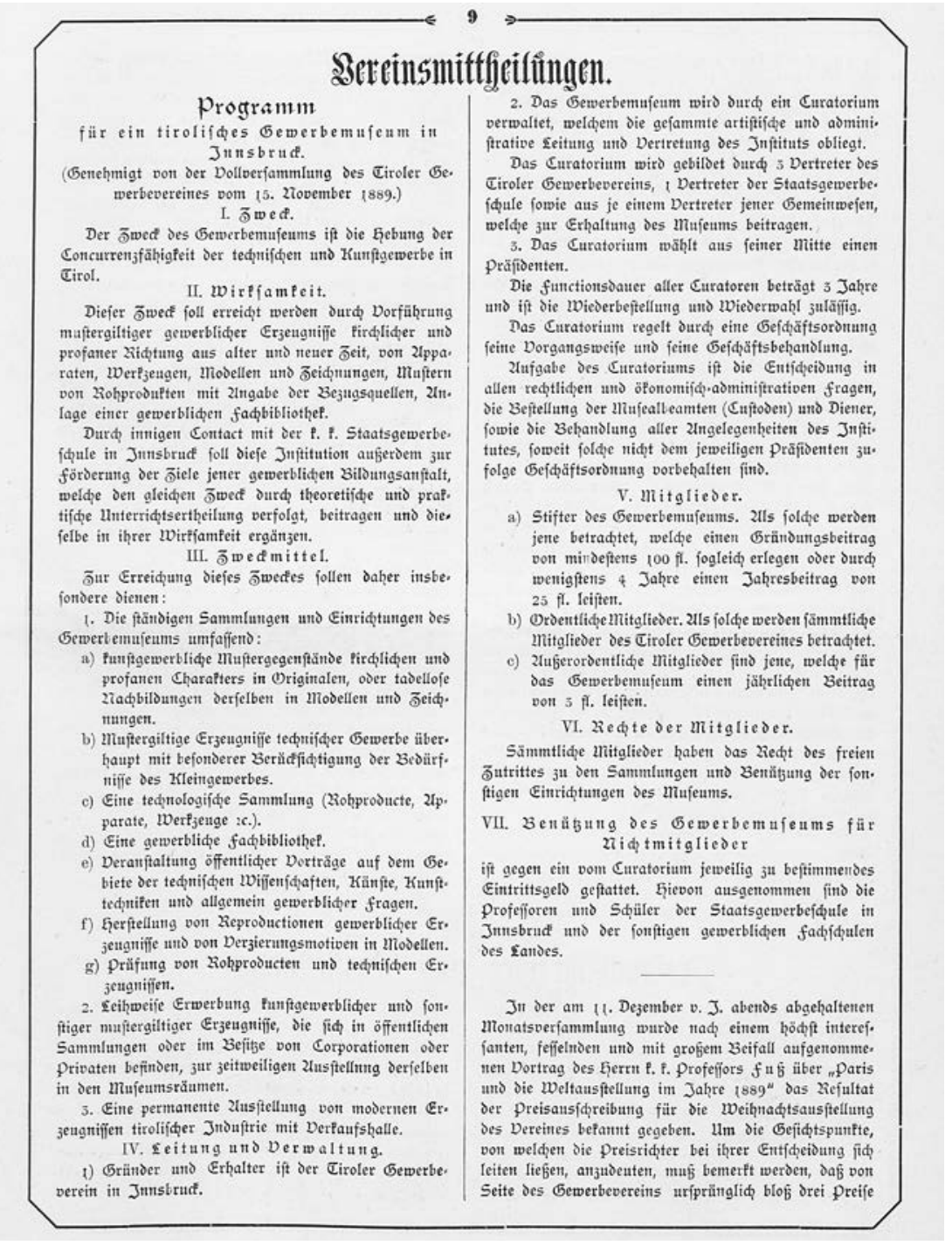

aus Mittheilungen 7. Jhg. Nr. 1/2 (1890), S. 9 
Als Protektor des neuen Museums konnte, wie für den Verein, Erzherzog Heinrich gewonnen werden. ${ }^{227}$

Damit wurden, zumindest vereinsintern, alle Voraussetzungen für einen raschen Fortschritt in der baldigen Museumseröffnung geschaffen.

In den letzten Vereinsmitteilungen des Jahres 1891 konnte die Redaktion die ersten Stifter des neuen Museums veröffentlichen, von denen manche, neben dem obligaten Geldbetrag, auch Sachspenden beigegeben hatten.

Als bekannteste Männer werden Anton von Schumacher (Handels- und Gewerbekammer-Präsident), die beiden Kammer-Vizepräsidenten Josef Wopfner und Franz Baur, der Innsbrucker Vizebürgermeister Wilhelm Greil, der Kaufmann und Innsbrucker Gemeinderat Karl Kapferer, der Seifenfabrikant Carl Alois Walde sowie die „Tiroler Glasmalerei und Kathedral-Glashütte Neuhauser, Dr. Jehle \& Co.“, ferner der Besitzer des Schlosses Au bei Brixlegg, Franz von Lipperheide, angegeben. Die Bregenzer Textilfabrik „Wilhelm Benger u. Söhne“ stellte dem Museumsprojekt einen Schaukasten mit einer Sammlung von Mustern mit „Ramie“ in verschiedenen Verarbeitungsstadien zur Verfügung. ${ }^{228}$

Allerdings schienen in den folgenden drei Jahren die Aktivitäten der Museumsbegründer kaum weitergekommen zu sein, wobei der Grund dafür in der schon Ende der 1880er Jahre begonnenen Vorbereitung zur Tiroler Landesausstellung lag.

Bereits auf einer 1887 stattgefundenen Gewerbevereinsversammlung hatten sich die Mitglieder in einer Resolution zur Abhaltung dieser Veranstaltung bekannt und der Handels- und Gewerbekammer für ihre dahingehenden Bemühungen gedankt.

Gleichzeitig sprachen sie die „Hoffnung aus, daß diese Ausstellung als eine allgemeine gewerbliche Landesausstellung womöglich im Jahre 1890 in Innsbruck

227 Anläßlich der Übernahme dieses Protektorates empfing der Erzherzog die Gewerbevereinsmitglieder J. Deininger, A. Kofler und A. Norz in Audienz. (Bote für Tirol und Vorarlberg 77. Jhg. Nr. 100 v. 4.5.1891, S. 852)

228 Mittheilungen 8.Jhg. Nr. 11/12 (1891), S. 61; in dieser Nummer findet sich auch eineAbhandlung der "Geschichte der Seiden- und Ramie-Industrie“. („Ramie“ bezeichnet einen Rohstoff, der aus der Ramiepflanze, dem Chinagras verwandt, gewonnen wird und dessen Fasern für Seilerwaren Verwendung fanden.) Schloßbesitzer F. Lipperheide, Mitglied des Gewerbevereines, hatte in einer Vereinsversammlung des Jahres 1889 eine engere Zusammenarbeit des Vereines mit dem Fremdenverkehrsverein beantragt, die auch beschlossen wurde. Erste Frucht davon war die Ausstellung „einfacher Musterausstattungen von Fremdenzimmern in Landgasthöfen“, die im Lokal des Gewerbevereines eröffnet werden konnte [vgl. Mittheilungen 6. Jhg. Nr. 7/8 (1889), S. 45]. 
stattfinden und rechtzeitig die nöthigen Vorbereitungen seitens hiefür berufenen Factoren ins Werk gesetzt" werde. 229

Auf der Generalversammlung des Gewerbevereines von 1894 mußte der Vereinsvorstand Dr. Kofler eingestehen, daß der „Verein im letzten Jahre nicht so ganz seine Pflicht gethan habe“, denn „der Ausschuß [...] war mit Ausstellungsarbeiten [zur Tiroler Landesausstellung; W.M.] überhäuft", sodaß er sich nicht mit dem früheren Eifer den Vereinsgeschäften hätte widmen können. ${ }^{230}$

\subsection{Neuerlicher Anlauf zur Museumserrichtung}

Ab 1894 wurden dann wieder verstärkt Aktivitäten zur Museumsgründung aufgenommen.

Wiederum bot dem Vereinsmitglied Leopold Lindner ein kaiserliches Regierungsjubiläum (das 50jährige) Anlaß, sich für das Gewerbemuseum einzusetzen. Konkreter Auslöser war die ablehnende Haltung des Gewerbevereins zum Wiener Vorschlag einer zentralen Reichsausstellung für Gewerbe und Kunstgewerbe. Die Tiroler bevorzugten in den einzelnen Kronländern stattfindende, unabhängige Veranstaltungen und schlugen als ihren Beitrag die Wiederbelebung der Museumserrichtungsidee vor.

Auf Antrag Leopold Lindners wurde dieser Vorschlag der Handels- und Gewerbekammer sowie dem Innsbrucker Gemeinderat übermittelt. ${ }^{231}$

Bei diesem zweiten Anlauf wurde eine engere Zusammenarbeit mit den Kammerorganen gesucht.

Am 11. Februar 1894 hielt Leopold Lindner auf einer "Gewerbegenossenschaftsverbands-Versammlung“ ein Referat über die „Errichtung eines tirolischen Gewerbe- und Kunstgewerbemuseums in Innsbruck“, worin er „kunstgewerbliche, technologische, naturhistorische usw. Sammlungen " untergebracht sehen wollte.

229 Ebd. 5. Jhg. Nr. 1/2 (1888), S. 3 f.; näheres zur - dann schlußendlich 1893 durchgeführten - Tiroler Landesausstellung im 4. Kapitel! In seinem Aufsatz „Zur Geschichte des Volkskunstmuseums" schreibt Anton Kofler, daß einige Aussteller der Landesausstellung mustergültige Gegenstände für die Sammlung des zu errichtenden Museums zur Verfügung gestellt hätten; nähere Angaben über die Art der Objekte finden sich jedoch nicht (vgl. Kofler 1929, S. 1).

230 Ebd. 10. Jhg. Nr. 1/2 (1894), S. 21; der Vorstand bat zu entschuldigen, daß die letzte Generalversammlung schon zwei Jahre her sei! (ebd.)

231 Ebd. Nr. 9-12 (1894), S. 67; sowie Bote für Tirol und Vorarlberg 80. Jhg. Nr. 263 v. 16.11.1894, S. 2102. 
Nach wie vor stand die Gewerbeförderung im Mittelpunkt: Lindner sprach davon, daß sich mit der Einrichtung eines solchen Museums das „Gros des Publikums an reelle, solide Meisterarbeit gewöhnen" und somit Abstand von den Massenerzeugnissen der Industrie, dem „Fabrikspovel“, gewinnen könnte. Weiters hob er den nationalen Wert dieser Institution hervor, in welcher vornehmlich „Tirolensien“ zur Ausstellung gelangen sollten. ${ }^{232}$

Damit verstärkte sich, ähnlich der Entwicklung des Gewerbevereines, auch in der Museumsfrage die Hinwendung zu einer eher kunstgewerblichen Ausrichtung, die auch aus dem neuen - inoffiziellen - Namen des Museums abzulesen war.

Als der Tiroler Gewerbeverein 1899 an den Ankauf eines eigenen Gebäudes zwecks Unterbringung der permanenten Ausstellung schritt, wurde die Idee der Museumserrichtung neuerlich aktiviert. ${ }^{233}$

Auf der Generalversammlung des Jahres 1899 hielt Anton Kofler ein Referat über das Gewerbemuseum, in dem er betonte, daß das Vorhaben nun schon seit zehn Jahren geplant sei und sich mit dem Einzug des Gewerbevereines in das neuerworbene Gebäude in der Meinhardstraße die Raumfrage vorerst gelöst hätte. Er forderte die Vereinsmitglieder auf, den vor zehn Jahren gefaßten Entschluß der Museumserrichtung in die Tat umzusetzen und stellte den einstimmig angenommenen Antrag:

\begin{abstract}
„Der Tiroler Gewerbeverein beschließt heute den 20. des Monats [Januar; W.M.] aus Anlaß des Regierungsjubiläums Seiner Majestät des Kaisers das vor zehn Jahren beschlossene Gewerbe-Museum einzurichten und zu diesem Zwecke die in der Meinhardstraße gelegene Realität Nr. 14 um den Betrag von 60.000 Gulden bzw. 58.000 Gulden anzukaufen. ${ }^{234}$
\end{abstract}

232 Tiroler Gewerbezeitung 3. Jhg. Nr. 5 (1894), S. 20; seit September 1892 und unter maßgeblicher Mithilfe von Dr. Hans Semper erschien dieses, der Handelskammer nahestehende, Blatt einige Jahre lang! Bereits 1893 hatte die Zeitung über die Idee einer Gewerbemuseumsgründung in Tirol berichtet und berief sich dabei vor allem auf die Argumente Deiningers. [ebd. 2. Jhg. Nr. 23 (1893), S. 94] Auch die Innsbrucker Nachrichten berichteten von der neuerlich aufgenommenen „Action“ einer Museumsgründung (40. Jhg. Nr. 271 v. 25.11.1893; S. 2 f.).

233 Der Verein hatte das alte katholische Vereinshaus in der Meinhardstraße angekauft. [Vgl. Gewerbe-Blatt 12. Jhg. Nr. 1 (1899) u. Bote für Tirol und Vorarlberg 84. Jhg. Nr. 284 v. 14.12.1898, S. 2384.]

234 Zuvor waren vom Verein u.a. Gebäude in der Maria-Theresien-Straße (Seewaldsches Haus) und in der ehemaligen Karlstraße (heute Wilhelm-Greil-Straße) ins Auge gefaßt worden [vgl. Gewerbeblatt 12. Jhg. Nr. 1 (1899), S. 1 ff.]. Am 31.1.1899 wurde der Kaufvertrag für das Haus in der Meinhardstraße unterschrieben und gleichzeitig beschlossen, daß die Realität bis in den 
In seinem Referat betonte Kofler die Wichtigkeit einer eigenen technologischen Abteilung innerhalb des Gewerbemuseums - ähnlich dem technologischen Gewerbemuseum in Wien - und daher wäre in die Museumsplanung auch ein „Kleingewerbesaal mit entsprechenden Maschinen, Behelfen und Einrichtungen für die Provinzen Tirol, Salzburg, Vorarlberg mit Sitz in Innsbruck“, einzuschließen.

Die Gesamtkosten für die Adaptierung bezifferte er mit 88.000 Gulden, wobei die Handels- und Gewerbekammer bereits 3.000 fl. für die Museumserrichtung gespendet hätte.

Durch den wieder hervorgehoben gewerbefördernden Charakter des Museums, schien die Verwirklichung nun möglich geworden zu sein. ${ }^{235}$

Franz Thurner, Redakteur des Gewerbeblattes, startete in der Zeitschrift einen neuerlichen Anlauf, indem er im Artikel „Ein Tiroler Gewerbemuseum“ auf die schon mehr als zehn Jahre alten Bestrebungen des Vereines hinwies.

In erster Linie waren für ihn gewerbepolitische Überlegungen Anlaß zur Errichtung, müsse es doch, seinen Worten zufolge, Ziel sein, ein „monumentales Werk zum Nutzen und Frommen des tirolischen Gewerbestandes zu schaffen“. Weiters bemerkte er, daß besonders das Handwerk „bedroht“, „verzagt“ und deshalb auch „kleinlaut“ geworden sei und bedauerte: „Sterben will es nicht, blühen läßt man es nicht!“ Eine Lösung dieser Krise des Gewerbestandes sah er einerseits im „Schutz vom Staat gegen [die] übermächtige kapitalkräftige Konkurrenz“, andererseits in Belehrungs- und Anschauungsmöglichkeiten. Seiner Meinung nach war eine solche Möglichkeit die Errichtung eines „Gewerbemuseums“, wobei er festhielt, daß sich dieser Name als „praktischer und entsprechender erwiesen“ hätte als die Bezeichnung „Kunst-Gewerbe-Museum“. Abschließend vermerkte er, daß die 10.000 fl. Spende von seiten der Innsbrucker Sparkasse ein erster Schritt zur Verwirklichung der Museumserrichtung wäre. ${ }^{236}$

Sommer umzubauen und um einen Stock zu erhöhen wäre, sodaß das Museum bis November fertig sein könnte. [Ebd., sowie Nr. 2 (1899), S. 6.]

235 Gewerbeblatt 12. Jhg. Nr. 1 (1899), S. 1 ff.; Johann Deininger, Ehrenmitglied des Vereines seit 1888, wandte zwar ein, „er sei kein Freund der Maschinen, doch sei deren Werth für so manche Zweige des Gewerbes von Bedeutung und [es] könnte durch das technologische Gewerbe-Museum das Kunstgewerbe und Gewerbe große Förderung erfahren“ - doch die Vereinsmitglieder Bernhard Zösmayr, Professor Heinrich Fuß, Hans Munding, Johann Georg Schwarzenbrunner äußerten sich positiv zum neuen Plan, einzig Hans Hörtnagl hatte seine Bedenken, wegen der großen Geldmenge, die aufgebracht werden müßte! (ebd.)

236 Ebd.Nr. 4 (1899), S.3f.; Thurner veröffentlichte auch die Satzungen des neuen „Nordböhmischen Gewerbemuseums", die sich mit den alten Statuten des hiesigen Museumsgründungsversuches deckten. 
Natürlich versuchte der Gewerbeverein bei den verschiedensten Stellen Subventionen für das zu errichtende Museum zu bekommen.

Die Stadt Innsbruck versprach, jährlich 1.000 fl. für den Bau zu spenden, die Sparkasse gab, wie bereits erwähnt, 10.000 fl. als Starthilfe. Auch die Handelsund Gewerbekammer trug mit $3.000 \mathrm{fl}$. zum Gedeihen bei; ebenso wollte das Handelsministerium, wie in einer Kammersitzung bekannt gegeben worden war, jährlich $3.000 \mathrm{fl}$. für die Museumserhaltung aufwenden. ${ }^{237}$

Einzig der Tiroler Landtag blieb der Gewerbemuseumsidee noch verschlossen und hatte ein Subventionsansuchen vorerst zurückgestellt und den Landesausschuß beauftragt, „seitens anderer Factoren Erhebungen zu pflegen und hierüber dem nächsten Landtage Bericht zu erstatten“.

Daraufhin wurde der antragstellende Gewerbeverein aufgefordert, eine einschlägige Berichterstattung abzugeben.

Im Antwortschreiben wird nun erstmals offiziell bekannt gegeben, daß die Handels- und Gewerbekammer, mit Beschluß vom 15. Februar 1900, die Agenden der Museumserrichtung vom Gewerbeverein übernommen hätte, da dieser

„nicht einmal eine Gewähr seines Fortbestandes bieten kann, jedenfalls aber unberechenbaren Wandlungen ausgesetzt und deshalb zur Durchführung so bedeutender Unternehmungen, wie die Gründung und Erhaltung eines Gewerbe- und Handelsmuseums für Tirol nicht geeignet ist. ${ }^{\text {“238 }}$

\subsubsection{Die Handels- und Gewerbekammer als neuer Träger der Museumsidee}

Mit der Übernahme der Idee der Museumsgründung durch die Handels- und Gewerbekammer begann ein neuer Abschnitt, war nun nicht mehr ein privater Verein Initiator des Vorhabens, sondern eine offizielle Standesvertretung mit öffentlich-rechtlichem Charakter.

Die Motive der Handels- und Gewerbekammer zur Übernahme von Trägerschaft und Erhaltung sind heute nicht mehr ganz zu ergründen, eine Ursache dürften aber die stark gestiegenen Errichtungskosten gewesen sein, die die Gewerbevereinsmittel bei weitem überstiegen.

237 Ebd. Nr. 6 (1899), S. 3 f. und 13. Jhg. Nr. 2 (1900), S. 3 f.

238 Vgl. Stenographische Berichte des Tiroler Landtages 16. Sitzung 4. Session VIII. Periode vom 19.5.1899, S. 264 f. u. Beilage 117 (Subventionsansuchen des Gewerbevereines), sowie Beilage 28 der 5. Sitz. 5. Sess. VIII. Per. v. 6.4.1900, „betreffend Gründung eines tirolischen Gewerbeund Handelsmuseum) in Innsbruck und Unterstützung desselben aus Landesmitteln“; Berichterstatter war Carl Payr. 
Bestärkt durch die Subventionszusagen waren der Gewerbevereinsvorstand und das gebildete Umbaukomitee an die Realisierung der Museumsidee gegangen. Der Plan, den Museumsbau dem Münchner Architekten Ludwig Lutz anzuvertrauen, ließ die Gesamtkosten mehr und mehr ansteigen, sodaß diese zu Beginn des Jahres 1900 bereits 150.000 fl. betrugen. Damit übertraf die Museumserrichtung die Kräfte des Vereines zunehmend; Anton Kofler suchte deshalb eine engere Zusammenarbeit mit der Handels- und Gewerbekammer und konnte dem Verein in der Generalversammlung des Jahres 1901 von der Übernahme der Gewerbemuseumsidee durch die Kammer berichten. ${ }^{239}$

Die Handels- und Gewerbekammer übernahm nicht nur die Gewerbemuseumsidee und die Verpflichtung, diese auszuführen, sondern hatte um die Jahrhundertwende den Beschluß gefaßt, ein neues eigenes Kammergebäude zu errichten. Dazu wurden die Gebäude Nr. 12 und 14 in der Meinhardstraße angekauft, das Haus Nr. 14 abgerissen und als neues Kammergebäude, nach den Plänen des Münchner Architekten Ludwig Lutz, wiedererrichtet.

In diesem Gebäude waren die ebenerdigen Räume mit ihren großen Fensterfronten für Ausstellungszwecke vorgesehen, die oberen Stockwerke waren teilweise als Verwaltungs- und Repräsentationsräume sowie zur Vermietung vorgesehen; weiters sollten dort die ersten Sammlungsgegenstände untergebracht werden. ${ }^{240}$

Als das Gewerbevereinsmitglied Franz Thurner 1899 in den Innsbrucker Nachrichten einen Beitrag über das in Entstehung begriffene Gewerbemuseum veröffentlichte, erhielt er eine interessante Entgegnung im katholischen Blatt Neue Tiroler Stimmen (dessen Untertitel „Für Gott, Kaiser und Vaterland“ lautete).

239 Gewerbeblatt 14. Jhg Nr. 4 (1901), S. 5 f.; Kofler beschrieb diesen Wechsel, als wäre er als unabhängige Person an die Kammer herangetreten und die Verbindung Kammer - Verein erst dadurch entstanden; daß die Beziehungen zwischen beiden Institutionen schon seit Vereinsbestehen gegeben waren und daß er Sekretär der Kammer war, erwähnte er nur beiläufig:. „[...] da wandte sich der Gewerbeverein, dessen Obmann Kammersekretär Dr. Anton Kofler war, in seiner Not an die Handels- und Gewerbekammer mit dem Ersuchen, die Sache des Museums in die Hand zu nehmen" (Kofler 1929, S. 2). Die später entstandenen Arbeiten zur Entstehungsgeschichte des Museums folgten dieser Version (Vgl. Paulin 1929, S. 3 f.; Stifter 1930, S. 12; sowie Ringler 1962, S. 69, der die Koflersche Darstellung wörtlich übernahm.).

240 Vgl. Mader 1951, S. 166 f.; die Fassadenfront des teilweise neugotischen Baues, in dem sich nach wie vor die Kammer befindet, ist bis heute so erhalten geblieben. Sie war mit Glasmosaiken der Tiroler Glasmalerei und Mosaikanstalt, nach Entwürfen des Haller akademischen Malers Alfons Sieber, geschmückt worden, die die verschiedenen Handwerke versinnbildlichen sollten. Die Innsbrucker Nachrichten widmeten dem Neubau einen eigenen Beitrag, der im Lob für die an der Ausführung beteiligten Handwerker (fast alle waren Gewerbevereinsmitglieder) nahezu werbemäßige Züge annahm (49. Jhg. Nr. 222 vom 27.9.1902, S. 5 f.). 
Darin mißbilligte der Autor (welcher mit Dr. C. S. signierte und sich als „Nichtgewerbetreibender" bezeichnete) Thurners politische Anspielungen, der den Landespolitikern schleppendes Vorgehen in der Frage der Gewerbeförderung vorgeworfen hatte und entgegnete ihm, daß er „nicht einzusehen [vermöge], was ein Kunstgewerbe-Museum mit Politik zu thun" hätte. ${ }^{241}$

Der Verfasser bezeichnete hingegen die gesamten Kosten einer Gewerbemuseumserrichtung als zu hoch und betonte, daß die Mehrzahl der heimischen Gewerbe (wie Schuster, Bäcker etc.) gar keinen Gewinn aus einer solchen Institution ziehen würden. Einzig das Kunstgewerbe könnte davon profitieren, dieses stünde aber schon, wie die Landesausstellung von 1893 bewiesen hätte, in der Blüte. Daher, sein Schluß, wäre „das geplante Museum fast vollständig wertlos“, weil es in Tirol selbst nur wenig große Industrien gäbe und die paar vorhandenen Betriebe, wie die Glasmalereianstalt in Innsbruck oder die Majolikafabrik Hußl in Schwaz, „ihre eigenen reichen Bibliotheken und Vorbildersammlungen“ hätten.

Nicht nur gewerbestandsmäßige Überlegungen bewogen Dr. C. S. zu dieser ablehnenden Haltung; mit ein Grund waren auch seine Ansichten über den Stellenwert des Museums im Verhältnis zum gegenwärtigen Kunstgewerbe. So meinte der Autor, daß sich dieses Museum „nicht auf teutsche [sic!] Vorbilder beschränken dürfe[...], sondern italienische, czechische, slovakische, englische und chinesische Erzeugnisse friedlich neben den deutschen ausstellen" müsse.

Seiner Ansicht nach könnte nicht eine „Vogel-Strauß-Politik“ Antwort auf das Eindringen der Secession in das Kunstgewerbe sein, denn wenn sich die Wiener Strömung innerhalb des Kunstgewerbes durchsetzen sollte, dann müßte ein „großes Stück unserer gegenwärtigen Gewerbe-Museen zum alten Gerümpel geworfen [werden] und [hätte] lediglich historischen aber keinen erzieherischen Zweck mehr, welch, letzterer' bei einem Kunstgewerbe-Museum denn doch die Hauptsache" wäre. ${ }^{242}$

Trotzdem der Autor der Museumsidee schlußendlich doch positiv gegenüber stand, enthielten seine Überlegungen einige grundlegende Kritikpunkte:

241 Thurners Beitrag erschien unter dem Titel „Ein Tiroler Gewerbe-Museum“ in den IN Nr. 66 (1899); die Replik von Dr. C. S., unter dem Titel „Das zu gründende Kunstgewerbemuseum“, in der Beilage der Stimmen 39. Jhg. Nr. 72 vom 29.3.1899, S. 5.

242 Ebd.; hingegen sah der nicht näher angegebene Autor in einem Gewerbemuseum keine Konkurrenz zum Ferdinandeum, müßte das Landesmuseum doch froh sein, „,wenn [es] Dinge [Kunstgewerbeobjekte; W.M.] abstoßen kann“. (Ebd.) 
- Die einseitige Ausrichtung der Museumsbetreiber auf Tiroler Volkskunst und Kunstgewerbe, das in solch einer Ausschließlichkeit - wie propagiert wurde nicht existierte.

- Damit verbunden war die Abkoppelung von kunstgewerblichen Strömungen im In- und Ausland (genannt wurden die Entwicklung der Wiener Secessionskunst, sowie die aufkommenden Einflüsse außereuropäischen Kunstschaffens, die das europäische Kunstgewerbe um die Jahrhundertwende entscheidend prägen sollten). Die Museumsinitiatoren setzten stattdessen auf eine allzu eingeschränkte Ausrichtung des heimischen Kunstgewerbes, auf althergebrachte Vorbilder einer Tiroler Volkskunst, die ideologisch mit Begriffen wie ursprünglich, urwüchsig oder bodenständig besetzt war.

- Dazu kam die vorgeschobene Behauptung, das Museum würde allen Gewerbetreibenden von Nutzen sein. Vielmehr hätte es doch, wie auch im Beitrag kritisiert wurde, kaum einer größeren Anzahl von Gewerbetreibenden Anregung geboten und wäre, wenn überhaupt, vorwiegend für das Kunsthandwerk von Bedeutung gewesen.

Da die Museumsbetreiber an der Idee eines bloßen Gewerbemuseums nicht mehr allzu sehr festhielten und diese rein aus Subventions- und Imagegründen vertraten, konnte sie diese Kritik aber kaum mehr treffen.

\subsubsection{Erste Museumspläne der Kammer}

In ihrem Bericht an den Tiroler Landesausschuß stellte die Kammer ein Konzept für das Museum vor. Dieses lehnte sich großteils an die schon bestehenden Vorstellungen (Hebung des Gewerbes, Erreichung dieses Zieles mittels Zurschaustellung mustergültiger Arbeiten, eine technische Sammlung von Rohprodukten, einer Fachbibliothek, einschlägiger Kurse und Veranstaltungen, ...) an. Eigens hervorgehoben wurde aber, daß im Museumsprogramm, „nach den Intentionen des k.k. Handelsministeriums, eine wesentliche Ausgestaltung zur besseren technischen Befähigung des Kleingewerbes" enthalten sei und daher

„an diesem Institute ein besonderer Gewerbeförderungsdienst, umfassend die Auskunftserteilung in allen technischen Fachfragen, die Veranstaltung zeitweiliger Ausstellungen kleingewerblicher Maschinen, die Abhandlung von Meistercursen und fachlichen Wandercursen, sowie von Wandervorträgen etc. eingerichtet"

werde. 
„Das tirolische Gewerbemuseum soll den Gewerbetreibenden jederzeit Aufklärung über die neuesten technischen Fortschritte in ihren gewerblichen Betrieben geben, und dieselben sollen über bewährte Productionsmethoden, über den Bezug von Rohmaterialien und dergleichen alle wünschenswerten Aufschlüsse erhalten können." 243

Damit stellten die Betreiber der Museumsidee in ihrem Unterstützungsansuchen die Betonung des Kunstgewerbes hintan und standen wieder eindeutig in der Tradition der Gewerbeförderungsaktionen.

Wahrscheinlich ist jedoch, daß dies aus rein subventionstechnischen Gründen geschah, um so den Landtag eher zu einer Beitragsleistung bewegen zu können. Gleichfalls schien es kammerintern notwendig zu sein, die Gewerbeförderung besonders herauszustreichen, um sich so das Wohlwollen aller in der Kammer vertretenen Fachrichtungen zu sichern. ${ }^{244}$

Diesem Ansuchen in seiner gewerbefördernden Intention stand ein im Landesausschußbericht erstmals dargelegter, detaillierter Plan gegenüber, worin die Betreibenden die Vorstellungen ihres Museums kundtaten: Demzufolge war vorgesehen, im Parterre des Gebäudes Nr. 14 einen größeren Raum für die permanente Ausstellung des Gewerbevereines zu adaptieren, in einem daran anschließenden, kapellenartigen Raum hätte die „, christliche Kunst einen entsprechenden Ausstellungsraum erhalten“ sollen; unmittelbar daran wäre eine „mit Glas überdeckte Halle [...] dem hiesigen Kunstvereine zur Veranstaltung zeitweiliger Kunstausstellungen überlassen“ worden. Die Räume des „Gewerbeförderungsdienst[es]" sollten, vorläufig, „einen großen Arbeitssaale [...] ein Lesezimmer [und ein] Auskunftsbureau“ umfassen. Laut Plan war der erste Stock „zur Aufnahme der kunstgewerblichen Sammlungen sowie der Sammlungen des Handelsmuseums bestimmt“, weiters war Platz für „zeitweilige Fachausstellungen, Ausstellungen von Lehrlingsarbeiten und dergleichen" vorgesehen. ${ }^{245}$

243 So der Kammerbericht an den Landesausschuß, in dem besonders auf das k.k. technologische Gewerbemuseum in Wien hingewiesen wurde, auf das auch A. Kofler 1899 aufmerksam gemacht hatte. (Vgl. Beilage 28 der Sten. Ber. d. Tir. Ltg. 5. Sitz. 5. Sess. VIII. Per. v. 6.4.1900, S. 2; Hervorhebungen im Original!)

244 Nach Kofler stellte die Kammer die „Bedingung, daß das neue Institut auch der Kaufmannschaft nutzbar gemacht und infolgedessen zu einem Handels- und Gewerbemuseum umgestaltet werden solle.“ (1929, S. 2) Im 1903 offiziell beschlossenen Titel „Handels- und Gewerbemuseum“ drückt sich das Vorhaben, ein Museum aller Handels- und Gewerbetreibendenden zu sein, ebenfalls aus!

245 Beilage 28 des Sten. Ber. d. Tir. Ltg. 5. Sitz. 5. Sess. VIII. Per. v. 6.4.1900, S. 3 f.; (Hervorhebungen von W.M.). 
Damit war einiges von der angestrebten technologischen Ausrichtung wieder zurückgenommen worden, und die eigentliche Ausrichtung - auf das heimische Kunstgewerbe - trat durch die Absicht Kunstausstellungen durchzuführen und einen Kapellenraum einzurichten wieder hervor. ${ }^{246}$

Der Bericht für den Landtag gibt auch Aufschluß über die personellen und finanziellen Vorstellungen der Museumsinitiatoren.

So müßte, nach den Plänen der Kammer, mindestens ein „fachlich befähigter" Beamtenposten geschaffen werden, den eventuell das Handelsministerium stellen könnte und dessen Aufgabenbereich nicht nur die Erledigung der laufenden Museumsgeschäfte sein sollte, sondern auch, im Auftrage der Gewerbeförderungsaktion, „alle nothwendigen Erhebungen und Verhandlungen mit Gewerbetreibenden und Genossenschaften hinsichtlich der gewünschten Beistellung von Maschinen und Arbeitsbehelfen und Abhaltung von Wandermeistercursen etc."

Die Gesamtkosten der Errichtung (incl. Gebäude und Grund) würden sich, nach den Angaben der Subventionswerber, auf 384.430 Kr. belaufen; die jährlichen Ausgaben werden mit $24.430 \mathrm{Kr}$. (incl. Gehälter), die Einnahmen mit 20.200 Kr. beziffert. Den offensichtlichen Abgang wollen die Betreiber nun durch das Subventionsansuchen beim Land abgedeckt sehen. ${ }^{247}$

In der Sitzung des Tiroler Landtages vom 28. April 1900 kam es erstmals zu einer längeren Diskussion über den Plan eines Tiroler Handels- und Gewerbemuseums. Nachdem Carl Payr zum Bericht des Landesausschusses, der die Stellungnahme

246 Bereits 1888 erschien in den Mittheilungen ein Artikel „Zur Kunstpflege in Tirol“ der den „Mangel eines passenden Ausstellungslocales in Innsbruck für die Werke lebender Künstler Tirols“ bedauerte, die „Frage nach einem Kunstausstellungssalon, den das Ferdinandeum wegen Platzmangels nicht bieten“ könne stellte und noch einmal den Wunsch zur Errichtung eines „Tiroler Museums für Kunst und Gewerbe“ bekräftigte [5. Jhg. Nr. 7/8 (1888), S. 41]. 1901 forderte Anton Kofler auf einer Vereinsversammlung den Anschluß des „Vereins für KirchenKunst und Gewerbe in Tirol“ an den Gewerbeverein. Dieser kirchlichen Kreisen nahestehende Kunstverein gab ab 1885, in Nachfolge des von 1866 bis 1869 erschienenen Blattes „Der Kirchenfreund“, die Zeitschrift „Der Kunstfreund“ heraus, die ab 1895 von der St.-LukasGilde (gegründet 1881) übernommen wurde. (Fischnaler Bd. IV 1930, S. 256) Neben dieser Publikation machte der Vereinigung vor allem durch die Veranstaltung von Ausstellungen mit Kirchenkunst und religiösem Kunstgewerbe auf sich aufmerksam (1900 im Innsbrucker Pädagogikum, 1901 im Ferdinandeum). (Fischnaler Bd. II 1930, S. 122) 1904 waren dem Verein u.a. die Gewerbevereinsmitglieder Leopold Lindner, Bernard Zösmayr und Anton Vinazzer beigetreten.

247 Beilage 28 des Stenographischen Berichtes des Tiroler Landtages 5. Sitz. 5. Sess. VIII. Per. v. 6.4.1900, S. 2 f. und S. 4 f.; als größte Subventionsposten waren 6.000 Kr. von Staatsseite, $2.000 \mathrm{Kr}$. von der Stadt Innsbruck, 3.600 Kr. vom Gewerbeverein und 1.000 Kr. von der Kammer angegeben (ebd., S. 4). 
der Kammer sowie ein Subventionsansuchen zum Bau und zum Erhalt des Museums enthielt (vorgesehen waren ein einmaliger Betrag von $10.000 \mathrm{Kr}$. und 2.000 Kr. jährlich), gesprochen hatte und diesen befürwortete, wurde die Debatte eröffnet. Der Abgeordnete Klotz hob hervor, daß er einer zeitlich unbeschränkten Subventionsvergabe nicht zustimmen könne, „denn gerade ins Dunkel hinein auf immer möchte ich doch nicht empfehlen, daß man das bewilligen soll“ und stellte den Antrag, die Subvention erstmals auf fünf Jahre hin zu vergeben. Ein weiterer Wortwechsel ergab sich aus einem Vergleich der Landeszuwendungen für Bauern und Gewerbetreibende, der vom Abgeordneten Schorn vorgebracht worden war. Josef Schraffl, der spätere Tiroler Bauernbundobmann, fand versöhnliche Worte, indem er betonte, daß das geplante Museum der Hausindustrie diene, die auch von Bauern betrieben würde. Weiters hob er hervor, „gerade für die Producte der Hausindustrie würde kein Absatz gefunden werden, wenn nicht ein solches Museum errichtet würde, wo solche Producte ausgestellt, gesehen und gekauft werden können" ${ }^{248}$. Schlußendlich wurde dem Antrag - mitsamt des Klotzschen Änderungsvorschlages - stattgegeben.

Der Tiroler Landtag stand damit aber keineswegs allen ähnlichen Museumsvorhaben ebenso wohlwollend gegenüber, wie aus seiner Ablehnung eines Unterstützungsantrages für das zu errichtende Bozner Museum ersichtlich wird.

Dieses Ansuchen, das in derselben Landtagssitzung unmittelbar nach der Subventionszusage für das Innsbrucker Gewerbemuseum behandelt worden war, stieß allgemein auf Ablehnung, obwohl zwei Abgeordnete das Ansuchen befürworteten. Der eine, Paul Welponer, berief sich unmittelbar auf die vorher getroffene Zusage für Innsbruck, der andere, Baron Georg Bernhard Eyrl von Waldgries und Liebenaich, Obmann dieses Bozner Museums, verwies auf die rege Sammeltätigkeit des Museumsvereines, dessen Exponate bereits jetzt vier bis fünf Säle ausfüllen und in erster Linie bodenständige Objekte, wie „Tiroler Bauerncostüme, Bauerntrachten " und kunstgewerbliche Erzeugnisse umfassen würden.

Prof. Hirn wandte sich gegen eine Subventionsvergabe nach Bozen, da, seiner Ansicht nach, einerseits die einschlägigen Ansuchen für Museumsunterstützungen überhand nehmen würden, und er andererseits die „Decentralisierung in Bezug auf die Museen mehr als ein Unglück als ein Glück betrachte[te]“. Er sprach sich deshalb für den Komitee-Vorschlag aus, dem Museum aufzutragen, sich noch

248 Stenographische Berichte des Tiroler Landtages 10. Sitz. 5. Sess. VIII. Per. v. 28.4.1900, S. 88 ff. (Antrag 35); einzig der Abgeordnete Julius Freiherr Riccabona von Reichenfels erachtete das ganze Projekt als zu aufwendig und zu kostspielig und warnte davor, „das ganze Wohl des Gewerbestandes von der Bewilligung dieser Subvention für das neu zu erstehende Handels- und Gewerbemuseum abhängig“" zu machen (ebd., S. 91). 
einmal um eine Subvention zu bemühen, „sobald das Musealgebäude errichtet“ wäre.

Trotz des wiederholten Hinweises des Antragstellers, daß dies ein analoger Fall zur Innsbrucker Museumsförderung wäre, wurde das Subventionsansuchen abgelehnt und der Komitee-Vorschlag angenommen. ${ }^{249}$

Die Vorgangsweise der Subventionsvergabe läßt den Schluß zu, daß es die Kammer vor allem ihren guten Beziehungen zu einzelnen Landtagsabgeordneten verdankte, ihre Unterstützungsansuchen mit den Gewerbeförderungsbestrebungen des Landes und des Staates zu verbinden und dabei kunstgewerbliche und volkskunstmäßige Vorstellungen, die längst schon ihre Sammeltätigkeiten bestimmten, in den Hintergrund treten zu lassen. Damit erreichten die Innsbrucker Museumsbetreiber, im Gegensatz zu den Boznern, die fast die gleichen Absichten bezweckten und um weniger Subventionsmittel als die Innsbrucker angesucht hatten, ein einkömmliches Startkapital von seiten des Landes. Die Bozner hingegen wurden, aufgrund ihres angeblich nicht den Landesintentionen entsprechenden Vorhabens, mittels des Vorwandes der Zentralisierung von Museumsbestrebungen, abgelehnt. ${ }^{250}$

249 Ebd., S. 92 ff.; Baron Eyrl hatte in seinem Befürwortungsstatement betont, daß „bereits gegen 70 Figuren gesammelt und zusammengestellt [worden wären], welche aus den verschiedensten Thälern die alten Costüme darstellen, wo die Textilindustrie in dieser Richtung ganz genau nachgewiesen ist, und diese Sammlung wird von den ausländischen Künstlern sehr häufig besucht." (ebd., S. 93)

250 Im Jahre 1913 entbrannte eine grundsätzliche Debatte zwischen Befürwortern und Gegnern des Gedankens der Museumszentralisation, die durch Subventionsansuchen der Stadtmuseen Bruneck, Lienz und Riva ausgelöst worden war. Dabei wandte sich der liberale Abgeordnete Baron Anton von Longo-Liebenstein mit dem Argument, „daß man im Gegenteil trachten soll, die wenigen im Lande befindlichen größeren Museen besser zu unterstützen und ihnen die Kunstschätze zuzuweisen“, (S. 259) gegen die Subvention kleiner Regionalmuseen, während sein Fraktionskollege Freiherr Paul von Sternbach Gegner der Museumszentralisation war, da, seiner Ansicht nach, „die Schätze, die in den Sammlungen geborgen liegen, allen und insbesondere dem lokalen Faktoren, den Gewerbetreibenden, die an Ort und Stelle werken, zugänglich gemacht werden“ sollte. (S. 259). Der liberale Innsbrucker Bürgermeister Dr. Greil schloß sich hingegen der Ansicht Baron Longos an, mit der Begründung, daß durch die Zentralisierung die Sammlungen „für Fremde leicht zugänglich“ wären! (ebd.) Der Historiker und damalige Rektor der Innsbrucker Universität Dr. Wilhelm Erben wandte gegen den, seiner Auffassung nach zwar zu Recht bestehenden, „Fremdenverkehrsstandpunkt“ ein, daß die „Schätze mit dem Orte, an welchem sie gefunden worden sind, mit dem sie verwachsen sind, im Zusammenhange bleiben sollen“ und schlägt den Aufbau einer „richtigen Museumsverwaltung“ in den kleinen Museen vor, um dort eine ,gerechte Behandlung und Aufbewahrung“ der Gegenstände gewährleistet zu sehen. (S. 260) Die beiden christlich-konservativen Abgeordneten Dr. Michael Mayr (Hall) und Karl Niedrist (Rattenberg) lehnen die Subventionierung kleiner Museen mit der Begründung $\mathrm{ab}$, sonst würde ja jedes Museum ansuchen! Schlußendlich wurde das ordentliche Ansuchen zwar abgelehnt, den drei Museen aber eine einmalige Zuwendung von $300 \mathrm{Kr}$. gewährt (Sten. Prot. d. Tiroler Landtages, 13. Sitz. 4. Sess. X. Per. vom 17.10. 1913, S. 258 ff.). 


\subsection{Der Weg zum „Museum für Volkskunst und Gewerbe“}

Gleichzeitig mit dem Subventionsgesuch an den Tiroler Landtag finden sich im Mitteilungsblatt des Gewerbevereines wieder Beiträge zu Museumsfragen. Darunter ein Aufsatz des Grazers Carl Lacher mit dem Titel: „Die Aufgaben der Kunstgewerbemuseen auf kulturhistorischem Gebiete“.

Der Autor ging in diesem Beitrag besonders auf die „Volksthümlichkeit" solcher Institutionen ein - im Zusammenhang mit der Auffassung, daß eben diese "Volksthümlichkeit, Zweckmäßigkeit, das Schlichte Arbeiten der Altvorderen“ dem heutigen „überladene[n] Kunstgewerbe“ fehlen würde - und brachte damit einen neuen Begriff und ein neues Moment in die einschlägige Diskussion.

Damit stand nicht mehr der Vorbildcharakter solch einer Sammlung in Bezug auf die Verbesserung der Konkurrenzfähigkeit gegenüber industrieller Produktion im Mittelpunkt, sondern deren erzieherische Funktion.

Demgemäß vertrat der Autor die Auffassung, daß die Beachtung der „volksthümlichen“ Arbeiten unserer Vorfahren „dem künstlerischen und gewerblichen Schaffen eine Volksthümlichkeit gesichert, die es vor der schädlichen Konkurrenz der Modethorheiten besser bewahrt hätte“251. Damit wurde explizit die ästhetische Funktion der ausgestellten Gegenstände - als Vorbilder einer zu bewahrenden Kunst und Kultur - angesprochen.

Seiner Meinung nach hätte solch eine Sammlung „volksthümlicher“ Gegenstände aber noch eine weitere Aufgabe: Sie sollte „die Liebe zur angestammten Scholle wecken".

Diesen Vorstellungen nach würde das Museum zu einer Sammlung nationaler Güter und, wie er weiters betonte, der „beste Führer für das ganze Volk durch die Vergangenheit seiner Heimath" sein.

Das Museum galt Lacher nach wie vor als Mustersammlung für das Kunstgewerbe, wobei er den Sinn einer solchen Vorbildfunktion in der damit erreichten „Bodenständigkeit" der Produkte sah und meinte, daß die so gefertigten Gegenstände „den Landeskindern lieb und werth“ werden und daneben „die fremden Besucher des Landes [anziehen] und zur Erwerbung kunstgewerblicher Gegenstände als Reiseerinnerungen" anregen würden. ${ }^{252}$

251 Gewerbeblatt 14. Jhg. Nr. 8 (1901), S. 2 f.; hier S. 3! Der Aufsatz war den Mitteilungen des Mährischen Gewerbemuseums in Brünn entnommen worden.

252 Ebd. Nr. 9 (1901), S. 4; weiters glaubte der Autor, daß damit ein größerer Absatz handwerklicher Produkte, ohne gleich für den „Weltmarkt“ arbeiten zu müssen, möglich sein würde (ebd.). 
Einerseits findet sich in diesem Aufsatz eine deutliche Akzentverschiebung in der Begründung des Sammelns und Aufstellens altertümlicher Gegenstände (sie werden nicht mehr nur als rein handwerkliche Vorbilder angesehen, sondern auch mit identitätsstiftenden Funktionen besetzt - als Zeugen von Heimat und Vergangenheit), andererseits verdeutlicht der Beitrag, daß sich patriotisch gebende sowie Heimat und Bodenständigkeit betonende Argumente mit der ökonomischen Verwertbarkeit der Objekte, besonders hinsichtlich des Fremdenverkehrs, nicht ausschließen müssen.

Die Verknüpfung von Ideologie und Ökonomie spielte ja von allem Anfang an in der Diskussion um Tiroler Volkskunst eine wichtige Rolle.

Auch wenn diese Gedanken hier sozusagen von Außen hereingetragen wurden, dürfte ihr Abdruck im Mitteilungsblatt den Diskussions- und Bewußtseinsstand innerhalb des Gewerbevereines verdeutlichen, denn dieser hatte es sich nach und nach zur Aufgabe gemacht, Tiroler Volkskunst zu retten und diese Rettung mit der Hebung des Gewerbes, in Form der Vermarktung, vor allem in der Fremdenindustrie, zu verknüpfen.

In den 1903 von seiten der Handelskammer vorgelegten „Statuten des tirolischen Handels- und Gewerbe-Museums in Innsbruck" kam die Betonung des tirolischen Kunstgewerbes und die Sammlung von tirolischen Altertümern ebenfalls deutlich zum Ausdruck.

Neben dem, aus früheren Statutenfassungen übernommenen Zweck der „Förderung von Handel und Gewerbe“, der mittels „Vorführung mustergiltiger gewerblicher Erzeugnisse, ..." erreicht werden sollte, hieß es nun bei der Aufzählung der Sammlungsgegenstände: „mit besonderer Berücksichtigung des alttirolischen Kunstgewerbes " $^{\text {"253. }}$.

Vier Jahre später (1907) wurde dieser inhaltliche Wandel der Museumsausrichtung in einer Namensänderung festgeschrieben. Anläßlich der Handelskammersitzung vom 10. Dezember 1907 wurde der Beschluß gefaßt, das Museum in Hinkunft „Museum für Volkskunst- und Gewerbe“ zu nennen. ${ }^{254}$

253 Statutenexemplar im Archiv des TVM, in den Prot. d. o. ö. Sitzung der Handels- und Gewerbekammer in Innsbruck vom 2.12.1903, S. 334 ff., sowie im Bericht über die Kammersitzung vom 2.12.1903 im Tirolschen Gewerbeblatt 16. Jhg. Nr. 12 (1903), S. 2 f. In die Sammelliste wurden „Erzeugnisse der tiroler Hausindustrie“ aufgenommen und es war geplant, eine „permanente Ausstellung von modernen Erzeugnissen tiroler Industrie zum Zwecke des Verkaufes" einzurichten. Das Museum wäre demnach eine Kombination aus dem ursprünglichen Gewerbemuseum und der permanenten Verkaufsausstellung des Gewerbevereines geworden.

254 Siehe das Prot. d. o. öff. Sitz. d. HGK in Ibk. vom 10.12.1907, S. 199 f. (Hervorhebung von W.M.!); Kofler begründete die Namensänderung mit dem Hinweis, daß die Bezeichnung 
Daß diese Namensumbenennung nicht nur auf dem Papier bestand, sondern realen Beweggründen entsprang, läßt sich aus den Einkaufsberichten ersehen, die aber leider nicht in größerem Umfang veröffentlicht wurden.

Neben Anton Kofler war es bis 1906 vor allem Josef Tapper, der den Einkauf von Sammlungsgegenständen bestimmte.

Der gebürtige Niederösterreicher Josef Tapper (1854-1906), der ab 1885 an der Innsbrucker k.k. Staatsgewerbeschule als Professor für dekoratives Zeichnen und Malen wirkte, betrieb diese Einkaufspolitik weniger aufgrund theoretischer Überlegungen, als vielmehr nach seiner, aus der Praxis gewonnenen Arbeitserfahrung.

Er blieb nicht nur bei seiner Sammeltätigkeit sondern versuchte mittels seines Berufes als Lehrer und Kunstgewerbeschaffender vielfache Anregungen in Bezug auf traditionelle, regionalbezogene Kunstgewerbetechniken zu geben.

Seine 1887 erstmals herausgegebenen 40 Blätter eines Vorlagenwerkes über Holzbrandtechnik machten diese Zierkunst bei den Tiroler Kunstgewerbetreibenden bekannt.

Daneben trug er mit Modellen und Auftragswerken zur Geschmacksbildung des Tiroler Kunstgewerbes bei (er fertigte eine Reihe von Möbeldekorentwürfen sowie Vorlagen zur Bemalung des gefertigten Steingutes der Schwazer Majolikafabrik A. Hußl).

Für die Glasmalereianstalt in Innsbruck schuf er eine Reihe von Entwürfen, darunter 1886 zwei „figurale Kartons für eine Kirche“ in der Schweiz. 255

An den Gebäuden der 1893 abgehaltenen Landesausstellung wurden von Tapper entworfene Wappen und Embleme angebracht; ferner waren die Flaggenmasten, Fahnen und Schilder dieser Veranstaltung nach seinen Vorstellungen gefertigt worden.

Auch zwei Ausstellungskojen (diejenige der Fischerei-Ausstellung und die der Sensenfabrik J. Grauß aus Jenbach) zeigten seine Handschrift.

Für die 1893 vorgenommene Enthüllung des Andreas-Hofer-Denkmals am Bergisel steuerte Tapper ebenfalls die Dekoration bei.

Schlußendlich stammen etliche Denkmale aus Tappers Entwürfen (u.a. eines zu Ehren des Absamer Geigenbauers Josef Stainer, das Trientl-Denkmal in Ötz,

„Handels- und Gewerbemuseum“ „vielfach die Meinung erweckte, als ob mit dem geplanten Museum auch eine Art von Musterlager verbunden sein würde“ und meint weiter, in Hinblick auf die Wahl der neuen Bezeichnung: „Zumal es gerade die Volkskunst ist, welche in unserem Museum am stärksten vertreten sein wird und die auf unsere Gewerbe in den verschiedenen Richtungen anregend und bildend wirken kann“. (S. 200) Vgl. auch den Hinweis der Namensänderung in den Innsbrucker Nachrichten Nr. 285 vom 11.12.1907, S. 3.

255 Vgl. den Nachruf im Tiroler Gewerbeblatt 19. Jhg. Nr. 11 (1906), S. 1 f.; dort die folgenden Angaben zu Tappers Leben und Schaffen. 
sowie die ,in byzantinischer Mosaik ausgeführte Gedenktafel für den Tiroler Freiheitskämpfer Straub in Hall“).

Josef Deininger würdigte in seinem Nachruf auf Tapper vor allem dessen „natürlichen Sinn für das Urwüchsige und im Zusammenhange damit sein lebhaftes Interesse für bäuerliche Sitten und Gebräuche, Dialekte, alte Bauerntrachten und für die primitiven und höher entwickelten Erzeugnisse alter Volkskunst Tirols“ und betonte, daß dies die Richtung seiner kunstgewerblichen Schöpfungen bestimmt hätte. ${ }^{256}$

Ab 1904 begann Tapper für das neue Gewerbemuseum zu sammeln und einzukaufen. Tapper erstand in der Folge eine Reihe von Objekten, die seinem Empfinden von Tiroler Volkskunst entsprachen. Leider findet sich von all diesen erworbenen Objekten keine detaillierte Aufzählung, sodaß hier nur die Sachgruppen umrissen werden können. Unter anderem erstand er für das zukünftige Museum „Mobilien, Täfelwerk, figurale Schnitzereien, Geräte, Werkzeuge und Textilerzeugnisse aller Art“.

Zu den Beweggründen, gerade Gegenstände der „Tiroler Volkskunst“ zu sammeln, schrieb Deininger im Nachruf:

„Denn er hat erkannt, daß mit solchen, auch kulturgeschichtlich wertvollen Objekten eine fruchtbringende Anregung für das moderne kunstgewerbliche Schaffen im Lande gegeben wird, durch die sich hierin offenbarenden einfachen und originellen Techniken in der Behandlung des Materials und die vom Naturtriebe bäuerlicher Künstler geleitete wahrhaft stilmäßige Anwendung der Dekoration. ${ }^{\text {"257 }}$

Neben seiner Tätigkeit als Einkäufer und Sammler wurde Tapper vom Kuratorium auch zum Direktor des Museums bestellt. ${ }^{258}$

256 Ebd.; der Nachruf auf Tapper erschien ursprünglich in den Innsbrucker Nachrichten Nr. 264 von 1906, und wird - auszugsweise - im Gewerbeblatt zitiert. Tapper hatte auf der Antwerpener Weltausstellung von 1894 Gelegenheit, seine Vorstellungen einer Tiroler Volkskunst vor größerem Publikum vorzuführen, als er dort von ihm „komponierte“ (sic!) Möbel im tirolischbäuerlichen Charakter präsentieren und die Anordnung der Gruppe „Tirol, Sektion alpin“ durchführen konnte (ebd.).

257 Ebd., S. 2; zur Erlangung dieser Objekte wird dort vermerkt, daß Tapper dabei besonders „seine hervorragende Gabe liebenswürdigen, treuherzigen Verkehrs mit der bäuerlichen Bevölkerung [...] zu statten" gekommen sei (ebd.).

258 Rechtliche Grundlage für die Bestellung Tappers zum Direktor des Museums war die von der Handels- und Gewerbekammer beschlossene „Geschäftsordnung für das Kuratorium 
In einem Schreiben des Ministeriums für Kultus und Unterricht an die Tiroler Statthalterei wird 1905 bestätigt, daß der Gewerbeschulprofessor Josef Tapper „die Bewilligung zur Übernahme der Direktorstelle des Handels- und Gewerbemuseums in Innsbruck bis auf Widerruf mit der Maßgabe erteilt [bekomme], daß die Erfüllung seiner lehramtlichen Pflichten [...] in keiner Weise beeinträchtigt werde ${ }^{\text {“259. }}$.

Im Jahre 1906 informierte die Statthalterei Erzherzog Franz Ferdinand über die geplante Museumserrichtung in Innsbruck, weiters über dessen Zielsetzung und die Bestellung Tappers zum Direktor. Der Erzherzog hatte sich ja im selben Jahr in einem Brief an die oberste Tiroler Behörde, besonders für die Erhaltung und Rettung heimischer Altertümer, sowie gegen deren Ausverkauf ins Ausland eingesetzt.

Erstmals findet sich nun offiziell, neben der bereits bekannten Gewerbeförderungsargumentation, die neue Begründung, daß durch die Einrichtung des Museums und der damit verbundenen Sammeltätigkeit Gegenstände vor dem Ausverkauf gerettet werden könnten; so hieß es im Brief der Statthalterei, in Bezug auf die Sammeltätigkeit Tappers, daß aus diesem

„Vorgang der Erhaltung der im Lande vorkommenden kunsthistorisch wertvollen Objekte eher ein Vorteil als ein Nachteil erwächst, da dadurch so manche derselben vor Raubzügen von Antiquitätenhändlern entzogen und dem Lande gerettet werden." ${ }^{\text {"60 }}$

Ein Kammerbeschluß im Jahre 1906 bekräftigt das gewandelte Sammelinteresse, denn dort heißt es: „Um nun das Kuratorium in die Lage zu versetzen, in Fällen

des Handels- und Gewerbemuseums“ (1904), die die Bestellung eines Direktors durch das Kuratorium vorsah! Dieses Kuratorium setzte sich (laut den Satzungen von 1903) aus zwei Vertretern der Kammer, drei des Gewerbevereines, je einem Vertreter des Landesausschusses, des Innsbrucker Gemeinderates, der Sparkasse Innsbruck, des Ferdinandeums, sowie der Gewerbeschule und der Handelsakademie zusammen.

259 TLA, Statthalterei Unterricht Nr. 91/2 ex 1905 und Nr. 15873/925 ex 1905; das Schreiben des Ministeriums vom 18.3.1905 trägt die Zl. 7592 und nimmt Bezug auf einen vorausgegangenen Brief der Statthalterei vom 26.2.1905 (Zl. 91), in dem, genauso wie im Brief der Tiroler Handelsund Gewerbekammer vom 2.12.1904 (Zl. 3219) an das Ministerium, um die Kenntnisnahme der unbezahlten Tätigkeit von Prof. Josef Tapper als Direktor des Museums gebeten wurde.

260 TLA, Brief der Statthalterei an den Erzherzog vom 29.8.1906 (Statth. Kunst Nr. 45587/256 ex 1906) sowie das, dem Vorhaben wohlwollend gesinnte, Antwortschreiben des erzherzoglichen Flügeladjutanten Brosch vom 11.10.1906 mit der Zahl 334 (Statth. Kunst Nr. 53718/332 ex 1906). Im Brief der Statthalterei wird die Zahl von bisher 2.000 gesammelten Gegenständen angegeben, die aus allen Teilen Tirols zusammengetragen und Tapper, trotzdem sie oft für den Antiquitätenhandel gedacht gewesen waren, überlassen worden wären. 
der Dringlichkeit tirolische Altertümer aufkaufen und so die Verschleppung ins Ausland verhindern zu können, ist es notwendig, daß dem Kuratorium ein entsprechendes Kapital zur Verfügung stehe“.

Daher wurde ein Antrag gestellt, der allgemeine Zustimmung fand, daß für die Bezahlung der Ankäufe ein Kapitalbetrag von 100.000 Kronen aufzunehmen wäre. ${ }^{261}$

Diese Kapitalaufnahme scheint wegen des Ankaufes einer „große[n] Sammlung von alten kunst- und hausgewerblichen Tiroler Gegenständen " notwendig geworden zu sein, wie Anton Kofler in der Generalversammlung des „Tiroler Gewerbevereins" von 1906 berichtete und darlegte, daß „der Handels- und Gewerbekammer die Mittel fehlen" würden und er dieser deshalb vorgeschlagen hätte, für den Ankauf ein Darlehen aufzunehmen. ${ }^{262}$

Aus den, wahrscheinlich um dieselbe Zeit entstandenen, „Satzungen des Museums für tirolische Volkskunst und Gewerbe in Innsbruck" geht ebenfalls die neue Ausrichtung (Sammeln von Gegenständen der Tiroler Volkskunst) hervor.

Es hieß dort in Bezug auf die Sammeltätigkeit der „Einkaufskommission“: Diese hätte „ihre Tätigkeit auf das gewerbliche und kunstgewerbliche Gebiet sowie auf das Gebiet der tirolischen Volkskunst zu beschränken und vom Sammeln rein historisch oder kunstgeschichtlich interessanten Objekten abzusehen "263.

261 Diesem Antrag wurde entsprochen, weil den verantwortlichen Kammerfunktionären, aufgrund der jährlichen Subventionszusagen der Stadt Innsbruck (1.000 Kr.), der Sparkasse (ebenfalls $1.000 \mathrm{Kr}$.), des Landes (500 Kr.) und des Gewerbevereines (600 Kr.), die Verzinsung der Kapitalaufnahme gesichert erschien (Innsbrucker Nachrichten Nr. 152 vom 6.7.1906, S. 5 f.). Vgl. die in der Kammersitzung vom 5.7.1906 abgehaltene Debatte zu diesem Beschluß, wo die Befürworter der Darlehensaufnahme vor allem damit argumentierten, daß ansonsten nicht genügend Geldmittel zum Ankauf von Sammelgegenständen zur Verfügung stehen würden und dies gerade zu einer Zeit, wo eine „stets wachsende Zahl von Agenten, welche im ganzen Lande von Ort zu Ort, ja von Haus zu Haus wandern, und alles, was ihnen nur einigermaßen geeignet erscheint, zusammenkaufen "würden, wie es A. Kofler in seiner Antragsbegründung drastisch formulierte! (Prot. d. o. öff. Sitz. d. HGK in Ibk., S. 161 ff., hier S. 162)

262 Gewerbeblatt 19. Jhg. Nr. 6 (1906), S. 4; diese Jahresversammlung fand 1906 ausnahmsweise im Juni statt. Bei den erwähnten Objekten dürfte es sich um Sammlungsgegenstände des Malers und späteren Museumseinkäufers Prof. Edgar Meyer handeln, der auf seinem Schloß Welfenstein eine Unzahl von Gegenständen zusammengetragen hatte (zu Meyer vgl. unten) siehe die Prot. d. o. öff. Sitz. d. HGK in Ibk. vom 5.7.1906, S. 162.

263 Die Satzungen befinden sich im Archiv des TVM und sind ohne Jahresangabe. (Hervorhebung von W.M.!) 
Kunibert Zimmeter, seit 1906 Redakteur des Tiroler Gewerbeblattes, beschäftigte sich in zwei Beiträgen für die Innsbrucker Nachrichten mit der gewandelten Ausrichtung der Museumssammlung auf Tiroler Volkskunst.

Zimmeter legte einerseits die neuen Ziele des Gewerbemuseums dar (es sollte nun „hauptsächlich instruktiven Charakter tragen“ und den besten gewerblichen Erzeugnisse Platz bieten), betonte aber, daß dies nur aufgrund einer „historischen Basis“ erfolgen könnte, indem in retrospektiver Weise der „Entwicklungsgang [des] tirolische[n] Gewerbe[s]" aufgezeigt würde.

Andererseits, ganz im Sinne des von ihm propagierten Heimatschutzvereines, verlangte er, daß „die Durchführung dieser Idee [...] vor allem rasches Handeln [erheischen würde], denn die Verschleppung der bedeutendsten und interessantesten älteren Werke heimischen Gewerbefleißes nimmt einen erschreckend raschen, unaufhaltsamen Verlauf ${ }^{\prime 264}$.

Als „tirolische Volkskunst“ verstand Zimmeter „nicht nur die primitiven Erzeugnisse naiver häuslicher Kunstübung, sondern das Gesamtereignis der kunstgewerblichen Entwicklung “265. Er sah den Zweck der Sammlung aber nicht nur im „wissenschaftlichen“ Bereich, vielmehr im „praktischen“, denn, wie Zimmeter betonte, lägen in der „Volkskunst [...] Keime für ein neues, aus dem natürlichen Bedürfnissen hervorwachsendes Kunstgewerbe ${ }^{\text {“266 }}$.

Rund zwei Monate später berichtete Zimmeter im selben Blatt, daß das Gewerbemuseum für eine Ausstellung über Volkskunst in Wien einige Objekte zur Verfügung gestellt hätte.

Den Wert der Sammlung sah er vor allem im Vorbildreservoir für das heimische Gewerbe, betonte aber weiters, daß „die ausgelegten Kosten [...] ein Nationalkapital, das reiche Zinsen trage“, wären.

264 Innsbrucker Nachrichten 53. Jhg. Nr. 57 vom 10.3.1906, S. 17 f.; er wies, im Zusammenhang mit den Museumsbestrebungen der Kammer und des Gewerbevereines, auf die permanente Ausstellung des Vereines hin, wobei er betonte, daß diese vornehmlich „merkantile Zwecke“ verfolgen würde (ebd.).

265 Ebd.; als Ursache des Niederganges und Ausverkaufes der Volkskunst gab er, bezugnehmend auf einen Beitrag von Michael Haberlandt, die „rapid fortschreitende Verkehrserschließung des Landes" an.

266 Ebd.; er hob die Bedeutung der Sammlung als Anziehungspunkt für Einheimische und Fremde hervor, wollte aber darin keinerlei Konkurrenz sondern eine „Ergänzung unseres mit vollem Recht weitberühmten Ferdinandeums" gesehen haben (ebd.). 
An den Schluß seines Artikels stellte er einen Aufruf an alle, „welche interessanten alttirolischen Hausrat in ihrem Besitze haben: Dinge, die oft sogar unbenützt am Dachboden liegen [...] im Museum zu deponieren"267.

\subsubsection{Bestrebungen zur Errichtung eines eigenen Museumsgebäudes}

Nun hatte die Kammer zwar eine beträchtliche Anzahl von Gegenständen für das zukünftige Museum gesammelt sowie mit Josef Tapper einen verantwortlichen Leiter für die Institution bestellt, doch noch immer kein geeignetes Gebäude gefunden, um die Museumsidee zur Verwirklichung bringen zu können.

Zwar war laut Beschluß von 1901 die Errichtung des Museums im neuerbauten Handelskammergebäude in der Meinhardstraße vorgesehen, doch lagen die Intentionen der Museumsbetreiber längst nicht mehr nur in der Errichtung eines einfachen Gewerbemuseums. Schon seit einiger Zeit schwebte ihnen ein Ort nationaler Kultur- und Kunstpräsentation vor, und dieses Museum sollte nach Außen hin die neue, patriotische Ausrichtung präsentieren.

Bereits auf der Generalversammlung des Jahres 1905 berichtete der Obmann des "Tiroler Gewerbevereins" und eifriger Museumsbetreiber Anton Kofler, daß das Museum eventuell im Jahre 1906 eröffnet werden könnte und verkündete dessen neue Intention: „Die Aufgabe des Museums wird es sein, alle im Lande befindlichen Reliquien tirolischen Kunstgewerbes zu sammeln und im Museum als Denkmal für unsere Vorfahren zur Ausstellung zu bringen." ${ }^{268}$

Ein Jahr später regte der Maler Edgar Meyer ${ }^{269}$, der nach dem Tode Tappers 1906 dessen Stelle als Einkäufer übernommen hatte, die Diskussion um den Museumsbau neu an.

267 Ebd. Nr. 103 vom 5.5.1906, S. 18; er hob als Grund für dieses eher ungewöhnliche Vorgehen Dinge zwar außer Haus, damit aber nicht aus dem Besitz zu geben, hervor: „Sie erweisen dadurch der Öffentlichkeit einen Dienst, ohne sich des ihnen vielleicht liebgewonnenen Besitzes zu entäußern“. (Ebd.)

268 Vgl. Gewerbeblatt 18. Jhg. Nr. 7 (1905); die Versammlung fand am 11.7.1905 statt.

269 Edgar Meyer (1853-1925), Sohn eines Innsbrucker Aquarellisten, studierte an den Akademien München und Weimar und wirkte ab 1886 als Professor an der Weimarer Kunstschule. Meyer, der Mitbegründer des radikal deutsch-nationalen „Tiroler Volksbundes“ (1905) war, baute sich die Ruine Welfenstein bei Sterzing zu einem romantischen Wohnsitz aus (1918 abgebrannt!) und legte dort eine große Sammlung kunsthistorischer Gegenstände an. Nach Hans Kramer hätte Meyer „überall, besonders in Tirol, nach Kostbarkeiten aus alter Zeit gefahndet und sie zusammengekauft“ und so nach und nach die „Burg mit Antiquitäten vollgestopft“. (1951, 
Er forderte in den Innsbrucker Nachrichten die Ergänzung und Erweiterung des Ferdinandeums, wobei seinen Vorstellungen nach die Sammlungen des „Gewerbe- und Volkskunstmuseums" mit einbezogen werden könnten.

Er wollte vor allem die kunstgewerbliche Bedeutung Tirols in der Vergangenheit aufzeigen - die "Lokalstile der Landesteile“ sollten vorgeführt werden und es müßte, seiner Ansicht nach, Aufgabe des künftigen Museums sein, „alles dies zusammenzufassen und dem Publikum möglichst übersichtlich darzustellen“.

Die Gedanken Meyers gingen damit weit über das bis dahin Geplante hinaus; ihm schwebte eine Art Freilichtmuseum vor, und er plädierte deshalb für einen Platz außerhalb der Stadt, da dort nicht nur „ein Kunstgewerbe-Museum in einer weit größer gedachten Ausdehnung entstehen könnte“, sondern es, in „landschaftlicher Umgebung“", möglich sein müßte, „einen Komplex von Baulichkeiten, [...] ein Stück Alttirol wo in charakteristischen Gebäuden die Sammlungen verwertet werden können" aufzubauen.

Seiner Ansicht nach sollte so ein Ensemble aus einer „Reihe der charakteristischesten Bauernhäuser" (er schlug je ein Objekt aus dem Unter- und Oberinntal, dem Paznaun- und Pustertal sowie einen Eisacktaler Hof vor), einem „südtiroler Edelsitz" und einem Hauptgebäude zusammengestellt werden, wobei all diese Objekte „getreue Nachbildungen möglichst charakteristischer Originale mit Benützung alter Stiegen, Holzgeländer, ..." sein sollten. ${ }^{270}$

Kurz darauf griff Leopold Lindner Meyers Vorschlag freudig auf, da ihm die Jahrhundertfeier zum Heldenjahr 1809 ein gebührender Anlaß zum neuerlichen Beschluß dieses Vorhabens war.

Lindner schlug zwei Grundstücke zur Verwirklichung des Planes vor: entweder südlich der Maximilianstraße oder zwischen dem Löwenhaus und dem Rundgemälde, wo eine Fläche von $6.000 \mathrm{~m}^{2}$ zur Verfügung wäre. ${ }^{271}$

Die Tiroler Handels- und Gewerbekammer zögerte nun nicht mehr lange und beschloß noch im Juli des Jahres 1907 den Ankauf der „Löwenhaus-Gründe“ von

S. 463) Weiters erwähnt Kramer, daß „in Tirol vor 1914 in Hotels und bescheidenen Gaststätten die Sitte auf[gekommen sei], sich vom Maler ein sogenanntes E.-Meyer-Stübele [...] einrichten zu lassen“. Täfelung und Möbel wären im sogenannten „Tiroler Renaissance“-Stil gehalten gewesen und hätten „alt deutschen Charakter“" gezeigt! (ebd., S. 462) Zu Meyer u.a. Fischnaler Bd. V 1934, S. 152, Österr. Biograph. Lexikon Bd. 5 1972, S. 420, sowie Pflaundler 1983, S. 259.

270 Innsbrucker Nachrichten Nr. 84 vom 13.4.1907, S. 17.

271 Ebd. Nr. 118 vom 25.5.1907, S. 18; einzig in den hohen Kosten für Grunderwerb und Museumsaufbau sah er ein Hindernis. 
den Erben des verstorbenen Brauereibesitzers Franz Pötsch um einen Preis von 185.000 Kronen. ${ }^{272}$

Damit konnte das gewählte Museums-Kuratorium nun endlich mit den Vorbereitungen des Museumsbaues beginnen. Noch im gleichen Jahr wurde ein Wettbewerb für den Bau ausgeschrieben, zu dem bis Jahresende 1907 an die 30 Entwürfe einlangten.

Laut Ausschreibungstext sah das vorgesehene Bauprogramm ein „Gebäude des Gewerbe-Museums [vor, das] bei Vermeidung einer anspruchsvollen Ausstattung den Charakter eines öffentlichen Gebäudes tragen" sollte. Besonders wertgelegt wurde auf eine „bequeme, zweckentsprechende Unterbringung der einzelnen Sammlungen", die in den beiden Stockwerken des geplanten Baues erfolgen sollte. Insgesamt war, laut einer Aufzählung in den Innsbrucker Nachrichten, die Anlegung

- einer technologischen Sammlung,

- einer Bibliothek,

- eines Zeitschriften- sowie eines Zeichenzimmers,

- von Sälen für Stücke aus „romanischer, gotischer Zeit“,

- einer „gotische[n] Kapelle“,

- von Räumen für die Zinnsammlung, die Objekte der Schmiedekunst, für Gläser und Majoliken und ferner je ein Saal für Stickereien und Webereien geplant.

Weiters sah das Konzept die Einrichtung eines Saales mit

- Tiroler Trachten,

- Produkten der Hausindustrie,

- Tiroler Hausgeräten,

- Gegenständen des modernen Kunstgewerbes,

- einer eigenen Zunftstube,

272 Vgl. Prot. d. o. öff. Sitz. d. HGK in Ibk. vom 5.7.1907, S. 109 f.; der von der Stadt, unter Bürgermeister Greil, gutgeheißene Plan der Bebauung sieht, neben der Errichtung eines zweistöckigen Gebäudes, die Anlage eines Parkes und einer Uferstraße entlang des Inns vor. Der Ankauf eines so kostspieligen Areals war möglich, weil bereits 1906 die Sparkasse der Stadt Innsbruck in ihrer Generalversammlung beschlossen hatte, für den Bau eines Gewerbemuseums in Innsbruck einen Maximalbetrag von 500.000 Kr., in jährlichen Raten von 100.000 Kr., zur Verfügung zu stellen. Vor allem Altpräsident Anton von Schumacher, der sowohl in der Kammer, in der Sparkasse, wie im Gewerbeverein führend tätig war, war diese materielle Unterstützung zu verdanken (Siehe Prot. d. o. öff. Sitz. d. HGK in Ibk. vom 2.10.1906, S. 170.). 
- Exponaten des Tiroler Schützenwesens,

- Tiroler Krippen

- sowie Modellen alter Tiroler Bauernhäuser vor.

Wie im Bericht weiters angegeben, sollte bei den bereits vorhandenen „Bauernstuben und Herrenzimmer[n], welche vollständig erhalten sind und samt Holztäfelung und Decke aufzustellen wären [...] die Anordnung derart [getroffen werden], daß dieselben in ihren ursprünglichen Ausmaßen und Fenstern einfach einzureihen sind“; insbesondere werden „neun[!] gotische Bauernstuben, drei Bauernküchen, 11[!] Renaissance-Bauernstuben, zwei Renaissance-Herrenzimmer, ein Barockzimmer, ein Zimmer im Zopfstil, ein Biedermeierzimmer, ein Rokokozimmer, drei moderne Zimmer und vier bis fünf Reservestuben“ erwähnt.

Für die religiösen Ausstellungsgegenstände sollte, laut den Vorstellungen der Planer, ein „Hof mit eventuellem Kreuzgange“ errichtet werden.

Im Preisgericht, das über die Entwürfe zu entscheiden hatte, saßen u.a. Graf Enzenberg, J. Deininger, Arch. Hellmessen, Edgar Meyer, Anton von Schumacher und Stadtbaurat Ed. Klingler.

Es prämierte den Münchner Architekten Gabriel von Seidl mit dem ersten, die Wiener Architekten Leopold Bauer und Heinrich Ried mit dem zweiten und dem dritten Preis. ${ }^{273}$

Da die vollständigen Unterlagen des Wettbewerbes ebenso wie die eingelangten Entwürfe und Vorschläge nicht mehr auffindbar sind, ist eine umfassende Beurteilung des Bauvorhabens nicht mehr möglich. ${ }^{274}$

Die Innsbrucker Nachrichten gingen in einem Beitrag auf den ersten Preis des Architekten Gabriel von Seidl ein und stellten zu seinem Vorschlag fest:

„Sein Bau hat weiters nicht mehr von einer Ritterburg, als nötig ist, um den mächtigen Turm zu motivieren, und genug vom Bürgerhause, um vollberechtigt einen dereinst ihn einschließenden Stadtteil zu beherrschen."

273 Laut Innsbrucker Nachrichten Nr. 292 vom 19.12.1907, S. 9, sowie Nr. 294 vom 21.12.1907, S. 9. Alle prämierten Entwürfe waren angekauft und öffentlich ausgestellt worden, ebenso einige eingelangte Vorschläge, die Anerkennung gefunden hatten.

274 Die Unterlagen wurden inzwischen wieder aufgefunden. Einige Einreichungen werden dieser Arbeit als Abbbildungen eingefügt. Eine Gesamtbewertung der Projekte kann an dieser Stelle aber nicht geleistet werden. 
Weiters wurde das „Konzept des gelungenen Hineinwachsens in die Landschaft“ gelobt, sowie der große Saal als „vaterländische Ehrenhalle“ bezeichnet. ${ }^{275}$

In der Wiener Bauindustrie Zeitung findet sich eine detaillierte Darstellung des zwar nicht prämierten, aber angekauften Projektes des Dresdener Architekten Alexander Tandler.

Das Preisgericht hatte sich über diesen Vorschlag folgendermaßen geäußert: „Motto ,Heimat' zeigt in der Gesamtanlage und Durchbildung bis auf einzelne Partien bei ansprechendem Grundriß ein malerisches Empfinden. " ${ }^{276}$

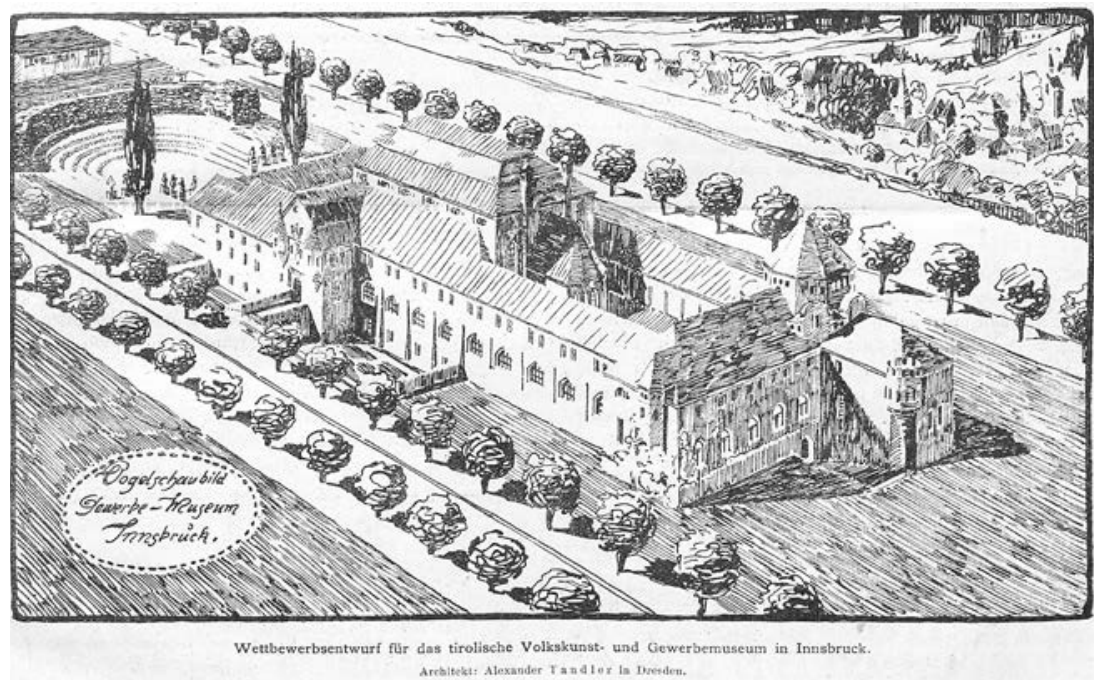

aus Wiener Bauindustrie Zeitung 25. Jhg. Nr. 38 (1908), S. 361

275 Innsbrucker Nachrichten Nr. 14 vom 18.1.1908, S. 17; in diesem Artikel, der mit „-bf-,, signiert ist, heißt es in Bezug auf die jetzt verstärkt auf Volkskunst ausgerichtete Sammeltätigkeit, dies müsse geschehen, da „vermögliche Fremde“ diese Gegenstände „für ein schönes Stück Geld“ abzukaufen versuchen und „die Bauern von heutzutage [...] keine verläßlichen Custoden mehr für unsere Schätze“ seien! (S. 14) Der Autor bemerkte eher herablassend, daß die Zeit der „lebendigen Entwicklung dieser Volkskunst im Volke selbst [...] vorläufig abgeschlossen“ wäre, aber vielleicht wieder eingebürgert werden könnte und man deshalb von einem Besitzer solcher Gegenstände bereits „Kunstsinn“ erwarten müsse, wollte man, daß er sich „davon nicht trenne"! Zu den neuen Plänen der Museumsbetreiber, die der Autor vor allem von Anton von Schumacher initiert sah, bemerkte er: „Das Volksleben der Vergangenheit selbst soll in die neuen Räume einziehen und den Besucher vom ersten Schritt durch das Tor an umgeben." (ebd.) Zwei Aufrißzeichnungen des Seidl-Projektes befinden sich im Archiv des Tiroler Volkskunstmuseums.

276 25. Jhg. Nr. 37 (1908), Titelseite; weitere sechs Abbildungen finden sich in der nächsten Nummer desselben Jahrganges (Nr. 38), S. 361 ff.; daraus die Kopie der Vogelschauperspektive. 
Die abgebildete Vogelschauperspektive zeigt deutlich den eklektizistischen Charakter des Entwurfes; Versatzstücke einer Burg, eines Klosters, einer Kirche bilden zusammen mit dem wuchtigen Hauptgebäude und den langgezogenen Saalgängen ein eigenartiges Ganzes. Gotische Maßwerkerker sollten dem Ensemble ein städtisches Gepräge geben, der amphitheaterartig gestaltete westliche Museumsvorplatz sollte das Auftreten und Aufmarschieren von Trachten-, Brauchtums-, Schützen- und Musikgruppen ermöglichen.

Dieser eingeschlagene Weg im Museumsbau übertraf alle bisher gefaßten Pläne und Vorstellungen:

- Die Versuche, ganze Stuben sowie komplette Bauernhäuser aufzustellen, lagen weit jenseits der bis dahin geplanten Vorhaben.

- Das zukünftige Museum sollte keine Mustersammlung sein, nicht mehr bloßes Gewerbemuseum, sondern eine Stätte der Präsentation der eigenen Nationalkultur in Vergangenheit und Gegenwart.

Nicht mehr die Leistungsschau, im Sinne einer konkurrierenden Präsentation von Objekten der ausstellenden Gewerbetreibenden, war gefragt, sondern eine kontemplative Sammlung, die gleichsam Quintessenz des Tiroler Kultur- und Volkskunstschaffens sein sollte.

Auch den Innsbrucker Museumsgründern war - ähnlich den Betreibern des bereits 1855 gegründeten „Bayerischen Nationalmuseums“ in München, das ebenfalls um die Jahrhundertwende eine Trachtensammlung sowie diverse Stuben aus dem Tiroler Raum erworben hatte - klar geworden, daß eine Gewerbeförderung, die nur auf einer reinen Vorbildsammlung basieren würde, „eher eine verhängnisvolle Wirkung“ ausüben mußte, „und daß es deshalb neuer, mehr elastischer Methoden bedurfte, um das Gewerbe zu fördern“"277.

Obwohl über die innere Ausgestaltung des geplanten Museums nichts zu erfahren war, sich keinerlei theoretische Äußerungen darüber finden und es daher schwierig ist, dieses Vorhaben hinsichtlich der Präsentation der Objekte einzuordnen, dürfte für dieses Innsbrucker Museumsvorhaben dasselbe zutreffen, was Norbert Schindler generell in Bezug auf das Museum des 19. Jahrhunderts geschrieben hat:

277 So Oskar Lenz in seinem Einleitungsbeitrag zur Festschrift des 100jährigen Bestandes des „Bayerischen Nationalmuseum München“, 1955, S. 28. Als 1929 der Bayerische Landesverein für Heimatschutz dem Museum eine Sammlung volkskultureller Objekte übergab, konnte dessen Abteilung für „Volkskunde und Volkskunst“ ausgebaut werden. 
„Das Museum des 19. Jahrhunderts ist die Zerstörung des sozialen Kontakts schlechthin, und das kontemplative Schweigen, auf dem es beruht, ist das Ergebnis einer künstlich herbeigeführten doppelten Isolation: der Kontextlosigkeit der (höchst spärlich beschrifteten) Ausstellungsstücke entspricht die Ratlosigkeit des sich selbst überlassenen Betrachters. “278

Meiner Meinung nach wäre dieser Feststellung noch hinzuzufügen, daß, trotz der „Ratlosigkeit des [...] Betrachters" gegenüber den sich nicht erklärenden Objekten, über diese, für den Besucher meist unbewußt, Ideologie transportiert werden kann und sei es die, daß er der Präsentationsabsicht folgt und in den Gegenständen DIE Tiroler Volkskunst erblickt.

Dies, sowie die ebenfalls von Schindler diagnostizierte „Verrätselung und Indexierung der Gegenstände, die sich nur dem ,Kenner“ entschlüsseln“ und denen ein „Bildungsverständnis [innewohne], das den ihm inhärenten Widerspruch von Exklusivitäts- und Verallgemeinerungsansprüchen dadurch ausbalanciert, daß es seine Ausschlußmechanismen verschweigt und über das von ihm affirmierte Unwissen vornehm hinwegsieht", scheinen mir die Hauptintentionen des Museums im 19. Jahrhundert gewesen zu sein. ${ }^{279}$

Letztendlich scheiterte der Seidl-Plan aber daran, daß seine Realisierung zu teuer gekommen wäre, denn trotz der reichhaltigen Unterstützung durch die Sparkasse (500.000 Kr.) und einer Zusage der Stadt Innsbruck, 100.000 Kr. vom Kaufbetrag des Baugrundes zu übernehmen, ${ }^{280}$ gelang es in den nächsten Jahren nicht, das nötige Kapital für das Vorhaben aufzutreiben.

Ein nicht näher bekannter Autor mußte in seinem Beitrag über die Idee eines „National-Museums“ in Innsbruck eingestehen, daß die Pläne zur Errichtung des Museums nun schon seit 16 Jahren bestehen würden, aber noch immer wegen Geldmangels nicht zur Verwirklichung gelangt wären. Auch das Seidl-Projekt sei

278 1984, S. 30.

279 Ebd.; die Loslösung der Objekte aus ihrem sozialen Kontext, der sparsame Gebrauch der Beschriftung usw. traf für die Sammlungspräsentation des Tiroler Volkskunstmuseums zu, sodaß die Kritik auch für diese Institution ihre Berechtigung hat. Aus all diesen Gründen kann die Museumskonzeption, auch wenn erst im 20. Jahrhundert durchgeführt, als eine des vorigen Jahrhunderts bezeichnet werden!

280 Vgl. Innsbrucker Nachrichten Nr. 203 vom 4.9.1908, S. 5 f.; es gelang den Betreibern wenigstens, für die zahlreicher werdenden Gegenstände des zukünftigen Museums von der Finanzlandesdirektion die Bewilligung zu erhalten, die Bauernstuben bis auf Widerruf, um eine Miete von 5 Kr./Monat, in der Dogana zu lagern (TLA, Präs. Nr. 4182 ex 1908; der zusagende Brief des Landes vom 8.7.1908 an die HGK trägt die Zl. 1822). 
nun „fragwürdig geworden“ und könne der hohen Kosten wegen nicht realisiert werden. Deshalb schlug der Verfasser ein Ausweichen auf andere Standorte, zum Beispiel ins Goldene Dachl, vor, stand aber auch einer Vereinigung mit dem Ferdinandeum positiv gegenüber und wünschte auf jeden Fall dem Projekt die möglichst baldige Ausführung. ${ }^{281}$

Am 12. Februar 1912 kam es im Hotel Greif zu einer Versammlung des „Tiroler Gewerbevereines“, bei der die ungelöste Standortfrage erörtert wurde.

Bei gutem Besuch (darunter neben Gewerbetreibenden zahlreiche Personen aus der Innsbrucker Künstlerschaft) und lebhafter Diskussion, so zumindest der wohlwollende Bericht in den Innsbrucker Nachrichten, stellten Architekt Arthur Payr und Prof. W. Baier ein von ihnen verfaßtes, neues Projekt vor, das den Standort Weiherburg vorsah.

Insgesamt sollte dieses Vorhaben nicht mehr als $400.000 \mathrm{Kr}$. kosten, und des bequemen Zugangs wegen war eine neue Straßentrasse zur Weiherburg geplant.

Schlußendlich war die Mehrheit der anwesenden Vereinsmitglieder für dieses Projekt. ${ }^{282}$

Kurze Zeit später wurde im selben Blatt unter dem Titel „Das Museum für Tiroler Volkskunst und Gewerbe auf der Weiherburg“ das neue Vorhaben näher erläutert. Das Projekt des Umbaues der Burg beinhaltete, daß der vordere alte Teil der Weiherburg vollständig erhalten bleiben würde, der rückwärtige Flügel aber neu zu erstellen wäre, da dieser nicht aus alter Bausubstanz bestand, sondern erst im 19. Jahrhundert errichtet worden war. Im Westen und Osten sah der Plan je einen Seitenflügelneubau vor.

Im Westflügel war die Errichtung einer Kapelle und eines dahinter liegenden Waldfriedhofs geplant. Der Ostflügel sollte hingegen mit den bereits bestehenden Jägerhäusern durch einen Säulengang verbunden werden.

Sogleich kamen erste Einwendungen zum geplanten Vorhaben, wobei vor allem die abgelegene Lage des Standortes bemängelt wurde, die sowohl Gewerbetreibende als auch Fremde von einer Besichtigung abhalten würde (so ein kritischer

281 Innsbrucker Nachrichten Nr. 58 vom 12.3.1910, S. 1 ff.; der Autor, der nur mit „-S“ unterzeichnete, berichtete, daß sich die meisten der angekauften Stuben noch an Ort und Stelle ihrer Herkunft befinden würden (S. 3) und zeigte sich erstaunt, daß „,noch so viel aufzutreiben war. Allerdings weiß jeder Kenner der Verhältnisse, daß mit diesen letzten Erwerbungen wohl [...] nun alle Quellen überhaupt versiegt sind“. (S. 2) Auch die Neuen Tiroler Stimmen hatten in einem Beitrag 1910 die Vereinigung mit dem Ferdinandeum als Vorantreibung des Museumvorhabens begrüßt (50. Jhg. Nr. 62 vom 17.3.1910, S. 1).

282 59. Jhg. Nr. 39 vom 17.2.1912, S. 3 f. 
Einwand Anton von Schumachers, der das Museum lieber zentral situiert haben wollte, dann aber aus pragmatischen Gründen für das Weiherburg-Projekt eintrat.). ${ }^{283}$

Daneben beteiligten sich viele prominente Personen der Stadt Innsbruck und des Landes Tirol an der Diskussion um den neuen Museumsstandort.

Ein weiterer Vorschlag für ein Museum in Stadtnähe kam von k.k. Baurat Architekt M. Haas, dem nur hier ein ausreichender Zustrom von Einheimischen und Fremden gesichert erscheint. Haas brachte auch ein inhaltliches Argument gegen die Adaptierung der Weiherburg, galt es ihm doch als bedenklich, daß „die historische Weiherburg mit zwei modernen langgestreckten Seitenflanken in seiner Wirkung profaniert würde“.

Stattdessen schlug er als Ausweichmöglichkeit vor, den alten Wappenturm wiederzuerrichten oder das alte Gymnasialgebäude (das „Theresianum“) bei der Hofkirche dafür zu verwenden. ${ }^{284}$

Einige Tage darauf findet sich in derselben Zeitung eine Entgegnung auf den Haas-Plan, wobei der Verfasser den Wiederaufbau des Wappenturms wegen des unzureichenden Grundlagenmaterials für nicht durchführbar hielt.

Bei der Adaptierung des „Alten Gymnasiums“ gab er zu bedenken, daß dort sicher nicht genügend Raum für die 14.000 Objekte zur Verfügung stehen würde, und daß es ihm unmöglich erschien, dort die Stuben einzubauen, weil ja die Erker nicht angebracht werden könnten.

Er hielt deshalb das Weiherburg-Projekt zwar nicht für ideal, aber doch aus finanziellen Gründen als das einzig Durchführbare. ${ }^{285}$

In erster Linie ging es bei der ganzen Debatte nicht um eine inhaltliche Museumsdiskussion, sondern um die Standortfrage: Weiherburg Ja oder Nein war der Tenor aller Beiträge.

283 Nr. 41 vom 20.2.1912, S. 1 ff.

284 Für die Ausgestaltung des Wappenturms hatte Haas dem Innsbrucker Verschönerungsverein und der Stadt dahingehende Pläne zukommen lassen (vgl. Innsbrucker Nachrichten Nr. 51 vom 2.3.1912, S. 17). Interessant ist, daß hiermit erstmals das „Theresianum“, die jetzige Heimstätte des Museums, ins Gespräch gebracht wurde.

285 Ebd. Nr. 54 vom 6.3.1912, S. 10 (der Artikel ist mit „-R. “ signiert); mit der Kritik des beschränkten Raumangebotes im alten Gymnasium hat Haas sicher dessen wunden Punkt getroffen, ist die Frage der mangelnden Depotfläche und der fehlenden Erweiterungsmöglichkeiten heute noch ungelöst! Der Einbau der Stuben (incl. deren Erker) konnte hingegen, dank des ausgeklügelten Einbauprogrammes, das einen Raum im Raum erzeugte, ohne Probleme durchgeführt werden. 
Die Kritik der Gegner des Weiherburg-Projektes bezog sich vor allem auf die beträchtliche Entfernung der Burg vom Stadtzentrum und der damit verbundenen Befürchtung eines daraus resultierenden geringeren Besucherzustromes.

Ein zweiter Ablehnungsgrund betraf vor allem die Ausbaupläne, da damit, so die Ablehnenden, das Gepräge der Burg zerstört würde.

Die Befürworter entgegneten dem, daß die Weiherburg ohne Zubauten in ihrer jetzigen Gestalt viel zu klein wäre, um all die Gegenstände des Museums aufnehmen zu können. ${ }^{286}$

In der Gemeinderatssitzung vom 25. April 1912 kam es dann zu einem Antrag von Gemeinderat Kapferer, der beinhaltete, das Museum auf der Weiherburg einzurichten. ${ }^{287}$

Die Gegner des Projektes versuchten weiterhin andere Standorte zu propagieren. In der Kunsthandlung Czichna wurden Planskizzen des Architekten Oskar Huber ausgestellt, der einen Museumsneubau nebst Künstlerhaus und Kursalon auf den „Zelgergründen“ verwirklichen wollte und für die Weiherburg die Errichtung eines kleinen Museums zu Ehren Kaiser Maximilians vorsah. ${ }^{288}$

286 In der am 10.6.1912 im „Breinößl“ stattgefundenen Monatsversammlung des „Tiroler Gewerbevereines“, die sich ausschließlich mit der Standortfrage des Gewerbemuseums befaßte, kamen fast alle Befürworter und Gegner des Weiherburg-Projektes zu Wort! Als Befürworter sprachen u.a. Arch. Hellmessen, Prof. Baier, Arch. Krapf, B. Zösmayr, A. von Schumacher, HGKVicepräs. Sonviko, HGK-Präs. Walter, BM Greil; als Gegner des Projektes deklarierten sich H. Roth (München), Ing. Allitsch, L. Lindner, GR K. Landsee, Dr. Lehndorf. Arch. Paulmichl machte auf der Versammlung den Vorschlag, alle „Dubletten an die Lokalmuseen abzugeben“, diese wären froh und so wäre Platz für ein kleineres Museumsprojekt. (Zit. nach Lang 1912, S. 53 ff.; der u.a. einen Bericht der Tiroler Stimmen über die Versammlung wiedergibt.) Leonhard Lang (1843-1928), Papiergroßkaufmann, vielfältiger Mäzen, Ehrenbürger der Stadt Innsbruck und vehementer Gegner des Weiherburg-Projektes, gab in diesem Buch vor allem die kritischen Einwände des Münchner Dekorationsmalers Ferdinand Wagner (1847-1927) wieder und nahm Originalberichte diverser Zeitungen zur Standortfrage des Gewerbemuseums auf. Zu Lang vgl. das Österr. Biogr. Lexikon Bd. 4 1969, S. 443 und Pfaundler 1983, S. 222; zu F. Wagner d. Jüng., Sohn des gleichnamigen Historienmalers (1820-1881), das Allg. Lexikon d. Bild. Künstler, 35. Bd., 1942, S. 32.

287 Neue Tiroler Stimmen 52. Jhg. Nr. 95 vom 26.4.1912, S. 3 f.; der Gemeinderat der Stadt Innsbruck stand mehrheitlich hinter dem Weiherburg-Plan weil damit für die, seinerzeit von der Stadt unter Bürgermeister Greil angekaufte, - in desolatem Zustand befindliche - Burg eine Verwendung gefunden war.

288 Ebd. Nr. 106 vom 9.5.1912, S. 2; die Verwendung der Weiherburg als „Kaiser-Max-Museum“ war von vielen Münchner Künstlern gefordert worden (vgl. Lang 1912). 
Eine Anzahl von Tiroler Künstlern (darunter der schon greise Defregger, ferner Egger, Wopfner, Schmidt) wandte sich gegen das beabsichtigte Museumsprojekt und verlangte die Beibehaltung der Weiherburg in ihrem Urzustand. ${ }^{289}$

Auf der Versammlung des Gewerbevereines schlug Prof. Allitsch eine „allgemeine Bürgerversammlung à la Schweiz" vor, um so den Museumsstandort Weiherburg, dem er persönlich nicht anhänge, abgeklärt zu wissen. ${ }^{290}$

Schlußendlich nahm die Diskussion der Standortfrage härtere und zynischere Formen an, sicher eine Folge der zugenommenen Verbitterung und Enttäuschung, daß einerseits das Museumsprojekt unter der gegebenen politisch-kulturellen Situation in Tirol nicht verwirklicht werden konnte, andererseits die Stadt Innsbruck nicht über genügend Mittel verfügte, um das Museum im Stadtzentrum zu errichten oder das Geld nicht dafür aufwenden wollte.

Schon sichtlich enttäuscht über die Entwicklung äußerte sich ein Kommentator in den Neuen Tiroler Stimmen:
„Wenn an maßgebender Stelle der ernste Wille vorhanden wäre, das Ge- werbemuseum mitten in die Stadt zu stellen, wohin es gehört [...], dann müßte die Ausführung denn doch möglich sein., Wo ein Wille ist, ist auch ein Weg. 'Die Stadt hat unter Bürgermeister Greil schon größere und teu- rere Werke gemacht. ${ }^{(2211}$

Sogar die sozialistische Volkszeitung konnte dem Standortstreit nichts mehr abgewinnen und vermerkte in ihrem Bericht über eine Versammlung des „Tiroler Gewerbevereines“: „Sonderbar berührte es, daß gerade diejenigen, welche die Erstellung eines Gewerbemuseums am meisten berühren sollte, die Gewerbetreibenden, beziehungsweise die Vertreter des Kunstgewerbes, eigentlich durch ihre Abwesenheit glänzten." Und weiter hieß es dort: „Wo waren alle die Schlosser, die Schmiede, Tischler usw., die von dem Gewerbemuseum durch Studien Belehrung und Anregung empfangen, die es eventuell mit Produkten eigener Er-

289 Vgl. Volkszeitung Nr. 156 vom 10.7.1912, S. 5; Tiroler Künstler verfaßten einen Protestbrief an den Innsbrucker Gemeinderat, auf den GR Mader reagierte: Zur „Vermeidung von Mißverständnissen [wäre] festzustellen, daß auch der Gemeinderat den Wunsch habe, die Weiherburg als historisches Gebäude zu erhalten." (Ebd. Nr. 158 vom 12.7.1912, S. 3.)

290 Neue Tiroler Stimmen 52. Jhg. Nr. 121 vom 29.5.1912, S. 1 f.; die Versammlung hatte am 20.5.1912 stattgefunden. - Über eine eventuell weiter geplante oder gar durchgeführte „Bürgerversammlung“ war allerdings nichts Näheres in Erfahrung zu bringen!

291 Nr. 134 vom 14.6.1912, S. 1 ff. 
zeugung beschicken wollen? Sie alle haben gefehlt. ${ }^{292}$ Dem Blatt zufolge waren Gegner und Befürworter des Vorhabens auch politisch gespalten: die „Angehörigen der Magistratspartei [= Liberale; W.M.] für Weiherburg“, das „klerikale Lager für Zelgergründe“; insgesamt hätten, der Zeitung nach, die Mitglieder des „Volkswirtschaftlichen Vereins" (Hoteliers, Kaufleute usw.) den Stadtstandort bevorzugt. In zynischer Art hatte das Blatt auch einen Vorschlag zur Lösung der Museumsfrage bereit: Demnach sollte ein Aufruf an alle „tirolisch-patriotisch gesinnten Geldmänner [gemacht werden und man] appelliere an ihren Patriotismus [...] dann wird eine Million Kronen bald beisammen sein, und das Museum kann in wenigen Monaten erstehen“. Wenn das nichts fruchte, ätzte die Zeitung weiter, und die
„klerikalen Interessenten schon das Gewerbemuseum auf den Zelger- gründen haben wollen [...] so mögen sie doch, da alle diese Leute, die Herrn Wachszieher Lindner, Papierhändler Lang usw. schwer vermögende Geldmänner sind, zu denen sich noch Herr von Sieberer gesellt, ihre mit Bank- und Staatsnoten und anderen Wertpapieren gefüllten Wertheimer aufsperren und ihnen soviele Tausender entnehmen, daß die Erbauung des Gewerbemuseums gesichert wird. ${ }^{\text {293 }}$

In den beiden Volkszeitungsbeiträgen lag, trotz des satirischen Einschlages, ein wahrer Kern verborgen: die Tatsache, daß es beim ganzen Unternehmen schon lange nicht mehr um die Errichtung eines Gewerbemuseums in Form einer Vorbild- und Mustersammlung ging. Daher war auch das Engagement der Gewerbetreibenden gering, da ihnen aus diesem Vorhaben kein größerer Nutzen erwuchs. ${ }^{294}$

292 20. Jhg. Nr.132 vom 11.6.1912, S. 6; stattdessen vermerkte das Blatt, wäre das Gros der Besucher Advokaten, Gastwirte, Handels- und Geschäftsleute gewesen, und da sich die Gegner und Befürworter des Projektes ungefähr die Waage gehalten hätten, „endete [die] Veranstaltung wie [das] Hornberger Schießen“! Die Zeitung selber favorisierte, zwar skeptisch, das Weiherburg-Projekt, weil eine Stadtlage, ihrer Ansicht nach, noch kein Versprechen für einen großen Besucherzustrom bedeuten müßte, wie das Beispiel des Ferdinandeums zeigen würde. Ferner böte die Weiherburg den Einheimischen, die unter der Woche sowieso keine Zeit für einen Museumsbesuch hätten, die Gelegenheit, am Wochenende „Natur und Kunst“ gemeinsam zu besuchen (ebd. Nr. 150 vom 3.7.1912, S. 5).

293 Ebd. Nr. 150 vom 3.7.1912, S. 5 f.

294 Die einfachen Handwerker und Gewerbetreibenden hatten im „Tiroler Gewerbeverein“ nie eine starke Position! (Vgl. Kapitel 4.) Der Volkszeitung war die mangelnde Beteiligung tatsächlich Gewerbetreibender an diversen Vereinsaktivitäten aufgefallen, und sie schrieb daher, bezugnehmend auf eine Versammlung zur Standortfrage des Museumsbaues, daß, trotz 180 ausgesandter Einladungen nur 30 Personen erschienen wären, und weiter: „Der Frage, wo das Gewerbemuseum errichtet werden soll, scheint leider nicht das Interesse entgegengebracht 
Die Intention der Betreiber bestand vielmehr in der Errichtung eines Nationalmuseums, einer nationalen Kunstgedenkstätte, die die Leistungen der Tiroler Volkskunst in Bezug auf Identitäts- und Integrationsfunktionen präsentieren sollte.

Die Betonung der nationalen Kultur, hier als Volkskunst hervorgehoben und für alle (DAS VOLK) propagiert, hatte ihren Ausgang in einem spezifisch tirolischen Problem: Die südlichen Landesteile, die italienischsprachigen Gebiete, befanden sich gerade um die Jahrhundertwende und verstärkt vor dem Beginn des Ersten Weltkrieges in einem heftigen Loslösungskampf gegenüber dem dominierenden „Deutschtirol“.

Das deutsch-national gesinnte Bürgertum empfand diese „walschen“ Autonomiebestrebungen als Bedrohung und reagierte darauf mit geradezu chauvinistischen Mitteln (vgl. die Aktivitäten des „Tiroler Volksbundes“, dessen Mitbegründer der eifrige Einkäufer und Museumsbetreiber Edgar Meyer war).

Nicht zuletzt war das Vorzeigen einer tirolisch-deutschen Nationalkunst (=Tiroler Volkskunst) ein wichtiges Hilfsmittel zur Stützung der deutsch-tirolischen Identität, und immer wieder wurde der besondere Charakter dieser Kunst (z.B. in der Stilfrage: die deutsche Gotik als DER Tiroler Kunststil) hervorgehoben!

\subsubsection{Die Stellung des Landes zur Museumserrichtung}

Die Einstellung des Landes zum Museumsvorhaben ist nicht ohne weiteres zu rekonstruieren.

Es finden sich von Landesseite kaum Stellungnahmen und wenn dies als Äußerung gewertet wird, so scheint die Position der offiziellen Landesvertretung eher abwartend gewesen zu sein, auch wenn jährliche Subventionsvergaben an die Museumsbetreiber erfolgten.

Einzig die regelmäßigen Unterstützungsansuchen und deren Prüfung und Gutheißung durch die Gremien des Tiroler Landtages zeigen deren Einstellung zur Museumserrichtung. Daran ist auffällig, daß, als die reale Museumsentwicklung schon längst in eine andere Richtung fortgeschritten war, das Argument der Gewerbeförderung und der Museumserrichtung als Vorbild- und Mustersammlung aufrechterhalten blieb.

zu werden, die sie tatsächlich verdienen würde." (Nr. 156 vom 10.7.1912, S. 5) Die geringe Zahl der Anwesenden, vor allem aus dem Künstlerkreis, beschloß dann die Ablehnung des Weiherburg-Projektes! (ebd.) 
Im 1908 gestellten Subventionsansuchen an den Tiroler Landtag, in dem der Berichterstatter Anton Kofler die Fortsetzung der Subventionsgewährung von 1900 forderte und gebilligt bekam, referierte er über den geänderten Museumsnamen, rechtfertigte aber die Änderung mit der dadurch verbesserten Möglichkeit der Gewerbeförderung.

Zur neuen Aufgabe des Museums meinte Kofler: „Um seine Ziele klarer zu bezeichnen“, hätte sich die in Entstehung befindliche Institution den

\begin{abstract}
„Titel ,Museum für tirolische Volkskunst und Gewerbe beigelegt [und sich vorgenommen], kunstgewerbliche und hausindustrielle Erzeugnisse aus allen Teilen des Landes, aus alter und neuer Zeit zu sammeln, um den Gewerbetreibenden mustergiltige, bodenständige Vorbilder zu bieten, nach welchen sie spezifisch tirolische Artikel, namentlich auch für den durch den Fremdenverkehr hervorgerufenen Bedarf sogenannte Fremdenartikel erzeugen können."
\end{abstract}

Nicht zuletzt betonte er im Ansuchen den unmittelbaren ökonomischen Verwertungszusammenhang der musealen Sammlungen für die Fremdenindustrie:

„Gerade unter dem Gepräge der alten tirolischen Volkskunst, dem sich auch die moderne Richtung nicht vollständig wird entziehen können, werden auch die neuen Arbeiten ein spezifisch tirolisches Gepräge erhalten, was gewiß zur Erhöhung der Absatzfähigkeit, insbesondere beim Fremdenpublikum ganz wesentlich beitragen wird. “2255

Das Gesuch der Tiroler Handels- und Gewerbekammer, der Tiroler Landtag möge die ausständige Subventionsrate für 1912 sowie ausnahmsweise auch schon die für die Jahre 1913-15 bewilligten Zuwendungen (im Ausmaß von 18.000 Kr.) flüssigmachen, wurde von den Abgeordneten bewilligt. ${ }^{296}$

In der Sitzung des Tiroler Landtages vom 3. Juli 1914 kam es, ausgelöst durch ein weiteres Unterstützungsansuchen für die Museumserrichtung, zu einer größeren Debatte zwischen den deutschen und den italienischen Abgeordneten.

295 Sten. Prot. d. Tir. Landtages 23. Sitz. d. 1.Sess. d. X. Per. am 4.11.1908, S. 579 f.; sowie Beilage 424 (Landesausschuß Zl. 15436/08/Ldtg. Zl. 513); (Hervorhebung von W.M.). Das Subventionsansuchen wurde bis 1913 bewilligt und umfaßte für das Museum eine jährliche Zuwendung von Landesseite im Ausmaß von 1.000 Kr. (fälschlicherweise im Prot. 2.000 Kr., vgl. Beilage). Die Beiträge für 1906-08 wurden nachträglich genehmigt. (Ebd.)

296 Ebd. 6. Sitz. d. 4. Sess. d. X. Per. d. Tir. Landtages am 10.5.1913, S. 106 f.; sowie Beilage 125 (Landesausschußzl. 731/VI/Landtagszl. 607 ex 1912). 
Berichterstatter Dr. Mayr beantragte, 20 Jahre lang jährlich 15.000 Kronen aus dem Landeshaushalt dem Museumskuratorium für die Rückzahlung eines Baukapitals von $300.000 \mathrm{Kr}$. zur Verfügung zu stellen.

Im Anschluß daran meldete sich der liberale Trentiner Großgrundbesitzer Dr. Silvio Viesi zu Wort und meinte, er könne der Subventionsvergabe für das „Museum für Industrie und Gewerbe“ nicht zustimmen, da damit bloß ein lokal begrenztes Vorhaben unterstützt werde, das keinen allgemeinen Sinn hätte. Daher forderte er für das Trentino auch auf diesem Gebiet Unabhängigkeit, nämlich die Möglichkeit, eigene solche Einrichtungen zu schaffen.

Sein nationalliberaler Kollege Guido Sartori, Abgeordneter des Städtebezirkes Arco, unterstützte diese Einwände und präzisierte sie noch: Der vorgegebene erzieherische und bildnerische Wert des Museums erschien ihm nebensächlich, auch wenn im Komitee nur darüber gesprochen worden wäre.

Sartori erklärte in seiner Rede, daß er sich die Gegenstände angesehen und dabei hätte feststellen müssen, daß diese Sammlung NICHTS mit Erziehung zu tun hätte und somit auch der Museumstitel „Volkskunst und Handwerk“ irreführend wäre; und überhaupt, wie er weiters betonte, käme in der Sammlung kein Trentiner Handwerk vor, sie enthielte gar nichts Trentinisches, auch wenn die Bewohner der südlichen Landesteile mitbezahlen müßten; vielmehr wäre sie eine rein „Tiroler Sache“, obschon ihr „Ruhm für [alle] Tiroler“ gälte.

Im Vergleich zum Münchner Gewerbemuseum, so Sartori weiter, befänden sich in den Tiroler Sammlungen keine alten und neuen Maschinen, Modelle etc., sondern diverse Geräte, Einrichtungen, Möbel aus den verschiedensten Epochen und Tälern Tirols, ferner eine Sammlung von Bräuchen und Sitten sowie Lebensweisheiten aus diversen Zeiten und Regionen; kurz gefaßt wäre die Institution seiner Meinung nach eher ein „Museo etnografico“ wie das Münchner „Nationalmuseum" und müßte daher auch so genannt werden.

Sartoris Kritik bezog sich nicht bloß auf die Subventionierung eines „ethnografischen Museums", vielmehr auf den Umstand, daß sich, seiner Ansicht nach, alles auf EINE Nation, nämlich auf die „deutsche“, beziehen würde und für „,unsere Nation" (= die italienische; W.M.) keinen Vorteil brächte.

Den Einwand, daß Trentiner Sachen neben deutsche Sammlungsstücke gestellt werden könnten, ließ er nicht gelten, würde doch, seiner Auffassung nach, die Einbeziehung aller Regionen (Venezien, Lombardei usw.) den Raum der Sammlung sprengen und einen zu großen Kontrast bilden.

Seiner Meinung nach wäre dies bloß eine Alibiaktion, wie sie jetzt schon im Museum geschehe, das Nons-, Fleims- und Fassataler Gegenstände aufstellen würde: Objekte, vor allem „Hirtendinge“, die nicht typisch für den Trentiner Raum wären und deshalb ein falsches Bild entstehen ließen. 
Insgesamt erschien ihm die Errichtung eines „ethnografischen Museums“ in Tirol als nicht vordringlich, da doch zum Beispiel Stuben, Trachten, Geräte, ... in Genüge vorhanden wären und im Moment keine Gefahr bestünde, daß ein „modernes Netz der Uniformität über die Täler“ gezogen würde.

Den Abschluß seiner Rede bildete ein Appell an die deutschen Abgeordneten: Sie sollten warten, bis sie sich ihr Nationalmuseum mit eigenen Geldern erbauen könnten und nicht darauf hoffen, Gelder aus den südlichen Landesteilen dafür verwenden zu können, die dann wichtigeren Projekten wie sozialen Institutionen (Schulen, Irrenanstalten und Behinderteneinrichtungen) fehlen würden. ${ }^{297}$

Interessant ist, wie nun von seiten des Berichterstatters Dr. Mayr auf diese Kritikpunkte eingegangen wurde.

Dieser argumentierte in erster Linie formal, indem er das Recht der Landeshauptstadt auf solch eine vermeintlich hohe Subventionssumme herausstrich, da immerhin die Stadt Innsbruck der größte Umlagenzahler des Landes wäre.

Auf die „Hinweise auf das Münchener Nationalmuseum usw.“ ging er nicht weiter ein, weil dies, seiner Ansicht nach, zu weit führen würde. Ferner wandte er sich mit Verweis auf die Landeseinheit entschieden dagegen, daß Sartori das Verbringen von Altertümern aus den italienischen Gebieten kritisierte. ${ }^{298}$

Aus dieser, im Zuge des Subventionsansuchens entstandenen, Debatte geht hervor, daß es im Landtag ein weitgehend unhinterfragtes Einvernehmen darüber gab, das Museum vornehmlich als Gewerbeförderungsinstitution zu betrachten. Auf abweichende Ansichten gingen die deutsch-tirolischen Abgeordneten nicht ein; sofern die Bedenken, wie oben geschildert, von italienischer Seite kamen, wurde ihnen ausgewichen, oder diese wurden als irredentistisch abgetan.

297 Ebd. 16. Sitz. d. 1. Sess. d. XI. Per. d. Tir. Landtages am 3.7.1914, S. 451 ff. und Beilage 127 (Landesausschuß Zl. 363/3/VI/ Landtagszl. 251 ex 1914); nach Sartori betrug der Preis des ganzen Unternehmens über $1 \frac{1}{2}$ Mill. Kronen, was ihm zu teuer erschien! Ich danke Paul Rösch für die Übersetzungshilfe, da die Diskussionsbeiträge von Viesi und Sartori in den Protokollen im italienischen Original wiedergegebenen sind.

298 Ebd., S. 453 f.; schlußendlich wurde der Antrag mit der Abänderung, den ersten Subventionsbetrag erst 1915 auszuzahlen, mehrheitlich und ohne weiteren Kommentar angenommen. (Ebd., S. 454.) 


\subsubsection{Die Sammlungsobjekte des „Museum für Volkskunst und Gewerbe“}

„Ein Erzeuger falscher Altertümer, der die Verwitterung durch Schrotschüsse erzeugte und der von einem Tisch sagte:

Jetzt müssen wir noch dreimal auf ihm Kaffee trinken, dann kann er ans Innsbrucker Museum weggeschickt werden. ${ }^{\text {“299 }}$

Obwohl vor dem Ersten Weltkrieg die Suche nach einem endgültigen Standort nicht von Erfolg gekrönt war und somit das Museum nicht eröffnet werden konnte, beschäftigte sich das Kuratorium eifrig mit dem Ankauf von Sammlungsgegenständen.

Welchen Objekten anfangs vornehmlich die Aufmerksamkeit der Museumsbetreiber galt, läßt sich nicht mehr genau feststellen, denn es sind keine genauen Beschreibungen der gesammelten Gegenstände erhalten. Die eventuell geführten Einkaufsbücher sind nicht mehr vorhanden, die erst später vorgenommene Inventarisierung gibt keinen genügenden Aufschluß darüber, von wo, von wem und wann die Gegenstände erworben wurden.

Ein guter Teil der Objekte gelangte über Antiquitätenhändler in den Besitz des Museums. Diese lieferten den Einkäufern die vielfach begehrten tirolischen Altertümer.

Daher finden sich im Museum dort regionale Häufungen an gesammelten Gegenständen, wo ein reger Antiquitätenhändler Zulieferer der Museumsbetreiber war (Brixlegger Gegend im Unterinntal, Meraner Gegend, ...), während andere Regionen (u.a. der Innsbrucker Raum) bei der Sammeltätigkeit nahezu nicht abgedeckt wurden, weil es dort an eifrigen Zuträgern fehlte oder diese die Gegenstände lieber ins Ausland verkauften.

Als 1906 Josef Tapper starb und somit als erster Sammler für das Museum ausfiel, folgte ihm Edgar Meyer in dieser Position nach. ${ }^{300}$

299 So Kafka in seiner Tagebuch-Aufzeichnung vom 26.9.1911; er berichtet dies in Zusammenhang mit Geschichten über eine Münchner Künstlerpension und eines Besuches bei Kubin (1951, S. 66).

300 Meyer war ein eifriger Sammler von Antiquitäten aller Art; seine eigene Sammlung auf Burg Welfenstein hatte legendären Charakter, und dieses Sammelverständnis scheint er auch bei seinen Aktivitäten für das zu gründende Volkskunstmuseum eingebracht zu haben. 
Nach Karl Paulin war das Museum rasch zum gesuchten Geschäftspartner für gerissene Antiquitätenhändler geworden: „Aus dem ganzen Land, den entferntesten Talwinkeln, den höchsten Gehöften stöberten die Händler Gegenstände aller Art auf und schleppten sie den Museumsvertretern zu. ${ }^{\text {“301 }}$

1907 kaufte die Handels- und Gewerbekammer, anscheinend noch auf Veranlassung des verstorbenen Josef Tapper, um 40.000 Kr. die Meyersche Zinnsammlung an. Zum Wie und Warum des Kaufes gab es daraufhin diverse Spekulationen in Innsbrucker Zeitungen. ${ }^{302}$

Karl Moeser schrieb in einem Artikel zum Volkskunstmuseum über die, seiner Meinung nach, „allzureich ausgefallenen“ Erwerbungen: Die „etwas eigenartigen Umstände, unter denen sie mitunter vor sich gegangen waren, gaben bald Veranlassung zu allerlei Gerede und zu manchen versteckten und offenen Angriffen, die sogar den Weg in die Presse fanden“.

\section{Allgemein meinte Moeser zur Einkaufspolitik: Diese wäre}

„leider in allzu reichlichem Maße auch außerhalb des Landes - in nervöser
Hast und ohne weise Schonung der Mittel besorgt worden, [sodaß] die
Sammlungen nicht jene Abrundung bekamen, wie sie die notwendige Vo-
raussetzung für die Eröffnung eines imposant gedachten Museum bilden
müßte, das die reiche Volkskultur eines so vielgestaltigen Landes wie Tirol,
zur Anschauung bringen und oben drein noch die fast unbegrenzten Auf-
gabe eines allgemeinen Kunstgewerbemuseums erfüllen sollte“.

Sein Fazit daraus war, daß die Mittel nie ausgereicht hätten und „nicht richtig verwendet" worden wären. ${ }^{303}$

Nach der 1910 beschlossenen Änderung der Museumssatzungen hatten sich die Einkäufer bei Beträgen über $200 \mathrm{Kr}$. „mit einer gemeinsam mit dem Ferdinandeum zu bildenden Kommission ins Einvernehmen zu setzen" (Punkt 5, 6. Absatz!).

301 1919, S. 5. In Seitentälern des Tiroler Oberlands hatten sich angeblich Händler als Einkäufer des Museums ausgegeben, um so leichter an Gegenstände heranzukommen, die sie dann auf eigene Veranlassung ins Ausland weiterverkauften.

302 Vgl. Innsbrucker Nachrichten Nr. 255 vom 6.11.1907, S. 9; die Angriffe eines nicht näher genannten Wochenblattes hatten den HGK-Präs. Walter zu einer offiziellen Erklärung genötigt.

303 Ebd. Nr. 301 vom 31.12.1917, S. 5 f.; der Artikel Moesers behandelt eigentlich die Frage der Zusammenlegung der Sammlungen mit dem Ferdinandeum. 
Dieser Änderung war eine lebhafte Diskussion vorausgegangen, die von seiten der Landesregierung angeregt worden war und die „Abgrenzung des Wirkungskreises des neugegründeten Museums für tirolische Volkskunst und Gewerbe gegenüber dem Landesmuseum Ferdinandeum" bewirken sollte. Um dies zu erreichen, war festgelegt worden, daß

- sich beide Institutionen „gegenseitig ergänzen und fördern und nicht [...] Konkurrenz machen" sollten;

- die Ferdinandeumsvertreter einer Angliederung der Sammlungen des Volkskunstmuseums an ihre Institution positiv gegenüberstehen würden;

- sich die Vertreter des neuen Museums verpflichteten, ihre Tätigkeit „auf das gewerbliche und kunstgewerbliche Gebiet“ zu beschränken und „vom Sammeln rein historisch oder kunstgeschichtlich interessanter Objekte" abzusehen und

- eine gemeinsam besetzte Kommission zu bilden, die bei Erwerbungen über $200 \mathrm{Kr}$. heranzuziehen wäre. ${ }^{304}$

Diese eher eng gehaltenen finanziellen Möglichkeiten für Neuerwerbungen wurden aber offenbar von Tapper und Kofler unterlaufen, indem sie immer öfters teure Objekte ohne Einvernehmen mit der Kommission, teilweise sogar aus eigener Tasche, erwarben.

1907 überstieg die Zahl der erworbenen Gegenstände zwar bereits die 5.000er Grenze, die von der Handels- und Gewerbekammer abzudeckende Bankschuld belief sich aber dadurch auf $132.590 \mathrm{Kr}$., für die Anton Kofler, bis zur Begleichung dieser Ausstände, persönlich die Haftung übernahm.

Da die Sammlung weiter um Objekte vermehrt wurde, wuchsen die Auslagen und erreichten um 1909 einen neuen negativen Höchststand von $400.000 \mathrm{Kr}$.

Als mit dem Jahr 1910 die gesamten Gegenstände in das Eigentum der Kammer übergingen, war das Inventar bereits auf 40.000 Stück angewachsen (der Anschaffungswert betrug laut Kammerbuchhaltung 503.826 Kr.). ${ }^{305}$

304 Vgl. die im Archiv des VKM befindlichen Satzungen, o. Jahr; sowie das Prot. d. 5. o.ö. Sitz. d. HGK in Innsbruck vom 7.12.1910, S. 70 ff.; dort ein Abdruck der geänderten Satzungen auf S. $71 \mathrm{ff}$.

305 Siehe die ausführliche Darlegung der Einkaufsaufwendungen bei Kofler 1929, S. 3 ff.; vgl. das Prot. d. o. ö. 5. Sitz. der HGK in Ibk. vom 13.12.1909, S. 76 f., wo für $1906100.000 \mathrm{Kr}$. an Zuwendungen (davon $65.000 \mathrm{Kr}$. wirklich erhalten) angegeben werden. Für die Zukunft sah der Finanzplan eine Zuwendung von 300.000 Kr. vor, die über ein Darlehen bei der Sparkasse aufgebracht werden sollte! Diese $300.000 \mathrm{Kr}$. schienen aber von der Sparkasse nicht so ohne weiteres zur Verfügung gestellt worden zu sein, mußte A. Kofler doch in einer Kammersitzung 
Ein Jahr später (1911) gelang es dann der Kammer mit Karl (von) Radinger (1869-1921) ${ }^{306}$ einen wissenschaftlichen Fachmann für die Museumsbetreuung zu gewinnen. Er übernahm als Kustos die Betreuung der Sammlung, die in einer ehemaligen Schafwoll-Fabrik lagerte (Egger\&Oberhammersche Fabrik in Wilten).

Radinger hatte sich schon vorher für diesen Posten empfohlen, als er sich 1909 in einem Aufsatz zum geplanten Museum äußerte.

Darin betonte er, daß sich die Begriffe Volkskunst und Volkskunde nicht decken würden und Überlegungen anzustellen wären, ob das zukünftige Museum ein Volkskunst- oder ein Volkskunde-Museum werden sollte. „Wir finden daher in einem Museum für Volkskunde vieles, was mit Kunst nichts zu tun hat, wie das Arbeitsgerät, die bei den verschiedenen Gebräuchen, beim Spiel, im Aberglauben verwendeten Gegenstände. "307 Für ihn ergab sich daher die Frage, ob sich das neue „Museum auf Objekte der Volkskunst beschränken oder [...] das Programm dahin erweitert werden [sollte], daß aus dem Museum für Kunst ein solches für Volkskunde wird? [...] Die Antwort kann, wie ich glaube, nur zugunsten des erweiterten Programmes ausfallen."

Den Anlaß für diese Erweiterung sah der promovierte Kunsthistoriker in der „Bedeutung der Volkskunst, [welche] noch [...] sehr umstritten“ wäre; außerdem, so Radinger weiter, würde eine „derartige Sammlung nur ein beschränktes, einseitiges Bild des tirolischen Volkslebens geben“, wobei aber sowohl „der Fremde und der Einheimische [...] in dem Museum ein Gesamtbild des Tiroler Volkes suchen“" würden.

In der Folge entwarf er Vorstellungen für ein zukünftiges Volkskunde-Museum, die alle bis dahin erarbeiteten Pläne weit übertrafen.

am 8.7.1910 berichten, daß es bisher nicht gelungen sei, das in Aussicht gestellte Darlehen zu realisieren, weil die Kammer nur einen Betrag von 6.000 Kr. zur Rückzahlung bewilligt habe. Deshalb schlug er ein Komitee zur Beratung all dieser Frage vor, in das Kammer-Präs. Walter, Vizepräs. Sonvico sowie die Funktionäre Gradischegg, Kirchmayr, Saler und Weyrer gewählt wurden. (Prot. d. 3. o.ö. Sitz. d. HGK in Ibk. vom 8.7.1910, S. 44)

306 Karl Radinger von Radinghofen, Sohn eines Offiziers, war promovierter Kunsthistoriker und Archäologe, ferner Privat-Dozent - er hatte sich 1896 in Innsbruck habilitiert - für klassische Philologie (bis 1904). Im Museumsbereich brachte er nach Innsbruck einiges an Erfahrung mit, arbeitete er doch von 1909 bis 1911 im städtischen Museum in Salzburg. Zu Radinger vgl. das „In Memoriam“ in den Tiroler Heimatblättern 31. Jhg. Heft 7/9 (1956), S. 69 sowie Österr. Biograph. Lexikon Bd. 8 1983, S. 376 f..

307 Radinger 1909/10, S. 33 ff.; die folgenden Zitate sind diesem Aufsatz entnommen. 
Seinen Überlegungen nach hätte die Volkskunde „alle Seiten des Volkslebens, seien sie schön oder häßlich, gleichmäßig zu erforschen“. Daher müßten im zukünftigen Museum all diese Seiten berücksichtigt werden; ästhetische Kriterien als alleinige Grundlagen für die Objektauswahl lehnte er ab.

Als äußere Konzeption schwebte ihm vor:

1. ein "Saal der Hausmodelle“:

Darin sollte aufgezeigt werden, wie sich „aus der Stammesart der Erbauer, dem Klima, der Bodenbeschaffenheit, dem Baumaterial heraus das Bauernhaus der einzelnen Landschaften entwickelt hat".

Ideal erschien ihm, wenn dafür im Stile Hazelius' ein eigenes Freilichtmuseum errichtet werden könnte, denn „nur in einem solchen kann das malerische Äußere in Verbindung mit der umgebenden Landschaft zur vollen Geltung kommen".

Ersatz für das Nichtzustandekommen eines Freilichtmuseums könnten Hausmodelle im Maßstab von 1:30 bilden, die aus allen Teilen des Landes charakteristische Häuser nachzubilden hätten. Weiters sah sein Konzept vor, Häusergruppen im Maßstab 1:100 originale Hausteile (Pfetten ...) sowie „gute farbige Abbildungen" von Hausdekorationen auszustellen.

2. ein "Saal der Trachten“:

Hier galt es ihm, „die noch lebenden oder vor kurzem ausgestorbenen Trachten in echten Exemplaren zusammenzubringen“, denn: „Unsere Trachten sind im Absterben begriffen“ und „auch die Festtrachten [wären] kaum lange zu erhalten [...], da die Stoffe zu ihnen nicht mehr hergestellt werden“.

Vorbild der Trachtenpräsentation war ihm das Germanische Museum, wo, seinen Ausführungen zufolge, ,jedes Kostüm auf [einer] drehbaren Figurine angebracht" wäre; von einer Aufstellung in einzelnen Stuben riet er entschieden ab.

Die Figuren selbst wären dem „Taltypus getreu wiederzugeben, [ein] allzu großer Realismus [wäre] aber als ablenkend zu vermeiden“308.

3. ein „Raum für Hausgeräte“:

Seinen Vorstellungen nach sollten hier „kleiner Hausrat und Hausindustrie“ zur Aufstellung kommen.

308 Ebd., S. 35 f. „Daß man nicht Wachsköpfe, sondern Schnitzköpfe wählt, ist in einem Holzschnitzerland wie Tirol eigentlich selbstverständlich“, fügt er noch zur Frage der Ausstattung des Trachtensaales hinzu. 
Thematisch wollte er den Raum in drei Bereiche teilen:

- Eß- und Trinkgeräte

- Beleuchtungsgegenstände

- Geräte der weiblichen und männlichen Hausarbeit, Hausindustrie (insofern sie über den eigenen Bedarf hinausging): Spinnräder, Holzschuhe etc., all das „Baschgelzeug des Bauern“, wie er betonte.

Besonders war ihm dabei die anschauliche und verständliche Präsentation der Objekte ein Anliegen, weswegen er neben den fertigen Produkten auch Rohmaterial auszustellen beabsichtigte: „Vollendete und noch in Arbeit befindliche Stücke wären zur Erläuterung der Technik beizugeben.“

4. ein „Saal der landwirtschaftlichen Geräte“:

Hier sollten alle im Ackerbau und in der Viehzucht verwendeten Geräte zur Aufstellung kommen. Inhaltlich wäre der Saal in

- „Ackerbaugeräte“

- „Geräte des Weinbaues und der Weinbereitung“

- „Viehzuchtgeräte“ einzuteilen.

Dabei wollte er besonders solche Stücke ausstellen, „die bereits den Fortschritten der Neuzeit haben weichen müssen“.

5. ein „Saal der Sittengeschichte“:

Hier kämen Masken, Kostüme aus Umzügen, Theater, Schützenwesen, Kinderspielzeug, Aberglaube zur Präsentation. Radinger gestand aber ein, daß sich „manche Gebiete der Sittengeschichte [...] in einem Museum überhaupt nicht darstellen" ließen.

6. ein Raum, den er „Das Bauernkirchlein“ betitelte.

Für die Präsentation des „Bauernbarock“ des 18. Jahrhunderts war das Bayerische Nationalmuseum sein Vorbild.

„Bei der Auswahl der Ausstattungsstücke wäre weniger auf den Kunstwert als darauf zu sehen, Stücke zusammenzubringen, welche für den Geschmack unseres Landvolkes bezeichnet sind“, charakterisierte Radinger die Intention dieses Raumes.

Daneben sollten hier, in einem sakristeiartigen Nebenraum, Votivbilder, Wallfahrtsandenken, Volkskultgegenstände, Marterln, Totenbretter, ferner große Stücke wie ein Palmesel ausgestellt werden; des weiteren ein Dorfbrunnen mit dem hl. Florian sowie ein „Bauerngartl“. 
7. die „Bauernstuben“:

Bei der Aufstellung der Stuben, welche seiner Ansicht nach „unmittelbar in das häusliche Leben der Bauern" einführten, käme es vor allem darauf an, nicht einfach „eine Wand des betreffenden Raumes heraus[zu]nehmen“ und so daraus eine Art Auslage/Guckkasten zu machen; auch sollte vermieden werden, Stücke „verschiedener Herkunft zu einem malerischen Interieur zu vereinigen“. Vielmehr gälte es zu zeigen, daß der „Bauer [...] seine Räume nicht wie der Stadtmensch [ausstatte], sondern so, wie es Sitte und Herkommen erheische“. Weiters wäre die lokale Verschiedenheit der Stuben zu präsentieren, und es sollten auch andere Räumlichkeiten, wie eine Wirtsstube oder eine Küche aufgebaut werden.

Ich bringe hier Radingers Überlegungen so ausführlich, da sie die ersten breiter angelegten Vorstellungen für das Innsbrucker Museumsvorhaben sind. Es war seine Absicht aufzuzeigen, welche Inhalte dieses Museum haben sollte und wie es diese zu präsentieren hätte, auch wenn er mit seinem Konzept vor allem auf die Darbietung einer bäuerlichen Welt abzielte.

Zu Beginn seiner Ausführungen betonte Radinger, daß für ihn „Volkskunst richtige Bauernkunst - im Gegensatze zur Herrenkunst" stünde. Seiner Ansicht nach wären darunter ,alle von Bauern und bäuerlichen Handwerkern mit künstlerischem Sinn hergestellten und verzierten Gegenstände des täglichen Lebens“ zu verstehen. Demnach sollte „das neue Museum [...] ein möglichst vielseitiges Bild des tirolischen Bauernlebens geben“309.

So richtig einerseits Radingers Überlegungen in Bezug auf die einseitige Verkürzung von Volkskunde auf Volkskunst waren, reduzierte er doch andererseits alles auf die bäuerliche Welt. Dadurch geriet ihm ein großer Personenkreis der Tiroler Gesellschaft aus dem Blickwinkel, der auch unter Volk subsummiert werden muß,

309 Ebd., S. 39; Radinger war sich übrigens der Lücken, welche die Sammlung aufwies, voll bewußt und schlug vor: diese "nach einem festen Programme durch systematisches Aufsammeln auszufüllen“, (ebd.) was leider nie in dieser geforderten Konsequenz in Angriff genommen wurde! Auf das Aussehen des Museums ging auch der Innsbrucker GR Kapferer in einer Gemeinderatssitzung ein: „Die Museumsgegenstände sollen wie in einem Panoptikum, und zwar die Trachten vermittels bekleideter Puppen, die Gebrauchsgegenstände auch wirklich wie für den Gebrauch benützbar aufgestellt werden." (vgl. Neue Tiroler Stimmen 52. Jhg. Nr. 95 vom 26.4.1912, S. 3 f.; hier S. 4) 
wenn dieses, ganz der Auffassung Radingers folgend, im Gegensatz zur Obrigkeit gesehen wird. ${ }^{310}$

Diesem Betonen einer rein bäuerlichen Tiroler Vergangenheit stand die Realität gegenüber,

1) daß trotz des bis ins 20. Jahrhundert hinein dominierenden Agrarsektors, Tirol nie ein reines Bauernland gewesen war. Bis in die Mitte des 18. Jahrhunderts bestand ein traditionelles Mischgewerbe, es gab ein ausgeprägtes Handwerk, einen florierenden Handel, der zum Teil von der bäuerlichen Bevölkerung betrieben wurde, und

2) daß es, damit zusammenhängend, DEN Bauern in Tirol nie gegeben hat. Eine Subsummierung der agrarischen Bevölkerung unter das Klischee des einsamen, mächtigen Bauern auf seinem Hof ging an der Realität vorbei. Vergessen wurde dabei, daß ein Großteil der bäuerlichen Betriebe Kleinbesitz war; ausgespart blieb bei dieser verkürzten Betrachtung die große Zahl der unterbäuerlichen Schichten: Knechte, Mägde, meist weichende Geschwister des erbenden Ältesten, die sich auf dem elterlichen Hof verdingt hatten; nicht mit einbezogen wurden ferner die Besitzlosen, die Tagelöhner, die Fahrenden, die Dörcher und Laninger, die als Arme abqualifiziert und abgeschoben wurden. ${ }^{311}$

Radingers Überlegungen sind deshalb von Interesse, weil sie - obwohl er selbst sie nie verwirklichen konnte, er starb ja 1921 und das Museum wurde erst 1929 offiziell eröffnet - zu einer Art Leitidee des späteren Museumsaufbaus wurden.

Obwohl sein Konzept nie ganz in die Realität umgesetzt wurde, blieb es das Vorbild, das die späteren Museumsbetreiber nachzuahmen versuchten. Diese Versuche blieben aber, da nie mit letzter Konsequenz verfolgt, immer weit hinter Radingers Absichten zurück.

Seine Vorstellungen müssen immer auch im Zusammenhang mit ihrer Entstehungszeit gesehen werden. Scheitern muß, wie später ansatzweise versucht, seine Überlegungen ohne gesellschaftlichen Bezug verwirklichen zu wollen - schon deshalb, weil seit der Entstehungszeit von Radingers Überlegungen der Stand der musealen Theorie und Praxis weiter fortgeschritten ist.

310 Radingers Ansichten waren damit nicht frei von jenen romantischen Überlegungen, die in der Volkskunst etwas „Gewordenes“ im Gegensatz zu jedem „Gewollten“ sehen wollten, für die sie Ausdruck eines organisch gewachsenen, homogenen Volkes waren. Damit war, wie Ernst Fischer betonte, aus dem Volk „eine Substanz jenseits der Klassen“ geworden, das zum „Träger einer kollektiven schöpferischen ,Volksseele‘ erklärt wurde“. (1985, S. 71)

3111807 wurden in Tirol 45.565 Personen als „Hilfsbedürftige“ und 15.338 als „Arme“ (davon ca. 10.000 als total Mittellose) gezählt; zusammen stellten diese beiden Gruppen von Armen $10 \%$ der damaligen Tiroler Bevölkerung! (nach Hartungen/Heiss 1984, S. 18 f.) 
Radinger begann, zumindest provisorisch, mit der Aufstellung und Inventarisierung der gesammelten Gegenstände, und Ende 1911 konnte er diese „Depotaufstellung" in der Oberhammerschen Fabrik beenden. ${ }^{312}$

Einen Überblick der Museumssammlungen gab Radinger im Aufsatz „Das Museum für tirolische Volkskunst und Gewerbe in Innsbruck", wobei er besonders die umfangreiche Möbelsammlung, die, ohne „Herrenmöbel“, ca. 150 Kästen, 70 Bettladen, 40 Tische und 250 Sessel umfaßte, erwähnte.

Weiters führte er zahlreiche Gegenstände der hausindustriellen Produktion (Spanschachteln, Strohmosaikkästchen u.ä.) sowie der „primären Volkskunst“ an, wozu er vor allem die „große Menge von Blockkästchen mit Kerbschnittschmuck“ zählte.

An Wirtschaftsgeräten nannte er „Glockenbögen, Ochsenjoche, Schafkampen, Sensenscheiden und Kumpfe“, weiters zahlreiche „Utensilien der Küche und der Milchwirtschaft, [...] Mohnstampfen, Butter- und Käsemodeln, Salzfasseln“; ferner Erzeugnisse der Textilkunst, diverse Gegenstände aus Eisen, Bronze und Zinn. „Bauernkultsachen“, „Volksschmuck“ und verschiedene „Volkskunsterzeugnisse“ würden die Sammlung ergänzen; ferner seien eine umfangreiche „Abteilung für Keramik und Glas“ sowie „eiserne und hölzerne Bauernuhren“ vorhanden.

Radingers Hoffnung war, daß jeder, nach erfolgter endgültiger Aufstellung der Objekte, „ein Bild des bäuerlichen und kleinbürgerlichen Lebens vor dem Maschinenzeitalter gewinnen " können werde. ${ }^{313}$

\section{Exkurs 2: Gewandeltes Sammelinteresse}

Wie aus diversen offiziellen Stellungnahmen hervorgeht, hatte sich das Sammelinteresse seit dem ausgehenden 19. Jahrhundert vor allem auf Altertümer und Objekte der Hausindustrie konzentriert.

Gleich den Bestrebungen der Heimatschützer, lagen die Intentionen des Kuratoriums auf dem Gebiet der Rettung und Erhaltung von Gegenständen aus der Tiroler Vergangenheit, von welchen angenommen wurde, daß sie vom Untergang bedroht wären.

312 Die Tafeln III (volkskundl. Gegenstände), VI (Eisen- und Möbelsaal) und VII (Keramik- und Zinnsammlung) bei Ringler 1962 bieten einen Einblick in diese Art der Depotaufstellung.

313 Zeitschrift für österreichische Volkskunde, 18. Jhg. (1912), S. 54 f. 
Viele Intellektuelle, so auch die Museumsbetreiber, waren der Ansicht, die moderne Zeit würde die Kultur der Vergangenheit unwiederbringlich zerstören.

Der Münchner Künstler Ferdinand Wagner bedauerte in seiner Stellungnahme zur Innsbrucker Museumserrichtung:

\begin{abstract}
„Früher - noch vor 30 bis 40 Jahren - war das ganze Tirol ein einziges Museum! Wer das noch gekannt hat, mag noch heute drüber in Entzücken schwelgen - aber: auch trauern und weinen über den ungeheuren, uneinbringlichen Verlust, den das Land erlitten durch Unverstand und rücksichtslos um sich greifende Wuchersucht! Tirol hat heute so gut wie nichts mehr - höchstens noch einige kümmerliche Reste der ehemaligen Herrlichkeit. ${ }^{\text {"314 }}$
\end{abstract}

Die hier vertretene Sichtweise war aber einseitig, hob sie doch vom umfassenden Gebrauch der Kulturgüter ab, machte aus ihnen rein ästhetische Gebilde, die bar jeder Beziehung zur realen sozio-ökonomischen Gegebenheit gesehen wurden.

Als Ursache der Veränderung der Lebensweise und des Gebrauches von Kulturgütern galt diesen Intellektuellen eine Sinnkrise der modernen Welt. Und Grund des Verschwindens vieler traditioneller Objekte war ihnen der moralische Verfall der Bevölkerung, die allzu nachlässig mit diesen Gegenständen umgegangen sei.

Innovation, Kultur als Prozeß, blieb bei solch einer Betrachtungsweise ausgeschaltet, jeglicher Wandel wurde als Verfall gewertet. Die sicherlich berechtigte Kritik an den kulturellen Entwicklungen verkümmerte zu einem Jammern über den Niedergang der einstigen Größe. Damit war eine wirkliche Auseinandersetzung mit der Lebensweise und der Kultur des Volkes, das zu retten vorgegeben wurde, nicht möglich.

Die Sammlungsgegenstände spiegeln eher die Ansichten und Vorstellungen der Personen wider, die diese Objekte zusammengetragen und ausgestellt hatten, als derjenigen Menschen (des Tiroler Volkes), deren Kultur- und Kunstäußerungen sie sein sollten.

$\mathrm{Zu}$ Beginn der 70er und 80er Jahre des letzten Jahrhunderts überwog der Gedanke einer edukativen Förderung und Ausbildung, um so die Konkurrenzfähigkeit des Handwerks und Gewerbes, gegenüber der industrie-maschineller Produktion zu sichern. Die Aufgabe der einschlägigen Museen war es daher, mustergültige Vorbilder - zwecks Schulung und Verbesserung der Handwerker - zu präsentieren.

314 Zitiert bei Lang 1912, S. 51. 
Albert Ilg vertrat diese Vorstellung in Bezug auf die Grödner Holzschnitzerei: „Nichts ist demnach klarer als dass eine zur Stunde in einem ganzen Völkchen von mehreren tausend Seelen lebendige Kunstindustrie erstens erhalten, genährt zu werden verdient" und „zweitens aber, dass dieses Gewerbe absolut nothwendig der Veredlung, die Ausübenden künstlerische Bildung bedürfen, um auf der Basis der materiellen Geschicklichkeit ihren Werken allgemein bedeutenden Werth zu verleihen “"315. Seiner Meinung nach waren aber die Grödner noch nicht zu dieser Einsicht gelangt. Deren Ideal war nach wie vor „der reiche Kaufmann, der als Hausiererbursche die Heimat verlassen und mit seinen hölzernen Pudeln und Hanswursten Tausende erworben hat".

Deshalb wäre den „Leuten solche Liebe und Achtung gegen ihrer Hände Werk einzuflössen, dass es ihnen nicht gleichgiltiges Fabricat ist, welches nur [...] Geld zu verschaffen “ helfe, sondern ihnen bewußt werde, „dass auch künstlerische Ehre durch die Güte und Schönheit derselben zu erstreben" sei.

Nach seiner Auffassung könne ein solcher Anstoß nur von außen erfolgen, jedoch verknüpft mit der „Ahnung dessen, was des Volkes Bedürfniss“ wäre. Daher gälte es dem Volk nicht irgendwelche abgehobene, künstlerische Stilformen aufzunötigen, sondern, nach Art der chemischen Wahlverwandtschaft, solche Elemente, die „ehemals gleichfalls einem gesunden künstlerischen Verlangen entsprochen haben“. Nur so, meinte Ilg abschließend, „werden die Grödner nicht mehr in starrer Anhängigkeit am urväterlichen Zopf eine Tugend erblicken“"316.

Ilg stand mit diesen Ansichten zwar in Analogie zum Aufgabenverständnis des Gewerbemuseums (Vorbild- und Mustersammlung zu sein), jedoch in Kontrast zu späteren Auffassungen, denen zufolge Volkskunst eine prinzipiell nachahmenswerte Kultur sei. Für Ilg galten nur Gegenstände einer bestimmten künstlerisch höher stehenden Zeitepoche als vorbildhaft, wozu er die gegenwärtige Grödner Schnitzerei nicht rechnete.

Die ab den 1880er Jahren verstärkt erfolgte positive Beurteilung des künstlerischen Charakters nationaler Erzeugnisse (Altertümer, hausindustrieller Produkte) geschah nicht zum Selbstzweck, sondern sollte neue, bessere Absatzmöglichkeiten für die sie kopierenden Künstler bieten.

315 Ilg 1871, S. 367 ff., hier S. 370 f.; sein Aufsatz trägt den Titel „Die Industrie des Grödner Thales in Tirol“; Albert Ilg war Mitarbeiter im Museum für Kunst und Industrie.

316 Ebd., S. 371. 
So formulierte ein Museumsbefürworter in Bezug auf das zu errichtende Gewerbemuseum: „Durch seines Reichtums an guten Vorbildern und Mustern für die Fortentwicklung des modernen heimischen Kunstgewerbes [scheint das Museum] von viel größerer Bedeutung [zu] sein, als viele bisher glauben wollen. ${ }^{\text {"317 }}$

$\mathrm{Zu}$ den an die Volkskunst erhobenen Forderungen von Materialehrlichkeit und Zweckmäßigkeit ${ }^{318}$ kamen nach und nach weitere ideologische Gehalte hinzu. So wurde sie auch als Ausdruck nationalen Gepräges verstanden: Tiroler Volkskunst als bodenständiges, heimatliches, deutsches Kunstschaffen galt als Veräußerlichung des innersten Wesens eines Volkes.

Volkskunst wurde als einem sogenannten Volkscharakter angemessene Kunst verstanden, auch wenn jedes Objekt (in der Realität des Sammelns, Aufbewahrens und Ausstellens) zuallererst auf seine Verwertbarkeit als Vorbild überprüft wurde. Somit wurden nicht bedingungslos alle Gegenstände der Vergangenheit gesammelt, sondern vornehmlich diejenigen, welche in irgendeiner Weise verwertbar erschienen (nicht nur ökonomisch!).

Ihre Brauchbarkeit mußte entweder im Vorbildcharakter für tirolische Fremdenartikel oder in ihrer Möglichkeit zur Identifikation mit einer fiktiven, großen Vergangenheit liegen. ${ }^{319}$

Objekte der Volkskunst können nun aber nicht losgelöst von ihrem unmittelbaren Gebrauchswert gesehen werden, denn sie waren nie auf rein ästhetischen Wert angelegte Gebilde, sondern hatten unterschiedliche Gebrauchsfunktionen im Alltag, Brauch, Kult etc..

Laut Bernward Deneke erhielten die Gegenstandsbereiche, die landläufig der Volkskunst zugeordnet werden, ihre Ausprägung, ,als sich in nachmittelalterlicher Zeit die materielle Kultur von Stadt und Land und der einzelnen gesellschaftlichen Gruppierungen stärker differenzierte“320.

317 Neue Tiroler Stimmen 50. Jhg. Nr. 62 vom 17.3.1910, S. 1.

318 Vgl. Deneke 1964, bes. S. $188 \mathrm{f}$.

319 Das Postulat eines einheitlichen Tiroler Bauerntums als nahezu immerwährende Grundlage der Tiroler Gesellschaft erfüllte seine Aufgabe vornehmlich in der Integration vormals ausgegrenzter Bevölkerungsgruppen und diente der Gesellschaftsstabilisierung in einer Zeit des rascheren sozio-ökonomischen Wandels. Die Gleichsetzung von Volkskunst mit Bauernkunst bot dabei weitreichende Identifikationsmöglichkeiten.

320 1980, S. 24. Er hob weiters hervor, daß damit „das Vorhandensein von klassen- und bildungsmäßigen Unterschieden [...] zu den Voraussetzungen für die Entfaltung von Volkskunst" gehört. (Ebd.) 
Die Umgestaltung der Produktion und Reproduktion ${ }^{321}$ in den letzten 150 Jahren (= industrielle Revolution) erwirkte bei diesen Objekten eine Ablösung des ursprünglichen Gebrauchswertes und führte zur Überhöhung der ästhetischen Anschauung, die als „sekundärer Gebrauchswert" bezeichnet werden kann.

Der Tauschwert der Objekte wurde immer vordergründiger; sie wurden zur WARE, wobei der ästhetische Schein ihren Wert bestimmte. ${ }^{322}$

Für I.-M. Greverus ist dieser „sekundäre Gebrauchswert“ aber nur scheinbar. Er ist nicht einlösbar und enthält unerfüllte Versprechungen: zum Beispiel den Wunsch, durch den Besitz solcher Gegenstände eine heile Vergangenheit wiederzuerlangen und mittels solcher Sehnsuchtsbefriedigung einen Ausbruch aus der unwirtlich erscheinenden industriell-modernen Welt erreichen zu können). ${ }^{323}$ So wird die Propagierung einer als heil angesehenen Volkskunst nur allzuoft zur Fluchthilfe aus der Realität. Begriffe wie Einfachheit, Natürlichkeit etc. kennzeichnen dieses Heile-Welt-Denken, das besonders im Zusammenhang mit dem aufkommenden Tourismus Verbreitung findet.

321 Bernward Deneke (1980, S. 24 ff.) gibt als Gründe, die zur Auflösung der Volkskunst führten, an:

- das Aufkommen neuer Materialien (billige Produkte wie Baumwollstoffe, Steingut, Emailgeschirr bewirkten das Außerverwendunggeraten von traditionellen Gütern),

- neue Produktionsformen im ländlichen Raum (vor allem die maschinelle Herstellung von Textilien),

- neue Kommunikations- und Distributionsmöglichkeiten, die überregionale Märkte begünstigten und zur Durchbrechung des „korrespondierenden Lebenshorizontes“ von Erzeugern und Konsumenten führten sowie damit verbunden die „Urbanisierung“ des ländlichen Raumes (z.B. die Übernahme von Konsumgewohnheiten, Moden usw. aus den Städten).

322 Greverus 1978, S. 128 ff. Sie beschreibt diesen neuen Warencharakter vieler Gegenstände der sogenannten Volkskunst: „Erst in dem Moment, wo das Kunstwerk um nichts als seiner selbst willen begehrt wird, verliert es seinen Gebrauchswert und wird zur Ware, sein Marktwert bemißt sich an ästhetischen Kriterien, die von seinem vormaligen oder auch gegenwärtig intendierten Gebrauchswert abstrahieren." (Ebd., S. 129.) Auch Krzysztof Pomian geht in seinem geistreichen Essay „Der Ursprung des Museums. Vom Sammeln“ auf dieses Paradox ein: „Wie könnte man ihnen [den Sammlungsstücken; W.M.!] auch einen Gebrauchswert zusprechen, daß (sic!) sie nicht gekauft werden, um gebraucht, sondern um ausgestellt, um angeschaut zu werden." (1988, S. 17)

323 Greverus, ebd. Auch B. Deneke zählt ähnliche Ziele der Beschäftigung mit Volkskunst auf „die Stabilisierung wirtschaftlicher Verhältnisse oder die Lösung anderer sozialer Aufgaben, die Erweiterung des der kunstgewerblichen Praxis dienenden historischen Mustervorrates, die Entfaltung eines nationalen Stils und die Rekonstruktion kultureller Verhältnisse der Vergangenheit“ - betont aber, daß sich „stets [...] unter ihnen auch eine Enthistorisierung der an konkrete geschichtliche Lebensbedingungen gebundenen Dingwelt" vollziehe (1980, S. 16). 
In Anlehnung an die Funktion von Kunst in der Werbung kann für den Gebrauch der Volkskunst als Fremdenverkehrswerbemittel festgehalten werden, daß „Kunst [...] als künstlerische Verpackung, als Verzierung, als Reklame zum Auslösereiz für den Kauf eines alltäglichen Konsumgegenstandes über das Scheinversprechen individueller Glücksmöglichkeiten" wird. ${ }^{324}$

Bereits am Beginn der Bestrebungen zur Rettung heimischer Altertümer waren Verflechtungen mit dem Fremdenverkehr gegeben. Diese reichten von der Herstellung artgerechter (in der Tradition sogenannter Tiroler Volkskunst stehender) Andenkenartikel und Fremdenzimmermöbel, über die in- und ausländische Präsentation heimischen, auf althergebrachte Motive bezogenen Kunstgewerbeschaffens (z.B. der permanenten Ausstellung des Gewerbevereines, der Tiroler Landesausstellung, div. Weltausstellungen), bis zur Aufstellung von Gegenständen der Tiroler Volkskunst im Volkskunstmuseum in Innsbruck. Die dort ausgestellten Objekte wurden häufig auf Fremdenverkehrsprospekten und anderen Werbeträgern abgebildet.

Eine Definition des Begriffes Volkskunst erfolgte in erster Linie durch die Art der gesammelten Objekte; einigende Prämisse war die „Homogenität des Materials“ ${ }^{“ 325}$ : Bauernkunst, Nationalkunst, der angenommene germanische Ursprung der Gegenstände waren in diesem Zusammenhang Ausgangspunkte der Sammelbestrebungen der Museumsbetreiber.

Bei solch einer Sichtweise von Volkskunst blieb deren gesamter primärer Bereich ausgeklammert (weder ging man auf den primären Gebrauchswert als Arbeitsgerät, Kleidungsstück, Gebrauchsgegenstand etc. ein, noch auf die dahinterliegen Gebrauchsbestimmungen als Liebesgaben, Machtgegenstände usw.

Übrig blieb einzig die Sicht auf die Gestaltung, in der Form, wie I.-M. Greverus es ausdrückt, eines „ästhetisch-hedonistischen Vergnügens“, welches unmittelbar aus den Objekten zu sprechen scheint und damit selber zu einem neuen Gebrauchswert wird.

324 Greverus, S. 130. Sie lehnt sich in ihren Ausführungen an die kritischen Arbeiten zur Warenästhetik an, die von Wolfgang F. Haug, zu Beginn der 70er Jahre, herausgekommen sind.

325 Als Unterschied zum „Kunstgewerbe“ führt B. Deneke für diese „Dingwelt“ der Volkskunst an, daß sie sich nur „partiell in die Abläufe der Stilgeschichte zwischen Gotik und Klassizismus einbinden“ lasse. Im Gegensatz zur Völkerkunst wäre die Volkskunst aber „vielfältig mit den Erscheinungen der Hoch- und Universalkunst verflochten“ (1980, S. 17 f.). 
Zahlreichen Bildbände über Volkskunst sowie in einschlägigen Sammlungen ausgestellte - für sich selbst sprechende - sogenannte volkskünstlerische Objekte sind Ausdruck dieser Entwicklung. ${ }^{326}$

\subsection{Die Entwicklung des Museums nach dem Ersten Weltkrieg}

\subsubsection{Neuerlicher Versuch der Vereinigung mit dem Ferdinandeum}

Mehrmals war die Vereinigung der Sammlungen des „Volkskunst- und Gewerbemuseums" mit dem Ferdinandeum gefordert worden; 1917/18 äußerte diesen Vorschlag niemand geringerer als Karl Moeser.

Moeser zufolge hatte bereits Josef Tapper um 1903/04 eine Vereinigung mit dem Ferdinandeum angestrebt und dort eine eigene „Abteilung für Tiroler Volkskunst“ errichten wollen.

Dieser Wunsch nach einem „vereinigten großen Landesmuseum“ hätte Tapper auch so lange zögern lassen, bis er sich endlich zur Mitarbeit am Kammerprojekt entschloß; Tapper wäre aber, „so lange noch Zeit war“, laut Moeser, im Ferdinandeum „nicht zu Wort [ge]kommen“327.

Bereits einen Monat vorher hatte Moeser auf den Umstand aufmerksam gemacht, daß die Sammlungen des „Volkskunstmuseums“ kriegsbedingt aus dem Oberhammerschen Fabriksgebäude ausgelagert werden müßten, und dieser Umzug der Objekte bot ihm Gelegenheit, auf die neuerliche Vereinigung mit dem Ferdinandeum zu drängen: „Zur Erreichung einer gedeihlichen Entwicklung für beide Institutionen gibt es kein anderes Mittel, als die Vereinigung des Museums für Volkskunst und Gewerbe mit dem Ferdinandeum. ${ }^{\text {" }} 28$

326 Greverus, S. 135. Daß dabei die materiellen Gegenstände selbst sowie die sozio-ökonomischen Gründe ihres Wandels nicht untersucht werden, ist, nach Greverus, ein Versäumnis der fehlenden anthropologisch-ethnologischen Interpretation. Denn die Forscher, die manchmal bloß Liebhaber wären, würden sich in ihren Aufzeichnungs- und Wiedergabebestrebungen nur allzuoft mit den Künstlern und „Verfechtern einer neuen Gebrauchskunst“ treffen (ebd.).

327 Vgl. seinen Beitrag in den Innsbrucker Nachrichten Nr. 301 vom 31.12.1917, S. 5 f. Da der Vereinigungswunsch so häufig geäußert worden sei, lag ihm, laut Moeser, ein „richtiges, gesundes Prinzip zugrunde“. (Ebd.)

328 Ebd. Nr. 269 vom 24.11.1917, S. 4. 
Vor allem der Wunsch einer baldigen Museumseröffnung schien die Triebfeder seiner Vereinigungsvorschläge gewesen zu sein. Dabei war ihm die Platzfrage kein Hindernis, konnte er sich doch eine Raumeinsparung durch die „Auswahl der aufnahmewürdigsten Stücke“ vorstellen sowie durch Reduktion und Verkauf der übrigen Bestände. ${ }^{329}$

Moeser war sich aber bewußt, daß solch eine Vereinigung auf das Selbstverständnis beider Institutionen schwerwiegende Auswirkungen haben würde und betonte, daß die von ihm vorgeschlagenen Maßnahmen ,eine innigere Verbindung beider Museen voraussetzt, als eine bloß räumliche Verbindung“. Und weiter: „Das Eine ist wohl sicher, daß eines der beiden Institute bei der Vereinigung seine selbständige Existenz zugunsten des Ganzen wird opfern müssen“, wobei ihm klar war, „daß dabei das jüngere Unternehmen zugunsten des alten, größeren und angeseheneren zurückzutreten hätte “330. Seine Vorschläge schienen aber bei den betroffenen Stellen keinen Anklang gefunden zu haben, denn sie wurden nicht mehr weiter verfolgt.

Auch die Kammer stellte nach Beendigung des Ersten Weltkrieges Überlegungen an, was mit der Sammlung weiter zu geschehen hätte.

Kammersekretär Dr. Friedrich Mader konnte in der Sitzung der Innsbrucker Kammer für Handel und Gewerbe am 20. Dezember 1918 berichten, daß sich die Sammlungen nach ihrer Aussiedelung aus der Oberhammerschen Fabrik im ehemaligen Gymnasium neben der Hofkirche befänden.

Er wies besonders auf den Ankauf der „Wöll'schen Trachtensammlung“ hin, die mit Mitteln des Staates, des Landes, des Landesverkehrsrates und der städtischen Verkehrssektion um $35.000 \mathrm{Kr}$. erworben worden war.

In Bezug auf die endgültige Unterbringung der Sammlung schloß sich der Kammervorsitzende allerdings nicht dem Antrag des Kammerrates Kirchmayr an, der einen definitiven Verbleib der Objekte im „Theresianum“ gefordert hatte. Auch der provisorische Vorsitzende Ferdinand Hieke verweigerte dem Antrag seine Zustimmung, weil, seiner Meinung nach, die damit verbundenen Umbau- und Erhaltungskosten die Kammerfinanzen übermäßig belasten würden; außerdem

329 Ebd.; die vorgeschlagene Vereinigung hielt er schon aufgrund der Kostenersparnis in der Verwaltung für überlegenswert.

330 Ebd. 65. Jhg. Nr. 10 vom 11.1.1918, S. 4; Moesers Ansicht nach, müßten nach erfolgter Vereinigung im Ferdinandeum zwei neue Fachsektoren errichtet werden: 1.) Kunstgewerbe, 2.) Volkskunde, Volkskunst. Weiters hoffte er, daß dieses neue vereinigte Landesmuseum vom Land Tirol in die Verwaltung übernommen werden könnte. 
erschien ihm das ehemalige Kloster und Schulgebäude als nicht für ein Museum geeignet. ${ }^{331}$

Erst der Tod Karl von Radingers 1921 rief das Museum und dessen Schicksal wieder in die Erinnerung der Öffentlichkeit zurück. So meinten 1921 die Innsbrucker Nachrichten, daß ,an keinem öffentlichen Unternehmen [...] wohl so viel herumgedoktert [worden sei] und [...] von Berufenen und Unberufenen so viele Ratschläge gegeben worden [seien], wie beim Gewerbemuseum“"332.

Die Sammlung war, seit ihrer Ausquartierung aus der Oberhammerschen Fabrik, im "Theresianum“ untergebracht worden, das, als ehemaliges Gymnasium der Stadt Innsbruck, seit einigen Jahren leer stand und vom Verfall bedroht war.

Das Blatt machte deshalb den Vorschlag, der Staat sollte dem Museum das „Theresianum “ zur Verfügung stellen, dieses könnte, durch den Verkauf überflüssiger Objekte, das Gebäude adaptieren und damit verhindern, daß „unsere sorgsam verpackte ,Volkskunst ${ }^{`}[. .$.$] weiterhin Jahr für Jahr in ihrer Grabesruhe von der$ Aufstellung träumen" wird müssen. ${ }^{333}$

Auch andere Tiroler Zeitungen machten sich Gedanken über die Zukunft des Volkskunstmuseums. Der Tiroler Anzeiger schrieb, daß über den Wert einer solchen Institution nichts ausgesagt werden könne, da das „Museum NIE eröffnet wird" und warf die Frage nach der Schuld für diesen Umstand auf. Seiner Ansicht nach müßte die Handels- und Gewerbekammer vor ein „Entweder - Oder“ gestellt werden, denn es ginge nicht an, daß „ob des Starrsinns Einzelner alles in ewige Erstarrung" geriet. Eine Lösung des Problems sah die Zeitung in der

331 Vgl. Prot. d. 2. Plenarversammlng d. HGK Ibk. vom 20.12.1918, S. 29 f.

332 68. Jhg. Nr. 160 vom 16.7.1921, S. 3; kritisch meinte der unbekannte Autor, daß zwar viele Museumsstandorte genannt worden seien, „schließlich [aber] alles beim Alten“ geblieben sei. (Ebd.)

333 Ebd.; das „Theresianum“, auch „Neues Stift“ genannt, stammt aus dem Jahr 1553, dürfte in seiner ursprünglichen Substanz aber noch älter sein. Ferdinand I. ließ es, in Ergänzung der Gedächtniskirche für Maximilian I., erbauen. Das Gebäude beherbergte ab 1563 die Franziskaner, nachdem die Jesuiten einen Einzug ins „Neue Stift“ abgelehnt hatten. Um 1719 erlebte das Gebäude einen Umbau, bei dem Georg Anton Gumpp die Nord- und Ostfassade barockisierte. Bis 1784, als Josef II. das Kloster aufhob, war es Heimstätte der Franziskaner. Danach war es bis 1790 theologisches Generalseminar und zeitweise im Besitz der Jesuiten. Die Franziskaner erhielten zwar das ehemalige kleine Krankenhaus wieder, das sie 1834 zu einem Kloster ausbauten, ab 1868 wurde das „Neue Stift“ k.k. Gymnasium und blieb es bis 1910; danach waren dort kurzzeitig diverse Ämter untergebracht, beherbergte aber auch verschiedenste Mieter. Nach dem Auszug der Schule verfiel aber das Gebäude zunehmend (weitere Angaben zur Baugeschichte des „Theresianums“ bei Hammer 1929, S. 11 ff.). 
Vereinigung mit dem Landesmuseum, wobei das Volkskunstmuseum eine „Vorhalle für das Ferdinandeum" sein könnte; weiters wäre endlich ein hauptamtlicher Kustos zu bestellen. ${ }^{334}$

Tags darauf brachte dasselbe Blatt einen Beitrag über „Ein fachmännisches Gutachten". In diesem hatte sich der Hauptkonservator des Landesamtes für Denkmalpflege in München, der vom Heimatschutzverein anläßlich des in Innsbruck 1923 abgehaltenen „Heimattages“ zur Begutachtung der Bestände gebeten worden war, wohlwollend über die Sammlungen des zukünftigen Volkskunstmuseums geäußert. Der Begutachter riet aber zur baldigen Aufstellung der Objekte, da die derzeitige Lagerung sehr ungünstig sei und nicht vor einem Schädlingsbefall schützen würde. ${ }^{335}$

Kurz darauf konnten die Innsbrucker Nachrichten vermelden, daß sich die Handels- und Gewerbekammer in erfolgreicher Verhandlung mit dem Bund zwecks Überlassung des „Theresianums“ befände. ${ }^{336}$

\subsubsection{Die Übernahme des Museums durch das Land Tirol}

Im Tiroler Landtag befaßte sich der Finanzausschuß wieder mit dem Volkskunstmuseum, und Franz Gruener (1879-1953) 337 , der das für das Museum gestell-

334 17. Jhg. Nr. 14 vom 17.1.1924, S. 3; der Artikel ist mit „-av-“ signiert. Ringlers eigenen Ausführungen zufolge war er bereits ab 1919, noch als Kunststudent, für den erkrankten Radinger zum „Hüter des eingelagerten Museumsgutes“ bestellt worden. Er erwähnt weiters, daß er diese Stelle bis 1922 innegehabt hätte: „Sie wurde zwar nie von Seiten der Kammer aufgekündigt, doch wurde sie in dem Augenblick illusorisch, als eines Tages auch in personeller Hinsicht andere Pläne und Absichten, wenigstens für die nächstfolgenden Jahre, die Oberhand gewannen." (Ringler 1962, S. 74)

335 Tiroler Anzeiger Nr. 15 vom 18.1.1924, S. 3 f.; wörtlich äußerte er sich über die Gegenstände: Die „Bedeutung der Sammlung [liege] in ihrer großartigen Reichhaltigkeit“ ferner wäre es mit ihr „möglich, das gesamte Gebiet der sogenannten Volkskunst, das heißt die bäuerliche und anschließende kleinbürgerliche Hauskultur für Tirol darzustellen." (ebd., S. 3)

336 Ringlers Angaben zufolge sei diese Meldung der Nachrichten (Nr. 83 vom 10.4.1924) einen Tag nach dem Bericht im Anzeiger erfolgt, dies kann aber nicht stimmen, da das Blatt die Notiz schon in der Nr. 14 vom 17.1.1924 gebracht hatte! (1962, S. 74)

337 Franz Gruener, gebürtiger Kremser, studierte Rechtswissenschaften in Wien und Innsbruck und kam, nachdem er zuvor den nationalen Burschenschaften und den Ansichten Schönerers angehangen hatte, zur Tiroler Sozialdemokratischen Partei! An den Friedensverhandlungen in St. Germain hatte er im Auftrag des österreichischen Nationalrates teilgenommen; weiters war er der Vertreter Tirols im österreichischen Bundesrat, sozialdemokratischer Abgeordneter im Tiroler Landtag, davor Mitglied der provisorischen Landesversammlung von 1918/1919, sowie Landeshauptmannstellvertreter (1919 bis 1928). Das Amt des Innsbrucker Bürgermeisters 
te Subventionsansuchen zur Bearbeitung übertragen bekommen hatte, urgierte zweimal bei der Kammer, um genaueres über die seiner Ansicht nach zu hohe Subventionssumme zu erfahren. In seinem Brief an die Kammer vom 24.10.1924 schlug auch Gruener eine „Zusammenlegung mit dem Ferdinandeum und [eine somit gegebene] Vereinfachung der Verwaltung" vor. ${ }^{338}$

Die Handels- und Gewerbekammer hatte im Subventionsansuchen für 1924 einen Betrag von 100 Mill. Kronen gefordert - im Landeshaushalt waren bloß 16.000 Papierkronen (= 1,16 Goldkronen) veranschlagt worden. Eindringlich verwies die Kammer auf die Bedeutung der Sammlung in Milliardenhöhe, die, ihrer Ansicht nach (Schreiben vom 10. Mai 1924), „vom heimatpolitischen, gewerbepolitischen und kulturellen Standpunkte [eine] hoch bedeutsame Angelegenheit" wäre, sodaß es die Kammer nicht verstehen könne, wieso, von seiten des Landes, so wenig Interesse und eine so geringe Subventionssumme dafür vorgesehen sei. ${ }^{339}$

Am 9. April 1925 wurde Gruener von seiten der Landesregierung als zuständiger Referent beauftragt, mit der Handels- und Gewerbekammer zu verhandeln, ob ihr Angebot an die Stadt Innsbruck nicht auch an das Land gestellt werden könnte. In der vertraulichen Sitzung vom 20. Mai 1925 wurde von seiten der

hatte er abgelehnt. Der literarisch-künstlerisch veranlagte Gruener war Kunstreferent Tirols, der auch mit eigenem Geld aushalf, wenn das Land nicht in der Lage war, Denkmäler zu retten (Volderer Kirche). In dieser Funktion wurde er zum maßgeblichen Wegbereiter der Eröffnung des Tiroler Volkskunstmuseums; Mader schrieb 1954, daß es eine glückliche politische Konstellation gewesen sei, die zur Verwirklichung der Museumspläne verhalfen, waren doch die „bürgerlichen Mitglieder der Tiroler Landesregierung [...] bestrebt, dem sozialdemokratischen Landeshauptmannstellvertreter Dr. Grüner ein politisch ungefährliches Referat zuzuweisen“, schlußendlich hätte man dann Gruener das Referat zur Museumserrichtung gegeben, „weil er für sich selbst drei Schlösser und viele Altertümer in Tirol erworben hatte“. Gerhard Oberkofler hat keine besonders hohe Meinung von Grueners sozialdemokratischem Wirken: „Wenig Glück hatte die Tiroler Sozialdemokratie dagegen mit Dr. Franz Gruener [...] Franz Gruener war ein talentierter Politiker, der aber durch geglückte Geschäfte vollständig die Fühlung zur Arbeiterschaft verloren hatte und im Jänner 1928 aus der sozialdemokratischen Partei austrat. Franz Gruener war eine exaltierte Einzelerscheinung." (1986, S. 178) - Gruener war dann nach 1945 wieder der SP beigetreten! Zur Person Grueners vgl. Lederer 1946, Schober 1984, S. 585 u. S. 588, sowie Köfler 1987, S. $144 \mathrm{ff}$.

338 TLA, Amt der Tiroler Landesregierung Abt. III bei 654/1928 XV-85; der zweite Brief Grueners an die Kammer ist mit 8.11.1924 datiert.

339 Ebd.; der Brief der Kammer trägt die Zl. 310/1. Bereits im ersten Brief vom 11.1.1924 (Zl. 310) hatte die Kammer eine höhere Subvention als für das Jahr 1923 gefordert (damals waren dem Museum 1.000 Kr. Subvention und 15.000 Kr. an Baukostenzuschuß gewährt worden); schlußendlich bewilligte der Landtag für 1924 einen Unterstützungsbetrag von $20.000 \mathrm{Kr}$. 
Landesregierung beschlossen, mit der Kammer nähere Übernahmebedingungen für die Museumssammlungen auszuhandeln. ${ }^{340}$

Bereits 1922 hatte Kammerpräsident Willibald Reder der Vollversammlung einen Bericht über die vergangene und zukünftige Entwicklung des Museums erstattet.

Darin führte er bezüglich des weiteren Verbleibes der Sammlungen aus, daß die, zur Adaption und Ausgestaltung des "Theresianums" erforderlichen, Mittel vorerst durch den Verkauf der „Löwenhausgründe“ aufgebracht werden könnten. Bedingung dafür wäre allerdings, daß die Verhandlungen mit dem Bund, zwecks Überlassung des Gymnasialgebäudes, erfolgreich abgeschlossen würden. ${ }^{341}$

Zwei Jahre später konnte der Kammeramtsdirektor den erfolgreichen Abschluß der Verhandlungen mit dem Bund vermelden. Es wurde vereinbart, für das "Theresianum“ zwischen dem Bund und der Kammer einen Mietvertrag von 30 Jahren abzuschließen.

Bis es allerdings zur erhofften Aufstellung der Objekte kam, waren noch größere Hindernisse zu überwinden.

Im Nordtrakt befand sich noch das Zoologische Institut der Universität Innsbruck, und es mußte erst abgewartet werden, bis dieses ins Gebäude der alten Universität übersiedeln konnte, bevor an eine Adaptierung zu denken war.

Der Kammeramtsdirektor berichtete weiters, daß die Kammer nicht über geeignete Barmittel für den Umbau verfügen würde und deshalb vorgesehen war, einige Museumsgegenstände zu veräußern; insgesamt wären Gegenstände im Wert von 500 Mill. Kronen zur Ausscheidung aus der Sammlung und zum Verkauf ins Auge gefaßt worden und sollten im Wege einer „Effektenlotterie“ abgegeben werden. ${ }^{342}$

In ihrem Brief an die Tiroler Landesregierung vom 19. Mai 1925 (Zl. 2002) präzisierte die Kammer ihr Angebot neuerlich und war diesmal zur Überlassung der

340 Vgl. Sten. Berichte des Tir. Landtages II. Per. 1. Sess. 1925, S. 17, sowie TLA Amt d. Tir. Landesregierung III bei 654/1928 XV-85; die Landesregierung hatte die Frage der Verhandlung mit der Kammer, zwecks Übernahme der Museumssammlung, auf ihren Sitzungen vom 15.5.1925 und 10.12.1925 beraten.

341 Prot. der 1. öff. Vollversammlung der Kammer für Handel, Gewerbe und Industrie in Innsbruck vom 2.3. 1922; Reder teilte, gestützt auf eine fachliche Überprüfung durch Baumeister Fritz, die bereits früher geäußerten Bedenken, daß das Gebäude für ein Museum ungeeignet wäre, nicht.

342 Vgl. 1. ord. öff. Vollversammlung der Kammer für Handel, Gewerbe und Industrie in Innsbruck vom 9.4. 1924, S. 8 f.; Ringler berichtet, eine Mitteilung der IN Nr. 83 vom 10.4.1924 zitierend, über diese geplante Aktion (1962, S. 74). 
Löwenhausgründe (die mit $21 \frac{1}{2} \mathrm{Mrd}$. Papierkronen veranschlagt wurden) bereit, falls das Land das Museum übernehmen würde.

Im Schreiben vom 10. Juni desselben Jahres (Zl. 2407/1) legte die Kammer dann ihre Vorstellungen nochmals dar und gab an, daß sie das Grundstück, das eigentlich für die Errichtung eines Gewerbeförderungsinstitutes vorgesehen war, dem Land im Falle der Übernahme der Museumssammlung überlassen würde. Das Land müßte aber dafür Sorge tragen, daß die Stadt Innsbruck einen geeigneten Ersatzgrund zur Verfügung stellen würde und selbst etwas zum Bau dieses Förderungsinstitutes beisteuern. ${ }^{343}$

Damit war die Kammer, entgegen ihrem ersten Angebot, das nur die unentgeltliche Überlassung der Sammlung im Gesamtwert von 653.452 Goldkronen sowie der „Lang'schen Stiftung“ in der Höhe von einigen Milliarden Papierkronen beinhaltete, bereit, dem Land Tirol die „Löwenhausgründe“ zu übergeben.

Am 21. Januar und am 19. Februar 1926 berichtete Franz Gruener in den Landtagssitzungen über den derzeitigen Stand der Verhandlungen und machte einen Vertragsvorschlag. ${ }^{344}$

Trotzdem Gruener bei der Budgetdebatte vom 14. Januar 1926 die Aufnahme eines Postens für den Ausbau des Volkskunstmuseums vermißt hatte, ${ }^{345} \mathrm{kam}$ es wenig später doch zu einem Vertrag zwischen der Kammer und dem Land Tirol: zwecks der „Überlassung der Sammlungen des tirolischen Museums für Volks-

343 TLA, Amt d. Tir. Landesregierung Abt. III bei 654/1928 XV-85; in ihrer Antwort auf das letzte Angebot der Kammer hatte die Landesregierung festgestellt, daß sie bereit sei, die Kammer zu unterstützen, „obwohl Gewerbeförderung nicht Landes- sondern Bundessache“ sei (ebd. Brief der LR vom 30.6.1925). In der Antwort auf den ersten Brief der Kammer hatte Franz Gruener festgestellt, daß er im Angebot der Kammer die Abgabe der Löwenhausgründe vermissen würde, „ohne die das Land nicht einsteigen will“ (Brief vom 9.5.1925)! - In ihrer Sitzung vom 14.5.1925 stimmte die Landesregierung dann einer Übernahme der Museumssammlung zu, wenn die Gründe im Tauschangebot eingeschlossen wären. (Ebd.)

344 Ebd. Abt. III 824/1926 XV-85; der erste Brief der Kammer an das Land, über die Bedingungen einer Sammlungsabtretung, erfolgte am 7.5.1925 (Zl. 2002). Die unentgeltliche Überlassung der „Löwenhausgründe“, zuerst als Schrebergartengründe, war auf der Kammervollversammlung am 29.4.1926 beschlossen und der Landesregierung am 7.6. desselben Jahres in einem Brief (Zl. 2150) mitgeteilt worden. Die endgültige Überlassung erfolgte in einem Brief an das Land Tirol vom 21.11.1927 (Zl. 1417). Eine Verständigung des Bundesministeriums für Finanzen, daß das „Theresianum“ eventuell dem Land überlassen werden könnte, war in einem Brief vom 25.2.1927 an Landeshauptmann Stumpf ergangen.

345 Vgl. Sten. Ber. d. Tir. Landtages II. Per. 2. Tag. 9. Sitz. vom 14.1.1926, S. 180; Gruener hatte mit dem Argument der Arbeitslosenbeschäftigung für den Ausbau des Museums geworben! Sein Antrag, 200.000 Schilling für den Bau des Museums vorzusehen, wurde angenommen. Im nächsten Budget waren 200.000 Schilling für das Museum veranschlagt worden (laut Sten. Ber. d. Tir. Ltg. II. Per. 4. Tag. 11. Sitz vom 15.12.1926, S. 291 ff.). 
kunst und Gewerbe einschließlich der hiezu gehörenden Teile der Lang'schen Stiftung und der Löwenhausgründe in Innsbruck, sowie des Bestandvertrages im alten Gymnasium zum Zwecke der Errichtung eines Museums für tirolische Volkskunst und Gewerbe“.

Dieser Vertrag vom 30. Juni 1926 sah in $\$ 1$ ) durch das Land vor: die Übernahme der Sammlung, der Lang'schen Stiftung, der Löwenhausgründe, sowie der Verhandlungen mit dem Bund zur Anmietung des „Theresianums“ auf 30 Jahre. Das Land Tirol mußte sich dafür in $\$ 2$ ) verpflichten: alle Gegenstände für ein, „der Öffentlichkeit zugängliches Museum für tirolische Volkskunst und Gewerbe in Innsbruck zu verwenden “, für die Erhaltung des Museums aufzukommen und die Deckung aller Sach- und Personalaufwände zu übernehmen.

Weiters wurde im Vertrag geregelt, daß das Land (\$ 3) das alte Gymnasium baulich auszugestalten hätte und für die Instandhaltung und Erweiterung der Sammlungen ( $\$ 4)$ aufkommen würde.

Der $\$ 5)$ verbot die Veräußerung von Sammlungsgegenständen ohne Zustimmung eines von der Landesregierung bestimmten Fachbeirates. Ein eventuell aus dem Verkauf erzielter Erlös durfte ausschließlich für die Erhaltung und Ergänzung der Sammlungen verwendet werden.

Zur Verwaltung war ein eigenes Kuratorium vorgesehen $(\$ 6)$, in dem die Kammer ein Recht auf 2/8 der Sitze haben sollte. Die übrigen Beisitzer konnte das Land bestimmen, wobei der Landeshauptmann oder ein von der Landesregierung namhaft gemachter Funktionär des Landes den Vorsitz zu übernehmen hatte.

Im Vertrag wurde auch festgelegt, daß für den Wirkungskreis des Kuratoriums eine eigene Geschäftsordnung zu erstellen wäre.

Schlußendlich sah $\$ 7$ ) die Anbringung einer Legende mit dem Hinweis auf die Kammer als Widmer der Sammlungen vor; und \$ 8) regelte das besondere Entgegenkommen der Museumsleitung bei einem eventuellen Sammlungsbesuch durch Gewerbetreibende. ${ }^{346}$

In der Folge hatte das Land Tirol als neuer Museumseigentümer noch zwei größere Probleme zu lösen:

- die Übernahme des „Theresianums“ vom Bund und

- die Aufbringung der nötigen Geldmittel zur Instandsetzung des Gebäudes sowie zur Einrichtung der Sammlung.

346 Der Vertrag mit der Zl. 650/27 findet sich im Archiv des TVM, sowie im TLA, Amt d. Tir. Landesreg. Abt.III Zl. 650/27 bei 5/XV-85 1936 und war von seiten des Landes von LHM Stumpf, LHMStv. Gruener und LR Pusch, im Namen der Kammer von Präs. Reder und KDir. Mader unterzeichnet worden. - Der Übergabevertrag ist datiert mit 30.6.1926. 
Zum Punkt 1) brachte der neue Kulturreferent Dr. Gamper einen Resolutionsantrag in den Tiroler Landtag, der die Landesregierung aufforderte, mit der Bundesregierung wegen des Gebäudeabtrittes in Verhandlung zu treten. ${ }^{347}$

Weitaus schwieriger gestaltete sich allerdings die Erlangung der nötigen Mittel für die Ausgestaltung des alten Gymnasiums. Nachdem ein von seiten des Landes Tirol beim Bundesministerium für Handel und Verkehr gestelltes Subventionsansuchen abgelehnt worden war, entschloß sich die Landesregierung, die Löwenhausgründe zuerst hypothekarisch zu belehnen und dann 1930 zu verkaufen. ${ }^{348}$

\subsubsection{Vorkehrungen zur Museumseröffnung}

Nachdem sich die Tiroler Landesregierung entschlossen hatte, den Großteil des nötigen Geldes für die Adaptierung des „Theresianums“ zum Volkskunstmuseum durch den Verkauf der Löwenhausgründe aufzubringen, stand der Museumserrichtung nichts mehr im Wege. ${ }^{349}$

Unter der Leitung des Archivdirektors Dr. Karl Moeser, der vom Kuratorium als Referent für den Museumsaufbau bestellt worden war, wurde das alte Gymnasium nach Plänen des Baurates der Tiroler Landesregierung Ing. Stuefer, umgebaut.

347 Vgl. Sten. Ber. d. Tir. Ltg. II. Per. 8.Tag. 10. Sitz vom 31.1.1929, S. 348; dem Abgeordneten Zösmayr zufolge wäre es ein Versäumnis Dr. Grueners gewesen, um die Überlassung des "Theresianums" beim Bund anzusuchen (ebd.).

348 Vgl. TLA, Amt d. Tir. Landesreg. Abt. III Zl. 1765/1 XV-85, Brief des BM für Handel und Verkehr vom 22.12.1928 (Zl. 131.939-14-1928), in dem mit Bedauern festgestellt wurde, daß dem Ministerium „Kredite für die Subventionierung nichtstaatlicher Museen nicht zur Vergügung stehen“. Weiters die Sten. Ber. d. Tir. Landtages II.Per. 8. Tag. 8. Sitz. vom 29.1.1929, wo eine weitere Belastung der Löwenhausgründe mit 80.000 Schilling angegeben wird (die Gesamtbelastung betrug somit 230.000 S). Insgesamt, so Dr. Gamper, hätte das Land nun bereits $760.884 \mathrm{~S}$ für das Museum ausgegegeben, und es gälte daher die „deutsche Öffentlichkeit auf dieses ganz einzigartige Haus aufmerksam zu machen“. In der 10. Landtagssitzung des Jahres 1929 wurde nachträglich beschlossen, nochmals 10.000 S an hypothekarischem Darlehen für den Ausbau aufzunehmen und, falls die Löwenhausgründe 1930 zum Verkauf gelangen sollten, abermals weitere $50.000 \mathrm{~S}$ für die Museumsausgestaltung zur Verfügung zu stellen (TLA ATLR Abt. III 364/7-1929).

349 Vgl. die Debatten zum Verkauf der Löwenhausgründe (Antrag des Kunstausschusses Post 68, sowie Beilage 5) in den Landtagssitzungen vom 18.u.19.12.1929; Sten. Prot. d. Tir. Ldt. III. Per. 2. Tag. 9. u. 10. Sitz., S. 13; ab 1930 verkaufte das Land Grundparzellen der Löwenhausgründe an verschiedene Siedler (s. TLA ATLR Abt.III 1206/56-XV-85 ex 1932). 
Bei der inneren Ausgestaltung der musealen Sammlungen dürfte aber Moeser keine glückliche Hand gehabt haben.

Auf seine Veranlassung hin wurde zwar mit der Restaurierung der zahlreichen Gegenstände begonnen. (Diese lagerten, teils jahrzehntelang, unter unzumutbaren Bedingungen in diversen Depots.) Es gelang ihm auch noch einige wertvolle Objekte zu erwerben (Tierburgerstube, div. Öfen), jedoch trat Moeser dann noch vor dem eigentlichen Beginn der Sammlungsaufstellungen, überraschend zurück.

Anscheinend hatte Moeser einen derart umständlichen Arbeitsstil, daß die geplante Eröffnung, unter seiner alleinigen Leitung, so bald nicht abzusehen war. Deshalb traf das Kuratorium Überlegungen, ihm eine Hilfskraft zur Seite zu stellen, um das Museum rechtzeitig für die Eröffnung fertig zu bekommen.

Diesen Plänen vermochte Moeser allerdings nichts abzugewinnen und trat von seinem Posten als Referent zurück. Franz Gruener erwähnte in einem Brief Moesers Rücktrittsbegründung, daß er ,jegliche Mitarbeit aufgeben müsse, wenn ihm die Arbeit nicht allein anvertraut bleibe" und vermerkte:

„Bei der Starre und Eigensinnigkeit sowie der fast sprichwörtlichen Langsamkeit des Herrn Dr. Möser und der umständlichen Genauigkeit desselben, ist jedoch an eine Vollendung der Arbeiten durch Herrn Dr. Möser allein nicht zu glauben"

und bedauerte, daß das Kuratorium Moeser zu lange nachgegeben hätte. ${ }^{350}$ Daraufhin wurden Dr. Josef Ringler und Dr. Vinzenz Oberhammer mit der Einrichtung des Museums betraut. Diese begannen ab März 1928 mit ihrer Arbeit. ${ }^{351}$

350 So in einem Brief Grueners, in dem er den Rücktritt Moesers zur Kenntnis nahm; Gruener hatte darin festgestellt, daß alle in Betracht kommenden Personen eine Zusammenarbeit mit ihm abgelehnt hätten, da, so Zitat Gruener: „Unter Dr. Möser gedeihlich nicht mitzuarbeiten ist.“ (TLA ATLR Abt. III 5-1936/XV-85)

351 Vgl. Ringler 1962, S. 76; Ringler äußert sich darin nicht inhaltlich zum Ausscheiden Moesers. Josef Ringler (1893-1973) promovierte 1921 mit einer kunstgeschichlichen Arbeit („Studien über die geistigen und künstlerischen Probleme in der Darstellung der Geburt Christi bis zur Renaissance") bei Moritz Dreger. Er war danach, bis zu seinem Eintritt ins Volkskunstmuseum, Assistent am Institut für Kunstgeschichte in Innsbruck. Seine Verbundenheit mit der christlichen Kunst, einschließlich der religiösen Volkskunst, bezeugt seine langjährige Tätigkeit im Tiroler Krippenverein, dessen Zeitschrift „Der Krippenfreund“ er bereits als Gymnasiast - unter einem Pseudonym - redigierte. Ringler veröffentlichte über 350 wissenschaftliche Arbeiten, sowie an die 700 Biographien über Tiroler Künstler für das Künstlerlexikon „Thieme-Becker“ (ein vollständiges Werkverzeichnis der Arbeiten Ringlers, zusammengestellt von Heinrich Braun, findet sich im Schlern 47. Jhg. (1973), S. 5 ff.). Für weitere Ausführungen zu Ringlers Wirken im Museum vgl. das nächste Kapitel, sowie Pfaundler 1973, S. 343 und die Würdigungen und Nachrufe von Colleselli 1968 und 1973. 
Um den Jahreswechsel 1928/29 konnte Ringler dem Finanzausschuß der Tiroler Landesregierung über die bis dahin getätigte Aufstellung der Museumssammlung berichten. Darin erwähnte er die Einrichtung eines großen sowie eines kleinen Volkskundesaales im Erdgeschoß und eines Kapellenraumes mit Gegenständen der religiösen Volkskunst. Im Trachtensaal, der sich ebenfalls im Erdgeschoß befand, waren vier große „Freivitrinen für Volkstrachten und fünf Wandvitrinen für Trachtenteile montiert" worden, wobei der Bildhauer Virgil Rainer die Figuren für den Trachtensaal gefertigt hatte. Die schmiedeeiserne Grabkreuzsammlung erhielt im Kreuzgang, die Gittersammlung im nördlichen Zwischengang ihre Unterkunft.

Im ersten Stock wurden in den nördlichen Zimmern ein „Saal des bürgerlichen Mobiliars" sowie ein Plastiken- und ein Eisensaal eingerichtet.

In den Gängen und den nördlichen Räumen des zweiten Stockes kamen die Möbel zur Aufstellung. Die Stuben wurden im ersten (Niederdorf, Pfalzen-Issing, Villanders, Rasen, Caldes, Burgeis) und im zweiten Stock (Tierburg, Monclassico, Dimaro, Fiss-Ladis, Kasern, Fondo und Sexten) eingebaut.

An „restlichem Interieur“ standen, laut Ringlers Ausführungen, noch die „Halle von Brixen, die gotischen Balkendecken von Lüsern, Passeier und aus dem Eisacktale, [sowie eine] Küche zur Rasener Stube und [der] Matscher-Plafond“ für eine eventuelle museale Verwendung zur Verfügung. ${ }^{352}$

Wie die vorgenommene Anordnung zeigt, waren einige Gedanken und Pläne Radingers übernommen worden, andererseits fand auch noch die GewerbemuseumsIdee ihren Niederschlag (so in den Materialsälen, wo Gegenstände gleichen Materials zusammen ausgestellt wurden).

Eine kritische Einschätzung der damaligen Museumskonzeption ist nicht leicht vorzunehmen, da diese Anordnung heute nicht mehr besteht und wenig Bildmaterial darüber erhalten ist.

Wie aber die wenigen Darstellungen zeigen, wurde vor allem versucht, die Gegenstände für sich selbst sprechen zu lassen und auf eine genaue Beschreibung zu verzichten. Somit sah das Museumskonzept die Objekte nicht als Produkte

Vinzenz Oberhammer (1901-1993) wechselte ab 1936 ins Ferdinandeum, wo er für die Gestaltung der Ausstellungen zuständig und ab 1937 Kustos war, bis er zum administrativen Direktor des Wiener Kunsthistorischen Museums (1954/55) berufen wurde.

352 TLA ATLR Abt.III Zl. 364/6-1929; sowie die genaue Aufstellungsangabe bei Ringler 1962, S. 79 und die dort beigefügten fotographischen Aufnahmen des Stubeneinbaues und der div. Säle (Tafel IV, V, VII und VIII). Zu den Stuben jetzt auch ein Beitrag von Hans Gschnitzer im Katalog 2 (1986). 
eines historischen Prozesses, wie dies etwa Radinger vorgeschwebt war, der die Präsentation halbfertiger, in der Herstellung befindlicher Gegenstände sowie die Beschreibung des Herstellungsprozesses und der verwendeten Rohmaterialien als ein Ausstellungsziel empfohlen hatte.

Die Gegenstände waren in erster Linie nach ihrer ästhetischen Qualität ausgewählt und aufgestellt worden. Grund dafür mag die wissenschaftliche Herkunft der beiden Betreuer gewesen sein, denn sowohl Ringler wie auch Oberhammer waren gelernte Kunsthistoriker.

Ihnen war die Aufstellung von Sammlungsgegenständen vor allem aus den diversen kunsthistorischen Museen vertraut, die ihre Objekte zumeist mit der „weihevolle[n] Behandlung der Klassiker" (Marcuse) präsentierten.

Ähnlich den kunstgeschichtlichen Sammlungen wurde das Volkskunstmuseum zu einer Stätte, die, um wiederum mit Marcuse zu sprechen, „die Entfernung von der Faktizität, die trostreiche Erhebung in eine würdigere Welt zugleich mit der zeitlichen Beschränkung auf das Feiertägliche im Individuum zu projizieren“" half. 353

Alles in allem bot die Sammlung keinen Einblick in die Lebenswelt, wie dies noch von Radinger (wenn auch vornehmlich für die bäuerliche Welt) gefordert worden war, sondern eine von den Alltagsmühen geläuterte, ästhetisierte Sicht der Tiroler Volkskunst. Daß dabei erst zur Volkskunst gemacht, was eigentlich zu sammeln vorgegeben wurde, kann als eine Art von „Rache der Objekte“ angesehen werden, wie dies Norbert Schindler bezeichnet. Denn, seiner Ansicht nach, würden die ausgestellten Gegenstände, „freigesetzt aus allen Praxisbezügen [...] ein seltsames ästhetisches Eigenleben [entfalten], [...] in einem neuen folkloristischen Glanz [erstrahlen], [...] wo sich ihre losgelassene Ästhetik mit dem Exotikbedürfnis eines auf sich und seine Phantasien zurückgeworfenen Publikums“ treffen würde. ${ }^{354}$

Dem Land Tirol war es seit der Museumsübernahme ein Anliegen, die Institution in eine dauerhafte Existenz zu überführen, und es suchte deshalb bei der Republik um eine Übernahme in den Bundesdienst für den Museumsdirektor Dr. Josef Ringler an. Diesem Ansuchen wurde nicht stattgegeben, „da“, so der Bundesminister für Unterricht in seinem Brief vom 1. Juli 1931, „im Moment keine

353 1965, S. 99; Marcuse schreibt weiters, daß die Existenz der Kunst, „seit mindestens einem Jahrhundert für den Bürger nur noch in der musealen Form“ bestehen würde (ebd.). Die erste Veröffentlichung dieses Aufsatzes, mit dem Titel „Über den affirmativen Charakter der Kultur“, erfolgte 1937.

354 1984, S. 30 (Hervorhebung von W.M.). 
Aufnahme in Bundesdienst möglich“ wäre. ${ }^{355}$ Ringler wurde daraufhin aus dem Landesetat als Landesbeamter bezahlt. ${ }^{356}$

Obwohl Ringler anläßlich seines Berichtes an den Finanzausschuß der Landesregierung neun Fach- (vier Haustischler, zwei Bildhauer, einen Faßmaler, einen Schlosser, sowie einen Tapezierer) und sechs Hilfskräfte als Werkstättenpersonal anführen konnte, war das Museum - nach erfolgter Aufstellung aller Sammelgegenstände - mit Personal, insbesondere mit Fachkräften/Akademikern, gering ausgestattet.

Mit Jahresende 1932 mußte sogar der eingestellten Sekretärin Gertrud Pesendorfer, „mit Rücksicht auf die eingeschränkten Einnahmen des Volkskunstmuseums" gekündigt werden. ${ }^{357}$

Auch weiterhin blieb die finanzielle Ausstattung des Museums ein nur zum Teil gelöstes Problem.

355 TLA ATLR Abt. III 856/19 XV-85 ex 1931 (übertragen auf 1640/1932 XV-85); das Schreiben von seiten des Landes an den Bundesminister stammt vom 5.4.1930 (Zl. 732 ex 1930); die Antwort aus dem Ministerium trägt die Zl. 10606/I/5.

356 Aus der Beantwortung (14.10.1932; Zl. III 1959/1-1932) eines Museumsschreibens (vom 22.9.1932) geht hervor, daß Dir. Ringler ab 1.3.1932 ein monatliches Entgeld von 470,60 S bezog, das in den Landeszuwendungen für das Volkskunstmuseum inkludiert war. (TLA ATLR Abt. III 1459/1 ex 1932)

Eigentlicher Grund für das Schreiben war die Bitte an die Landesregierung, die bereits genehmigte Subventionssumme von 10.000 S auszuzahlen, da die Einnahmen aus den Eintrittsgeldern stark zurückgegangen seien. Im Jahresabschluß 1931 (Schreiben des Museums an die TLR vom 10.3.1932) standen den Ausgaben von 45.554,06 S Einnahmen in der Höhe von 49.814,03 S gegenüber! Größter Aufwandsbetrag war die Verwaltung mit 20.602,52 S, gefolgt von den Auslagen für Restaurierungen und die Werkstätte: 9.044,04 S, sowie den Erwerbungen im Ausmaß von 5.406,20 S und den Ausgaben für die Gebäudeeinrichtung mit 4.816,- S. Bei den Einnahmen führten die Eintrittsgelder mit 17.404,14 S, gefolgt von den div. Subventionszuwendungen (Bund: 12.300,-, HGK: 5.000,-, Land: 3.000,-, sowie Stadt: 1.300,-). (Vgl. TLA ATLR Abt. III XV-85 Zl. 1459/1 ex 1932.)

357 Brief an Pesendorfer vom 29.9.1932 (Zl. III-1490/1-1932) im TLA ATLR Abt. III-1932 Zl. 1490/1 XV-85); Pesendorfer wurde ab 1939 durch das NS-Regime zur Museumsdirektorin bestellt; außerdem war sie in dieser Zeit auch Leiterin der „Mittelstelle Deutsche Tracht“. (vgl. Kapitel 6.1) Auch heute noch ist das Museum, besonders im Fachbereich, mit Personal unterbesetzt (zwei Akademiker, ein Bibliothekar, vier Werkstättenangestellte), wie ich anläßlich meines Ferialpraktikums im Sommer 1984 feststellen konnte. Fast die gesamte Arbeitszeit des wissenschaftlichen Personals ist mit der Aufrechterhaltung der laufenden Geschäfte ausgefüllt, sodaß weiterführende Arbeiten (bessere Ausgestaltung der Sammlungen, didaktische Hilfeleistungen, wie Beschriftungen, ergänzendes Informationsmaterial etc.) kaum bewältigt werden können. 
Es gelang allerdings für 1934 von seiten des Bundes (Unterrichtsministerium), trotz der bereits 1932 erlassenen Subventionssperre für Bundesländermuseen, eine Zuwendung in der Höhe von 800 ,- $S$ zu erlangen. ${ }^{358}$

Bereits zwei Jahre zuvor hatte Museumsdirektor Ringler in einem Brief an den Kulturreferenten des Landes Prof. Gamper eine neuerliche Zuwendung von Landesseite verlangt, da noch zahlreiche Rechnungen offen seien und die diversen Restaurierungen immer größere Summen ausmachen würden. ${ }^{359}$

Im Übernahmevertrag für die Museumssammlungen war zwischen Land und Kammer vereinbart worden, eine eigene Geschäftsordnung (GO) für den Wirkungskreis des Kuratoriums zu erlassen. Mit Beschluß der Landesregierung wurde diese am 5. März 1931 in Kraft gesetzt.

Im $\$ 2$ ) der GO wurde das Land als Museumseigentümer festgehalten und die Museumsverwaltung einem Kuratorium übertragen (\$3), dessen Mitglieder zu 6/8 von der Regierung und zu 2/8 von der Kammer zu beschicken wären. Die Funktionsdauer des Kuratoriums wurde auf vier Jahre festgelegt. Den Vorsitz des Kuratoriums sollte der Landeshauptmann oder ein von der „Landesregierung namhaft gemachter Funktionär des Landes“ innehaben, den Stellvertreter konnte die Kammer bestimmen.

Dem Kuratorium oblag (\$5) u.a. der Voranschlag, der Rechnungsabschluß, die Antragstellung auf Anstellung oder Entlassung ständiger Angestellter, die Beschlußfassung der laufenden Gebarung, die Festsetzung der Preise und der Bedingungen sowie die Überwachung und Leitung des inneren Dienstes.

In der Kompetenz der Landesregierung blieb u.a. (\$6) die Genehmigung des Voranschlages und des Rechnungsabschlusses, die Anstellung, Entlassung sowie

358 Vgl. den ministeriellen Brief vom 22.5.1934 (Zl. 1571 2-I-6a) mit der Subventionszusage für das Museum; die Subventionssperre für Bundesländermuseen wurde von Bundesseite ab 29.12.1932 (Zl. 34.255) erlassen (vgl. TLA ATLR Abt. III 706/1934 XV-85).

359 Brief Ringlers vom 11.1.1932, in dem er u.a. die letzten Kosten für die Restaurierung der Krippensammlung mit 3.935,50 S bezifferte und bemerkte, daß zur Deckung dieser Auslagen bereits Gelder aus dem Baufond verwendet worden seien! Ein Akt aus dem Jahr 1935 zeigt, daß die Gebahrung der Museumsauslagen nicht immer der Gepflogenheit eines ordentlichen Kaufmannes entsprach. Auf dieses Konto waren die Erlöse aus dem Verkauf von Baugründen beim Schlosse Mentlberg und beim Löwenhaus - die sich in Landesbesitz befanden eingezahlt worden. Das Geld wurde dann aber „zur Begleichung von Rechnungen des Volkskunstmuseums sowie zur Dotierung desselben“ verwendet, und der Aktenverfasser riet nun von der "Weiterführung" dieses Kontos, das LR A. Gebhart am 3.2.1930 eröffnet hatte, $\mathrm{ab}$, „da dessen Schaffung ohnehin nicht allgemeinen Verrechnungsvorschriften entsprochen hatte“. U.a. wurden aus diesem Konto fünf Zuwendungen an das Museum oder direkt an seinen Direktor (im Ausmaß von je 2.800,- bis 4.500,- S) getätigt. Die Verwendung der Gelder blieb aber unbekannt oder wurde allgemein gehalten („zur Begleichung von Rechnungen“, „zur Vergütung der laufenden Aufträge") (TLA ATLR 5/XV-85 ex 1935). 
die dienstrechtliche Behandlung dauernd Angestellter und als wichtiger Punkt die „Genehmigung der Veräußerung von Musealgegenständen“. Die Veräußerung von Musealgegenständen wurde weiters im \$9) an den „Vorschlag eines von der Landesregierung bestellten Fachbeirates" und an die Genehmigung durch die LR geknüpft. \$10) legte die Verwaltung des Museums durch einen Direktor fest. ${ }^{360}$

Dieser GO war die „Ordnung für den Referenten“vorausgegangen, die 1926 von Landesamtsdirektor Dr. Pochels und HR Dr. Moeser verfaßt worden war. Diese Ordnung regelte die Aufgaben des vom Kuratorium bestellten Referenten (dieser Posten war eine Art Vorläufer der späteren Direktorenstelle). Daneben bestand eine ebenfalls von Pochels und Moeser im selben Jahr verfaßte Kuratoriums-GO, deren Punkte im Großen und Ganzen in die oben angeführte GO Eingang fanden (die Kuratoriumsperiode betrug nur drei Jahre). ${ }^{361}$

Nach 1945 wurde die GO mehrmals geändert, weil, wie in einer Begründung der GO-Änderung von 1963 ausgeführt wurde, die frühere GO (in ihrer letzten Fassung vom 9. Februar 1948) eher auf Vereinsbasis angelegt gewesen sei und „nicht mehr einer Institution, die mit allen ihren Beständen zum Eigentum des Landes gehört und zur Gänze aus Subventionen des Landes erhalten wird“ entsprochen hätte.

Die Zahl der Kuratoriumsmitglieder wurde ab 1963 mit 15 festgelegt. Der LR stand die Bestellung von elf Mitgliedern zu (dazu zählten der Landeskulturreferent als Kuratoriumsvorsitzender in Vertretung des LHM sowie zwei weitere Mitglieder der LR, ferner der Landesamtsdirektor, je ein Vertreter des Landesfinanzreferenten, des Landesbaudirektors sowie der Landeskulturabteilung, weiters ein Vertreter des Ferdinandeums, der Landeskonservator, ein Vertreter des Heimatschutzvereines und der Referent für Brauchtum und Schützenwesen). Die restlichen Sitze standen der Kammer zu. Der Museumsdirektor nahm laut GO an den Sitzungen mit beratender Stimme teil. ${ }^{362}$

Bis 1954 waren an den Kuratoriumssitzungen, mit Beschluß der LR vom 9.5.1947 (Zl. IVb-321/47), je ein Vertreter der Bauern- und der Arbeiterkammer teilnahmeberechtigt. Dem Vorschlag, wie schon in der Zwischenkriegszeit auch

360 Je ein Exemplar der „Geschäftsordnung des Tiroler Volkskunst-Museum“ (genehmigt mit Beschluß der TLR vom 5.3.1931, Zl. III-459/1; gez. Bundsmann) befindet sich im Archiv des TVM sowie im TLA ATLR Abt. III bei 5/1936 XV-85.

361 Die „Ordnung" und die GO befinden sich im Archiv des TVM.

362 GO-Änderung vom 21.1.1963 Zl. IVd-209/2/63a; ein Exemplar befindet sich im Archiv des TVM. 
den Innsbrucker Bürgermeister mit ins Kuratorium aufzunehmen, wurde allerdings nicht entsprochen. ${ }^{363}$

Der $\$ 1)$ der 1931 erlassenen Geschäftsordnung definierte als Zweck der Institution: $\mathrm{Da}$

„das tirolische Museum für Volkskunst und Gewerbe [...] die Aufgabe [habe] durch fachgemässe Aufstellung, Erhaltung und Zugänglichmachung der in ihm bereits vorhandenen und neu zu erwerbenden Gegenstände volkstümlicher Kunst und kunstgewerblichen Charakters tirolischer Herkunft das Interesse und das Verständnis für das Wesen tirolischer Eigenart zu wecken und überdies der künstlerischen und kunstgewerblichen Produktion Unterlagen für die Erkennung überkommener Schaffensart zu bieten ${ }^{\text {“364. }}$.

Damit war offiziell die gewandelte Ausrichtung des Museums festgeschrieben worden. Zwar blieb es nach wie vor bei der Betonung der Förderung des heimischen Gewerbes (unter dem Gesichtspunkt der „Erkennung überkommener Schaffensart"), dies aber in sehr ideologischer Form, wie aus dem neu definierten Museumszweck: der Interessens- und Verständnisweckung der tirolischen Eigenart, hervorgeht.

Die so heraufbeschworene Eigenart wurde aber eher durch die Auswahl der dargebotenen Gegenstände erreicht, als daß sie in diesen schon selbst enthalten wäre. Dadurch wird das Museum zum Vertreter und Produzenten einer als einzigartig angesehenen Tiroler Volkskultur/-kunst.

363 Ringler hatte 1954 von seiten der LR den Auftrag erhalten, „Vorschläge für die Ausgestaltung eines Kuratoriums zu machen und Persönlichkeiten hierfür bekannt zu geben“" (Brief DDr. Luggers an Ringler vom 10.5.1954 und die Antwort Ringlers vom 12.5.1954). In einem Vermerk an die LR war von Ringler der Wunsch geäußert worden, den Referenten für Brauchtum HR Dr. J. Schumacher ins Kuratorium zu berufen, da es mit ihm eine „vielfache Zusammenarbeit [...] in Trachtenangelegenheiten " gäbe (s. den Ordner über Kuratoriumsangelegenheiten, Jahr 1954, im Archiv des TVM).

364 Hervorhebung von W. M.. Auch in der GO von 1963 blieb dieser volkstumspflegerische Paragraph erhalten: „Das Tiroler Volkskunstmuseum hat die Aufgabe, Gegenstände volkstümlicher Kunst oder kunstgewerblicher Natur von Tiroler Herkunft zu sammeln, zu erhalten und zur Schau zu stellen. Es soll dadurch das Verständnis für das Wesen tirolischer Eigenart wecken und beleben, sowie dem künstlerischen und kunstgewerblichen Schaffen Anregungen, vor allem für die Bewahrung und Pflege heimischen Brauchtums geben." 


\subsubsection{Museumseröffnung}

Am 15. Mai 1929 konnte das „Tiroler Volkskunstmuseum“, im Beisein zahlreicher Prominenz (darunter Bundespräsident Wilhelm Miklas, der Tiroler Landeshauptmann Dr. Stumpf, sein Stellvertreter Dr. Gruener und Handelskammerpräsident Willibald Reder) offiziell eröffnet werden.

Die dem Museum neu zugedachte Aufgabe wird aus den dabei gehaltenen Ansprachen sowie den kurz darauf verfaßten einschlägigen Beiträgen ersichtlich.

Die nun präsentierte Museumsaufstellung war weit entfernt vom Charakter einer reinen Gewerbesammlung, die bloße Vorbild- und Musterfunktion zu erfüllen hatte. Sie war vielmehr ein Produkt der Anschauungen über Volkskunst, die in den späten 20er Jahren unseres Jahrhunderts, sowohl in Tirol als auch in Österreich, herrschten.

So ist für den Tiroler Volksboten das Museum „nicht nur ein Stolz unseres Landes, sondern ein eindrucksvolles Zeugnis der gesamten österreichischen und deutschen Kulturentwicklung".

Damit wurde die ausgestellte Sammlung Teil der Suche des neuen Staates Österreich nach einer eigenen Identität. Diese Suche schwankte zwischen einer Abgrenzung vom Deutschen Reich und dem Gefühl, zum deutschen Kulturkreis zu gehören. ${ }^{365}$

Ein weiteres zentrales Thema bei der Museumseröffnung, welches in vielen Beiträgen anklang, war die als dekadent angesehene Gegenwart, der die Museumssammlung als Kontrast gegenübergestellt wurde.

So meinte der Tiroler Anzeiger, daß

„die Eröffnung des Tiroler Volkskunstmuseums [...] zu jenen stilleren aber umso nachhaltigeren Ereignissen [gehöre], die der heute vergötterten und verhätschelten ,Masse' nichts zu bedeuten scheinen. Für diese kommt

365 36. Jhg. Nr. 20 vom 16.5.1929, S. 9; weitaus deutsch-nationalistischere Töne hatte der Leiter des Friesen-Museums in Föhr Dr. Carl Häberlin in seiner Grußadresse an den Tiroler Landeshauptmann Dr. Franz Stumpf angeschlagen: „Jedenfalls reichen wir dem Tiroler Bruderstamm vom Nordseestrand die Hand und wünschen den Bestrebungen des Museums das Allerbeste." Eine direkte Teilnahme an der Eröffnungsfeier mußte er aber, aufgrund der hohen Kosten, absagen (vgl. sein Schreiben, das er seiner 1926 in Kiel erschienenen Ausgabe der „Inselfriesischen Volkstrachten“ beigelegt hatte, im TLA unter Nr. 2241/1!). 
nichts in Frage, was nicht wägbar und meßbar ist. Diese moderne ,Masse ist der geborene und geschworene Feind aller echten Kultur, welche die Gesellschaft harmonisch gliedern aber nicht nivellieren will.“

In dieser Äußerung zeigt sich schon die dem Museum zukünftig zugedachte politische Aufgabe: einerseits materielle Verkörperung des ständischen Staatsgedankens zu sein, andererseits, wie das Blatt betont hatte, die "geistige Physiognomie des Tiroler Volkes von Nord- und Südtirol [...] in den feinsten Zügen [zu] porträtier[en]“. Die Errichtung dieser Institution war ja „nicht nur eine kulturelle, sondern auch eine politische Tat erster Ordnung", da damit, wie es in der Zeitung weiter hieß, „eine mächtige, überwältigende Apologie für die Einheit des von der Gewalt zerrissenen Landes" errichtet worden wäre.

Der Verfasser erhoffte sich durch die Sammlung nicht nur eine Anregung für das Gewerbe, sondern auch eine Abkehr von der bloßen Zurschaustellung des „kernigste[n] Tiroler Volkstum[es]“. Seiner Ansicht nach wäre das Museum dazu da, aus ihm zu lernen und so „neue Kraft für die organische Wiederbelebung der Tiroler Volkskultur zu sammeln“. Denn es wäre „die große Offenbarung dieses Museums“, „jene[n] Kunstsinn, der die Tiroler Bauernstube, ja die Geräte des täglichen Gebrauches adelt" zur Ausstellung zu bringen. ${ }^{366}$

Mittelpunkt all dieser patriotischen und heimatbetonenden Ansichten war das Gedenken an die, seit dem Ende des Ersten Weltkrieges, abgetrennten südlichen Landesteile. Mit Südtirol waren jetzt nur mehr die deutschsprachigen Gebiete gemeint.

Für Museumsdirektor Josef Ringler war das Museum ein „Denkmal, beredter als jedes andere, für die Zusammengehörigkeit von Nord- und Deutschsüdtirol“"367.

Kunibert Zimmeter betonte in einem Beitrag über das Museum, daß dessen Sammlung ein „noch ungeteilte[s] Tirol“, die „kulturelle Einheit, die sich über Jahrhunderte bildete“ zeigen würde. Weiters waren ihm die Gegenstände Zeugnis

366 22. Jhg. Nr. 111 und 112 vom 15. und 16.5.1929, S. 1 sowie S. 5; Bundespräsident Miklas hob in seiner Eröffnungsrede ebenfalls den patriotischen Wert des Museums hervor: „Die Begriffe Volk und Heimat klingen nirgends so echt, so tief verwurzelt im Boden und Volkstum, wie im Land Tirol." (ebd.)

367 Zit. in Volkszeitung Nr. 112 vom 16.5.1929, S. 4. Interessant, daß sich ausgerechnet dieses sozialdemokratische Blatt zum Sprachrohr für das Gedenken an die Abtrennung der südlichen Landesteile machte: „Eigenartig berührte, daß von den drei Tiroler Rednern (Gruener, Reder, Stumpf) auch nicht mit einem Worte des im Museum doch so besonders hervortretenden Teils unseres Landes, das unter uns, mit uns weiterlebt, gedacht wurde: Südtirols. Falsche Rücksicht oder Vergeßlichkeit? Beides war bei einem so besonderen Anlasse, des Zusammengehörens zu gedenken, nicht am Platze!“ (Ebd.) 
einer einstmaligen kunstgewerblichen Größe des Landes, „die heute unerreichbar" wäre. ${ }^{368}$

Der Jesuit und damalige Prodekan der Innsbrucker Theologischen Fakultät Dr. Pangerl hob in seiner Eröffnungsrede den Wert des Museums zur „Vertiefung der Liebe zur Heimat" hervor und drückte seine Hoffnung aus, daß die Sammlung die „Wertung des Volkstums [...] für die Zukunft“ verbreiten werde können. ${ }^{369}$

Für Josef Manfreda, Bildhauer und Lehrer an der Innsbrucker Fachschule für Hochbau und Elektrotechnik, war die Aufgabe des Museums „mit bloßem Anschauenlassen und Schützen nicht erfüllt“. Wie er in seinem Aufsatz „Volkskunstmuseum und Museumspolitik“ betonte, sei der "Zweck“ des Museums „nicht bloß in der üblichen Absicht einer öffentlichen Deponierung historischer und materieller Werte oder in einer Schaustellung, aus welcher die Besucher ersehen sollen, was unsere Vorfahren geleistet haben“, „sondern hauptsächlich - und darin unterscheidet sich die moderne Museumsführung von der alten - in der Lebendigmachung und Lebendigerhaltung der wertvollen Kulturkräfte auf dem Gebiete der volkstümlichen Kunst".

Daher sollte diese neue Sammlung ,keine bloße Aufbewahrungsstätte für volkskundliche Reliquien, kein Leichenhaus der Volkskunst, auch kein bäuerliches Trophäenarsenal sein“, sondern auf einer „gesunden“ und zeitgemäßen $\mathrm{Mu}$ seumspolitik aufbauen, um so etwas „Lebendiges, rastlos und zeitgemäß Arbeitendes“ bieten zu können. Das Ziel müßte eine „aktive Lebendigkeit desselben“ sein, die nur erreicht werden könnte, indem die "Gegenstände [einer] breiten Öffentlichkeit mit entsprechender Erklärung und Propaganda zugänglich“ würden. Nur so könnte die beabsichtigte „Volkskunsterneuerung“ erreicht werden, die sich aber nicht in einem bloßen Kopieren der Vorbilder erschöpfen dürfte, sondern eine „richtige Erkennung und Förderung der künstlerischen Impulse im

368 So in seinem Bericht über „Das Museum für tiroler Volkskunst in Innsbruck“, erschienen in der Beilage zum Tiroler Anzeiger 22. Jhg. Nr. 126 vom 4.5.1929 „Die deutsche Familie“ Nr. 9, S. 269 ff. Für Zimmeter war das Museum ,vielleicht eines der vollkommendsten Institute dieser Art [...], insoferne es die Kultur eines wenn auch kleinen Gebietes in fast allen ihren die Volkskunst betreffenden Äußerungen in einer Überfülle von Beispielen zur Darstellung bringt“ (S. 271) und er hob hervor, daß zum Glück mit dem Sammeln „noch rechtzeitig begonnen [worden sei], ehe die allgemeine Verschleppung bäuerlichen und bürgerlichen Hausrats“ eingesetzt hätte (S. 269).

369 Innsbrucker Nachrichten 76. Jhg. Nr. 111 vom 15.5.1929, S. 6; im Übrigen hoffte er auf eine vertiefte Beziehung zwischen der Universität und dem Museum, indem zum Beispiel, ähnlich Graz und Wien, auch hier in Innsbruck Vorlesungen über Volkskunst abgehalten werden sollten (ebd.). 
Sinne eines stets neu zu schaffenden, echten, bodenständigen, also tirolerischen Kunstgewerbes" beinhalten müßte. ${ }^{370}$

Der Direktor des Mährischen Gewerbemuseums und spätere Leiter des Salzburger Museums Carolino Augusteum (1921-33) Julius Leisching sah die vordergründigste Funktion des neuen Museums in der Volkstumspflege. Diese hielt er, in ihrem Festhalten am „Ächten“, „angesichts der wachsenden Trachtenfeste, [für] um so wichtiger, als hier fern von allem theatralischen Aufputz die Überlieferung für alle Zeiten festgelegt “werden würde. Er stellte der Institution das beste Zeugnis aus, würde sie doch, seiner Ansicht nach, „den Begriff, Volkskunst' im weitesten Sinne auf[fassen], im Sinne des Völkischen ${ }^{\text {"371. }}$.

Fast alle Veröffentlichungen zur Museumsentstehung hoben dessen Aufgabe als völkisch-nationale Bildungseinrichtung hervor. So auch Julius Leisching, der die neue Institution als „Nationalmuseum“ rühmte, welche mit ihren „Schätzen das Spiegelbild einer vielhundertjährigen echten, reichen und deutschen Volkskultur in der Südmark" verkörpern würde. ${ }^{372}$

Herbert Stifter sah in seinem Beitrag die Bedeutung des Museums vor allem in der Vermittlung von „Ehrfurcht [...] vor der Heimat, vor dem Volke, vor diesem deutschen Stamme nördlich und südlich des Brenners, der da in seinem großen Durchschnitt als universeller Künstler gezeigt wird“.

Demzufolge sind ihm die in der Sammlung gezeigten Objekte, deren Entstehung er vor allem „organisch“ sah, Zeugen der Schaffenskraft des Tiroler Volkes. Und deshalb hob er auch den „Volksgenius“ und die Gabe dieses Volkes hervor, „sich seine eigensten ästhetische Begriffe“ zu schaffen: Denn „all dies [die Volkskunst; W.M.] schuf das Leben selbst, eines aus dem anderen leitend, Glied an

370 Garanten für diese Erneuerung waren Manfreda in erster Linie die Künstler, die allein „geistige, produktive Träger und Führer der Volkskunst" wären (Tiroler Anzeiger 22. Jhg. Nr. 252 vom 31.10. 1929, S. 5 f.). Seiner Meinung nach wäre eine eventuelle Vereinigung mit dem Ferdinandeum nur ein „unbefriedigendes Flickwerk gewesen“, und deshalb plädierte er für die organisatorische Eingliederung der Volkskunstgegenstände des Landesmuseums in die Bestände des Volkskunstmuseums (ebd.), was 1931 geschah.

371 Leisching 1929, S. 232. Er trat für ein, zumindest räumliches, Zusammengehen der volkskünstlerischen und kunsthandwerklichen Gegenstände des Ferdinandeums mit denen des Volkskunstmuseums ein (ebd.).

372 Leisching 1931, S. 134. Dieser verfaßte seinen Beitrag in der Funktion als „Vorsitzender des Verbandes kunstwissenschaftlicher und kultureller Museen Österreichs“. 
Glied schließend, namenlos und in tausendfältigem Überschuß, wie eben nur die Natur zu zeugen und zu spenden weiß ${ }^{\text {“373 }}$.

In Karl Paulin erweckte „das Museum in seinem Reichtum und seiner Mannigfaltigkeit, die die alte Einheit Tirols dies- und jenseits des Brenners ebenso beweist, wie den Farbenreichtum und die Tiefe seiner volkstümlichen Kultur, die allgemeine Bewunderung", und er hob besonders dessen "großen heimatlichen Gedanken" hervor. ${ }^{374}$

Die Begriffe Heimat, Bauernkultur und Deutschtum waren deshalb nicht von ungefähr Bestandteile der ersten Museumsankündigungen.

Die meisten der geäußerten Ansichten über Aufgabe und Funktion des Museums entsprachen eher einem Wunschdenken der Redner als der Realität. Als Beispiel dafür kann die oft zitierte enge Verbindung der musealen Sammlungen zum Tiroler Bauerntum gelten. In einem Artikel der Tiroler Bauernzeitung über die Museumseröffnung wurde der Verklärung des Tiroler Bauern weiter Vorschub geleistet, indem der Verfasser die Ansicht vertrat, daß sich ein Museumsbesuch als bester Garant zur eigenen Identitätssteigerung erweisen würde:

„Ihr werdet bei einem solchen Besuch geradezu einen neuen Grund finden, Stolz darauf zu sein, daß ihr von Tiroler Bauern Herkommen seid. Wenn die sozialistische Zeitung wiederum von Tiroler Bauerntrotteln schreibt, dann möget ihr auch antworten. Das haben wir schon gesehen, was die Tiroler Bauern sind, im Tiroler Volkskunstmuseum haben wir's gesehen. ${ }^{\text {375 }}$

373 Stifter 1930, S. 7 f. Als Motto stellte er seinem Aufsatz die Worte Goethes: „Was du ererbt von deinen Vätern hast, / Erwirb es, um es zu besitzen“ (aus Faust I) voran. (ebd., S. 7)

374 Paulin 1929, S. 7; bereits zu Beginn seiner Arbeit bezeichnete er das Museum als „einzigartige[s] Kulturbild“ sowie als „Kleinod alpenländischer Volkskunde“. (ebd., S. 2)

375 Die Zeitung ließ einen anonymen Berliner Museumsbesucher zu Wort kommen, für den in der Sammlung in „konzentrierter Form die Seele Tirols sichtbar und fühlbar" wurde und betonte, er habe „noch nie [...] ein so schönes Nationaldenkmal gesehen, wie dieses Museum das das Leben eines Volkes von der Wiege bis zum Grabkreuz eingefangen hätte und es mit einer solchen Gegenwartslebendigkeit erhält“. Ferner lobte er an der Sammlung, daß sie „Tirol in seinem inneren Reichtum und der teil rührenden Naivität und Zartheit“ darstellen würde (28. Jhg. Nr. 36 vom 29.8.1929, S. 4 f.). Das Blatt selbst erinnerte sich beim Anblick der Sammlungen an die verlorene Landeseinheit: „Südtirol ist im Volkskunstmuseum [...] stark vertreten. Wie das anheimelt, wenn man durch die Südtirolerkammern geht und den Südtiroler Hausrat und die Südtiroler Trachten vor sich sieht und die Namen der Täler liest. Wahrlich, das ist ein gleichwertiges Stück unserer Heimat und das soll auf immer verloren sein.“ (ebd., S. 5) 


\section{B E S U C HEN S I E D A S \\ TIROLER \\ VOLKSKUNST= \\ MUSEUM \\ Innsbruck, Universitätsstralle 2* Neben der Hotkirche \\ Größtes Heimatmuseum der deutschen Alpen= länder + Ein herrliches Denkmal deutscher Bauernkultur aus Nord= und Südtirol}

22 Tiroler Bauernstuben von der Gotik bis zum Rokoko, große Sammlung alter Originaltrachten aus Nord- und Südtirol, Bauernmöbel von primitiven, frühmittelalterlichen Typen bis zu den reichbemalten Schränken der Rokokozeit. Reichhaltige Sammlung von Gegenftänden kirchlicher und profanerVolkskunlt. Schmiedearbeiten.

Eintritt 1 Schilling * Geoffnet von 9-5 Uhr, an Sonn- und Feiertagen von 9-12 Uhr

aus TIROL. Natur Kunst + Volk Leben 2. Bd. (hg. Landesverkehrsamt für Tirol) Innsbruck 1931, S. 425 
In der Realität jedoch mußte auch die Bauernzeitung ihre hohen Ansprüche zurücknehmen und bekennen, daß zwar die Fremden einen Museumsbesuch als lohnend empfinden würden, dies aber bei den Einheimischen nicht so wäre:
„Und wir haben es so nahe, wir haben diesen Schatz in unseres Landes Mitte, Bauern und Bäuerinnen, wenn ihr zum Markt nach Innsbruck kommt oder sonst zu Geschäften und ihr erübrigt euch eine freie Stunde oder besser zwei oder drei, geht hinein in das Tiroler Volkskunstmuseum. Da seht ihr hübsch beisammen die echte einheimische Tiroler Bauern- kunst, seht wie geistig hoch schon eure Voreltern gestanden, von denen ihr abstammt [...]. ${ }^{\text {(376 }}$

Anläßlich der feierlichen Museumseröffnung gab es einige wenige kritische Stimmen. So brachte das Wochenblatt Der Oberländer bereits im Frühjahr 1929 einen „Innsbrucker Brief“, worin der Verfasser in zynischer Weise auf die beabsichtigte Museumseröffnung einging.

Nach Meinung dieses Artikelschreibers wäre es besser gewesen, das in den Sammlungsankauf und die Museumsadaptierung investierte Geld an Arbeitslose weiterzugeben. Denn Tirol sei heute total verarmt, und daher

„soll zuerst an die Armen gedacht werden, die bald nicht mehr wissen, wie sie ihr Leben fristen können und erst dann sollen die Theater, Kunst- und höheren Bildungsstätten kommen, denn wie wird unser Landl in wenigen Jahren aussehen, wenn wir nur mehr, Gstudierte und Arbeitslose haben“.

Weiters kritisierte dieser Brief das Verhalten der Volksvertreter, besonders Dr. Grueners, die unfähig gewesen seien, die wahren Probleme und Nöte des Volkes zu erkennen. „Aber geht einmal hinein in die Hütten der Armen und es wird Euch die Erkenntnis kommen, daß die Hebel an anderer Stelle angesetzt werden müssen, um ein wahrer Vertreter des Volkes zu sein.“"377

376 Beschwichtigend schrieb die Zeitung zwar, daß „ein guter Teil dieser Besucher [das Blatt schrieb von 15.000 Personen, die das Museum seit seiner Eröffnung im Mai besucht hätten, der Artikel erschien im August; W.M.] bäuerlichen Kreisen“ angehören würden (ebd.).

377 1. Jhg. Nr. 6 vom 8.2.1929, S. 2 f.; der Brief ist mit dem Pseudonym „-Kritikus-“ gezeichnet. Anläßlich der Museumseröffnung erschien im selben Blatt ein weiterer „Innsbrucker Brief“ zur Thematik „Volkskunstmuseum“, worin wieder die geringen Löhne der Arbeitenden, sowie das, nach Meinung des Schreibers, falsche „Heimatverständnis“ der zuständigen Politiker, die nach wie vor der vergangenen Monarchie und deren Kultur und Kunst anhängen würden, beklagt wurden (1. Jhg. Nr. 20 vom 17.5.1929, S. 3 f.; dieser „Brief“ findet sich auch im Tiroler Wastl 24. Jhg. Nr. 1156 vom 15.5.1929, S. 3 f.). Daneben richtete sich die Kritik des Blattes vor allem gegen Politiker im Allgemeinen, deren große Pensionen und gegen die „rote Gefahr“ im 
Zusammenfassend läßt sich festhalten, daß das Museum und seine Sammlung als Hort der Stiftung und Bildung von Heimat gesehen wurde. Dies vor dem Hintergrund der sich verschlechternden Lebensbedingungen (Weltwirtschaftskrise) sowie der regionalen Sinnkrise seit der Abtretung Südtirols. Im Museum, mit seinen zahlreichen Exponaten aus den südlichen Landesteilen, konnte dieses Verlustes gedacht werden. Daneben schuf die Betonung der deutsch-tirolischen Kunst und Kultur eine Identifikationsmöglichkeit mit „Deutsch-Österreich“, das seit seiner Entstehung in seiner Existenz für kaum lebensfähig gehalten wurde.

Besonderen, wobei vor allem der sozialistische Politiker Dr. Franz Gruener im Mittelpunkt der Kritik stand. Dieser „Schloßherr von Itter“, so das Blatt bereits im ersten „Brief“ (Nr. 6, S. 2), sei „Nutznießer einer Mieterschutzwohnung im Zentrum von Innsbruck“. 



\section{Kurzgefaßte Museumsgeschichte seit der Wiedereröffnung 1948 bis in die späten 60er Jahre}

\subsection{Die Zeit von 1938 bis 1945}

Die einzige Veröffentlichung, welche auf das Museum in der NS-Zeit eingeht, ist der 1962 vom ehemaligen Museumsdirektor Josef Ringler verfaßte Aufsatz über das „Tiroler Volkskunstmuseum“. Er schreibt allerdings in einer derart distanzierten Weise über diese Epoche, daß einem uninformierten Leser auf den ersten Blick gar nicht bewußt wird, daß Ringler selbst der 1938 abgesetzte Direktor war. Außerdem geht er kaum auf inhaltliche Vorgänge der Jahre 1938-45 ein, sondern versucht, den formalen Museumsablauf wiederzugeben.

In seinem 1947 verfaßten 10. Jahresbericht, der die Aktivitäten des Zeitraumes 1938 bis 1945 zusammenfaßt, berichtet er, daß „die Vorgänge und Veränderungen im Tiroler Volkskunstmuseum während des verflossenen Systems nur sehr schwer zu rekonstruieren" seien, da

„Tatsache ist, dass in den Tagen des Zusammenbruchs über Veranlassung der damaligen Leiterin des Museums, Frau Gertrud Pesendorfer, zahlreiche Aktenbestände, Korrespondenzen u.a., hauptsächlich die Mittelstelle ,Deutsche Tracht' betreffend, im Keller des Museums verbrannt wurden.“

Dabei, vermerkte er weiter, „wurde, wohl irrtümlich, auch das Ausleihbuch des TVM [Tiroler Volkskunstmuseums] verbrannt ${ }^{\text {“378. }}$.

Ringler war als Museumsdirektor mit Dekret vom 16. März 1938 seines Postens enthoben worden. Als kommissarischer Leiter wurde der ehemalige Referent des Museums, Archivdirektor i. R. Dr. Karl Moeser, eingesetzt.

Der Anspruch der ehemaligen Museumssekretärin und Trachtenspezialistin Gertrud Pesendorfer auf diesen Posten dürfte aber immer stärker geworden sein, da

378 Er vermerkte dies, da in der NS-Zeit wohl umfangreiche Neuzugänge erfolgt waren, deren Inventarisierung aber unterblieb. Daneben seien „beträchtliche Veränderungen durch Verkauf oder Tausch" erfolgt. (Archiv des Tiroler Volkskunstmuseums, Bericht über die Geschäftsjahre 1946-47 = 10. Jahresbericht - im folgenden als Bericht TVM zitiert - verfaßt von Museumsdirektor Dr. J. Ringler, S. 1 ff., hier S. 1) 
sie, laut Protokoll vom 26. September 1939, die Geschäfte von Moeser übernahm. Moeser fungierte fortan als „wissenschaftlicher Berater bei Erwerbungen“"379.

Unter Moesers und Pesendorfers Einfluß wurden im Ostflügel des Kreuzganges befindliche Fresken religiöser Thematik („Jesus im Weinberg“, „Christus in der Kelter" und „Mariä Verkündigung"), die im Auftrag des Kuratoriums in der Zeit von 1932 bis 1934 vom akademischen Maler Hans Andre angefertigt worden waren, überdeckt.

Dabei wurde in Kalk getränkte Jute verwendet, sodaß die Fresken nach 1945 nicht mehr gerettet werden konnten. ${ }^{380}$

Neben der kriegsbedingten Auslagerung und der nach 1945 erfolgten Zurückstellung der Objekte gingen während der NS-Zeit viele Gegenstände im Tauschwege oder durch Veräußerungen verloren.

Ringler vermerkte, daß in der NS-Zeit keine Kontrollmöglichkeiten über die Museumsführung bestanden, da ab 1938 keine Kuratoriumssitzungen abgehalten wurden, aber auch der bestehende und offiziell niemals aufgelöste Fachbeirat nicht mehr herangezogen wurde. So sei es wahrscheinlich, daß Moeser die Veräußerungen alleine getätigt hätte. Erst im Nachhinein und daher sehr unvollständig, so Ringler, hätte er diese Transaktionen schriftlich niedergelegt. ${ }^{381}$

379 Vgl. Ringler 1962, S. 82 ff., sowie seine Angaben im Bericht TVM; Zwischen Ringler und Moeser dürfte es einige Differenzen gegeben haben. Dies zeigen gegenseitig voneinander angelegte Aktennotizen. So die Feststellung Moesers, Ringler hätte „eine ungerechtfertigte [finanzielle] Besserstellung [...] gegenüber den anderen Beamten“ erhalten (nach diesen 1938 verfaßten „Bemerkungen zur Geschäftsordnung und zum Betrieb des Volkskunstmuseums“ bezog Ringler zusätzlich zu seinem Gehalt nach „Stufe 1 der IV. Dienstklasse“ 1.700,- Schilling an jährlichen Zulagen). Ob diesem Vorwurf wirklich Moesers Sorge um die Benachteiligung anderer Landesbeamter vorausging, oder ob hiermit nicht alter Unmut gegen Ringler beglichen wurde (Ringler war Moeser 1928, nach dessen nicht ganz freiwillig erfolgtem Ausscheiden aus der Museumsleitung, als neuer Hauptverantwortlicher gefolgt), läßt sich nicht mehr eindeutig klären. Als Ringler nach seiner Wiedereinsetzung als Museumsdirektor 1945 diese Bemerkungen Moesers - worin sich dieser auch abschätzig über die Kuratoriumstätigkeit unter Ringlers Leitung geäußert hatte - las, konnte er es nicht unterlassen, dazu eine handschriftliche Stellungnahme anzufügen: „Echt Möser!/ alt[testamentarischer] Neid!/ Dr. Ringler“. (Archiv des TVM) Ringler selbst war in der NS-Zeit aber nicht ganz zur persona non grata erklärt worden, sondern leitete die Denkmalämter der Provinzen Südtirol und Trient. Hier war er vor allem mit der Sicherung und Bestandsaufnahme der Südtiroler Kunstdenkmäler beschäftigt (vgl. Colleselli 1968 und 1973).

380 Ringler 1962, S. 82.

381 Bericht TVM, S. 3; zu den Einkäufen vermerkte Ringler, daß ihm die „Erwerbung von einem Wagen, Truhen und Kästen bei der Firma Rebitsch in Brixlegg [ganz unverständlich sei], zumal die meisten dieser Gegenstände [sich] in einem sehr desolaten Zustand“ befänden. Weiter bemängelte er, daß „für diese Gegenstände [...] erstaunlich hohe Preise bezahlt“ wurden (ebd.). 
An Erwerbungen aus dieser Zeit erwähnte Ringler die Anschaffung von Figuren des „Thaurer und Imster Schemenlaufens“ für den Maskensaal und betonte, daß damit dieser Raum „für das Fremdenpublikum einen besonderen Anziehungspunkt“ erhalten habe. Weiters führte er die Anfertigung von neuen „maßstabgetreuen Bauernhausmodellen“ an, die vom ehemaligen Gewerbeschulprofessor Viktor Hofer gefertigt wurden. Diese Modelle ersetzten die „kleinen malerischen Bauernhausmodelle Schafferers" ${ }^{\text {"382. }}$.

\section{Mittelpunkt der Museumsarbeit war aber ab 1938 die Trachtenforschung.}

Laut Ringler erhielt Gertrud Pesendorfer den Direktorenposten, da sie das „uneingeschränkte Vertrauen“ Gauleiter Hofers besessen habe und sie sei von diesem vor allem „mit der Neugestaltung des Museums [...], namentlich mit dem Ausbau des Trachtenwesens", betraut worden. ${ }^{383}$

382 Ringler 1962, S. 82; zu den insgesamt 25 Hausmodellen - 10 unter Leitung Hofers gefertigte Miniaturen im Maßstab 1:35, drei aus Rinde gefertigte Häuser von Erich Zogler und das Legat Scherer - jetzt Hans Gschnitzer in seinem Beitrag des Katalog 2 (Gschnitzer/Menardi 1986, S. 5 ff.), worin alle Modelle kurz beschrieben und einige fotographisch dargestellt sind.

383 Bericht TVM, S. 1; an anderer Stelle vermerkte er zynisch: „Die ganze Museumstätigkeit war auf das Trachtenwesen, nicht nur Tirols, sondern aller deutschen Gaue abgestellt“. (Ebd., S. 2.) Pesendorfer hatte einschlägige Arbeiten zum Trachtenwesen und zum bäuerlichen Handwerk vorgelegt, so in ihrem Aufsatz zu „Tiroler Volkskunst und Handwerk“ [in: TIROL 4. Folge Heft 1 (1939), S. 24-39, ebd. 2. Folge Heft 4 (1929), S. 76-86, ein Aufsatz „Zur Trachten-Sammlung des Tiroler Volkskunstmuseums"], oder in zahlreichen Zeitungsbeiträgen, wie im Artikel „Tiroler Hausindustriegenossenschaft" in der "Deutschen Volkszeitung" vom 8.11.1938. Weitere Aufsätze von ihr finden sich in der „Pause“ Heft 4/5 (1939), der „Deutschen Volkskunde“ Heft 2 (1940), in der „Alpenheimat“ (1939 und 1945) und in der Beilage „Die Warte“ der Zeitung „Die Furche“ Nr. 35 (1952). Die Kontinuität ihres Schaffens, unter verschiedensten Ideologien, über alle Brüche politischer Systeme hinweg, zeigt sich in den diversen Neuauflagen ihrer Trachtenbücher, die, meist unter Abänderung oder Weglassen verfänglicher Vorwörter, bis in jüngste Zeit immer wieder neu aufgelegt werden (z.B. ihr 1938 bei Callwey erschienenes Werk „Neue deutsche Bauerntrachten: Tirol“ mit Zeichnungen von Gretel Karasek, das in veränderter Form 1966 und 1982 in Innsbruck bei der Wagner'schen Universitätsdruckerei als „Lebendige Tracht in Tirol" herauskam - in der Auflage von 1982 sogar wieder mit den Illustrationen von Karasek!) Auf G. Pesendorfer (1895-1982) und ihr Wirken ist bislang in der volkskundlichen Forschung noch nicht eingehend eingegangen worden! - Auch Annemarie Lener behandelt in ihrer Dissertation zur „Entstehung der Tiroler Tracht im 19. und 20. Jahrhundert“ die Person G. Pesendorfer und ihr Werk - sowie generell das Tirolische Trachtenwesen - völlig unkritisch. Ohne geringste wissenschaftliche Reflexion und Analyse stellt sie darin die Tiroler Tracht als natürlich entstanden dar und geht nicht auf die ambivalente Rolle Pesendorfers in und nach der NS-Zeit ein. Damit leistet sie der Mythologisierung der Tiroler Tracht Vorschub, anstatt eine, längst notwendige, aber bis jetzt noch nicht stattgefundene, Aufarbeitung dieser ideologischen Funktion zu unternehmen. Tiroler Tracht gilt nicht nur als „Kleid der Ahnen“, sondern auch als Ausdruck der Eigenartigkeit und der Eigenständigkeit der Tiroler. In der Trachtenerneuerung propagiert und in den Trachtennähkursen realisiert, war die Trachtenpflege, oder was die dafür 
In der Folge war im Museum eine Trachtenwerkstätte errichtet worden. Der aufgelassene Krippensaal wurde in Schulungsräume der NS-Frauenschaft umgestaltet und, in Zusammenarbeit mit der „Kulturkommission“, in Südtirol eine Trachtenbestandsaufnahme durchgeführt. Zeitweise waren in der Trachtenwerkstätte des Museums an die 30 Frauen beschäftigt (zum Vergleich lag die Anzahl der Museumsaufseher bei 10 bis 15 Personen).

„Von Königsberg, Berlin, Westfalen, dem Rheinland, von Ostdeutschland und Schwaben bis nach Südtirol waren junge Damen als Sachbearbeiterinnen, Schneiderinnen, Zeichnerinnen, Malerinnen, Fotografinnen, Bibliothekarinnen und Sekretärinnen beschäftigt",

vermerkte Ringler im Bericht TVM und fuhr, sicher mit einem Seitenhieb auf die ehemalige Leiterin, fort: „Das Haus glich mehr oder weniger einer Zentrale der Reichsfrauenschaft." ${ }^{884}$

Gegen Ende des Zweiten Weltkrieges, als klar war, daß Innsbruck nicht mehr von Bombenabwürfen verschont bleiben würde, war die Museumsdirektion dann vor allem mit der Sicherung und Auslagerung der Museumsgegenstände beschäftigt. Bereits im Sommer 1943 wurden zerbrechliche Gegenstände (Keramik, Glas, ...) in Kisten verpackt und auswärts gelagert. Nach und nach verlagerte die Museumsleitung das ganze Interieur des Museums in auswärtige Depots; sogar die Stuben wurden abgebaut und zur Sicherung abtransportiert. ${ }^{385}$ Ein Bombenangriff am 15. Dezember 1944 beschädigte das Museumsgebäude durch einen Treffer. Dabei wurde das Renaissanceportal beim Eingang vollständig zerstört. Ebenfalls in Mitleidenschaft gezogen wurde die Gebäudeecke gegen die Hofkirche sowie die

Berufenen (wie Pesendorfer etc.) als solche ansahen, für einen Teil der tirolischen Gesellschaft zu einem nicht unwichtigen Integrations- und Identifikationsmuster geworden, die auch von seiten der Landesobrigkeit reichliche Unterstützung erhielt. Dabei befand und befindet sich diese Pflege aber in einem Zwiespalt: einerseits muß sie sich den Vorwurf der Erstarrung und des damit verbundenen Uniformwerdens von Tracht gefallen lassen, andererseits ihre Nähe zur Vermarktung in Form von Dirndl und Trachtenlook. Auf all dies geht aber A. Lener in ihrer Arbeit (1983) nicht ein.

384 Ebd., S. 2, an anderer Stelle berichtete er, daß dem Museum und seiner Leiterin „reiche Mittel für die interne Ausgestaltung und für Erwerbungen zur Verfügung" standen, wodurch die Trachten- sowie die Möbelsammlung „eine bedeutende Vermehrung“ erlangt hätten. (Ringler 1962, S. 83)

385 Bericht TVM, S. 4, sowie Ringler 1962, S. 83; die Gegenstände waren in Depots nach Mariastein, Schloß Lichtwehr im Unterinntal und Petersberg im Oberinntal sowie in das Kloster Stams gebracht worden. Einige Ladungen „minderwertigen Museumsgutes“ (ebd.) landeten in einem Depot im Schloß Ambras (vgl. Trapp 1947, S. 65). 
westliche Hälfte der Fassade. Ringler betont aber in seinem 10. Jahresbericht, daß das Museum „im großen und ganzen [...] durch eine erfolgreiche Bergungsaktion vor größeren Verlusten verschont geblieben" sei.

\subsection{Das Volkskunstmuseum nach 1945}

Nach dem Zusammenbruch der Nazi-Herrschaft führte wieder Karl Moeser die Museumsgeschäfte. Am 2. November 1945 erfolgte die neuerliche Amtsübernahme durch Josef Ringler, der dem Museum bis zu seiner Pensionierung zum Jahresende 1958 vorstand. Die ersten Aufgaben Ringlers nach seiner Wiedereinsetzung waren die Instandsetzung des Gebäudes (Sommer 1946 und 1947) und die Rückführung der ausgelagerten Museumsgegenstände. Während des Winters 1946/47 und im Frühsommer 1947 wurden die Stuben wieder eingebaut.

\subsubsection{Wiedereröffnung}

Am 28. August 1948 konnte das Museum in Anwesenheit alliierter und österreichischer Behördenvertreter sowie zahlreicher geladener Gäste aus Kultur und Wirtschaft wiedereröffnet werden. Die feierliche Eröffnung nahm Landeshauptmannstellvertreter Dr. Gamper vor. Aus den diversen Eröffnungsansprachen geht deutlich die, dem Museum in der Aufbauphase der Zweiten Republik, neu zugedachte Funktion hervor.

So bezeichnet der alte und neue Museumsdirektor Dr. Ringler das Museum als eine „Schatzkammer des Tiroler Volkes“,

„dem [zum] geistigen und handwerklichen Wiederaufbau eine Sammlung von Vorbildern gestellt wird, die zur Belehrung und Anregung im besten Sinne dienen mag. Es soll so das [...] Museum nicht nur, wie es ursprünglich gedacht war, den heimischen Gewerbestand fördern, sondern ihm jetzt besonders nach manchen Verirrungen der jüngsten Vergangenheit wieder einer neuen Veredelung und Blütezeit zuführen helfen. “"386

386 Bote für Tirol Nr. 38 vom 24.9.1948, S. 6. 


\subsubsection{Neue Aufgaben}

Das Museum wurde zum Ort der Integration und Identifikation des angerufenen Tiroler Volkes sowie zu einer Stätte, die von den „Verirrungen der jüngsten Vergangenheit" absehen helfen sollte. Wie das aber mit der Präsentation derselben Gegenstände, unter gleicher Konzeption wie in der Zeit der Verirrung, bewältigt werden soll, geht aus der Rede des Museumsdirektors nicht hervor.

Hier wurde durch die Präsentation der ausgestellten Gegenstände als neutrale Dinge, die für sich sprechen würden und die es nur wertneutral anzusehen gälte, von der Tatsache abgesehen, daß die Gegenstände nie für sich selbst sprechen. Diese sind immer, ebenso wie die Wahrnehmung durch den jeweiligen Betrachter, "Produkte eines historischen Prozesses“", wie es der Museumstheoretiker Detlev Hoffmann ausdrückt, der weiter meint: „Wer aber die Objekte eines Museums ihrer Historizität entkleidet, macht sie zu Funktionen seiner - subjektiven Interpretationswillkür. “387

Dieser subjektive Interpretationswille der Museumsbetreiber kam in der Eröffnungsrede Ringlers zum Ausdruck. Darin hatte er betont, daß das Museum nicht „etwas Abgeschlossenes“ sein solle, sondern den Kontakt mit „Handwerk und Gewerbe der Gegenwart“ suchen müsse, um diesen „eine Blutzufuhr aus formkräftigen Epochen [zu] bedeuten und [auch] mit den gewerblichen Schulen im engsten Kontakt leben“ müsse. ${ }^{388}$

Damit wurden wieder eigene Bedürfnisse in die Gegenstände hineinprojiziert. Die ausgestellten Objekte sollten, wie schon zu Zeiten des „Tiroler Gewerbevereins" formuliert, dem vermeintlich ideen- und perspektivenlosen Handwerk Vorbild, Anschauungsmaterial sein; auch wenn sie dann meist bloß williges Kopiermaterial sind. Bereits 1919 hatte Kunibert Zimmeter gemeint: „Wir haben eine gemeinsame, festgesetzte Kultur, die uns niemand nehmen kann, wenn wir sie nicht selbst aufgeben. [...] überall wo man die Dokumente alter, bodenständiger Kultur schützt, werdet ihr die Perlen unserer Tiroler Kunst hervorschimmern sehen." Laut Bernward Deneke wird durch diese Verabsolutierung ästhetischer Codes davon abgesehen, daß die sogenannte Volkskunst ihre jeweilige Ausprägung nicht in einer Abgeschlossenheit empfing, sondern, ,in der Verflochtenheit mit

387 1979, S. 101 (Hervorhebung im ersten Zitat von W.M.!); Norbert Schindler spricht von einer „Rache der Objekte“: „Freigesetzt aus allen Praxisbezügen, entfalten sie ein seltsames ästhetisches Eigenleben, erstrahlen in einem neuen folkloristischen Glanz." (1984, S. 30)

Bote für Tirol Nr. 38 vom 24.9.1948, S. 6. 
den zeitgebundenen allgemeinen und regionalen Entwicklungen von Wirtschaft, Gesellschaft und Kultur ${ }^{\text {“389. }}$.

Die Vorstellung, es gäbe „einheitliche, nach den Prinzipien von örtlichen oder landschaftsgebundenen Volkskunststilen gestaltete Ensembles“, entspringt dem Wunschdenken, überkommene wirtschaftliche Verhältnisse durch die Besinnung auf die Volkskunst stabilisieren und somit eine Lösung gegenwärtiger sozialer Probleme herbeiführen zu können. Oft ist dies auch mit der Hoffnung verbunden, die kulturelle Vergangenheit rekonstruieren zu können. Für Bernward Deneke besteht dabei ein Trugschluß:

„Schon der lebhafte Handel mit Gebrauchsgütern und die Überführung von älteren, unmodern gewordenen Ausstattungsgegenständen aus den Städten auf das Land widersprachen einer solchen Annahme [einer einheitlichen Volkskunst, W.M.]." ${ }^{\text {390 }}$

Zur Unterstreichung des praktischen Bezugs des Museums wurden in den folgenden Jahren einige Sonderausstellungen abgehalten, die die Verbindung des Museums mit dem Handwerk und Gewerbe verdeutlichen sollten.

Von den 13 derartigen Ausstellungen, die bis in die 70er Jahre abgehalten wurden, sind sechs dem Kunstgewerbe oder überhaupt der Kunstgeschichte zuzurechnen (u.a. zwei Ausstellungen des Tiroler Künstlers Max Spielmann, zwei weitere in Zusammenarbeit mit dem französischen Kulturinstitut über französische Tapisserien und Bühnenbildner). Einzig die Ausstellungen „Essen und Trinken“ (zusammen mit dem Ferdinandeum) sowie die Schau „Alte Spielkarten“, die vom Linzer Stadtmuseum übernommen wurde, behandelten volkskundliche Themen im engeren Sinne.

Nur die erste Sonderausstellung mit der Thematik „Grabgestaltung“, die schon 1932 in den Räumen der Tiroler Handels- und Gewerbekammer durchgeführt

389 1980, S. 20; das Zimmeter-Zitat findet sich in den Mitteilungen des Vereins für Heimatschutz in Tirol 3. Jhg. Heft 2-4 (1919), S. 19.

390 Ebd., S. 44; nach Deneke vollzieht sich in der Beschäftigung mit der Volkskunst „eine Enthistorisierung der an konkrete geschichtliche Lebensbedingungen gebundenen Dingwelt“ (ebd., S. 16). Dies wird auch an den Beständen des VKM nachvollziehbar: Wie wäre es sonst erklärbar, daß dort so unterschiedliche Gegenstände, wie die herrschaftlichen Stuben- und Deckengetäfel (z.B. Tierburger sowie Calderer Stube), jedoch auch so profane Dinge wie Mausefallen oder Kienspanhalter unter einen Hut zu bringen sind. Verbindendes Element all dieser Dinge ist eben der Rekurs auf eine gemeinsame kulturelle Herkunft (vgl. Zimmeter-Zitat oben). 
worden war und für die zeitgenössische Kunstschmiede Objekte zur Verfügung gestellt hatten, stellte den Versuch einer Zusammenarbeit mit dem Gewerbe dar.

Nach 1945 war es vor allem das religiös motivierte Kunstschaffen, das als heimisches Kunstgewerbe präsentiert wurde (z.B. 1953 in der Ausstellung „Krippen unserer Zeit"). ${ }^{391}$

Der Versuch, auf breiterer Basis eine engere Zusammenarbeit mit Handwerk und Gewerbe durchzuführen, schien nicht mehr die vornehmliche Aufgabe der praktischen Museumsarbeit gewesen zu sein.

Die Krippenausstellungen erfreuten sich eines großen Publikumsinteresses, kamen doch allein 1959 und 19606.120 Besucher. ${ }^{392}$

Ähnlich den 20er und 30er Jahren erachtete es das Museum auch nach 1945 als seine Aufgabe, volkskünstlerisch tätige Personen sowie volkstümliche Organisationen zu belehren und zu beraten.

Vor allem mit dem Tiroler Heimatwerk gab es eine engere Zusammenarbeit in der Trachtenerneuerungsbewegung.

\section{Exkurs 3: Zum „Tiroler Heimatwerk“}

Die Gründung des Tiroler Heimatwerkes erfolgte 1934. Die theoretische Grundlegung der Heimatwerksidee vertrat für Österreich vor allem Viktor (von) Geramb, der 1934 maßgeblich an der Entstehung des Steirischen Heimatwerkes beteiligt war. Für Geramb war diese Bewegung die „sittliche Verpflichtung, mit ganzer Kraft für die Erhaltung altererbten, durch die heraufziehende Industrialisierung schwergefährdeten Volksgutes einzutreten “393.

391 Die Ausstellung brachte Leistungen zeitgenössischer, heimischer Krippenbauer (u.a. Josef Kröll, Sepp Baumgartner, Johannes Obleitner, Siegfried Hafner, Gustav Resatz und der beiden Frauen Maria Delago sowie Fini Platzer) zur Schau. 1954 wurde Emil Baumann eine eigene Veranstaltung gewidmet [vgl. Kulturberichte Folge 88/89 (1956) und den Beitrag J. Ringlers, „Emil Baumann, ein Tiroler Krippenbauer unserer Zeit“, in der Gugitz-Festschrift, Wien 1954].

392 Vgl. Ringler 1962, S. 89 f.; diese, jährlich in den unteren Räumen des Nordtraktes veranstaltete, Krippenausstellung entwickelte sich zum Besuchermagneten und konnte in den 50er und 60er Jahren jeweils an die 4.000 Personen erzielen. Heute ist dieser Krippensaal ganzjährig zugänglich.

393 So zitiert ihn Ringler bei seinem Vortrag anläßlich der 2. Jahreshauptversammlung des Vorarlberger Heimatwerkes 1958-59, S. 81 ff., hier S. 82; zum Tiroler Heimatwerk Ringler 1959, S. 153 ff. Die Gründung der Heimatwerke in den anderen österreichischen Bundesländern erfolgte unter wechselnden politischen Systemen (NS-Herrschaft, 2. Republik): 1941 in OÖ, 1944 in Salzburg, 1954 in NÖ, 1958 in Vorarlberg und im Burgenland. 
Nach Ringler war es Ziel des Tiroler Heimatwerkes - das auf genossenschaftlicher Basis geführt wurde - die „Not der Bergbauern durch die Schaffung von gewerblicher, hausgewerblicher und künstlerischer Heimarbeit zu lindern“"394.

Wichtiger noch als die rein ökonomische Grundsetzung scheint mir der ideologische Charakter dieser Institution gewesen zu sein, der auch in diversen Ausführungen Ringlers zum Ausdruck kommt. So meinte dieser, in Bezug auf die Motive der Entstehung des Tiroler Heimatwerkes, daß „Volkstums- und Brauchtumspflege“ als Triebfedern für die Gründung anzusehen wären.

In der „schöpferischen Kraft des Volkes“ und in der „echten Volkskunst“, die nicht der Mode unterworfen oder saisonbedingt sei, sondern „Bestand“ habe, sah der Direktor des Tiroler Volkskunstmuseums Josef Ringler eine Möglichkeit, dem, „im Zuge der Industrialisieung“ aufgekommenen, „Geschmacksverfall“ entgegenzuwirken.

„Aufgabe soll es sein, diese Standesgruppe [Bauern, Arbeiter und Kleinbürger; W.M.] wieder zu einer schlichten, dem jeweiligen Stand angemessenen Lebensform zurückzuführen."

Dies könnte aber nur unter Einbezug von „Gediegenheit, Echtheit“ geschehen. Nicht Propagierung bloßer „Nachahmung [...], sondern Neuschöpfung auf Grundlage des Ererbten“, wäre dabei die „erzieherische, aufklärende“ Aufgabe des Heimatwerkes. ${ }^{395}$

Ringler galt die Heimatwerksidee als Gegenbewegung zur - in den Augen der großen Masse - zerbrochenen bürgerlichen Welt. Für ihn war diese Idee (ähnlich der Bauhausbewegung, der neuen Sachlichkeit) eine Antwort auf die Suche nach neuen Ansätzen, die „ländliche Handwerker, die noch stärker alter handwerklicher Tradition verbunden waren“, gefunden hatten.

„Dem Zurück zur Natur folgte der Ruf nach Zurück zu volkstümlicher Kultur, die allzeit der Nährboden war, auf dem dann die Spitzenleistungen

394 Ringler 1958-59, S. 83.

395 Ebd., S. 83 ff. Wie er ferner betonte, dürfe der Dekor nicht den „Sinn des Gegenstandes aufheben“ (S. 84), dieser müßte allzeit einen „realen Sinn haben“ (S. 85) - gegen den Kitsch der Fremdenverkehrsindustrie gewandt, in deren Produkte er keinen Sinn entdecken wollte und konnte. Der „Götze Fremdenverkehr“" (S. 91) erschien ihm überhaupt nicht sehr förderlich für die Heimatwerksidee. 
eines Volkes oder Stammes in künstlerischer und kunsthandwerklicher Beziehung erwuchsen. ${ }^{\text {" } 396}$

Wie Museumsdirektor Josef Ringler im Jahresbericht 1948 vermerkte, wurde ab 1948 die hauseigene Trachtenwerkstätte aufgelassen, da

„die Führung eines Damenschneidereibetriebes, in den Räumen des $\mathrm{Mu}$ seums und auf dessen Namen, ohne daß dem Museum daraus ein materieller Nutzen, sondern nur beträchtliche Opfer erwuchsen, [...] sich als völlig untragbar erwiesen [hätte], umsomehr als die Räume der Werkstätte dringend für museale Aufgaben benötigt wurden “. 397

Somit wurde die unmittelbare praktische Arbeit im Museum selber nicht mehr weitergeführt. Wie aber aus einer um 1958 entstandenen Schrift über die Tätigkeiten des Museums zu entnehmen ist, stellte die Trachtenerhaltung noch immer ein wichtiges Element für die offizielle Landeskultur dar. Darin wurde angeführt, daß das Museum nach wie vor ,stark in Fragen der Förderung des Trachtenwesens und Wiederbelebung der tirolischen Trachten in Anspruch genommen" werde. Das Museum sei bisher von 61 Gemeinden und Gruppen in ihren „Bemühungen um die Einführung und Verbesserung von Musik- und Schützentrachten“ herangezogen worden und hätte diese durch „die Bereitstellung von Entwürfen unterstützt“. In 21 Fällen seien „neue Marketenderinnentrachten in enger Zusammenarbeit mit der um die Herstellung erneuerter Trachten alt bewährten Firma Lodenbauer entstanden“. Und der vermutliche Verfasser Josef Ringler schloß seine Darstellung pathetisch: „Die vaterländischen Feiern [...] boten einen prächtigen Einblick über die auf diesem Sektor geleisteten Arbeiten. ${ }^{\text {“398 }}$

396 Ebd., S. 81, dort bezeichnet er die „Heranbildung künstlerisch empfindender Handwerker als Hoffung für höhere Würde im Leben und Alltag“. (Ebd.) Eine eingehende Befassung mit dem Tiroler Heimatwerk kann hier, aus Platzgründen, nicht erfolgen. Der heutige Stellenwert des Heimatwerkes liegt sicher nicht mehr so sehr in der Bergbauernhilfe, als im Verkauf von Trachten und kunstgewerblichen Produkten, die schon längst den Absatz von traditionellen Bauernprodukten, wie Schafwolle etc. übertreffen.

397 Bericht über das Geschäftsjahr 1948, S. 2 (im Archiv des TVM).

398 Die Darstellung findet sich unter dem Titel „Vom Tiroler Volkskunstmuseum“, o. O. o. J. im Archiv des TVM; Die Kulturberichte Folge 88/89 (1956) brachten die Mitteilung, daß die Serie der von Gretel Karasek hergestellten Originalaquarelle Nordtiroler Trachten mit Südttiroler Trachtenbildern fortgesetzt wird. Ihre 16 Bilder von Nordtiroler Trachten waren Anfang der 50er Jahre in der Zeitschrift Tyrol Nr. 1 (1951) und Nr. 2 (1952) veröffentlicht worden. Bereits 1935 war durch dieselbe Malerin der erste Versuch einer Trachtenerneuerung erfolgt. Die 16 Tafeln mit Entwürfen waren damals, inklusive eines Begleittextes von Josef Ringler, vom Gewerbeförderungsinstitut der Innsbrucker Handelskammer herausgebracht worden. 
Auch nach der Pensionierung Ringlers blieb die Trachtenberatung wichtiger Bestandteil der alltäglichen, praktischen Museumsarbeit. Wenngleich Dr. Franz Colleselli ${ }^{399}$, der ab 1953 im Volkskunstmuseum beschäftigt war und 1959 die Direktion übernommen hatte, dieser Beratung nicht so unvoreingenommen gegenüberstand wie sein Vorgänger.

So meinte Colleselli im Jahresbericht 1966, daß die Trachtenberatung zwar „nicht zeitraubend, dafür aber umso undankbarer“ werde, da meist gegen die „vorgefaßte Meinung von Musikkapellen und Schützenkapellen“ agiert werden müsse. Und er betonte weiter, daß, obwohl das Land Tirol daran interessiert sei, die
„historischen Trachten, die als lebende Tracht zu existieren aufgehört hat, wenigstens bei den genannten Formationen unverfälscht der Nachwelt als Erinnerung an die ruhmreiche Zeit der Tiroler Freiheitskriege zu erhalten, fruchte [dieser Wunsch des Landes; W.M.] nur in den seltensten Fällen“,

Vom 3. bis 13.6.1936 fand in den Räumen des Tiroler Gewerbeförderungsinstitutes ein Kurs „zur Vervollkommnung im Schneidern von Trachtendirndeln“ statt. Dabei kam es zu einer Abgrenzung gegenüber dem Dirndl als „bloße Modekleidung“. Wie in einem Artikel, den die Zeitung Tiroler Gewerbe veröffentlichte, über diesen Kurs ausgeführt wurde, sollten die dort geschaffenen und ausgestellten Dirndln „keine geckenhafte Nachäffung von Kleidern unserer Ahnen sein“, sondern vielmehr „den guten Geschmack, den unsere Großeltern auch für Kleidung hatten, wieder wecken, und [...] dazu beitragen, den bodenständigen Geist, der in den Bergen und Tälern Tirols in den Jahrhunderten seiner großen Geschichte emporwuchs, wieder in uns zu erneuern“; und so nicht zuletzt den „Wert und Unwert unserer Umgebung, der Menschen in ihrem Charakter wie in ihrem Aeußern [...] vermitteln “, denn, wie das Blatt betonte, äußere sich „der Charakter eines Menschen [...] ja vielfach auch in seiner Kleidung“. Eigens verwiesen wurde auf das, vom Gewerbeförderungsinstitut herausgegebene und dort erhältliche, Heft „Neue Tiroler Trachten“, dessen darin enthaltene Schnittmuster „lediglich an Zunftmitglieder der einschlägigen Branchen abgegeben werden“. (1. Jhg. Nr. 1 vom August 1936, S. 3)

399 Franz Colleselli (1922-1979) war promovierter Kunsthistoriker und trat nach Beendigung des Studiums 1949 in den Landesdienst ein, wo er zunächst im Landesregierungsarchiv beschäftigt war. Ab 1953 wechselte er ins Volkskunstmuseum über, wo unter seiner Leitung die endgültige Inventarisierung sämtlicher Gegenstände betrieben wurde. Nach der Übernahme der Direktion führte er die Neuaufstellung der Sammlungen durch, wie sie im Großen und Ganzen heute noch besteht. Colleselli ist ferner Verfasser des "Begleiters durch das Volkskunstmuseum“ (1973) und Autor einer umfassenden Arbeit zu den „Tiroler Bauernmöbeln“ (Erstauflage 1967, jetzt bereits in 5. Auflage, überarbeitet von Hans Gschnitzer). Landeshauptmannstellvertreter Dr. Fritz Prior nannte ihn in seiner Grabrede einen „Streiter für die gesunde Gemeinschaft und die gesamte Kultur, denn er [Colleselli; W.M.] bewahrte nicht nur, sondern hatte den vollen Glauben an den Bestand des Echten und Wahren auch in Zukunft" und weiter: Er hatte die „Überzeugung, daß die gute Tiroler Volkskultur ungeachtet aller vom Kommerz bestimmter Einflüsse auch in Zukunft leben wird“ (zitiert bei Hörmann 1979, S. 26.) 
da heutzutage „auf Originalität [...] nicht mehr Wert gelegt“ werde. ${ }^{400}$ Zwei Jahre später machte Colleselli in seinem Tätigkeitsbericht die Feststellung, daß sich die Aufgabe der Trachtenberatung „dadurch erschwert, daß vielfach das Verständnis für die bodenständigen Trachten fehlt und ,attraktive Uniformen' für den Fremdenverkehr gewünscht werden “401.

Auch Gertrud Pesendorfer konnte sich in den späten 40er und 50er Jahren wieder der Trachtenerneuerung widmen. Innerhalb der Landwirtschaftskammer hielt sie über 100 Nähkurse in ganz Tirol ab und trug so zur Erneuerung der Frauentrachten bei. ${ }^{402}$

Es zeigt sich daraus, daß das Museum auf einen engen Begriff von Volkskunst und damit verbunden von Volkstumspflege ausgerichtet war. Von der Vorstellung der Hebung und Förderung heimischer Gewerbe waren diese praktischen Tätigkeiten schon weit entfernt.

Bei all diesen Äußerungen zu musealen Belangen wird ein theoretischer Ansatz, nämlich der Begriff des Wahren und Echten, verwendet, der diese Überlegungen von vornherein einer Besetzung mit ideologisierenden Vorstellungen öffnet.

400 Jahresbericht für das Jahr 1966, S. 3, im Archiv des TVM.

401 Tätigkeitsbericht 1968 vom 10.4.1969; und in einem später verfaßten Bericht (o.Jahr) hieß es ebenfalls, in Bezug auf die vom Museum durchgeführte Beratung von Brauchtumsvereinen in Trachtenfragen: „[...] wobei immer wieder festgestellt werden muß, daß unter der Bevölkerung völlig falsche Vorstellungen von der einstigen bäuerlichen Standeskleidung herrschen. Dies erschwert eine sachliche Beratung ungemein." (S. 4) - Beide Berichte befinden sich im Archiv des TVM.

402 Über 100 Tiroler Gemeinden, so Ringler 1962 im Kapitel „Trachtensammlung und Trachtenwesen “, hätten sich vom Volkskunstmuseum in der Trachtenerneuerung, besonders für ihre Musikkapellen und Schützenkompanien, beraten lassen. Dieses Ergebnis wäre anläßlich des 150-Jahr-Gedenkens an das 1809er Jahr, 1959, „eindringlich demonstriert" worden (S. 92). Zu den neuen Bestrebungen von G. Pesendorfer meinte er, ohne irgendeine kritische Anmerkung zu ihrer Rolle in der NS-Zeit: „Damit hatte die 1939 gegründete und nach manchen Schwierigkeiten und Unzukömmlichkeiten 1948 aufgelassene Trachtenwerkstätte beim Tiroler Volkskunstmuseum eine weitaus sinnvollere und zweckentsprechendere Nachfolge gefunden.“ (!) Und weiter zu den Tätigkeiten der „Mittelstelle Deutsche Tracht“: „Die in diesem Zusammenhang [der Erneuerung der Frauentrachten; W.M.] groß angelegte Bestandsaufnahme von Volkstrachten in Südtirol, die von der gleichen Stelle in Angriff genommen wurde, blieb leider ein Torso." (ebd.) Ringler war nicht der einzige, der auf solch unkritische Weise an die Tätigkeiten der „Mittelstelle Deutsche Tracht“ heranging. Auch die volkstumspolitischen Aktionen der NS-Zeit in Südtirol waren als groß angelegte Aufnahmen gemacht worden, um den durch die Option heimatlos gewordenen SüdtirolerInnen ihre Kultur in die neu zugeteilten Gebiete mitgeben zu können, wurden bis heute kaum kritisch untersucht, und deren Ergebnisse sind noch immer für manche Wissenschafter unhinterfragtes und unkritisch gebrauchtes, empirisches Material ihrer Veröffentlichungen. 
Carl Dahlhaus hat am Beispiel der Volkslieddiskussion die „Dialektik von ,echt und ,unecht "“ aufgezeigt und festgehalten, daß sich dieser Ansatz immer in der eigenen Begrifflichkeit verfängt, denn

\begin{abstract}
„Echtheit ist ein Reflexionsbegriff, zu dessen Wesen es gehört, daß er über sein Wesen täuscht. Und von der Fragwürdigkeit der Kategorie bleibt auch die gemeinte Sache nicht unberührt. Es scheint [...] als sei das sekundäre, reflektierte Volksliedsingen, das sich als ,ursprünglich' begreift, obwohl es abgeleitet ist, zu eben der ,Unechtheit' verurteilt, der es gerade entkommen möchte, so daß es in der inneren Konsequenz der ,Folklore` läge und nicht ein zufälliges, sie von außen ergreifendes Mißgeschick wäre, wenn sich die Schlagerindustrie ihrer bemächtigt. Das Echte ist, als Setzung der Reflexion und des Wunsches, nach seinen eigenen Kriterien unecht. “403
\end{abstract}

Mehr noch in Ringlers als in Collesellis Ansichten steckt die - im wahrsten Sinne des Wortes - konservative Vorstellung, „[d]aß Ursprüngliches besser sei als Abgeleitetes, verbunden mit dem Mißtrauen gegen Gemachtes und Hergestelltes, dem man das Gewordene und Naturwüchsige entgegensetzt", wie es Carl Dahlhaus formulierte. ${ }^{404}$

Damit knüpften die Vorstellungen der beiden Direktoren wieder an die der ersten Museumsbetreiber an. Ausgangspunkt der Museumstätigkeiten ist nicht der historische Bestand, vielmehr werden die Gegenstände so aus dem einstigen Verband herausgelöst und nach einseitigen Kriterien (meist einer nicht weiter hinterfragten, subjektiven Ästhetik) eingeteilt.

Dadurch wird unweigerlich manches verworfen, anderes akzeptiert, ohne daß die Prämissen solch einer Auswahl objektivierbar wären. Schlußendlich wird nicht die Volkskultur einer bestimmten Epoche und damit die Volkskunst dieser Zeit dargestellt und bearbeitet, sondern die zur echten Tiroler Volkskunst erklärten Objekte.

403 1967, S. 57; wenn man Volksliedsingen durch Trachten-selbst-nähen sowie Trachtenerneuerung/erhaltung und Schlagerindustrie durch Modeindustrie ersetzt, stimmt diese Feststellung auch für die Trachtenbewegung, wie dies anhand des schon vor einiger Zeit aufgekommenen Trachten-Looks und der rustikalen Modewelle empirisch belegt werden kann und sich auch in der früh(er)en Zusammenarbeit des Museums mit einem Innsbrucker Bekleidungshersteller dokumentiert.

404 Ebd., S. 56. 


\subsection{Besucherfrequenz}

Ein Museum lebt vordergründig nicht nur von seiner musealen Tätigkeit (sammeln, inventarisieren, konservieren), sondern auch vom Kontakt zum Publikum. Obwohl reine Häufigkeitszahlen wenig über die Besucher aussagen (wenn nicht zumindest neben der Frequenz auch andere Parameter, wie Herkunft, Geschlecht und Alter sowie qualitative Angaben zu Motiven und Eindrücken des Museumsbesuches, mitberücksichtigt werden), so sind sie doch Ausdruck der Akzeptanz des Museums durch die Öffentlichkeit.

Leider wurde, aus welchen Gründen auch immer, eine Publikumserhebung nie durchgeführt. Die vorhandenen Zahlen geben bloß Auskunft über die Gesamtbesucherzahl eines Jahres und schlüsseln lediglich - zumindest für manche Jahre - die Schulklassen- und Gruppenbesuche extra auf.

Eine Erfassung der Herkunft, des Geschlechtes und Alters der Museumsbesucher wurde bislang ebenso wenig vorgenommen, wie eine Untersuchung der Besuchsmotive und der vom Museum gewonnenen Eindrücke.

Somit bleibt ein genaues Profil der typischen Besucher des Tiroler Volkskunstmuseums im Unklaren. Es kann hier lediglich ansatzweise versucht werden, die häufigsten Gruppen der Museumsbesucher darzustellen.

Für 1963 vermeldete Museumsdirektor Franz Colleselli in seinem Jahresbericht eine gesamte Besucherzahl von 45.045 Personen. Davon waren rund $10 \%$ Schüler, was unter dem Durchschnitt ausländischer, vergleichbarer Museen lag. Dies bewog ihn zur Feststellung, daß es „doch auch bei uns möglich sein [müßte], den Museumsbesuch sinnvoll in den Unterricht der verschiedenen Schulgattungen einzubauen “ 405 .

Auch das Jahr zuvor waren nur ca. $10 \%$ der Gesamtbesucherzahl Schüler gewesen (47.010, davon 4.845 aus Schulen). 1960 lag der Anteil der Schüler mit 7,2 \% sogar noch darunter (mit 3.801 an der Gesamtbesucherzahl von 52.840 Personen).

405 Bericht für das Jahr 1963, o. Jahr, S. 2. Die folgenden Angaben der Besucherzahl sind den betreffenden Jahresberichten entnommen, die sich alle im Archiv des TVM befinden. Für die Jahre 1929 bis 1943 und 1948 bis 1960 finden sich die Zahlen auch bei Ringler 1962, S. 95 (incl. der Anzahl der Gruppen- und Schulklassenbesuche, letztere machen meist ca. $10 \%$ der jährlichen Gesamtbesucherzahl aus, wenn eine durchschnittliche Zahl von 25 Schülern/Klasse angenommen wird). 
In den folgenden Jahren stieg diese Zahl nie beträchtlich, sodaß Collesellis Vorstellung eher ein Wunsch blieb: 1969 lag die Zahl der das Museum besuchenden Schüler bei rund 8.000 und erreichte damit ca. $13 \%$ der Gesamtbesucherzahl von 62.146 Personen. Auch in den 70er Jahren (1974, 75 und 76) hielt die Zahl der vergebenen Schülerfreikarten bei gut 10.000, was knapp $10 \%$ der Gesamtbesucherzahl entsprach.

Wenn nicht Schulklassen das Gros der Besucher stellten, welche Gruppe war es dann?

1948, im Jahr der Wiedereröffnung, wurden ganze 3.016 Besucher gezählt. Ein Jahr später, als erstmals wieder vermehrt Fremde in Tirol und Innsbruck zu Besuch waren, betrug die Besucherzahl bereits 10.989 (eine Steigerung um mehr als das Dreifache).

In den folgenden Jahren kletterte die Gesamtbesucherzahl immer weiter hinauf, übertraf bereits 1951 die größte Besucherzahl der Vorkriegszeit $(34.595 \mathrm{zu}$ 1930: 29.644) $)^{406}$ und erlangte 1957 einen ersten Höchststand von 51.459 Personen. Ein Jahr später (1958) war die Besucherzahl/Jahr um über 10.000 auf 40.305 Personen abgesunken. Der damalige Jahresbericht gab als Gründe dafür das Wetter, die gleichzeitige Abhaltung einer Maria-Theresien-Ausstellung in Innsbruck und die französische Devisensperre an.

Da für 1959 wieder eine Besucherzahl von 50.887 Personen angegeben wurde und diese im folgenden Jahr wieder zunahm, scheinen die Gründe plausibel zu sein. Museumsbesucher sind in der Zweiten Republik vor allem Touristen, die Tirol und Innsbruck besuchen. Dieser Eindruck bestätigt sich heute jedem, der dem Museum einen Besuch abstattet. Vor allem Reisegruppen aus den romanischen Ländern (Italien, Frankreich), scheinen den Museumsbesuch fix in das Programm eingeplant zu haben.

406 Bereits ein Jahr später (1931) war die jährliche Besucherzahl wieder auf 19.816 gesunken und fiel bis 1934 auf 13.555 Personen/Jahr. Dieser Rückgang ist insofern interessant, da er bereits vor der Einführung der Tausend-Mark-Sperre (1933) so drastisch ausfiel. Der Unterschied 1932-1933 betrug immerhin noch -3.649 Personen (von 17.949 auf 14.300), was auf einen relativ hohen Anteil inländischen und heimischen Besuches schließen läßt. Österreichs Wirtschaft befand sich nach der Weltwirtschaftskrise von 1929 in einer argen Krise, sodaß der Inlandstourismus drastisch zurückging. Nach der Einführung der Tausend-Mark-Sperre durch das Deutsche Reich brach der Reiseverkehr von Deutschland nach Österreich nahezu zusammen (so sank die Anzahl der gemeldeten Deutschen in Tirol von 335.000 (1931/32) auf 10.400 (!) (1933/34). Die Gesamtzahl der Fremdenmeldungen in Tirol nahm im selben Zeitraum von rund 634.000 auf $300.000 \mathrm{ab}$ ). - Zur Tausend-Mark-Sperre und ihren Auswirkungen auf den Tiroler Fremdenverkehr vgl. Nussbaumer 1988, S. 307 ff., bes. S. 314 ff. 
Dir. Franz Colleselli hielt 1969 in seinem Kuratoriumsbericht fest, daß man „ohne zu übertreiben [...] das Volkskunstmuseum für das Fremdenverkehrsland Tirol als treffliches Aushängeschild unserer einzigartigen Volkskultur ansehen“" könne.

Für 1955 vermeldete der einschlägige Jahresbericht 50 Reisegesellschaften aus Frankreich, 30 aus Deutschland, 15 aus England, 12 aus Holland, 11 aus Belgien; hingegen bloß 7 aus Österreich. In den folgenden Jahren belief sich die Gesamtzahl der Reisegruppen auf über 100/Jahr. 1956 wurden gar 280, 1957119 und 1958139 Gruppenbesuche im Museum gezählt. ${ }^{407}$

Bei den Einzelreisenden waren im selben Jahr die Besucher aus Deutschland an erster Stelle.

Die folgende Graphik soll einen Überblick über die Entwicklung der gesamten jährlichen Museumsbesucher bieten, wobei ich hier die Besucherzahlen in Gruppen zu fünf Jahren zusammengefaßt habe (Ausnahme die Zeitspanne von 1973 bis 1976, die nur vier Jahre umfaßt, da mir nach 1976 keine Zahlen mehr zur Verfügung standen). ${ }^{408}$

407 Nach Ringler 1962, S. 95. Leider finden sich dort diese Gesamtzahlen nicht nach den einzelnen Herkunftsländern der Besuchergruppen aufgeschlüsselt, doch dürfte die Reihenfolge der Jahres 1955 in der Folgezeit gleich geblieben sein. In einer Darstellung des Tiroler Volkskunstmuseums im „Mitteilungblatt der Museen Österreichs“ schrieb Josef Ringler, daß in den Monaten Juni bis September mehr als 80 \% der Museumsbesucher Ausländer seien und nannte der Reihenfolge nach: „Reichsdeutsche, Engländer, Franzosen, Belgier, Dänen, Amerikaner“. (1952, S. 24)

408 Die Werte stammen aus Ringler 1962, S. 95 und den jeweiligen Jahresberichten. 


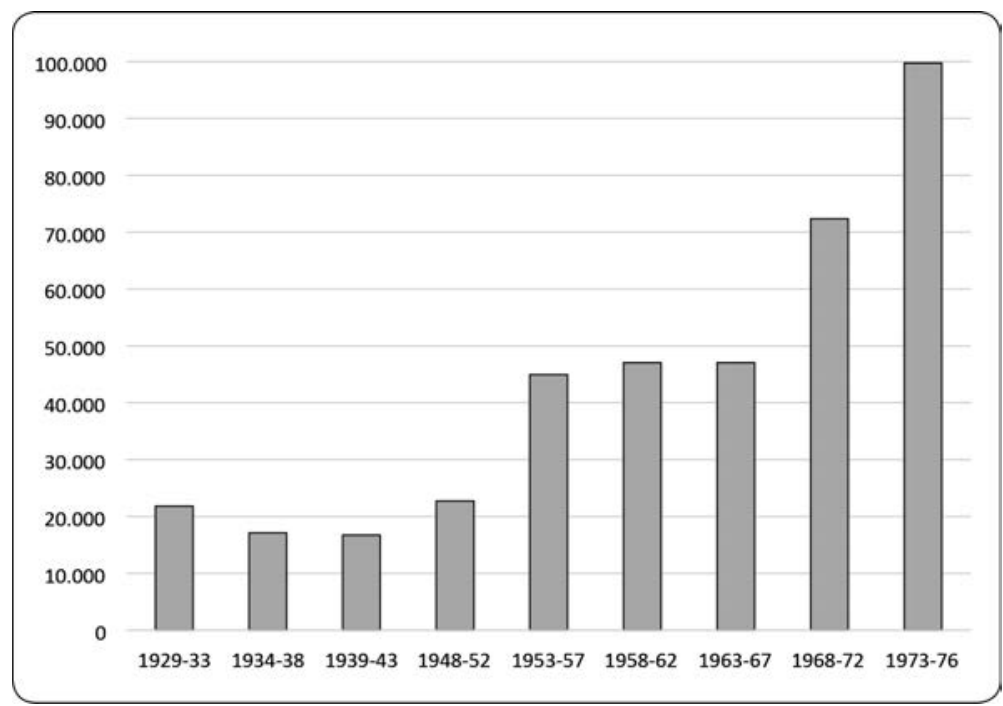

Graphik 4: Besucherzahlen im Volkskunstmuseum - Fünfährige

Durchschnittswerte von 1929 bis 1976

Aus diesem langfristigen Vergleich der Besucherfrequenz des Tiroler Volkskunstmuseums läßt sich nun Einiges ablesen:

- Vor dem Zweiten Weltkrieg dürften vor allem die inländischen Museumsbesucher überwogen haben. Die jährliche Zahl des Museumspublikums überstieg nie 30.000 Personen und sank nach den ersten beiden Jahren auf Werte unter 20.000/Jahr ab.

Mit 8.555 Museumsbesuchern wurde im Kriegsjahr 1940 der absolute Niedrigststand vor der Wiedereröffnung 1948 erzielt (warum gerade in diesem Jahr und wieso die Besucherfrequenz in den beiden folgenden Jahren, die das $\mathrm{Mu}$ seum noch geöffnet hatte, wieder anstieg, läßt sich nicht rekonstruieren).

Über die Anzahl der Besucher während der NS-Herrschaft, die aus dem "Altreich“ vor allem wegen der „Mittelstelle Deutsche Tracht“ kamen, sind ebenfalls keine genauen Angaben zu machen.

- Nach der Wiedereröffnung des Museums (der Wert für das Jahr 1948 errechnet sich ja nur vom August, dem Eröffnungsmonat, bis zum Jahresende und verfälscht deshalb das Bild ein wenig) übertraf die Besucherfrequenz 1951 den Jahreshöchststand der Ersten Republik und stieg zügig an. 
1957 wurde erstmals die 50.000er Grenze überschritten. Im folgenden Jahrzehnt hielt sich die jährliche Besucherzahl bei 50.000 Personen. Die Gründe der jährlichen geringfügigen Schwankungen sind nicht mehr nachzuvollziehen, könnten aber unter Umständen, saisonalbedingt, in der unterschiedlichen Touristenfrequenz liegen.

- Von 1968 auf 1969 fand erstmals wieder ein größerer Zuwachs an Museumsbesuchern statt (+12.459 Personen). Damit erreichte die Zahl des Publikums zu Beginn der 70er Jahre die 80.000er Grenze (1970: 76.726, 1971: 77.255) und kam ab 1972 an die 100.000 Museumsbesucher pro Jahr heran (1972: 95.416). Diese magische Anzahl wurde erstmals 1975 (mit 102.589) übertroffen. Die Zahl der Besucher liegt seitdem jährlich weit darüber (1976: 114.449). ${ }^{409}$

Mit dieser Besucherfrequenz ist das Tiroler Volkskunstmuseum im vordersten Feld aller österreichischen Museen zu finden.

Dies geht auch aus einem österreichischen Museumsführer der Vorkriegszeit (erschienen 1935) hervor. Für das in Wien befindliche „Österreichische Museum für Volkskunde“ verzeichnete dieser „Führer“ 1933 eine Besucherzahl von 8.400, 1934 von 7.000 und ca. 5.000 für das Jahr 1935.410

409 Nachfolgend die vollständige Liste aller jährlicher MuseumsbesucherInnen (die Klammerzahlen ab dem Jahr 1960 sind die Werte aus den Jahresberichten, die mitunter von den Ringlerangaben von 1962 abweichen; für die Graphikberechung habe ich die Ringlerzahlen verwendet!):

\begin{tabular}{|c|c|c|c|c|c|c|}
\hline 1929: & 26.346 & 1939: 17.394 & 1952: 34.970 & 1962: 47.010 & 1972: & 95.416 \\
\hline 1930: & 29.644 & 1940: 8.555 & 1953: 41.551 & 1963: 45.045 & 1973: & 90.601 \\
\hline 1931: & 19.816 & 1941: 19.729 & 1954: 41.048 & 1964: 48.712 & 1974: & 90.454 \\
\hline 1932: & 17.949 & 1942: 22.998 & 1955: $\begin{aligned} 44.876 \\
\\
(52.037)\end{aligned}$ & 1965: $51.705(6)$ & 1975: & 102.589 \\
\hline 1933: & 14.300 & 1943: 14.743 & 1956: 46.069 & 1966: 42.258 & 1976: & 114.449 \\
\hline 1934 & 13.555 & & 1957: 51.459 & 1967: 47.700 & & \\
\hline 1935 & 15.864 & 1948: 3.016 & 1958: 40.305 & 1968: 49.687 & & \\
\hline 1936 & 17.220 & 1949: $\begin{array}{ll}10.979 \\
\\
(10.989)\end{array}$ & 1959: 50.887 & 1969: 62.146 & & \\
\hline 1937 & 17.662 & 1950: 28.670 & 1960: 52.840 & 1970: 76.726 & & \\
\hline 1938 & 20.729 & 1951: 34.595 & 1961: 43.707 & 1971: 77.255 & & \\
\hline
\end{tabular}

410 „Die Museen Österreichs“, Wien 1935, S. 198 und S. 228. In dieser Publikation wird zwar die Zahl der jährlichen Besucher des Tiroler Volkskunstmuseums für 1935 mit 2.500 Personen (S. 49) angegeben (ohne Schulklassen), dies kann aber nicht ganz stimmen, da Ringler 1962, S. 95 für dieses Jahr 15.864 Besucher angibt und sich die Differenzsumme nicht nur aus den Schülerzahlen ergeben kann. 
Auch in der Zweiten Republik ist der Unterschied in der Besucherzahl zwischen dem Volkskunstmuseum und dem Museum für Volkskunde in Wien beträchtlich.

1968 hatte das „Österreichische Museum für Volkskunde“ in Wien eine Besucherzahl von 3.650 Personen, davon waren 438 Schüler; 1971 waren es 5.069 Personen (430 Schüler) und 1974 waren es 7.189 BesucherInnen (1.215 Schüler).

Damit erreichte dieses Museum im Jahr nicht einmal die Besucherzahl, die das Volkskunstmuseum in Innsbruck in einem Sommermonat zu verzeichnen hatte.

Auch das „Steirische Volkskundemuseum" kommt in seinen Besucherzahlen nicht an die Innsbrucker Werte heran: 1968 wurden dort 4245 Besucher gezählt, davon fast die Hälfte Schüler (2.743), 1971 waren es 4.454 (2.861 Schüler) und 1974 4.276 Personen (2.600 Schüler).

Einzig das „Salzburger Volkskundemuseum“, das sich im Schloß Mirabell befindet und damit einen ausgezeichneten Standort aufweist, kommt annähernd an die Zahlen des Innsbrucker Museums heran: 1968 besuchten es 66.154 Personen, 197180.465 (davon 19.680 Schüler) und 197452.177 (14.683 Schüler). ${ }^{411}$

Das Innsbrucker Museum erreicht mit diesen Besucherwerten eine einzigartige Stellung unter den volkskundlichen Sammlungen, nicht nur in Österreich, sondern in ganz Mitteleuropa. Mit der Überschreitung der 100.000er Grenze in der jährlichen Besucherzahl rangiert es gleich hinter den großen Wiener Sammlungen (Schatzkammer, Kunsthistorisches Museum, ...) sowie den großen kulturellen und kunsthistorischen Anziehungspunkten der Länderhauptstädte (Schloß Belvedere, Schloß Hohensalzburg etc.).

Werden zum jährlichen Museumspublikum noch die Besucher der Innsbrucker Hofkirche gerechnet, deren Verwaltung seit 1969 im Wirkungsbereich des Volkskunstmuseums liegt, so nimmt das Volkskunstmuseum einen Spitzenplatz in der Besuchergunst der österreichischen Museen ein.

1974 betrug die Zahl der Hofkirchen-Besucher 162.691 (+11.666 Schülerfreikarten), 1975168.098 (+11.798 Schülerbesuche) und 1976186.413 Personen $\left(+10.691\right.$ Schülerfreikarten). ${ }^{412}$

Sicherlich ist der optimale Standort des Tiroler Volkskunstmuseums ein Hauptgrund für den großen Besucherandrang.

411 Die Zahlenangaben finden sich in der Arbeit von Wolfgang Gürtler über die „Österreichische volkskundliche Museologie“, Wien 1976, S. 58 ff. Gürtler führt die großen Unterschiede in den Besucherzahlen auf den jeweiligen Standort des Museums und den Fremdenverkehr zurück: in Wien sei der Standort ungünstig, Graz habe wenig Fremdenverkehr, allein in Salzburg und Innsbruck seien sowohl Standort wie Fremdenbesuch optimal (ebd., S. 60).

412 Die jeweiligen Zahlen für die Hofkirchenbesucher finden sich in den betreffenden Jahresberichten des TVM. 
Mitten im Zentrum von Innsbruck, in unmittelbarer Nähe zur Altstadt und zur Hofburg ist es ein bequem erreichbarer und gern besuchter Fixpunkt der diversen Tourismusprogramme. ${ }^{413}$

Die zentrale Lage und die Möglichkeit, am Landestheaterplatz in unmittelbarer Nähe bequem in die Reisebusse ein- und aussteigen zu können, sind, in Zeiten des kurzweiligen Massentourismus, ein nicht zu unterschätzender Vorteil, der so manches Manko in punkto Präsentation und moderner Museumsgestaltung aufzuheben vermag.

Inwieweit die ausgestellten Gegenstände selbst größere Anziehungskraft auf die Besucher ausüben, oder ob nicht allein der Name der Institution - „Tiroler Volkskunstmuseum" - eigene Erwartungshaltungen erweckt, ist aufgrund fehlender Untersuchungen zur Besuchermotivation nicht zu ergründen.

Die Tiroler Fremdenverkehrswerbung hat jedoch lange Zeit mit dem Klischee der Tiroler Volkskunst Erwartungshaltungen zu erzeugen versucht und Prospekte und Selbstdarstellungen oft mit Objekten und Motiven aus dem Volkskunstmuseum, rein aufgrund ästhetischer Kriterien, ausgestattet, ohne die Gegenstände näher zu erläutern. ${ }^{414}$

\subsection{Die Neugestaltung der Schausammlungen}

Die Aufstellung im Tiroler Volkskunstmuseum, wie sie sich ihre Betreiber in den 20er Jahren vorgestellt und durchgeführt hatten, läßt sich heute nur noch durch Fotografien und Beschreibungen rekonstruieren.

Dieser Versuch muß unvollständig bleiben, da die Eindrücke und Empfindungen, die die damaligen Museumsbesucher von dieser Präsentation erhielten, nicht mehr nachvollziehbar sind.

Ich konnte daher zur Rekonstruktion der damaligen Präsentation bloß die Darstellungen diverser Autoren verwenden, die diese nach der Museumseröff-

413 Dies zeigt sich im Vergleich zum Museum Ferdinandeum, das zwar nicht allzuweit vom Volkskunstmuseum entfernt ist, aber in Gegenrichtung zu Zentrum und Altstadt liegt und mit Reisebussen umständlicher zu erreichen ist. 1986 verzeichnete das Museum Ferdinandeum 45.832 Besucher seiner Schausammlungen; im Zeughaus, das ebenfalls zum Ferdinandeum gehört, aber verkehrstechnisch sehr ungünstig außerhalb des unmittelbaren Stadtzentrums im Pradler Saggen liegt, wurden im gleichen Jahr 9.730 Besuche registriert (laut „Ferdinandeum Jahresbericht 1986“ in: „Veröffentlichungen des Museum Ferdinandeum“ Bd. 67 Jahrgang 1987, S. 156).

414 Die Tiroler Fremdenverkehrswerbung ist ein (zumindest kulturhistorisch) noch kaum behandeltes Thema und auch die 1986 in Innsbruck entstandene Dissertation von Theresia Sonnewend: „Das Tiroler Volksbild in Plakaten und Prospekten des 20. Jahrhunderts“ stellt nur einen ersten Versuch zu seiner Behandlung dar. 
nung von 1929 niedergelegt hatten; daneben auch spärlich vorhandene fotografische Abbildungen von Aufstellungsarrangements.

Wer die Abbildung des Volkskundesaales, die sich auf Tafel VII des Ringleraufsatzes zum Volkskunstmuseum findet, betrachtet, kann sich ungefähr eine Vorstellung der theoretischen Überlegungen der Museumsgestalter machen.

Ähnlich der Depotaufstellung von 1910 (Tafel VI und VII) finden sich zahlreiche Gegenstände an Wänden, in Vitrinen, oder frei stehend ausgestellt.

Auf den ersten Blick entbehrt die Art der Präsentation jeglicher Logik, stehen dort Spinnräder neben, an der Wand hängenden, Ochsenjochen, finden sich in den Vitrinen, nach Größe geordnet, abwechselnd gehängt, sodaß sich beinahe ein geometrisches Muster ergibt, Teller, Henkel- und Stilgatzen sowie „Granten(=Preiselbeer)riffler“.

Dies alles ohne jegliche Beschriftung oder einen näheren Hinweis auf Herkunft, Herstellung und Verwendung.

Dieses Konzept der ästhetischen Präsentation der Gegenstände um ihrer selbst willen, die für sich selbst sprechen und als Zeugen alter Tiroler Volkskunst Anschauungs- und Nachahmungsmaterial sein sollten, blieb bis in die 60er Jahre erhalten.

Es überdauerte damit die Zeit des Nationalsozialismus, wo die damalige Leitung an der gesamten Substanz und Präsentation nichts veränderte, sondern nur dem Regime unangenehme Gegenstände entfernte (Krippensammlung, Gegenstände aus dem Bereich der religiösen Volkskunst).

Nach der Wiedereröffnung im Jahre 1948 präsentierte sich das Museum noch immer im Geist der Begründer. Die Stuben waren, nach kriegsbedingter Auslagerung, wieder eingebaut, die auf Veranlassung der Nazis ausgeschiedenen religiösen Gegenstände wieder in die Sammlung aufgenommen worden, am Gesamtkonzept aber wurde nichts geändert.

Erst mit dem Arbeitsbeginn von Franz Colleselli im Jahr 1953 kamen neue Ideen ins Museum. Colleselli übernahm nicht nur die aufwendige und zeitraubende Aufgabe einer vollständigen Inventarisierung aller im Museum befindlichen Gegenstände, er wollte das Museum ausstellungsmäßig umgestalten.

Bis dahin bestanden keine eigentlichen Depots. Die vorhandenen Gegenstände wurden entweder aufgestellt (Möbel, die nicht zur Präsentation kamen, landeten auf dem Dachboden des Hauses - bis der Rechnungshof die bestehende Feuergefahr beanstandete.) - oder in ausgestellte Truhen und Kästen (!) aufbewahrt (diverse Kleinobjekte). Bei einer Gesamtausstellungsfläche von $6.430 \mathrm{~m}^{2}$ standen nur $65 \mathrm{~m}^{2}$ Depotraumfläche zur Verfügung. 
In einem Bericht, der um die Mitte der 60er Jahre verfaßt worden sein muß, beklagte Colleselli: „Nach wie vor fehlt es dem Museum aber noch an geeigneten Räumen, um die auf dem Dachboden und auswärts gelagerten kostbaren, aber von großen Temperaturschwankungen und Feuchtigkeit gefährdeten Möbel unterzubringen. “ ${ }^{15}$

Die Schaffung zeitgemäßer Depots wurde zur dringlichsten Aufgabe. Schlußendlich wurde die Auflassung der alten Lagerräume mit der Anlegung einer „Studiensammlung" verknüpft, in der die nicht mehr zur Ausstellung gelangenden Gegenstände so verwahrt werden sollten, daß ein Zugang für interessierte Personen jederzeit möglich war.

Als erste Studiensammlung wurde ein neues Trachtendepot angelegt, wofür eigene Schränke entwickelt und gebaut wurden, die eine fachgerechte Aufbewahrung der Textilien ermöglichten.

Zur Errichtung dieses Depots fand sich im zweiten Stock ein Raum, auf dessen $50 \mathrm{~m}^{2}$ Grundfläche ursprünglich eine weitere Stube hätte eingebaut werden sollen.

Eine zweite Studiensammlung konnte einen Stock tiefer, genau unter dem Trachtenraum, errichtet werden. Da dieser Raum (mit ebenfalls $50 \mathrm{~m}^{2}$ Fläche) eine Saalhöhe von vier Metern aufwies, wurde ein Zwischenboden aus Gitterrost eingebaut, der eine bessere Raumausnutzung ermöglichte und doch genug Tageslicht in den Raum ließ.

In diesem Depot wurden nun vor allem Krippen, Kleinplastiken, Klosterarbeiten, Votivgaben, Model usw. gelagert.

Insgesamt betrug die neugeschaffene Nutzfläche in beiden Räumen $304 \mathrm{~m}^{2}$ (bei einer Schrankfläche von $45 \mathrm{~m}^{2}$ ). ${ }^{416}$

415 O. Jahr, S. 3; Bericht im Archiv des TVM. Als Konsequenz der Überprüfung (1966-68) hatte der Rechnungshof als Lösung des Raum- und Depotmangels gefordert, daß alle „Gegenstände, die keinerlei künstlerischen oder musealen Wert besitzen oder dem Museum in keiner Weise mehr dienlich sein können, [...] ausgeschieden und bestmöglich verwertet werden" sollten. (ebd.)

416 Colleselli 1964, S. 5 ff.; zum Konzept der neugeschaffenen „Studiensammlungen“ meinte er in diesem Arbeitsbericht, daß sie die Gegenstände aufnehmen sollten, die im Zuge der Neugestaltung als „für den Laien unwichtige und uninteressante Stücke [ausgeschieden worden seien], ohne deswegen in der Versenkung zu verschwinden." (ebd., S. 7) Über die Prämissen der Auswahl dieser „uninteressanten und unwichtigen Stücke“ schrieb er nichts. Es dürften aber in erster Linie ästhetische Kriterien gewesen sein: die schönen Stücke blieben in der Sammlung, weniger schöne und sich ähnelnde Gegenstände wanderten ins Depot. 
Colleselli ging vom Konzept der werkstofflichen Präsentation ab. Bisher wurden die Objekte dem Material nach in eigene Säle zusammengefaßt. Es gab einen „Textilsaal“, einen „Eisensaal“, Fachsammlungen für die Werkstoffe Kupfer, Zinn, Bronze, Glas und Keramik. Neues bestimmendes Ausstellungsprinzip sollte nun die „kulturgeschichtliche Sicht" der Sammlungen sein. Josef Ringler entwarf in verschiedenen Aufsätzen ein Bild der neuen Ideen seines Nachfolgers:

„Das Einteilungsprinzip entspricht nun nicht mehr handwerklichen und werkstofflichen Gesichtspunkten, sondern geht von dem Grundsatz des Volkskundlichen aus. In der Beziehung der Volkskunst zum Leben und Wirken vor allem des bäuerlichen Menschen in Tirol liegt das Merkmal der neuen Ordnung. So wurden völlig neue Beziehungen zwischen den einzelnen Gegenständen gefunden, die nicht vom Äußeren, sondern vom inneren Sinn und Zweck des Gegenstandes ausgehen. [...] Ein Rundgang durch das Museum ist nun zugleich ein Gang durch das bäuerliche Leben im Verlaufe des Alltags, des bäuerlichen Jahres und des bäuerlichen Lebenslaufes." ${ }^{117}$

Die neue Einteilung des Museumsbestandes sollte folgendes Aussehen haben (die Stuben blieben unverändert ${ }^{418}$ :

Erdgeschoß: Krippensammlung

Hausmodelle

1. Stock:

Süd/Ost-Gang: Speis und Trank

417 Ringler 1967, S. 171. An anderer Stelle schrieb er, daß für Colleselli neben dem sachlichinhaltlichen Ausstellungsgedanken „ÄSTHETISCHE GRUNDSÄTZE eine große Rolle“ gespielt hätten, da das ,ganze Ausstellungsgut [...] in gefälliger Form in eigens zu diesem Zwecke angefertigten Schaukästen und Vitrinen dargeboten“ werde, „die sich auch in ihrer Form dem Inhalt anpassen“. (Ebd., S. 175 f.; Hervorhebung von J.R.)

418 Ebd.; im Jahresbericht 1966 hatte Colleselli ein 13 Punkte umfassendes Programm für die Neuaufstellung dargelegt, das im Großen und Ganzen mit dieser Einteilung ident ist (S. 2):
a) Tiroler Haustypen
g) Geräte für die Feld- und Ackerbestellung
b) die Räumlichkeiten des Tiroler Hauses, vor allem die Stuben
h) Milchbereitung und ihre Verarbeitung
c) Küchengeräte
d) Geräte im Zusammenhang mit Essen und Trinken
i) Erntebrauchtum
k) Hausfrauliche Arbeiten, Verarbeitung von Flachs, Wolle, Weberei
e) Beleuchtung
1) Handwerksgeräte und Erzeugnisse
f) Wärme
m) Grödner Hausindustrie
n) Handel, Verkehr, Zunftwesen 
Nordgang: Licht und Wärme

Westtrakt: Bestellung von Acker und Feld

Nordtrakt: Handarbeit (der Frauen)

Hausindustrie, daran anschließend:

Handel, Verkehr und Zunftwesen

Freizeit, Spiel und Brauch

2. Stock:

Ostgänge: Trachtenfiguren

Möbel

Nordtrakt: Lebensstationen und religiöse Volkskunde

Damit wurde mit der Idee des Gewerbemuseums, Vorbild- und Mustersammlung zu sein, endgültig gebrochen.

Die Sammeltätigkeit der Gründer, die anfangs eher von Handwerk und Gewerbe bestimmt war, sah eine Aufstellung der Erwerbungen vor allem „im Sinne des Handwerks" vor und es wurde, mit Bedacht darauf, die „volkskünstlerische Dekoration [der ausgestellten Objekte] herausgestellt ${ }^{\text {“419. }}$.

Diese geplante Zusammenarbeit mit dem Gewerbe stellte sich aber nie so recht ein, und die eigentliche Zielsetzung des Museums lag bald auf volksbildnerischem Gebiet. Diesem Umstand wurde jetzt auch in der Museumsaufstellung Rechnung getragen.

Es kam zur Umgestaltung nach „volkskundlichem Charakter“, indem eine Bestandsgliederung nach der Beziehung Mensch - Tätigkeit erfolgte. Die „Gewohnheiten und Bräuche" des Tiroler Volkes sollten ab nun in den Mittelpunkt gestellt werden. ${ }^{420}$

Daraus ergab sich schon die erste Problematik. Denn ohne Abklärung was, unter dem Tiroler Volk zu verstehen sei, konnte eine solche Umgestaltung nicht gelingen.

419 Ringler 1967, S. 14 (Hervorhebung von W.M.). Wie Ringler weiters betonte, war es den Gründern des Museums darum gegangen, „für alle Zweige des durch die Technik bedrohten Handwerkes mustergültige Vorbildersammlungen zu schaffen, an denen sich die Handwerksmeister und Gesellen stilistisch wie handwerklich schulen konnten." (Ebd.)

420 Ebd.; Ringler forderte auch, daß „dauernd für die Verlebendigung des Museumsgutes etwas geschehen“ müsse, wollten die Museen „nicht Leichenkammern der Kunst sein“. (Ebd.) 
Allzuschnell wurde in der Museumsausgestaltung (ähnlich Radingers Konzeption; s. Kap. 5.3.3) wieder die Beziehung Mensch und Tätigkeit in einseitiger Ausrichtung auf bäuerliche Kultur und deren materielle Gegenstände verkürzt.

Dies wird verständlich vor dem Hintergrund einer Zeit, in der in Tirol unverkennbar wurde, daß die bäuerlich-ländliche Kultur im Schwinden begriffen ist. Dies nicht nur zahlenmäßig (die Anzahl der erwerbstätigen Personen aus Landund Forstwirtschaft an der Gesamtbevölkerung sank bis 1961 auf 25,3 \% ${ }^{421}$ ), sondern auch qualitativ. Auch in Tirol wurden kulturelle Gepflogenheiten und Wertvorstellungen, rascher als manchen lieb war, über Bord geworfen. Dies geschah durch den Wandel der kulturellen Äußerungen im Zuge der sich durchsetzenden Kulturindustrie, besonders durch den zunehmenden Fremdenverkehr.

Der Versuch, diesen Prozeß des Wandels durch bloßes Festhalten an Traditionen zu stoppen, vielleicht sogar umkehren zu können, mußte aber ebenso scheitern wie 80 Jahre zuvor das Vorhaben der Gewerbeförderung, Veränderungen in diesem Wirtschaftsbereich durch Festlegung auf bestimmte vorgegebene Muster aufzuhalten.

Wenn jetzt, nach Colleselli, das Museum zum „Gang durch das bäuerliche Leben im Verlaufe des Alltags, des bäuerlichen Arbeitsjahres und des bäuerlichen Lebenslaufes" werden sollte, dann verdeckt diese neue Ausrichtung, bewußt oder unbewußt, die Tatsache, daß die Gegenstände, die zur Neuadaption herangezogen wurden, nicht nach diesen Gesichtspunkten gesammelt worden waren und sich deshalb nicht ohne weiteres in ein solches Konzept einordnen ließen.

Denn eigentlich überwiegen im Museum schöne, reich verzierte Objekte, die nicht im Alltag Verwendung fanden, sondern u.a. als Liebesgaben oder Brauchgegenstände dienten. Gegenstände des alltäglichen Gebrauches fehlen großteils in der Sammlung des Museums.

Entweder weil sie bei den Sammlern und Einkäufern keine Beachtung gefunden hatten, da sie nicht verziert und ausgeformt waren, oder weil ihnen keine Aufmerksamkeit geschenkt worden war, da sie noch zum überwiegenden Teil in Verwendung standen. Weiters waren Gegenstände, die außer Gebrauch kamen, oft in einem solchen Zustand, daß sie, aufgrund ihres unscheinbaren und abgenutzten Äußeren, bei den Sammlern ebenfalls auf wenig Beachtung stießen. 
Beispiele dafür finden sich bei der Tracht, wo die Sammlung mehr Stücke der Festtagskleidung umfaßt als solche Utensilien, die im Alltag getragen wurden. Die Alltagskleidung wurde oft aufgetragen, das heißt an jüngere Verwandte weitergegeben oder einfach durch die ständige Benutzung abgetragen und verschlissen. Diese fand dann wenig Beachtung bei den Sammlern, entsprach sie doch nicht deren Vorstellung vom heroischen Kleid des Tiroler Bauern.

Ähnliches geschah bei den Möbeln, wo die Sammlung vor allem die schön verzierten Stücke umfaßt, die Brautfuhren, Hochzeitsgaben waren und deshalb in den Heimstätten einen Ehrenplatz bekamen, aber nicht das gesamte Mobiliar eines Hauses repräsentieren können. Die einfachen Möbelstücke, wie Schemel, Kommoden, Bettstatten etc. fanden ebenfalls in den Augen der ersten Sammler wenig Beachtung, waren sie doch kaum verziert und daher kein Beweis des Schmuckbedürfnisses und somit nicht DIE künstlerischen Äußerungen des Tiroler Volkes.

Was die unzähligen Gebrauchsgegenstände anbelangt, lag es nicht im Interesse der ersten Sammler und Museumsbetreiber hier eine repräsentative Auswahl zu treffen, wollten sie doch kein Volkskundemuseum errichten.

Daher ist kaum ein Bereich des täglichen Lebens mit den im Museum vorhandenen Gegenständen abzudecken; sei es der der Landwirtschaft mit deren Arbeitsverrichtungen, der diversen Gewerbe oder des Haushaltes.

Schon gar nicht lassen die im Museum befindlichen Gegenstände einen zeitlichen oder räumlichen Vergleich zu, sind sie doch eher eigenwillig zustande gekommene Auswahlstücke, die durch unterschiedlichste Umstände ins Museum gelangten. ${ }^{422}$

So mußte sich die neue Gestaltung über mehr Lücken in ihrer Sammlung hinwegschwindeln, als sie abzudecken vermochte, da sich die betreffenden Gegenstände nicht im Museumsbesitz befanden.

Franz Colleselli sah als Gründe für die Neugestaltung des Museums eine Veränderung der Darbietungsweise seit der Erstaufstellung, da seither neue Objekte hinzugekommen seien und es „gegenüber früher [eine] ganz andere Bevölkerungsschicht des Besucherpublikums" gäbe.

422 Während meines Museumspraktikums (1984) pflegte einer der Lieferanten, ein älterer Mann, seine gesammelten Schätze (ältere Gebrauchsgegenstände, wie häusliches Gerät, kleinere Werkzeuge etc.) vor dem Abliefern im Museum selbst zu verzieren (zu beschnitzen oder zu punzieren) und älter zu machen, da er meinte, so verschönert und gealtert würden sie dort leichter angenommen werden. 
Mittelpunkt der Museumsabsichten war nicht mehr der Förderung des heimischen Kunstgewerbes (der die Objektaufstellung nach Werkstoffgruppen entsprochen hatte), sondern die neue Aufgabe, Identitäts- und Integrationsmöglichkeit für möglichst viele Bevölkerungsschichten zu bieten.

Wie Franz Colleselli formulierte, sei es nun neue Aufgabe des Museums, die „Beziehung der Volkskunst zum Leben und Wirken vor allem der bäuerlichen Menschen in Tirol aufzuzeigen “423.

Dieser neuen Ausrichtung wurden Bestandteile der alten Sammlung geopfert (u.a. einige Möbelstücke, die diverse Tischler dem Museum, als Beweis ihres tirolischen Kunstgewerbefleißes, überlassen hatten).
„Mancher Besucher von früher wird in der Neuaufstellung den einen oder anderen Gegenstand vermissen, vor allem die Liebhaber bürgerlicher Wohnkultur, denen die feinen furnierten und eingelegten Rokoko- und Luis-Seize-Möbel abgehen werden."

Josef Ringler vertröstete eventuell enttäuschte Besucher der neuaufgestellten Sammlung damit, daß, wenn die Depotfrage gelöst sei, wieder Platz für das „bürgerliche Mobiliar frei“ werden würde. ${ }^{424}$

Als Resümee läßt sich zum theoretischen Konzept der Neuaufstellung sagen: So richtig und für die damalige Zeit fortschrittlich der Gedanke eines Museums nach „kulturgeschichtlicher Sicht[weise]“ (Ringler) war, so wenig konnte dieser Anspruch eingelöst werden, da das Tiroler Volk auf den bäuerlichen Bevölkerungsanteil eingeschränkt und in mythologisierter Weise gesehen wurde.

Auch wenn das Museumskonzept Kultur auf mehr als bloß künstlerische Äußerungen festlegt und es die dadurch gewonnene Sicht auf die Lebensweise der Menschen ermöglicht, Kultur nicht abgehoben und losgelöst von jeglichem gesellschaftlichen Bezug - als geistige Welt - anzusehen, mußte dieses Konzept doch scheitern, da es nicht zu Ende geführt wurde.

Nicht zu Ende gedacht war es deshalb, weil letztendlich wieder das ästhetische Prinzip im Vordergrund stand. Es manifestierte sich zwar nicht mehr in Form

423 So dieser in seinem Jahresbericht 1966, S. 1.

424 In seiner Darstellung „Das neue Gesicht des Tiroler Volkskunstmuseums“ in der Tiroler Tageszeitung Nr. 132 vom 10.6.1967. 
einer Werkstoffsammlung, dafür aber in Gestalt einer Leistungsschau nationaler Kultur.

Den eingeschlagenen Ansatz zu Ende zu denken hieße, um mit Herbert Marcuse zu sprechen, daß Kultur

„das jeweilige Ganze des gesellschaftlichen Lebens [zu umfassen hätte], sofern darin sowohl die Gebiete der ideellen Reproduktion (Kultur im engeren Sinne, die ,geistige Welt') als auch der materiellen Reproduktion (der ,Zivilisation') eine historisch abhebbare und begreifbare Einheit bilden“

würden. ${ }^{425}$

Die neu gewählte Präsentation der Objekte im Volkskunstmuseum blieb aber hinter dieser Auffassung weit zurück.

Obwohl anstelle der stofflichen Ordnung funktionale Gesichtspunkte traten, blieb erhalten, daß die Gegenstände allein für sich zu sprechen und als Vorzeigeobjekte zu dienen hatten. Es war nicht Aufgabe der Objekte zu zeigen, wie es war, wie sie hergestellt wurden und wozu sie gedient hatten, sondern, nach Konrad Köstlin, „Geschmacksbildung als einen Teil des [regionalen] Identifizierungsangebotes" zu liefern.

Für K. Köstlin stellt das Museum die „inventarisierte Geschichte [...] die ,große Geschichte der Region" dar, in der Identität gestiftet und vermittelt wird. Nicht „wahre“ Abbildung der Ereignisse, sondern die Interpretation dieser Ereignisse sei wesentlichste Aufgabe der Institution Museum. ${ }^{426}$

Daher ist es auch unmöglich, von Objekten an sich zu sprechen, die einfach ohne weitere Erläuterung ausgestellt, ihre Geschichte erzählen würden. Wie K. Köstlin weiter meint, gibt es „Anschauung allein, wie sie von den Gegenständen ausgeht, [...] nicht“, da diese „Relikte ja nicht ohne Grund und damit auch nicht ohne Umfeld in ihre neue Wirkung in der Gegenwart gelangt" seien und deren „Brauchbarkeit und mithin auch Anschaulichkeit [...] sich schon im Verlauf des Tradierungsvorganges immer wieder neu" konstituieren würde. ${ }^{427}$

425 Marcuse 1965, S. 62.

426 1982b, S. 51. Für Köstlin ist das Museum somit eine Art von lokaler/regionaler „Sinngebungsinstanz", in der "Integrationsformeln entwickelt und vermittelt werden“. (Ebd.)

427 Ebd., S. 55; für ihn ist sowohl die Verwendung von Gegenständen als Antiquitäten als auch deren Musealität Ausdruck ihrer „Brauchbarkeit“. (Ebd.) 
Auch für die neue Sammlungspräsentation des Volkskunstmuseums gilt diese Feststellung! Diese hatten ab nun nicht mehr „mustergiltige“ Vorzeigestücke (wie es noch in den ersten Statuten hieß), sondern Belege der Tiroler Volkskultur zu sein. Damit erhielten sie ein Etikett aufgedrückt, das sie im realen Gebrauch so nie gehabt hatten.

Daß diese Art der Präsentation nicht nur für das Tiroler Volkskunstmuseum, sondern für fast alle österreichischen Volkskundemuseen typisch war/ist, zeigte Wolfgang Gürtler in seiner Dissertation, worin er harte Kritik am volkskundlichen Museumswesen übt. Seine Kritik der Sammlungen umfaßt drei Punkte:

- die einseitige Art der Sammlungen und deren schlechte Dokumentation,

- die vornehmliche Präsentation von „schönen“ Objekten, und

- die seltene Erneuerung der ständigen Ausstellungen, „wodurch das Museum von einem Institut der Vermittlung wissenschaftlicher Erkenntnis zur Schaubude degeneriert" werde.

Zur Verteidigung der Museumsbetreiber muß gerechterweise gesagt werden, daß ihre Institutionen personell meist stark unterbesetzt sind, sodaß die laufende $\mathrm{Mu}-$ seumstätigkeit kaum mehr Zeit für große Umgestaltungen und die Durchführung gut vorbereiteter Ausstellungen läßt.

Als ersten Ansatz einer Änderung des Museumswesens forderte Gürtler eine Aussprache zwischen den politisch Verantwortlichen und den Museumsleitern (sowie den Universitätsinstituten für Volkskunde), um die Möglichkeiten abzuklären, daß volkskundliche Museen zu „Volkskundemuseen im Sinne der wissenschaftlichen Disziplin werden könnten“".

Er war sich aber dabei bewußt, daß dies nur durch verstärkte bauliche, personelle und finanzielle Aufwendungen sowie durch theoretischer Neuüberlegungen geschehen könnte.

„Ansonsten“ würden diese Museen „weiterhin eine Art volkstümliches „Kunstgewerbe für bäuerliche Konsumenten bis zum Beginn des 20. Jahrhunderts zeigen“, und sollten sich, Gürtlers Vorstellungen zufolge, auch dahingehend umbenennen! $!^{428}$

Fürs Tiroler Volkskundemuseum treffen sicherlich auch heute noch einige der Überlegungen Gürtlers zu. Sowohl finanziell als auch personell ist das Museum unterbestückt und die räumliche Situation läßt nicht viel Spielraum für eine not-

428 1976, S. 91. Gürtler hat seine Arbeit vor zwölf Jahren verfaßt; es scheint, daß große Teile seiner Forderungen noch immer ungehört geblieben sind - zumindest im Bereich der universitären, museumsdidaktischen Ausbildung. 
wendige Umgestaltung, wollen die Betreiber nicht auf wesentliche Stücke der Sammlung verzichten (von umfangreicheren Neuerwerbungen ganz zu schweigen).

Diese formalen Gegebenheiten wären - neben der inhaltlich-theoretischen Arbeit zu den Objekten - bei einer beabsichtigten Neuaufstellung zu berücksichtigen. 


\section{Bibliographie}

\section{1. a) Zeitungen, gedruckte und ungedruckte Quellen:}

Bot(h)e für Tirol und Vorarlberg

Der Oberländer

Innsbrucker Nachrichten

Kulturberichte aus Tirol

Kunstgewerbeblatt. Vereinsorgan der Kunstgewerbevereine Berlin, Dresden, Düsseldorf, Elberfeld, Frankfurt a. M., Hamburg, Hannover, Karlsruhe I. B.,

Königsberg i. Preussen, Leipzig, Magdeburg, Pforzheim und Stuttgart

Mittheilungen der k. k. Central Commission zur Erforschung und Erhaltung der

Kunst- und historischen Denkmale

Mitteilungen des Vereins für Heimatschutz in Tirol

Mittheilungen des Tiroler Gewerbevereins

Neue Tiroler Stimmen

Protokolle der ordentlichen öffentlichen Sitzungen der Handels- und Gewerbekammer Innsbruck

Stenographische Berichte des Tiroler Landtages

Tiroler Anzeiger

Tiroler Gewerbe

Tirol/isches/er Gewerbeblatt

Tiroler Gewerbezeitung

Tiroler Tageszeitung

Tiroler Wastl

Tiroler Landesarchiv Akten der Präsidialabteilung, der Statthalterei, sowie Akten der Abteilung III (Kunst)

Volkszeitung

\section{2. b) Selbständig und unselbständig erschienene Schriften}

Adorno, Theodor W.: Dissonanzen. Musik in der verwalteten Welt. Göttingen 1958.

Allgemeines Lexikon der Bildenden Künstler, 35. Bd. (hg. U. Thieme/F. Becker). Leipzig 1942.

Angerer, Johann: Vergleichende Betrachtungen über den Fremdenverkehr in Tirol und in der Schweiz. Innsbruck 1899. 
Barnay, Markus: Die Erfindung des Vorarlbergers. Ethnizitätsbildung und Landesbewußtsein im 19. und 20. Jahrhundert. Bregenz 1988.

Bauer, Otto: Die Nationalitätenfrage und die Sozialdemokratie (1906/07). In: O. Bauer, Werkausgabe Bd. 1. Wien 1975.

Bauer, Otto: Der Kampf um Wald und Weide (1925). In: O. Bauer, Werkausgabe Bd. 3. Wien 1976.

Bausinger, Hermann: Zur Kritik der Folklorismuskritik. In: Populus Revisus (hg. H. Bausinger u.a.). Volksleben Bd. 14, Tübingen 1966, S. 61 ff.

Bausinger, Hermann: Heimat und Identität. In: Heimat und Identität - Probleme regionaler Kultur (hg. K. Köstlin u. H. Bausinger). Neumünster 1980, S. 9 ff.

Bausinger, Hermann: Volkskultur und Sozialgeschichte. In: Sozialgeschichte in Deutschland Bd. III (hg. W. Schieder/V. Sellin). Göttingen 1987.

I. Bericht über die Thätigkeit des Tiroler Gewerbevereines (Verwaltungsperiode vom November 1880 bis Februar 1882) Innsbruck 1882.

Berlepsch-Valendas, Hans Eduard von: Gothisches aus Tyrol. In: Kunstgewerbeblatt. Vereinsorgan der Kunstgewerbevereine Berlin, Dresden, Düsseldorf, Elberfeld, Frankfurt a. M., Hamburg, Hannover, Karlsruhe I. B., Königsberg i. Preussen, Leipzig, Magdeburg, Pforzheim und Stuttgart, 4. Jahrgang, 8. Heft, Leipzig 1888, S. 139-145.

Berufsstatistik 1910, Heft 7, Ergebnisse für Tirol und Vorarlberg (=Österr. Statistik N.F. 3. Bd./Heft 7). Wien 1915.

Berufsstatistik 1910, Heft 1, Hauptübersicht und Besprechung der Ergebnisse (=Österr. Statistik N.F. 3. Bd./Heft 1). Wien 1916.

Blaschke, Jochen: Volk, Nation, Interner Kolonialismus, Ethnizität. Konzepte zur politischen Soziologie regionalistischer Bewegungen in Westeuropa. Berlin 1985.

Bolognese-Leuchtenmüller, Birgit: Bevölkerungsentwicklung und Berufsstruktur - Gesundheits- und Fürsorgewesen in Österreich 1750-1918. Wien 1978.

Brecht, Bertolt: Flüchtlingsgespräche. Frankfurt/Main 1984.

Bruckmüller, Ernst: Sozialgeschichte Österreichs. Wien 1985.

Burke, Peter: Helden, Schurken, Narren. Europäische Volkskultur der frühen Neuzeit. Stuttgart 1981.

Colleselli, Franz: Die Einrichtung der Studiensammlung am Tiroler Volkskunstmuseum. In: Mitteilungsblatt der Museen Österreichs Nr. 13., Wien 1964, S. $5 \mathrm{ff}$.

Colleselli, Franz: Museumsdirektor Hofrat Dr. Ringler zum 75. Geburtstag. In: Der Schlern, 42. Jhg. (1968), S. 3 f.

Colleselli, Franz: Josef Ringler $\dagger$. In: Österreichische Zeitschrift für Volkskunde, N. S. Bd. XXVII (1973), S. 51. 
Dapra, Josef: Geschichte Tirols von 1900-1914. Phil. Diss. Innsbruck 1948.

Dahlhaus, Carl: Zur Dialektik von „echt“ und „unecht“ (Diskussionsbeitrag zum Aufsatz: Volkslied - Schlager - Folklore von F. Bose.). In: Zeitschrift für Volkskunde, 63. Jhg. (1967), S. 56 f.

Deneke, Bernward: Die Entdeckung der Volkskunst für das Kunstgewerbe. In: Zeitschrift für Volkskunde, 60. Jhg. (1964), S. 168 ff.

Deneke, Bernward: Europäische Volkskunst. In: Propyläen Kunstgeschichte, Supplementband 5. Frankfurt/Main 1980, S. $11 \mathrm{ff}$.

Denkschrift zur Feier des 20jährigen Bestandes des Landesverbandes für Fremdenverkehr in Tirol. Innsbruck 1910.

Dörrer, Anton: Die „Tyroler Nation“ in Wien. In: Jahrbuch für Landeskunde von Niederösterreich, N.F. XXIX (1948), S. 280 ff.

Egg, Erich: Chronik des Ferdinandeums 1823-1973. In: Veröffentlichungen des Tiroler Landesmuseums Ferdinandeum, Bd. 53 (1973), S. 5 ff.

Emmerich, Wolfgang: Zur Kritik der Volkstumsideologie. Frankfurt/Main 1971.

Erhard, Benedikt: Bauernstand und Politik. Zur Geschichte des Tiroler Bauernbundes. Wien 1981.

erziehung heute Heft 1/2 (1984): „helden“.

Fischer, Ernst: Von der Notwendigkeit der Kunst. Frankfurt/Main 1985.

Fischer, Peter G.: Freie und genossenschaftliche Interessensvertretungen der gewerblichen Wirtschaft in Österreich vom Vormärz bis zum „Ständestaat“. In: Zur Geschichte der Handelskammerorganisationen. Schriftenreihe der Bundeskammer der gewerblichen Wirtschaft, Heft 37 (1978), S. 7 ff.

Fischnaler, Konrad: Chronik von Innsbruck, Bd. I-IV. Innsbruck 1930; Bd. V, Innsbruck 1934.

Fontana, Josef: Der Kulturkampf in Tirol. Bozen 1978.

Fontana, Josef: Geschichte des Landes Tirol (1848-1918), Bd. 3 (hg. J. Fontana u.a.). Bozen-Innsbruck 1987.

Forcher, Michael: Tirol im 19. Jahrhundert: Zwischen Irredentismus, Deutscher Frage und Verfassungskämpfen. In: Tirol im Jahrhundert nach Anno Neun (hg. E. Kühebacher). Schlern Schriften Nr. 279, Innsbruck 1986, S. 9 ff.

Frecot, Janos: Museum, Trödel, Kinderzimmer. In: Kunst - Gesellschaft - Museum (hg. H. Kurnitzky). Notizbuch 3 (1980), S. 157 ff.

Gamper, Hans: Wohin steuern wir? - Das Wirrspiel der Gegenwart im Spiegel Tirols. Innsbruck 1925.

Gamper, Hans: Kleinod Tirol. In: Stimme Tirols, 5. Jhg., Nr. 26 (1950), S. 2.

Geissler, Franz: Die Entstehung und der Entwicklungsgang der Handelskammern in Österreich. In: Hundert Jahre Österreichischer Wirtschaftsentwicklung 1848-1948 (hg. H. Mayer). Wien 1949, S. 21 ff. 
Geissler, Franz: Von der österreichischen Handelskammer in Wien zur Handelskammer für Wien. In: Wirtschaftspolitische Blätter 21. Jhg. Nr. 1 (1974), S. $2 \mathrm{ff}$.

Gerhardinger, H./Egert, F./Huter, F. (Hg): Tiroler Wirtschaft in Vergangenheit und Gegenwart, Bd. 2. Schlern Schriften Nr. 78, Innsbruck 1951.

Greverus, Ina-Maria: Kultur und Alltagswelt. München 1978.

Grimm, Jacob und Wilhelm: Deutsches Wörterbuch, 12. Bd., Leipzig 1951, Sp. $453 \mathrm{ff}$.

Gschnitzer, Hans/Menardi, Herlinde: Tiroler Volkskunstmuseum - Katalog 1: Essen und Trinken - Feuer und Licht. Innsbruck 1983.

Gschnitzer, Hans/Menardi, Herlinde: Tiroler Volkskunstmuseum - Katalog 2: Stuben - Öfen - Hausmodelle. Innsbruck 1986.

Günther, Adolf: Die Alpenländische Gesellschaft. Jena 1930.

Günther, Adolf: Die gewerbliche Wirtschaft in Tirol. Tatsachen und Probleme. In: Tiroler Wirtschaft in Vergangenheit und Gegenwart, Bd. 3., Schlern Schriften, Nr. 79, Innsbruck 1951.

Gürtler, Werner: Über die Vorstellung von der sogenannten kulturellen Einheit Tirols. Erläutert am Beispiel der Techet-Affäre. In: Tirol im Jahrhundert nach Anno Neun (hg. E. Kühebacher). Schlern Schriften, Nr. 279, Innsbruck 1986, S. $177 \mathrm{ff}$.

Gürtler, Wolfgang: Österreichische volkskundliche Museologie. Versuch einer Standortbestimmung. Phil. Diss. Wien 1976.

Hacker, Dieter: Unsere Nationalgalerie. In: Kunst - Gesellschaft - Museum (hg. H. Kurnitzky). Notizbuch 3 (1980), S. $123 \mathrm{ff}$.

Hammer, Heinrich: Der Bau des „Neuen Stiftes“ in Innsbruck und seine Geschichte. In: TIROL. Natur Kunst + Volk Leben, 2. Folge, Heft 4 (1929), S. $11 \mathrm{ff}$.

Hanisch, Ernst: Provinz und Metropole. Gesellschaftsgeschichtliche Perspektiven der Beziehungen des Bundeslandes Salzburg zu Wien (1918-1934). In: Beiträge zur Föderalismusdiskussion (hg. A. Edelmayer u.a.). Salzburger Dokumentationen, Bd. 54, Salzburg 1981, S. 67 ff.

Hanisch, Ernst: Wirtschaftswachstum ohne Industrialisierung: Fremdenverkehr und sozialer Wandel in Salzburg 1918-1938. In: Mitteilungen der Gesellschaft für Salzburger Landeskunde 125. Vereinsjahr (1985), S. 817 ff.

Hartungen, Christoph von/Heiss, Hans: Tirol um 1800. Eine Annäherung. In: sturzflüge, Nr. 7, März/April 1984, S. 12 ff.

Hartungen, Christoph von/Pallaver, Günther: Einleitung. In: Arbeiterbewegung und Sozialismus in Tirol (hg. Chr. v. Hartungen u. G. Pallaver). Bozen - Innsbruck 1986, S. 7 ff. 
Hein, Wolfgang: Zur Theorie der regionalen Differenzierung kapitalistischer Gesellschaften in der industriellen Revolution. In: Provinzialisierung einer Region. Zur Entwicklung der bürgerlichen Gesellschaft in der Provinz (hg. Gert Zang). Frankfurt/Main 1978, S. 31 ff.

Helczmanovszki, Heimold: Die Entwicklung der Bevölkerung Österreichs in den letzten 100 Jahren nach den wichtigsten demographischen Komponenten. In: Beiträge zur Bevölkerungs- und Sozialgeschichte Österreichs (hg. H. Helczmanovszki). Wien 1973, S. $113 \mathrm{ff}$.

Hocke, Manfred: Denkmalschutz in Österreich. Wien 1975.

Hörmann, Magdalena: Hofrat Dr. Franz Colleselli, Direktor des Tiroler Volkskunstmuseums, gestorben. In: Kulturberichte aus Tirol, 33. Jhg., Folge 271/272 (1979), S. 26.

Hoffmann, Detlev: „Laßt Objekte sprechen!“ Bemerkungen zu einem verhängnisvollen Irrtum. In: Das Museum Lernort contra Musentempel (hg. E. Spickernagel/B. Walbe). Gießen 1979, S. $101 \mathrm{ff}$.

Iggers, Georg G.: „Neue Geschichtswissenschaft“ - Vom Historismus zur Historischen Sozialwissenschaft. München 1978.

Ilg, Albert: Die Industrie des Grödner Thales in Tirol. In: Mittheilungen des k.u.k. österreichischen Museums für Kunst und Industrie (Monatsschrift für Kunst und Kunstgewerbe) 6. Jhg., Nr. 67 (1871), S. 367 ff.

Jeggle, Utz/Korff, Gottfried: Zur Entwicklung des Zillertaler Regionalcharakters. In: Zeitschrift für Volkskunde, 70. Jhg. (1974), S. 39 ff.

Juen, Johann/Nussbaumer, Josef: Kirche und Land Tirol I.Teil: Ein geschichtlicher Rückblick. In: Heile Welt in der Region? Beiträge zum politischen und sozialen System Tirols (hg. H. Fischer und S. Preglau-Hämmerle). Bregenz 1983, S. $178 \mathrm{ff}$.

Kafka, Franz: Tagebücher 1910-1923. Frankfurt/Main 1951.

Katalog der Tiroler Landesausstellung (hg. Executiv Comité). Innsbruck 1893.

Köfler, Gretl: Franz Maria Gruener. In: Gaismair-Kalender. Innsbruck - Bozen 1987, S. $144 \mathrm{ff}$.

Köstlin, Konrad: Die Regionalisierung von Kultur. In: Heimat und Identität Probleme regionaler Kultur (hg. K. Köstlin u. H. Bausinger). Neumünster 1980, S. $25 \mathrm{ff}$

Köstlin, Konrad: Folklorismus als Therapie? Volkskultur als Therapie? In: Folklorismus (hg. E. Hörandner u.a.). Neusiedl/See 1982a, S. 129 ff.

Köstlin, Konrad: Das Museum zwischen Wissenschaft und Anschaulichkeit. Zum Verhältnis von Recherche und Präsentation. In: Museen in der Provinz (hg. M. Scharfe). Untersuchungen des Ludwig-Uhland-Institutes der Universität Tübingen, Bd. 54., Tübingen 1982b, S. 47 ff. 
Kofler, Anton: Zur Geschichte des Tiroler Volkskunstmuseums. In: TIROL. Natur Kunst + Volk Leben, 2.Folge, Heft 4 (1929), S. 1 ff.

Korff, Gottfried: Folklorismus und Regionalismus. Eine Skizze zum Problem der kulturellen Kompensation ökonomischer Rückständigkeit. In: Heimat und Identität - Probleme regionaler Kultur (hg. K. Köstlin u. H. Bausinger). Neumünster 1980 .

Kramer, Dieter: Der sanfte Tourismus. Wien 1983.

Kramer, Hans: Edgar Meyer als Künstler und als Bauherr. In: Der Schlern, 25. Jhg. (1951), S. 458 ff.

Kramer, Hans: Die Entwicklung des Fremdenverkehrs in Tirol vor 1914. In: Der Schlern, 36. Jhg. (1962), S. $319 \mathrm{ff}$.

Krammer, Josef: Analyse einer Ausbeutung I. Geschichte der Bauern in Österreich. In: In Sachen, Heft 2 (1976).

Kunzenmann, Werner: Tirol und Österreich. In: Der Anteil der Bundesländer an der Nationswerdung Österreichs (hg. W. Jamber). Wien 1971.

Lang, Leonhard (hg.): Das tirolische Volkskunst=Gewerbemuseum. Innsbruck 1912.

Lederer, Hans: Franz Gruener - eine literaturhistorische Skizze. Innsbruck-Salzburg 1946.

Leisching, Julius: Innsbruck: Eröffnung des Tiroler Volkskunstmuseums. (In: Amtliche Mitteilungen des Verbandes kunstwissenschaftlicher und kulturhistorischer Museen Österreichs.) In: Belvedere (Monatsschrift für Sammler und Kunstfreunde), 8. Jhg., Heft 7 (1929), S. 231 f.

Leisching, Julius: Das Tiroler Volkskunstmuseum in Innsbruck. In: TIROL. Natur Kunst + Volk Leben (hg. Landesverkehrsamt Tirol), 2. Bd. (1931), S. 130 ff.

Lener, Annemarie: Die Entwicklung der Tiroler Tracht im 19. und 20. Jahrhundert. Phil. Diss. Innsbruck 1983.

Lenz, Oskar: Kunst und Kunsthandwerk - Meisterwerke im Bayerischen Nationalmuseum München. Festschrift zum 100jährigen Bestehen des Museums. München 1955.

Lewald, August: Tyrol, vom Glockner zum Orteles, und vom Garda zum Bodensee. 2 Bde., München 1835.

Lutz, Gerhard: Das Amt Rosenberg und die Volkskunde. In: Volkskunde als akademische Disziplin. Studien zur Institutionenausbildung (h. W. Brückner/ K. Beitl). Österreichische Akademie der Wissenschaften, Phil.-histor. Klasse, Sitzungsberichte Bd. 414 (= Mitteilungen des Instituts für Gegenwartsvolkskunde Nr. 12). Wien 1983, S. $161 \mathrm{ff.}$

Mader Friedrich: Kammergeschichte 1900-1938. In: Tiroler Wirtschaft in Vergangenheit und Gegenwart, Bd. 2 (hg. H. Gerhardinger/F. Egert/F. Huter). Schlern Schriften, Nr. 78, Innsbruck 1951, S. 165 ff. 
Mader Friedrich: 25 Jahre Tiroler Volkskunstmuseum. In: Tiroler Tageszeitung, 10. Jhg., Nr. 71 vom 27.3.1954, S. 7.

Marcuse, Herbert: Über den affirmativen Charakter der Kultur. (Erstveröffentlichung 1937) In: Kultur und Gesellschaft I. Frankfurt/Main 1965, S. 56 ff.

Marek, Richard: Handelskammer und gewerbliche Wirtschaft Tirols 18511900. In: Tiroler Wirtschaft in Vergangenheit und Gegenwart, Bd. 2 (hg. H. Gerhardinger/F. Egert/F. Huter). Schlern Schriften, Nr. 78, Innsbruck 1951, S. $129 \mathrm{ff}$.

Matis, Herbert: Die Habsburgermonarchie (Cisleithanien) 1848-1918. In: Handbuch der Europäischen Wirtschafts- und Sozialgeschichte. Bd. 5, Stuttgart 1985, S. $474 \mathrm{ff}$.

Mauthe, Jörg: Die große Hitze oder Die Errettung Österreichs durch den Legationsrat Dr. Tuzzi. Wien 1974.

Mumelter, Norbert: 60 Jahre Heimatschutz in Tirol. In: Tiroler Heimatblätter, 44. Jhg., Heft 1/3 (1969), S. 1 ff.

Mundt, Barbara: Die deutschen Kunstgewerbemuseen im 19. Jahrhundert. Studien zur Kunst des 19. Jahrhunderts Bd. 22. München 1974.

Natter, Bernhard: Die „Heimat“ und die „Tiefen der Seele“. Volksbildungsliteratur im „Ständestaat“ am Beispiel der Zeitschrift „Ruf der Heimat“ (1935-38). Phil. Diss. Innsbruck 1984.

Nussbaumer, Josef: Die „Tausend-Mark-Sperre“ vom Mai 1933 und der Tiroler Fremdenverkehr. In: Tirol und der Anschluß (hg. Th. Albrich u.a.). Innsbruck 1988, S. 307 ff.

Oberkofler, Anton/Egger, Josef: Gewerbe- und Industrieausstellung des Bezirkes der Handels- und Gewerbekammer von Bozen vom 18. September bis 5. Oktober 1887. Auch in: Tirolensien I (Separatabdrücke aus Artikeln des „Tiroler Volksblatt"). Bozen 1899, S. 83 ff.

Oberkofler, Gerhard: Die Tiroler Arbeiterbewegung von den Anfängen bis zum Ende des Zweiten Weltkrieges. 2.Aufl. (Materialien zur Arbeiterbewegung, Nr. 43). Wien 1986.

Obermair, Hannes: Bibliographie zur Reiseliteratur über Tirol. In: Der Schlern, 57. Jhg. (1983), S. $223 \mathrm{ff}$.

Österreichische Landeskommission für geistige Zusammenarbeit (hg): Die Museen Österreichs. Wien 1935.

Österreichisches Biographisches Lexikon, 1815-1950 Bd. 1 bis 8 (hg. Österreichische Akademie der Wissenschaften). Wien $1957 \mathrm{ff}$.

Opperer, Georg.: Heimatkunde. In: Tiroler Heimatblätter, Heft 1, 1. Jhg. (1923), S. 1. 
Otruba, Gustav: Wachstumsverschiebungen in den Wirtschaftssektoren Österreichs 1869-1961. In: Vierteljahresschrift für Sozial- und Wirtschaftsgeschichte, 62. Bd. (1975), S. 40 ff.

Pallaver, Günther: Kirche in Tirol. Vom Hexenwahn zum Herz-Jesu-Bund. In: sturzflüge, Nr. 7, März/April 1984, S. 39 ff.

Paulin, Karl: Wie das Museum für tirolische Volkskunst- und Gewerbe in Innsbruck entstand. In: Bergland. Illustrierte alpenländische Monatsschrift, 11. Jhg., Nr. 5 (1929), S. 2 ff.

Paulin, Karl: Tiroler Köpfe. Innsbruck 1953.

Payr, Carl: Resultate der von der Handels- und Gewerbe-Kammer in Innsbruck im Auftrage Seiner Excellenz des Herrn Handels-Ministers berufenen Enquete zur Erhebung der Lage und Bedürfnisse des Kleingewerbes. Innsbruck 1872.

Payr, Carl: Zur Geschichte des Constitutionellen Vereins in Innsbruck und des Deutschliberalen Vereins in Tirol. Innsbruck 1902.

Pecht, Friedrich: „Kunst und Kunstindustrie“ auf der Wiener Weltausstellung 1873. Stuttgart 1873.

Pfaundler, Gertrud: Tirol Lexikon. Innsbruck 1983.

Plant, Fridolin: Alttirolische Bauernhöfe. In: Chronik des Österreichischen Touristenclubs, Jhg. 1883. Wien (1884).

Pomian, Krzysztof: Der Ursprung des Museums. Vom Sammeln. Berlin 1988.

Radinger, Karl von: Das Museum für Tirolische Volkskunst und Gewerbe. In: Der Föhn, 1. Jhg. (1909/10), S. 33 ff.

Radinger, Karl von: Das Museum für tirolische Volkskunst und Gewerbe in Innsbruck. In: Zeitschrift für österreichische Volkskunde, 18. Jhg. (1912), S. 54 ff.

Riedmann, Josef: Tirol. In: Österreich 1918-1938, Bd. 2 (hg. E. Weinzierl/K. Skalnik). Graz 1983, S. 961 ff.

Ringler, Josef: Das Museum für tirolische Volkskunst und Gewerbe in Österreich. In: Tiroler Heimatblätter, 6. Jhg. (1928), S. 279 ff.

Ringler, Josef: Kunsthandwerk in alter und neuer Zeit. In: Österreichische Rundschau. Sonderheft Tirol, 3. Jhg., Nr. 8/9 (1948), S. 184 ff.

Ringler, Josef: Das Tiroler Volkskunstmuseum in Innsbruck. In: Mitteilungen der Museen Österreichs (Ergänzungsheft 1). Wien 1952, S. 21 ff.

Ringler, Josef: Die künstlerischen und sozialen Grundlagen der Heimatwerkidee. In: Jahrbuch des Vorarlberger Landesmuseumsvereins. (1958-59), S. 81 ff.

Ringler, Josef: Das Tiroler Heimatwerk. In: Tiroler Heimatblätter, 34. Jhg. (1959), S. $153 \mathrm{ff}$.

Ringler, Josef: Das Tiroler Volkskunstmuseum. In: Beiträge zur Kultur- und Kunstgeschichte Tirols. Festschrift Landeshauptmann Prof. Dr. Hans Gamper, Bd. 3 (hg. F. Grass). Schlernschrift, Nr. 167. Innsbruck 1962, S. 67 ff. 
Ringler, Josef: Die Neugestaltung des Tiroler Volkskunstmuseums. In: Mitteilungsblatt der Museen Österreichs, Nr. 16. Wien 1967, S. 170 ff.

Ringler, Josef: Von der äußeren und inneren Neugestaltung des Tiroler Volkskunstmuseums. In: Kulturberichte aus Tirol, Folge 175/176 (1967), S. 13 ff.

Rohn, Heinrich: Rechtliche Grundlagen des Heimatschutzes. Bericht erstattet in der Sitzung des Tiroler Landesverkehrsrates vom 14. Dezember 1912. Innsbruck 1912.

Schindler, Norbert: Spuren in der Geschichte der „anderen“ Zivilisation. In: Volkskultur (hg. R. v. Dülmen/N. Schindler). Frankfurt 1984.

Schmidt, Leopold: Die Historisierung der Volkskunde als museologisches Problem. In: Forschungen und Fortschritte 37 (1963), S. 249 ff.

Schober, Richard: Geschichte des Tiroler Landtages im 19. und 20. Jahrhundert. Innsbruck 1984.

Seberiny, Hans: 25 Jahre Heimatschutzbewegung in Tirol. $=8$. Flugschrift des Vereins für Heimatschutz in Tirol. Zugleich auch in: Tiroler Heimatblätter, 11. Jhg. (1933).

Siber, Alfons: „Restaurierungen“ und Heimatschutz. In: Der Föhn 2. Jhg. (1910/11), S. 75 ff.

Sonnewend, Theresia-Maria: Das Tiroler Volksbild in Plakaten und Prospekten des 20. Jahrhunderts. Eine volkskundliche Interpretation nordtiroler Fremdenverkehrswerbung. Phil. Diss. Innsbruck 1986.

Staffler, Johann Jakob: Tirol und Vorarlberg statistisch, mit geschichtlichen Bemerkungen. Innsbruck 1839.

Stifter, Herbert: Tiroler Volkskunst - Das Museum für tirolische Volkskunst und Gewerbe in Innsbruck. In: Almanach (hg. Hotel Tyrol-Innsbruck), 5. Jhg. (1930), S. 7 ff.

Stolz, Otto: Die Ausbreitung des Deutschtums in Südtirol im Lichte der Urkunden, Bd. 3/1. München 1932.

Stolz, Otto: Geschichte des Landes Tirol, Bd. 1. Innsbruck 1955.

sturzflüge, Nr. 7 (1984): „Diroll 1809 oder: der AH-Effekt“.

sturzflüge, Nr. 15/16 Mai/August 1986: Die Geschichte der Juden in Tirol.

Tappeiner, Franz: Grabungen und Funde im Puster- und Eisack-Thale im Jahre 1887. In: Mittheilungen der K.K. Central-Commission zur Erforschung und Erhaltung der Kunst- und historischen Denkmale, N.F. XV, Wien 1888, S. 100-231.

Trapp, Oswald: Die Kunstdenkmäler Tirol in Not und Gefahr. Innsbruck 1947.

Ucakar, Karl: Die Entwicklung der Interessenorganisationen. In: Das politische und soziale System Österreichs (hg. H. Fischer). Wien 1982, S. 397 ff.

Weissensteiner, Robert: Die Geschichte Südtirols im Spiegel des christlichsozialen Blattes „Der Tiroler“ 1914-25. Phil. Diss. Innsbruck 1979. 
Weitlaner, Paul: Der Heimatpfleger. In: Tiroler Heimatblätter, Heft 12, 7. Jhg. (1929). S. $392 \mathrm{f}$.

Wenger, Karl/Seidel, Hans: Freie Verbände in der gewerblichen Wirtschaft. In: Verbände und Wirtschaftspolitik in Österreich (hg. Th. Pütz). Schriften des Vereins für Socialpolitik, N.F. Bd. 39. Berlin 1966.

Zimmeter, Kunibert: Tiroler Volkskunst. In: Der Föhn, 2. Jhg. (1910/11), S. $201 \mathrm{ff}$.

Zimmeter, Kunibert: Die Kunst in Tirol - Tiroler Heimatkunst. Sonderband 5. Wien 1923.

Zimmeter, Kunibert: Ein Tiroler fährt in die Welt. Innsbruck 1947.

Zwanowetz, Georg: Die Industrialisierung Tirols und Vorarlbergs bis etwa 1914. In: Berichte über den 11. österr. Historikertag in Innsbruck; 1971. Veröffentlichungen des Verbandes österreichischer Geschichtsvereine 19 (1972), S. $152 \mathrm{ff}$. 


\section{Anhang Abbildungen}

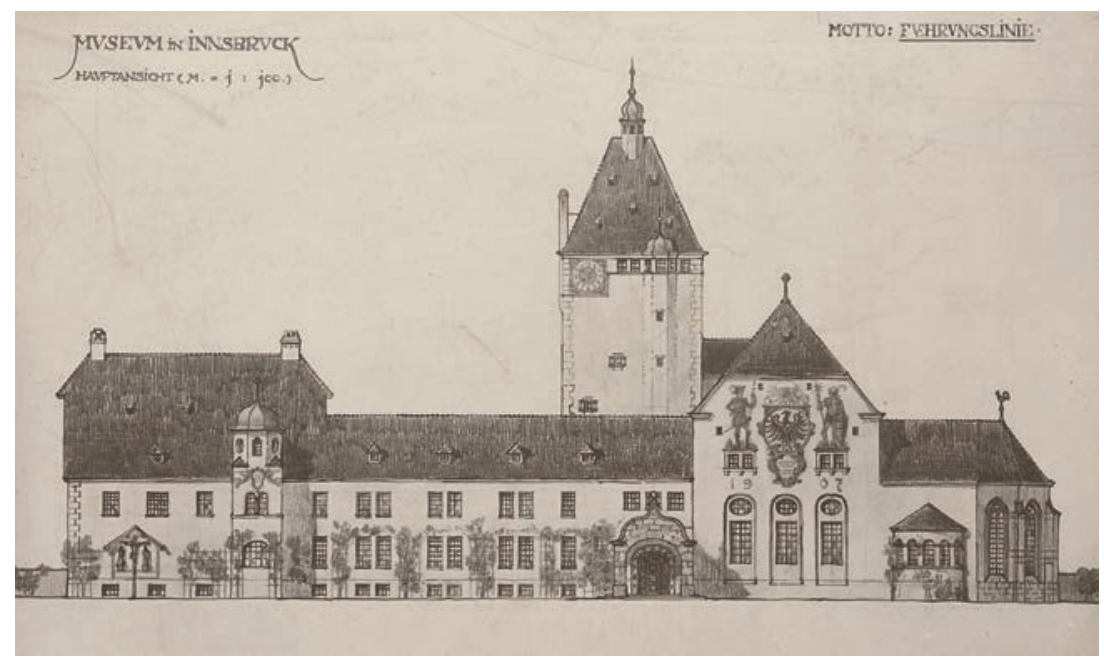

Wettbewerb für einen Neubau des Tiroler Volkskunstmuseums auf den

Löwenhausgründen, 1907. Entwurf „Führungslinie“, Architekt Dr. Gabriel v. Seidl in München. Siegerprojekt. Quelle: TVKM.

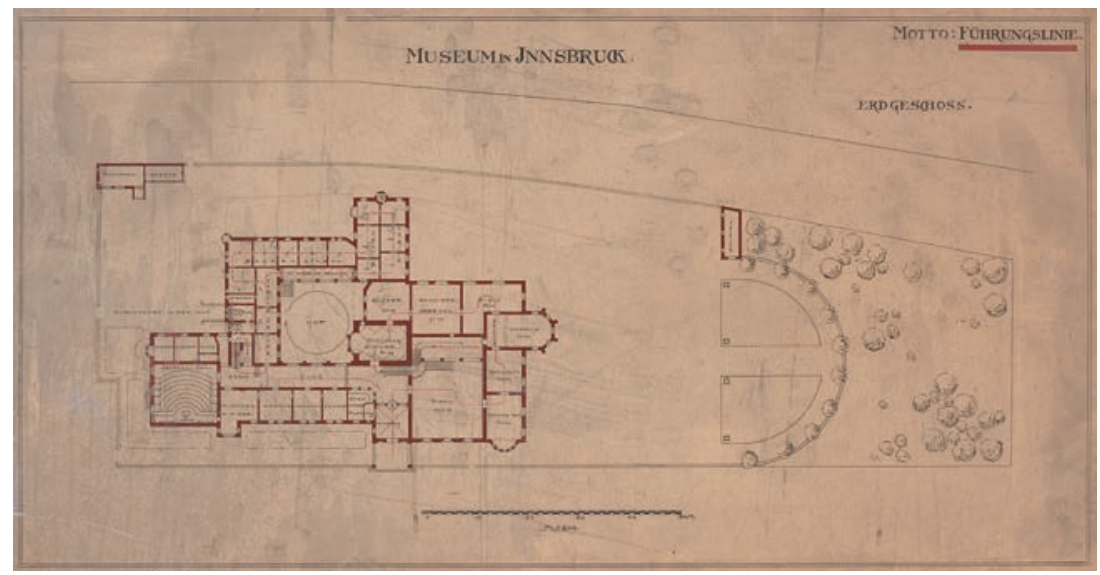

Wettbewerb für einen Neubau des Tiroler Volkskunstmuseums auf den Löwenhausgründen, 1907. Entwurf „Führungslinie“, Architekt Dr. Gabriel v. Seidl in München. Siegerprojekt. Quelle: TVKM. 


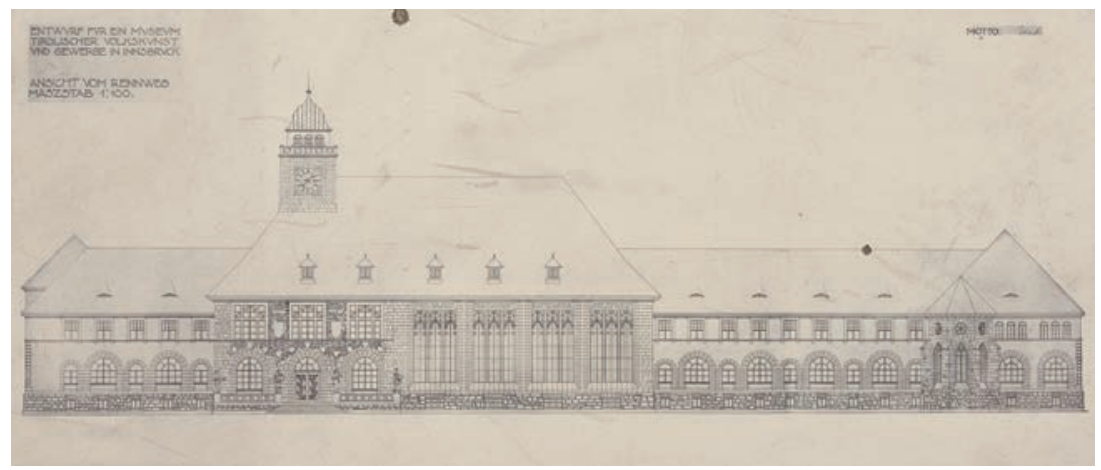

Wettbewerb für einen Neubau des Tiroler Volkskunstmuseums auf den Löwenhausgründen, 1907. Entwurf „Jda“, Architekt Leopold Bauer, Wien. Zweites Siegerprojekt. Quelle: TVKM.

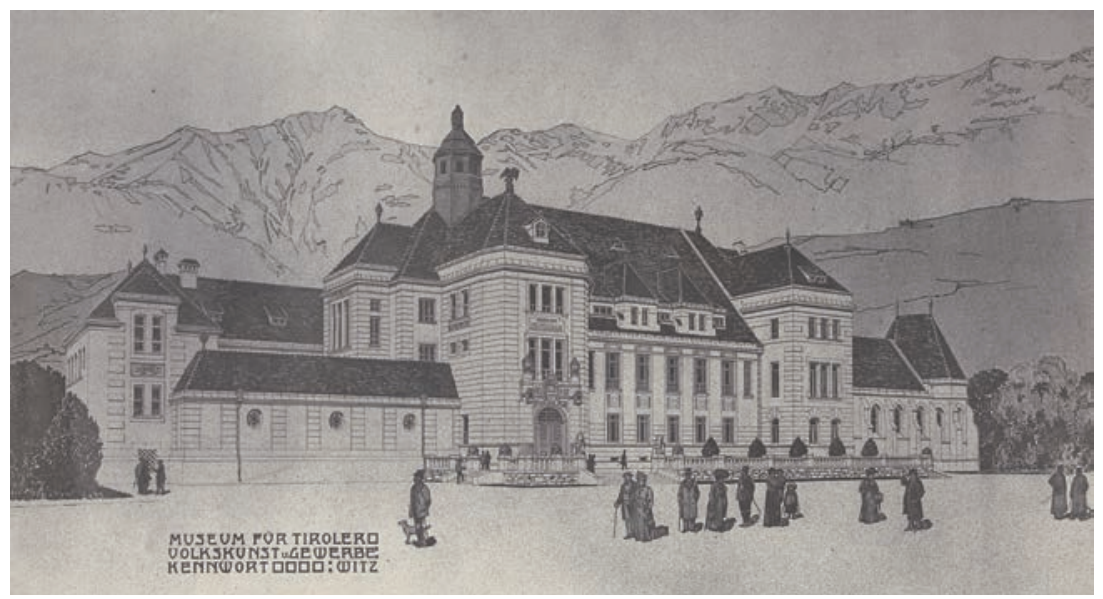

Wettbewerb für einen Neubau des Tiroler Volkskunstmuseums auf den Löwenhausgründen, 1907. Entwurf „Witz“, Verfasser Architekt Max Hegele, Wien. Platz vier mit Ankaufsempfehlung. Quelle: TVKM. 


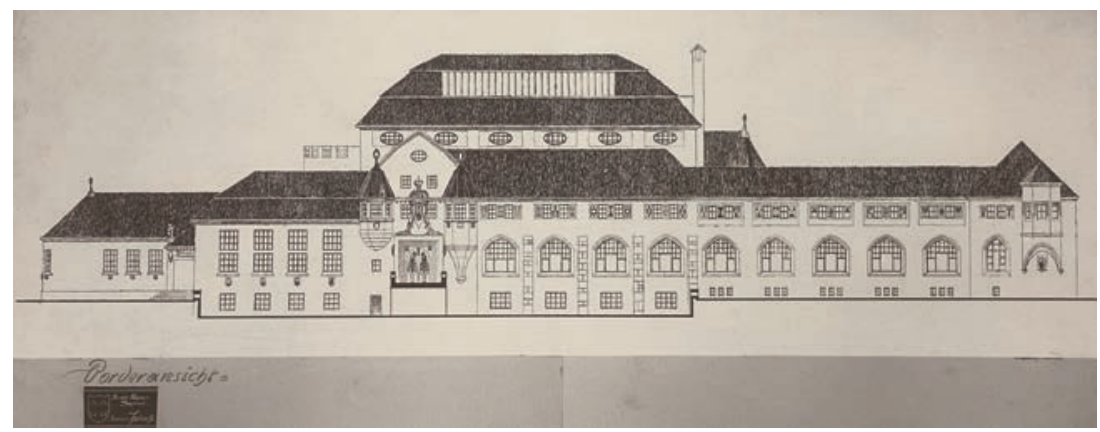

Wettbewerb für einen Neubau des Tiroler Volkskunstmuseums auf den Löwenhausgründen, 1907. Entwurf „Heimath“, Architekt Alexander Tandler, Dresden. Platz fünf mit Ankaufsempfehlung. Quelle: TVKM.

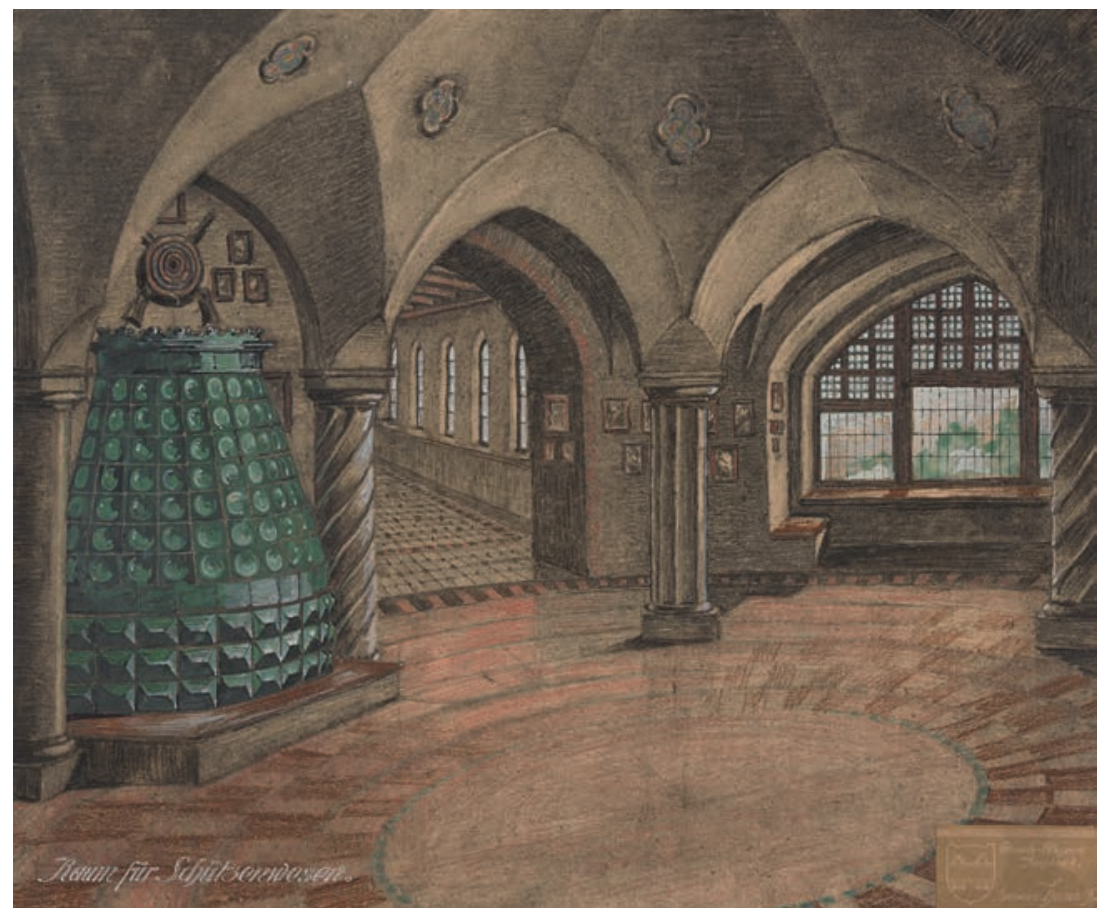

Wettbewerb für einen Neubau des Tiroler Volkskunstmuseums auf den Löwenhausgründen, 1907. Entwurf „Heimath“, Architekt Alexander Tandler, Desden. Platz fünf mit Ankaufsempfehlung. Quelle: TVKM. 


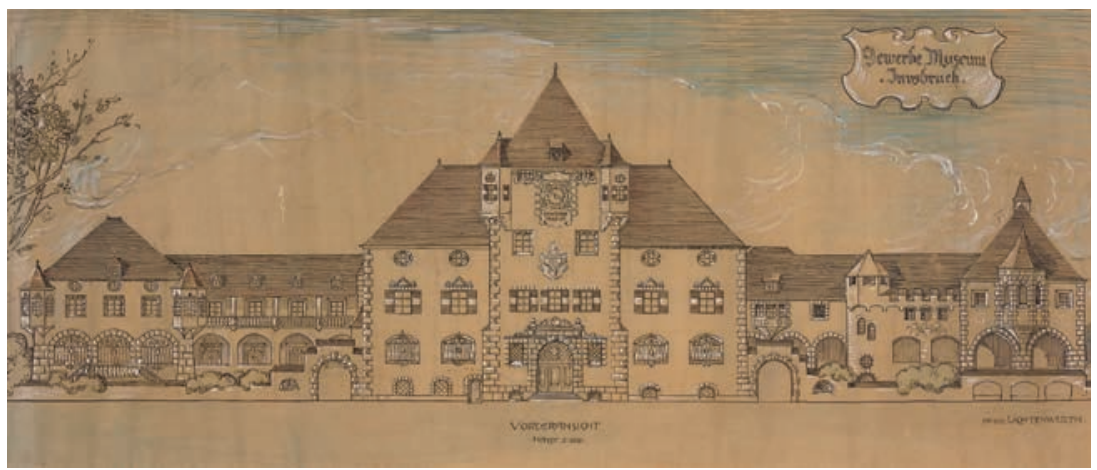

Wettbewerb für einen Neubau des Tiroler Volkskunstmuseums auf den Löwenhausgründen, 1907. Entwurf „Lichtenwerth“, Architekt Oskar Huber, Innsbruck. Platz sieben mit Ankaufsempfehlung. Quelle: TVKM.

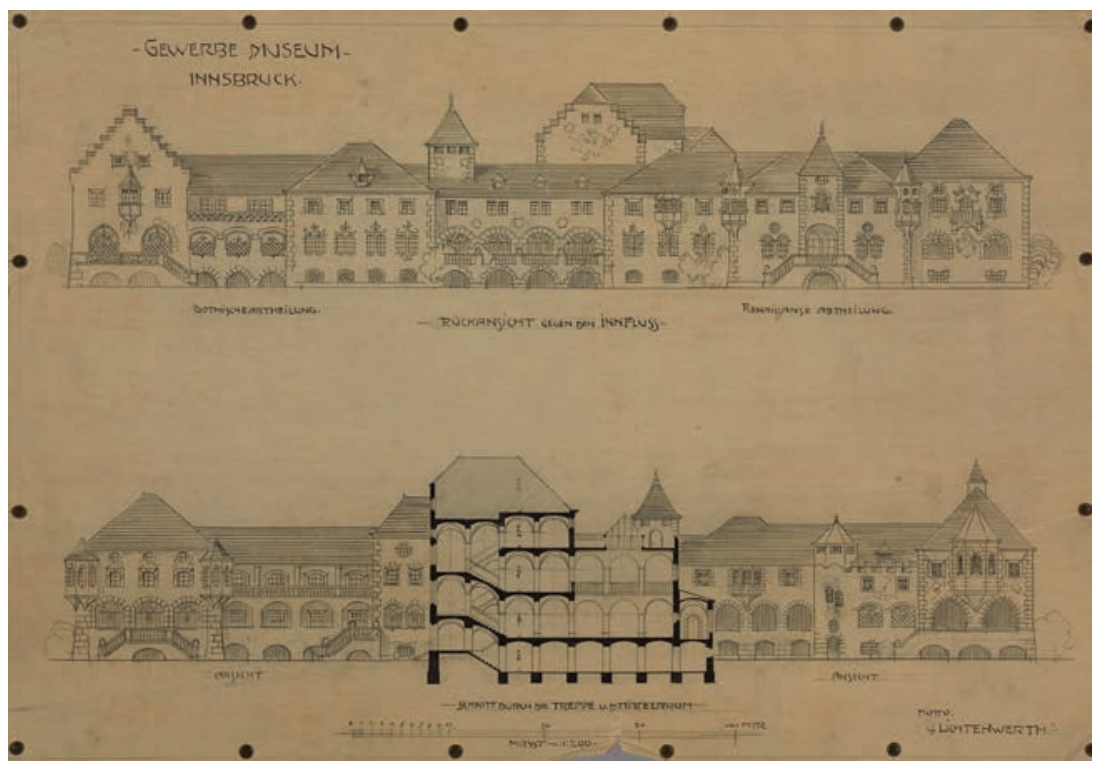

Wettbewerb für einen Neubau des Tiroler Volkskunstmuseums auf den

Löwenhausgründen, 1907. Entwurf „Lichtenwerth“, Architekt Oskar Huber, Innsbruck. Platz sieben mit Ankaufsempfehlung. Quelle: TVKM. 


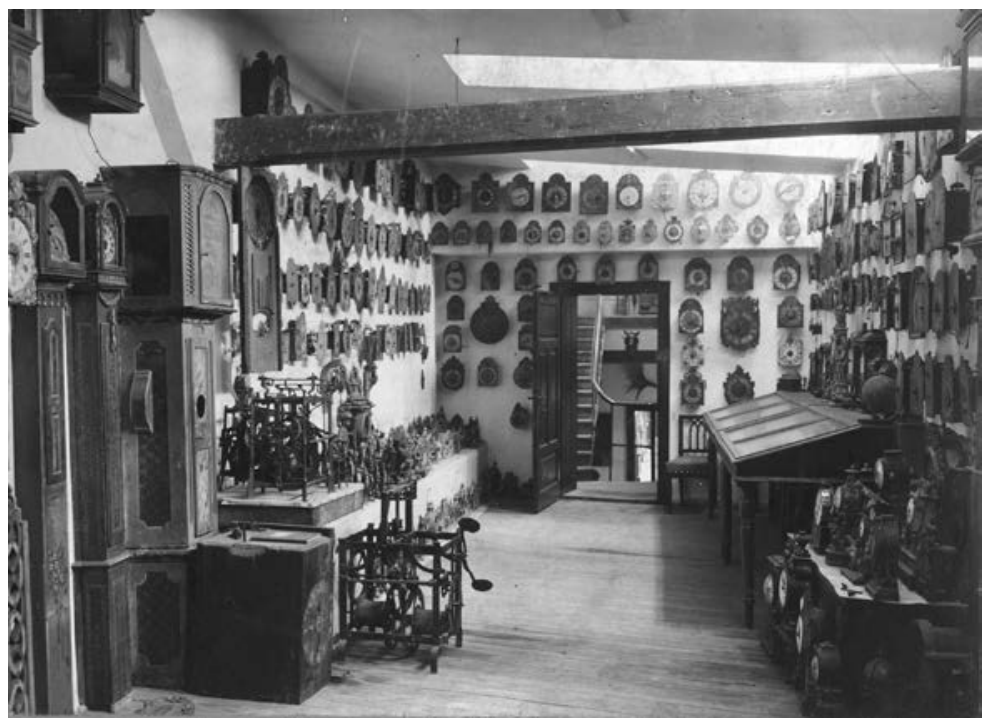

Uhren-Depotaufstellung in der „Egger-Oberhammerschen Fabrik“ in Innsbruck-Wilten, 1910. Quelle: TVKM.

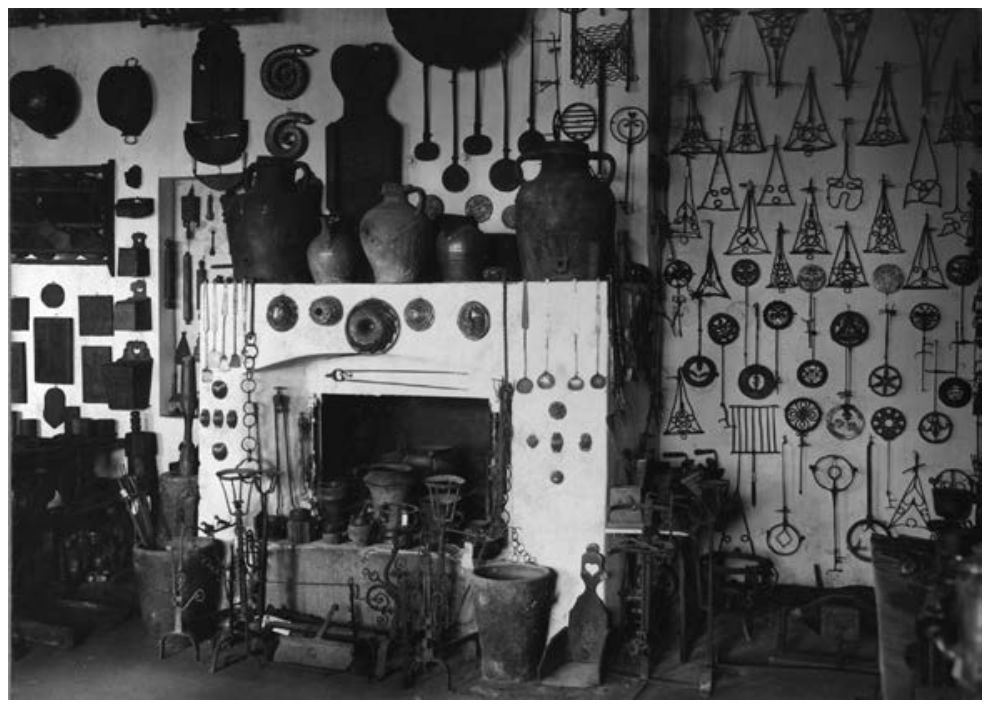

Eisensaal-Depotaufstellung in der „Egger-Oberhammerschen Fabrik“ in Innsbruck-Wilten, 1910. Quelle: TVKM. 


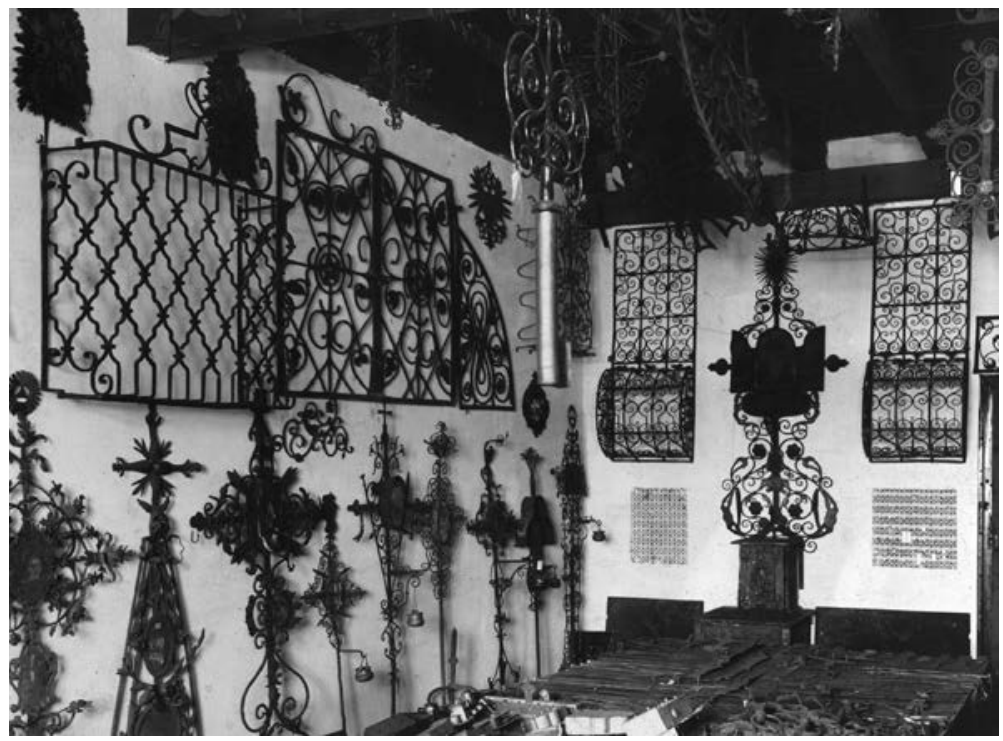

Schmiedeeisen-Depotaufstellung in der „Egger-Oberhammerschen Fabrik“ in Innsbruck-Wilten, 1910. Quelle: TVKM.

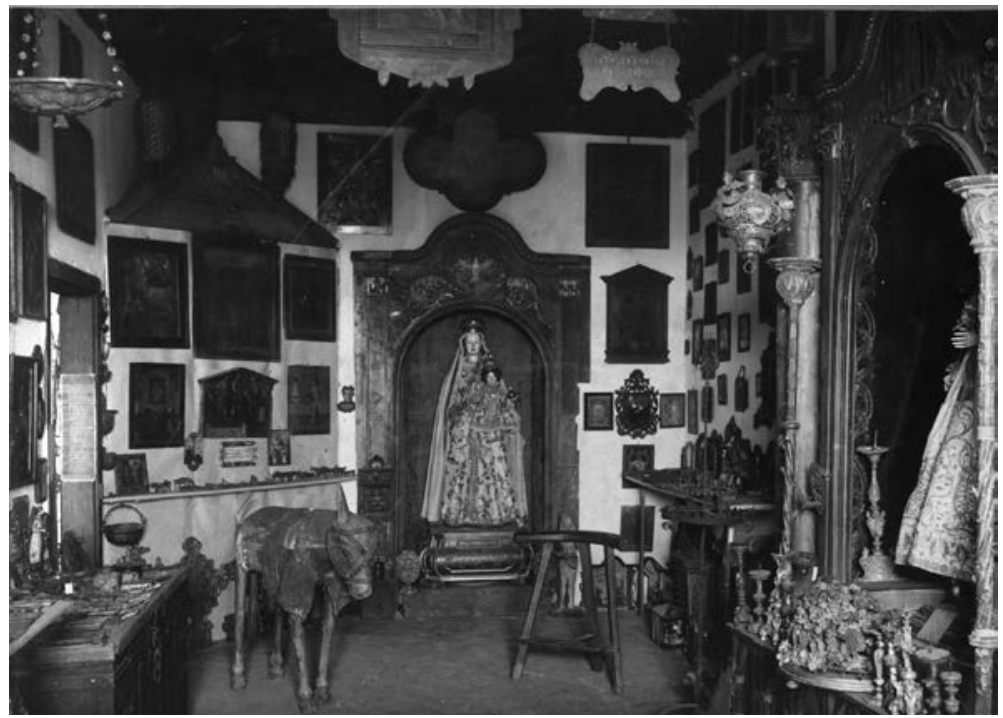

Sakralgegenstände-Depotaufstellung in der „Egger-Oberhammerschen Fabrik“ in Innsbruck-Wilten, 1910. Quelle: TVKM. 


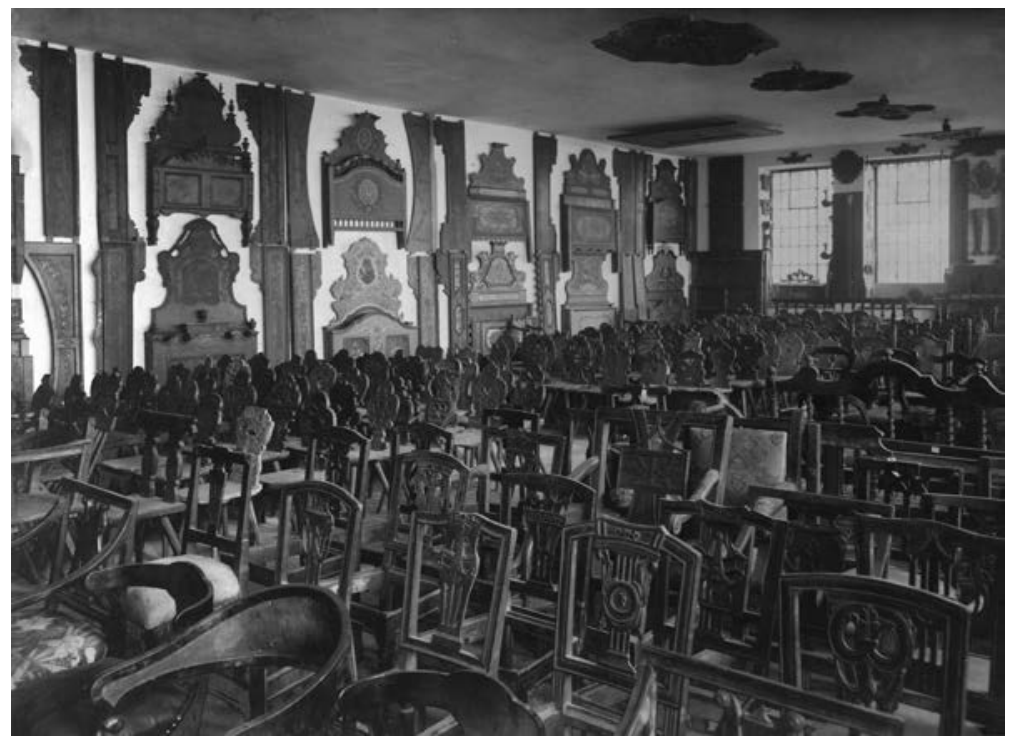

Möbelsaal-Depotaufstellung in der „Egger-Oberhammerschen Fabrik“ in Innsbruck-Wilten, 1910. Quelle: TVKM.

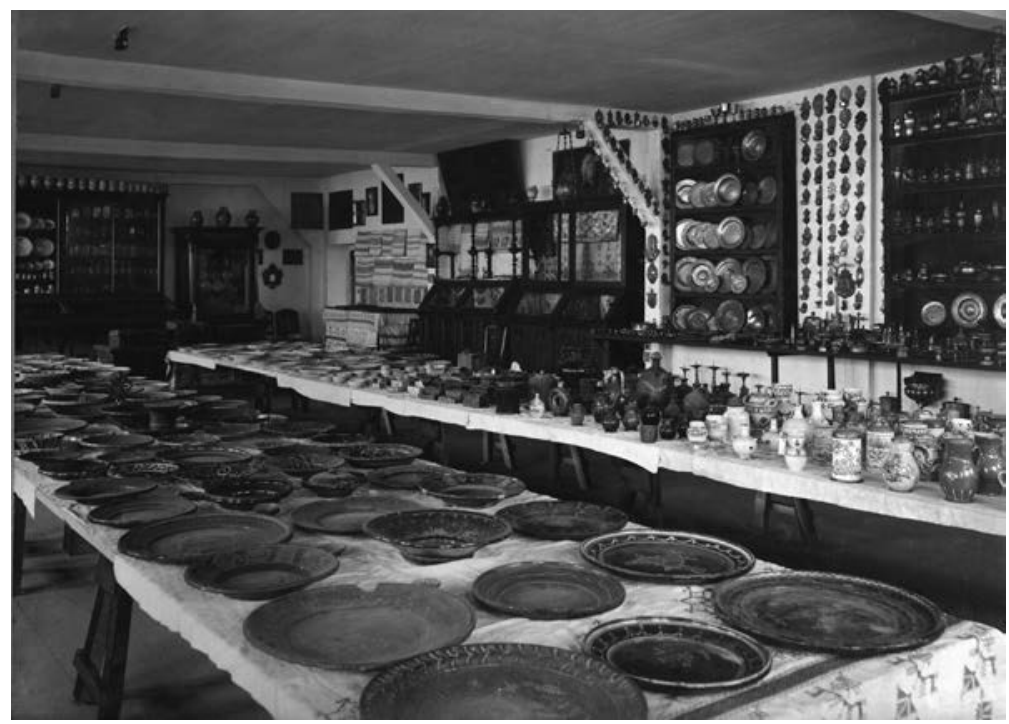

Keramik- und Zinnsammlung-Depotaufstellung in der „Egger-Oberhammerschen Fabrik“ in Innsbruck-Wilten, 1910. Quelle: TVKM. 


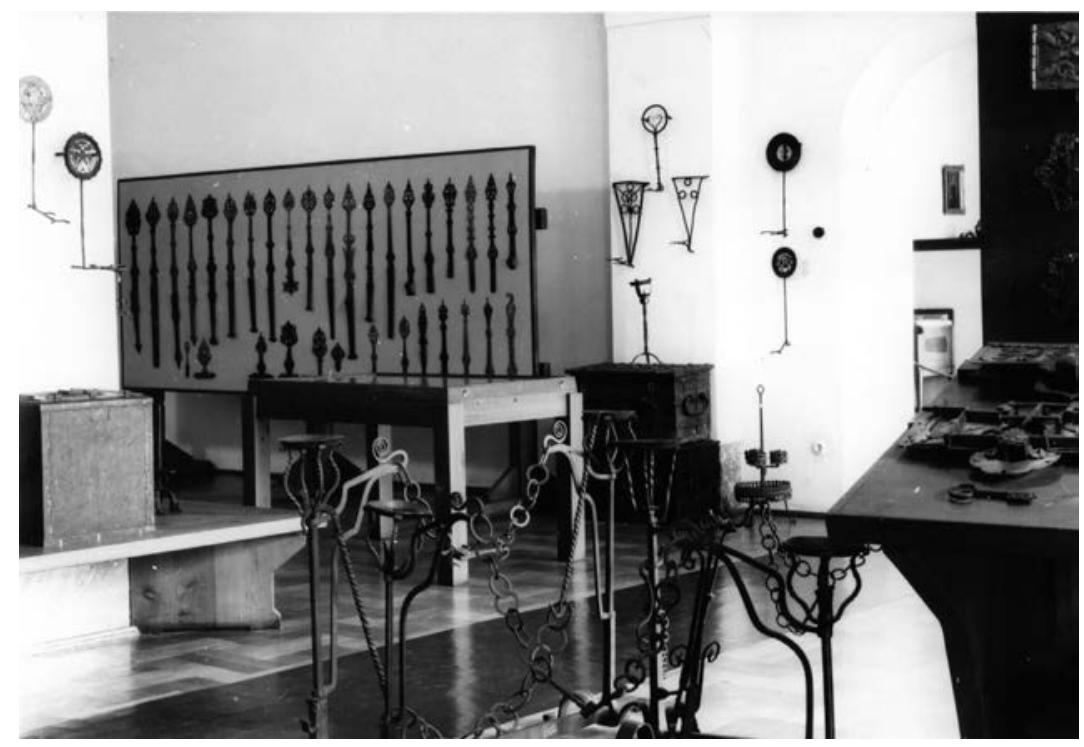

Tiroler Volkskunstmuseum in der Universitätsstraße. Aufstellung von 1929: Kleineisengegenstände im Saal 3. Quelle: TVKM.

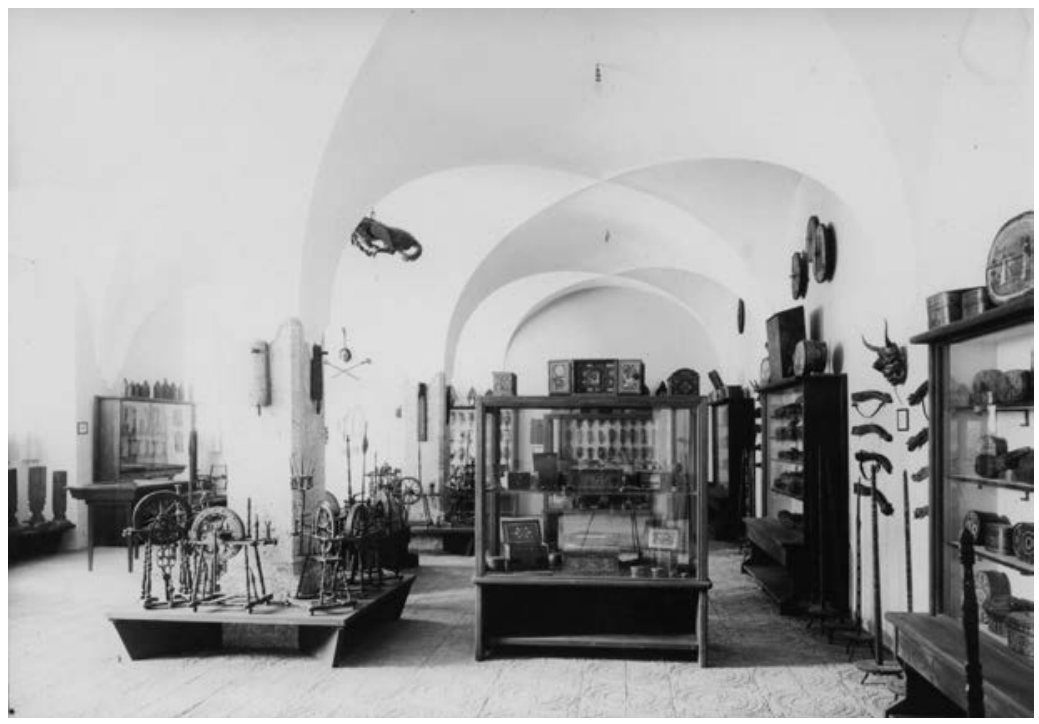

Tiroler Volkskunstmuseum in der Universitätsstraße. Aufstellung von 1929: Blick in den Volkskundesaal (Raum 1 und 2). Quelle: TVKM. 


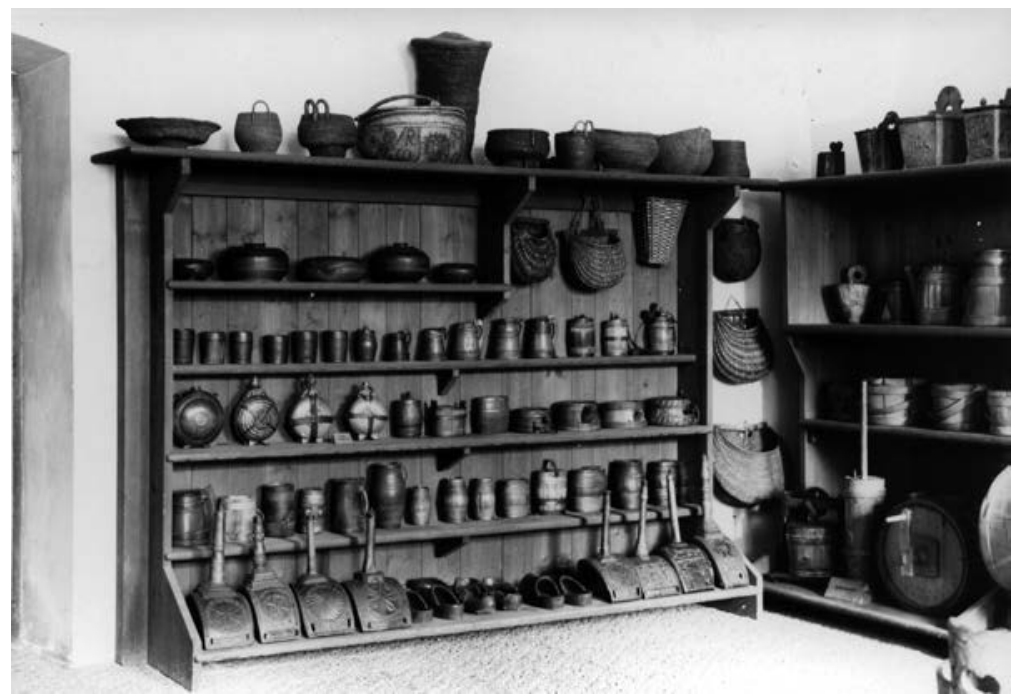

Tiroler Volkskunstmuseum in der Universitätsstraße. Aufstellung von 1929: Bäuerliche Geräte aus Holz. Quelle: TVKM.

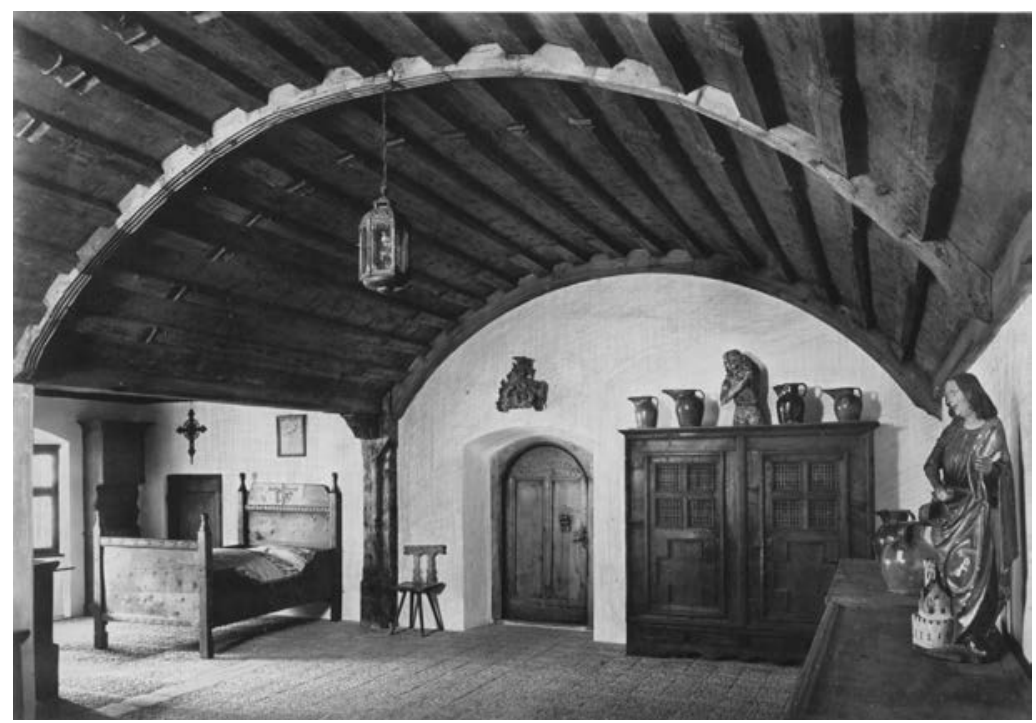

Tiroler Volkskunstmuseum in der Universitätsstraße. Aufstellung von 1929: tonnengewölbte Balkendecke aus dem Oberkoflerhaus, Brixen a. E. (1. Stock). Quelle: TVKM. 


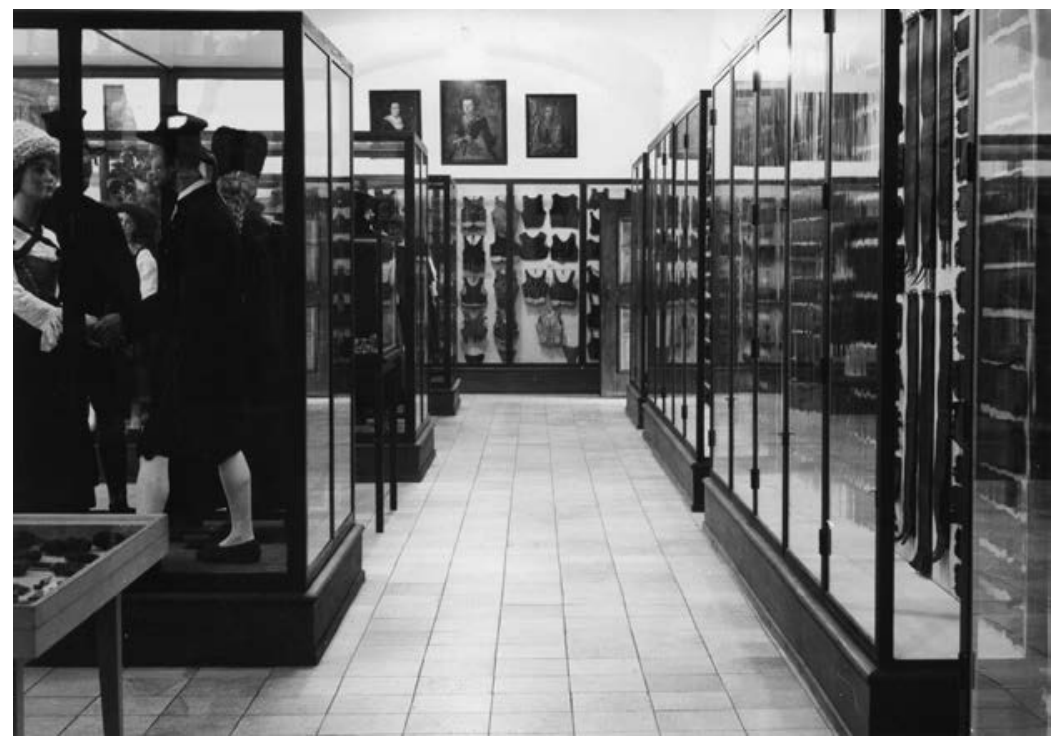

Tiroler Volkskunstmuseum in der Universitätsstraße. Aufstellung von 1929:

Trachtensaal (Raum 5). Quelle: TVKM.

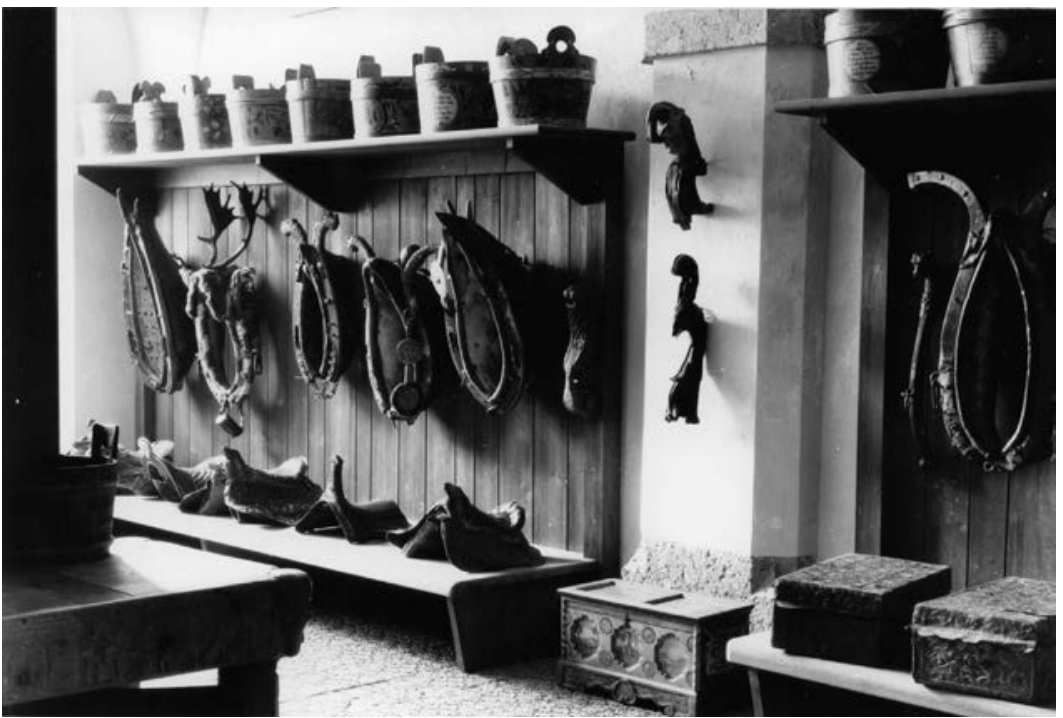

Tiroler Volkskunstmuseum in der Universitätsstraße. Aufstellung von 1929: Volkskundliche Sammlungen (Raum 1 und 2). Quelle: TVKM. 


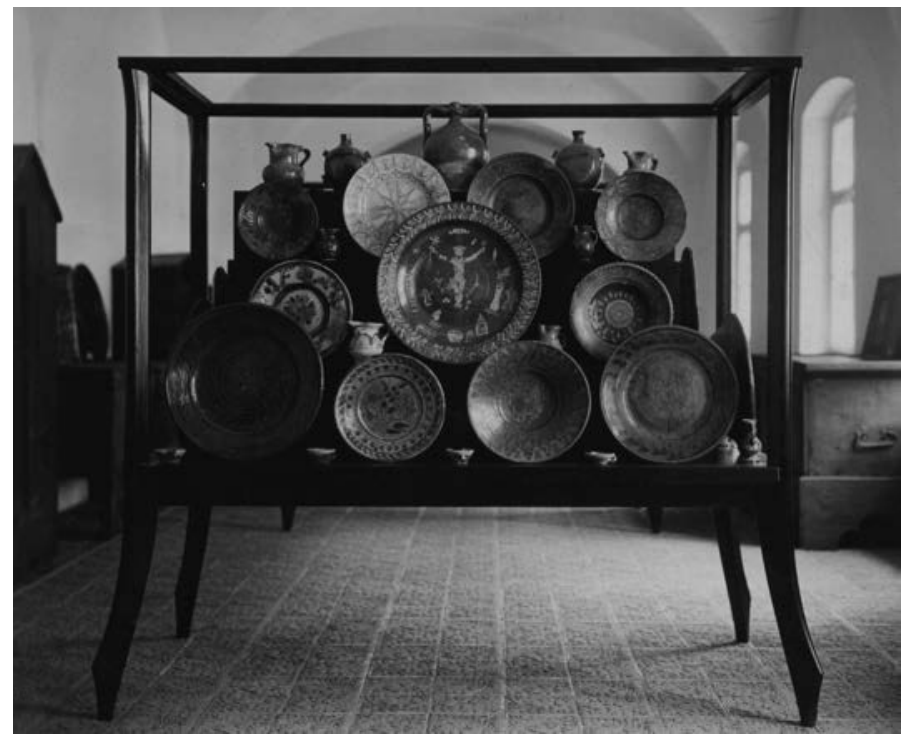

Tiroler Volkskunstmuseum in der Universitätsstraße. Aufstellung von 1929: Vitrine mit Keramik (Oberer Kreuzgang). Quelle: TVKM.

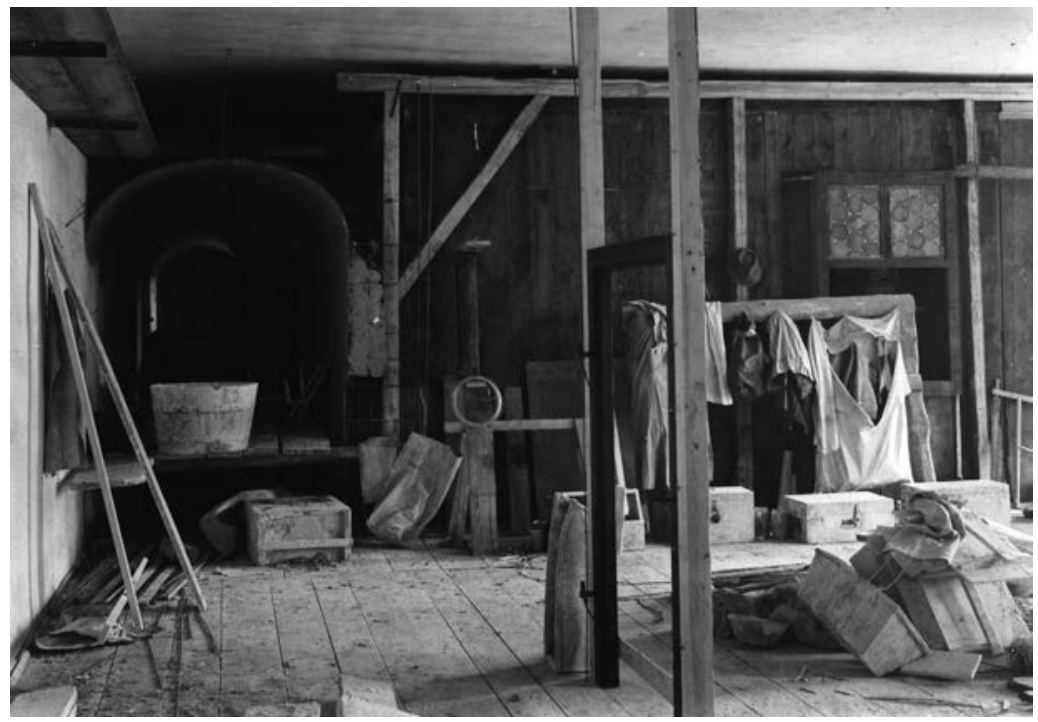

Tiroler Volkskunstmuseum in der Universitätsstraße. Einbau der Stube aus Monclassico bei Malé, Sulzberg sowie des Trachtendepots (2. Stock). 1928. Quelle: TVKM. 



\section{Neu aufstellen. Über das Volkskunst- museum seit 2008}

Seit den späten 1980er Jahren wurde von Vertretern der Kulturabteilung des Landes Tirol und des Volkskunstmuseums mehr oder weniger intensiv über eine Neuaufstellung des Volkskunstmuseums diskutiert. Die letzte Neukonzeptionierung basierte auf den Ideen von Franz Colleselli, der 1959 die Direktion von Josef Ringler übernahm und in den folgenden 10 Jahren das Museum neu ausrichtete. Seine Aufstellung sollte die nächsten Jahrzehnte im Wesentlichen unverändert bestehen bleiben. Dabei nahmen die Umbaupläne durchaus konkrete Konturen an. 1992 wurden im Hinblick auf einen anvisierten Erweiterungsbau in der Angerzellgasse, für den es galt, Rücklagen anzusammeln, sogar die Eintrittspreise verdoppelt. Trotz umfangreicher Gespräche, politischer Willensbekundungen und ersten Planungen verebbte jedoch dieses Vorhaben: Statt Depotflächen und Sonderausstellungsräumen wurde am angedachten Bauplatz die Volksschule Innere Stadt errichtet. Die Pensionierung von Hans Gschnitzer, der das Museum seit 1979/80 geleitet hatte und Plänen für eine Neugestaltung stets skeptisch gegenüberstand, war Anlass, neuerlich über Umbau und Neuaufstellung nachzudenken. Eine 2004 in Auftrag gegebene Machbarkeitsstudie sah großzügige Bauvorhaben vor - etwa die komplette Unterkellerung des Gebäudes oder den Ausbau des Dachbodens zu Schauräumlichkeiten. Das Konzept - ohne Einbeziehung der damaligen Museumsleitung entstanden - wurde schließlich aufgrund der hohen Kosten verworfen. Außerdem hatte der Landesrechnungshof bereits zuvor angemerkt, dass das Gebäude im Eigentum der Burghauptmannschaft des Bundes stehe und man vor einer solch gravierenden Baumaßnahme eine Eigentumsübertragung anstreben solle.

Schließlich brachte die Gründung der Tiroler Landesmuseen-Betriebsgesellschaft 2007 den wesentlichen Impuls: Zu den Aufgaben des neu bestellten Geschäftsführers Wolfgang Meighörner sollte auch die Organisation eines Umbaus des Volkskunstmuseums mit einem gedeckelten Budget von sieben Millionen Euro gehören. Am 31. Dezember 2007 wurde das Museum schließlich für Besucher*innen geschlossen. Zu diesem Zeitpunkt lagen zwar erste Architekturpläne vor, jedoch noch kein wissenschaftliches Konzept. Grundlage der Neukonzeption sollte vielmehr eine „Vision“ sein, die von der beauftragen „Ideenschmiede“ Steiner Sarnen Schweiz erdacht wurde. Weil man „unvorbelastet" an die Neuaufstellung herangehen wollte, wurde dieses Papier ohne die wissenschaftliche Leitung des Museums und ohne externe fachliche Beratung erstellt. Zahlreiche Stereotypen des Alpinen und klischeehafte Erwartungshaltungen fan- 
den sich in dieser „Vision“ wieder. So sollte beispielsweise zu einem „Trachtentänzchen" vor einer stilisierten Bergkulisse geladen werden, während die Stubenfenster mit alpinen Panoramen ausstaffiert werden sollten.

Nach einer intensiven Diskussion über dieses Vorhaben und Fragen über den Nutzen eines wissenschaftlichen Konzepts konnte zu Jahresbeginn 2007 mit der Erarbeitung eines durch die Museumsleiterin Herlinde Menardi und dem damals neu bestellten wissenschaftlichen Mitarbeiter Karl C. Berger begonnen werden. Der Marburger Volkskundler Martin Scharfe wurde zum wichtigen Mitkämpfer. Beraten wurde dieses Konzeptteam außerdem von Heimo Kaindl, Direktor des Diözesanmuseums Graz und Christoph Haidacher, dem späteren Direktor des Tiroler Landesarchivs. Von Beginn an gab es einen gewissen Zeitdruck, schließlich stand eine zentrale Rahmenbedingung vor dem Beginn der Konzeptionsarbeit schon fest: Am 18. Mai 2009 sollte das Museum seine Pforten wieder öffnen. Dieses Datum wurde einerseits mit Verweis auf die erstmalige Eröffnung des Museums am 15. Mai 1929 gewählt. Andererseits gab es starke Bestrebungen, die Eröffnung in den Kontext der Feierlichkeiten zum „Gedenkjahr 2009“ zu stellen - in Erinnerung an die Kämpfe am Bergisel im Zuge des fünften Koalitionskrieges sollten in Tirol zahlreiche Veranstaltungen stattfinden: Ähnlich wie die Eröffnung 1929 sollte auch die Neuaufstellung 2009 ein Ausdruck der ,geistig-kulturellen Landeseinheit" sein. Wenngleich dieser Anspruch im Vertrag zur Gründung der Tiroler Landesmuseen Betriebsgesellschaft im Hinblick auf Ferdinandeum und Volkskunstmuseum dezidiert genannt wird, ${ }^{1}$ zeigte sich die Museumsleiterin ob des Einbeziehens in das „Gedenkjahr 2009“ skeptisch und lehnte schließlich auch einen „landesüblichen Empfang“ mit Schützenabordnungen für die Eröffnungsfeierlichkeiten ab. Dass die Eröffnung des Museums im offiziellen Gedenk-Programm des Landes keine Berücksichtigung fand, entsprach somit den Wünschen der Museumsleitung, war aber insbesondere Ausdruck einer gewandelten Priorität: Für 2009 war ursprünglich auch die Eröffnung des „Bergiselmuseum“ geplant, in welchem das „Riesenrundgemälde“ - eine monumentale Darstellung der dritten Bergiselschlacht - gezeigt werden sollte. Tatsächlich wurde „Das Tirol Panorama mit Kaiserjägermuseum" nach intensiven inhaltlichen, denkmalschützerischen sowie medialen Diskussionen erst 2011 eröffnet.

Die Diskussion um die Neukonzeptionierung des Volkskunstmuseums geschah hingegen fast gänzlich ohne öffentliches Interesse, ohne große mediale Aufmerksamkeit und war auch anders gelagert. Dies brachte zweifellos einige Ruhe und ließ Raum für Grundlegendes: Zu Beginn konnte so über das Museale und museale Sammlungen, die Rolle von Objekten in Museen sowie die Aufgabe von Museen im 21. Jahrhundert debattiert werden. Im Nachhinein betrachtet waren 
diese Gespräche das eigentlich Herausfordernde - schließlich führten sie nicht nur zu einer Neuaufstellung von Objekten, sondern zu einer Neupositionierung des Museums insgesamt. Nachgedacht werden musste auch über die diffuse Bezeichnung „Volkskunst“ und damit über den Namen des Museums: In der sich zur Europäischen Ethnologie gewandelten Volkskunde wurde diese Begrifflichkeit seit vielen Jahrzehnten kaum mehr als analytische Kategorie verwendet. Der Wiener Volkskundler Leopold Schmidt hatte, indem er auf die Unklarheit des Begriffes hinwies, Mitte der 1960er Jahre eine Fachdiskussion anstoßen wollen - die jedoch wenig Widerhall fand, nun aber wieder aufgegriffen werden sollte. Schmidts Meinung nach war Volkskunst „so gut wie zur Gänze als ,angewandte Kunst' aufzufassen“" und „mit ihren Stoffen eng verbunden“.2 Seine Überlegungen erweiterten den ,alten“ Volkskunstbegriff. Zu Beginn des 20. Jahrhunderts als umfassende, kunstfertige Ausdrucksform der "Volkskultur" verstanden, setzte sich der Begriff - als Antithese zu „Hochkunst“ - auf das bildnerische Schaffen anonym bleibender Protagonist*innen fest. Schmidt betonte dagegen funktionelle Zusammenhänge und legte damit die Basis, um „Volkskunst“ als Ausdruck von Wertevorstellungen zu verstehen. Tut man dies, werden die Beziehung des Menschen zu seinen Dingen und der Sitz der Dinge im Leben in den Vordergrund gestellt, die äußere Ästhetik dementsprechend relativiert: Die einst unterstellte Anonymität weicht dem Verhältnis von Individuum und Gesellschaft sowie dem Spannungsfeld zwischen herrschender Kultur und kulturellem Widerstand. Prozesse des Wandels, des Kulturkontakts und Kulturkonflikts, der tradierten Ordnungen oder des symbolischen Nutzens sind Eckpunkte eines solchen Verständnisses von Volkskunst. Der Begriff „Volkskunst“ ist solchermaßen zwar historisch bedingt, jedoch keineswegs eine rein historische, rückwärtsorientierte Kategorie. Da das Leben durch Erfahrungen vergangener Zeiten, die sich der Mensch zunutze macht, geprägt ist, bleibt Vergangenes in der Kultur längerfristig präsent. ${ }^{3}$ In einem solchen Spannungsfeld zwischen Dauer und Veränderung gelegen, zeugt „Volkskunst“ - als materielle Manifestation des kollektiven Gedächtnisses - von den mannigfaltigen Bedeutungen und vom Nachleben historischer Kultur in der Gegenwart.

Die Frage nach dem Nachleben, nach den Bedeutungen der Vormoderne für die Moderne wurde zu einer Art Grundidee für die Umsetzung der für die Neuaufstellung erdachten Themenbereiche „Das Pralle Jahr“, „Das Prekäre Leben“, „Erb-gut" (Studiensammlung), „Schein und Sein“ (Tracht), „Miniaturen des Evangeliums“ (Krippen) sowie „Mein und doch nicht mein“ (Stuben). „Das

2 Vgl. Schmidt, Leopold: Volkskunst in Österreich, Wien u.a. 1966, S. 15.

3 Vgl. Gerndt, Helge: Kulturwissenschaft im Zeitalter der Globalisierung. Volkskundliche Markierungen. Münchner Beiträge zur Volkskunde, Band 31, Münster u.a. 2002, S. 51. 
Pralle Jahr" wurde als Zyklus konzipiert, welcher die religiös begründete Gliederung des Kirchenjahres als eine wichtige Grundlage für die Ordnung des Lebens der Vormoderne präsentiert, die bis heute nachwirkt. Durch die Dominanz des Festlichen und Öffentlichen verkehrt es sich allerdings ins Lustvolle ${ }^{4}$ und steht deshalb dem „Prekären Leben“ gegenüber - einer vormodernen Sichtweise auf den Lebenslauf, der durch Übergangsriten strukturiert wurde und in der das Intime, Sorgen, Ängstlichkeit und ein religiös-magisches Weltbild dominierten. Während das „Pralle Jahr" als heller und bunter Rundgang inszeniert werden sollte, sah das Gestaltungskonzept für das „Prekäre Leben“ einen düster-emotionalen Ablauf vor. Tatsächlich wurden Szenographie, Inszenierung und Gestaltung für die Vermittlung fachlicher Inhalte wichtig, auch deshalb, weil Objekte nur eine materielle Seite historischer Realitäten zeigen. Außerdem besteht in einem Museum, welches „Volkskunst“ in Namen trägt, die Objektsammlung vorwiegend aus ästhetischen und besonderen Stücken, weshalb auch über Art und Werdegang dieser Sammlung nachgedacht werden musste: Was wurde denn eigentlich alles gesammelt und warum? Warum wurde etwas nicht gesammelt? Dementsprechend: Was wurde präsentiert und was verborgen? Damit auch: Was soll zukünftig präsentiert werden? Was werden wir verbergen und unbeachtet lassen - bewusst oder unbewusst? Inwieweit ist das Museum nicht deshalb nur ein Ort des Erinnerns, sondern auch ein Ort des Vergessens und der kulturellen Demenz? ${ }^{25}$ Welchen Zusammenhang gibt es zwischen dem Materiellen und dem Immateriellen - etwa in Hinblick auf Gefühle und Emotionen? Was können die primär nach ästhetischen Kriterien zusammengetragenen Objekte über kulturelle Abgründe aussagen - über das Gefahrvolle, Ängstliche und Sorgenreiche, das Ärmliche und Ungewollte, Schäbige und Übelriechende, Defekte und Abgenutzte, Wertlose und unbrauchbar Gewordene?

Damit auch Besucher*innen mit solchen Fragen konfrontiert werden, etablierte sich relativ früh in der Konzeptionsfindung Luzifer als lästiger Störer und kritische Fragefigur. Der „Lichtbringer“ befand sich in Form eines schaurig-schönen barocken Theaterkostüms für das Nikolausspiel im Museum und sollte im zukünftigen Museum im Aufgangsbereich zu den Dauerausstellungsbereichen eine zentrale Position einnehmen. Als „radikalen Aufklärer“" wurde ihm eine neue Rolle zugedacht, indem er Besucher*innen zum eigenständigen Denken animieren und sie dadurch zur „neuen Rolle des kritischen und selbstkritischen Museologen“ füh-

4 Vgl. Raumbuch Neuinszenierung, Thesen von Martin Scharfe zum Prallen Jahr, S. 51, Archiv TVKM.

5 Vgl Scharfe: Martin: Eine Lanze für Luzifer. In: Österreichische Zeitschrift für Volkskunde, Band LXIII/112, 2009, S. 323-329, hier: S. 329. 
ren sollte. ${ }^{6}$ Die daraus entwickelte Inszenierung präsentiert das diabolische Kleinod Tiroler Volkskunst inmitten aufgehäuften Kulturmülls: Brauchbares befindet sich neben Unbrauchbarem, Schönes neben Hässlichem, Interessantes neben Abfall. „Wer aber“, lästert Luzifer, „kennt den Unterschied?“ Mittels Leuchtschrift wurde der Verführer und Hinterfrager außerdem in anderen Ausstellungsteilen präsent: Inmitten der gezeigten Prunkstücke und repräsentativen Endprodukte, die einst als Ausdruck der Kreativität und Geschicklichkeit des „Volkes“ interpretiert wurden, spottete er: „Reichtum und Wohlstand ist im Museum leicht zu dokumentieren. Aber Armut, die nichts besitzt?" Anderswo ätzt er über das „Trachtenkostüm als Zwangsjacke“ oder über das „Museum als Theater“. Selbst den Namen des Museums greift der „Verstellte“ auf und resümiert: „Volkskunst ist das, was Volkskunstforscher als Volkskunst bezeichnen."

Luzifers Hinterfragen bzw. das Bemühen um eine kritische Selbstreflexion, beeinflusste in der Zeit der Neuaufstellung verschiedene Details und ganz unterschiedliche Entscheidungen.

Beispielsweise wurden alle Museumstexte und Objektbeschriftungen konsequent dreisprachig umgesetzt. Keineswegs war dies lediglich ein besucherorientiertes Service, denn die Reihenfolge der Sprachen - Deutsch, Italienisch, Englisch - wurde auch als inhaltliches Statement verstanden. Das Italienische, im Museum früher stark kaschiert, erhielt eine neue Sichtbarkeit. Dieser grenzüberschreitende Gedanke verwies auf die Sammlungsgeschichte. Ein wichtiger Teil der Kulturgüter wurde bereits vor dem Ersten Weltkrieg erworben, zahlreiche Objekte wurden in italienischsprachigen Gegenden Alt-Tirols angekauft, die heute zu Italien gehören. Bei früheren Aufstellungen wurde diese geographische Herkunft jedoch nur bei wenigen Gegenständen genannt. Wurden welche angeführt, wurden die deutschsprachigen Namen der Täler oder die antiquierte Bezeichnung „Welschtirol“ verwendet. Deshalb konnte es bei Besucher*innen zum Missverständnis kommen, dass alle Objekte im Tiroler Volkskunstmuseum geographisch aus dem Bundesland Tirol oder Südtirol kommen würden. Bei der Neuaufstellung sollte - mit Verweis auf die Europaregion Tirol-Südtirol-Trentino - Gegenstände, die einst im heutigen Trentino in Gebrauch waren oder auf denen eine italienische Inschrift zu entziffern war, sichtbarer werden. Daraus resultierte freilich die Frage nach dem Umgang mit geographischen Bezeichnungen, schließlich gibt es für viele Trentiner Städte, Orte und Täler deutschsprachige Namen. Die Lösung, sich an der Verwendung gebräuchlicher Ortsnamen zu orientieren und beispielsweise den Städtenamen „Trient“ in der deutschsprachigen und „Trento“ in der italienischsprachigen Variante zu verwenden, war nur auf den ersten Blick ein pragmatischer Ansatz. Eingedenk der mehrsprachigen Ortsnamen Südtirols

$6 \quad$ Ebda. S. 337. 
erhielt die gleiche Frage nämlich eine politische Dimension. Im „alten“ Volkskunstmuseum wurden noch viele Objekte explizit mit dem Vermerk „Südtirol“ hervorgehoben - was im Anbetracht der an und für sich spärlichen Beschriftung eine privilegierte Auszeichnung darstellte. Im „neuen“ Volkskunstmuseum wollte man die Bezeichnung „Südtirol“ dagegen nach Möglichkeit vermeiden. Dafür sollten (sofern das Nennen von Herkunftsbezeichnungen sinnvoll und soweit dies überhaupt dokumentiert war) Gemeindenamen und Täler angeführt werden - in der italienischen Übersetzung selbstverständlich die offiziellen italienischen $\mathrm{Na}$ men, wie Bressanone, San Candido oder Val Pusteria. Wurde „Südtirol“ als geographische Herkunft genannt, wurde dies mit „Alto Adige“ übersetzt. Allerdings bezog sich diese Neuerung zunächst nur auf die digitalen Daten des Museumsguide und erst mit der Erneuerung der Objekt- und Vitrinenbeschriftung ab 2019 wurde sie auch allgemein sichtbarer. Dennoch war dies angesichts der Geschichte des Volkskunstmuseums und der bis heute andauernden Diskussion über die Toponomastik in Südtirol eine durchaus tiefgreifende Änderung.

Solche nur auf den ersten Blick klein erscheinenden Änderungen gab es einige: Seit der Neueröffnung können Besucher*innen die 14 Stuben betreten und werden nicht mehr durch eine Kordel an der Türschwelle daran gehindert - wodurch es zu einer anderen Raumwahrnehmung kommt. Eine kleine, früher stets verschlossene Tür im ersten Stock gewährt Zutritt hinter die Stuben. Die Sicht auf die Rückseiten enttarnt die historischen Räume als szenische Einbauten und große museale Objekte, die nach ihrem Erwerb im frühen 20. Jahrhundert aus ihrem baulichen Kontext genommen, transloziert und für die Eröffnung 1929 in leeren Museumshallen wieder aufgebaut wurden. Die für den Stubentrakt verfassten Texte räumen mit dem früher mitunter bewusst offen gelassen Missverständnis auf, dass es sich hier um „Bauernstuben“ handle. Begleitende Zitate weisen schließlich darauf hin, dass es in den Stuben einst sehr dunkel war, der Gestank (nicht nur im Winter) in den Räumen nur schwer auszuhalten war und der heutige, oftmals verklärt-romantische Eindruck täuscht. Die beiden Stubentrakte, die seit der Eröffnung 1929 von Umbaumaßnahmen verschont geblieben sind und sich seither materiell mehr oder weniger unverändert präsentieren, sollten sich durch diese inhaltlichen Nuancen doch grundlegend wandeln. Jahre nach der Eröffnung wurden sie zu Schauplätzen, in denen moderne Kunst Platz fand. Dies hat die Räume neuerlich verändert. Eine derartige korrigierende Sichtweise traf insbesondere die Neuaufstellung der Trachten. Jahrzehntelang waren sie als Vor- und Idealbild im Museum aufgestellt. Die aktuelle Präsentation thematisiert hingegen die Überhöhung der ländlichen Kleidung seit dem 19. Jahrhundert und verweist auf das „selbstgesponnene Bedeutungsgewebe" (Geertz), in welches sie bis heute eingewoben wird. Auch die „Mittelstelle Deutsche Tracht", die während der NS-Zeit im Museum angesiedelt war, wurde angesprochen - wenngleich zunächst ziemlich verhalten. Gera- 
de deshalb war es eine besondere Chance, dass in den Jahren 2014-2019 das Forschungsprojekt „Trachtenpraxis im 20. und 21. Jahrhundert“ in Kooperation mit dem Institut für Geschichtswissenschaften und Europäische Ethnologie der Universität Innsbruck umgesetzt werden konnte.

Als am 18. Mai 2009 das Tiroler Volkskunstmuseum nach 16 Monaten der Neuausrichtung und des Umbaus wieder eröffnet wurde, war das Museum zur Baustelle geworden. Nicht, weil die nur provisorisch fertiggestellte Elektrik, das unausgereifte digitale Vermittlungssystem oder die anfangs problembehaftete Klimatechnik noch zu bearbeiten waren; vielmehr sollte erst in den folgenden Jahren einiges von dem umgesetzt, erprobt oder entwickelt werden, was zuvor angedacht worden war. Die erste Zeit nach der Wiedereröffnung war jedoch auch von Kernarbeiten eines Museumsbetriebs geprägt: Zeitintensiv war die notwendige Umstellung auf ein neues Inventarisierungsprogramm, zumal die Daten des seit den 1990er Jahren verwendeten Programms mit dem neu eingeführten nicht kompatibel waren. Im Hinblick auf die nunmehr engen Verbindungen mit dem Ferdinandeum durch die Gründung der Landesmuseen-Betriebsgesellschaft wurde ein Positionspapier entwickelt, welches in einem detaillierten Sammlungskonzept mündete.

Die jährlich wechselnden Sonderausstellungen nach der Neueröffnung begaben sich auf die Suche nach wenig beachteten Facetten der Kultur, nach dem Beklemmenden oder Immateriellen. Die erste Schau widmete sich dem Phänomen „Schmerz“ (2010), einige Jahre später wurde „Dreck“ (2013) zum Ausstellungsthema. Mit „Ton um Ton“ (2012) wurde über die „hearing culture“ und damit über die Geschichtlichkeit des Akustischen nachgedacht. „Feuer“ (2018) rückte neuerlich etwas nicht materiell Fassbares in den Mittelpunkt, ebenso wie „Auf der Kippe. Eine Konfliktgeschichte des Tabaks" (2019). Diese wurde zur ersten Schau, die durch einen externen Kurator umgesetzt wurde. Nicht alles, was gezeigt oder ausprobiert wurde, war erfolgreich oder wurde weiter verfolgt. Doch prägte jede Schau auf ihre Weise das weitere Arbeiten im Museum. Die Präsentation „Ladinia“ (2011) warf erstmals die Frage nach dem Umgang mit Minderheitensprachen auf: Nicht Deutsch, sondern Ladin Dolomitan war Hauptsprache der Schau. Werke ausgewählter Künstler*innen der Gegenwart ließen die Sonderausstellung auf die Dauerausstellung ausstrahlen. Solche Verbindungen zwischen historischen Objekten und moderner Kunst wurden ab 2015 zu einem eigenständigen Ausstellungsformat weiterentwickelt. Gabriela Oberkofler („Prekäre Leben“, 2016), Rainer Schiestl („Nothelfer“, 2017), Gitti Schneider („Dass der Himmel über mir sich kläre“, 2018) sowie Carmen Brucic („In den leeren Spiegeln“, 2019) fanden im Museum höchst unterschiedliche Betätigungsfelder - und jeweils eigene Blickweisen und Kontexte auf das im Museum Vorhandene. Der 
irische Konzeptkünstler Gareth Kennedy nahm sich der Kulturkommission in Südtirol während der NS-Zeit an, die Schau „Die unbequeme Wissenschaft. Akt II“ (2016) wurde in teilweiser Abstimmung mit dem Projekt Trachtenpraxis umgesetzt. Ein durch das Entfernen einer Zwischenwand entstandener Saal vor den Stuben war Schauplatz für ein diskussionsreiches „Stubenforum“. Dieses Format hat nicht nur dem Raum seinen Namen gegeben, sondern wurde in etwas geänderter Form als Gespräch zwischen Expert*innen wiederholt. Bei allen Ausstellungskonzepten stand fachliche Wissensvermittlung, aber auch und insbesondere Kreativität im Mittelpunkt. Das Konzept von „Hinter der Maske“ (2014) wurde so zu einem kreativen Spiel zwischen Zeigen und Verbergen und gerade dadurch zu einem museologischen Experimentierfeld. Mit spielerischen Mitmachstationen versuchte „Mehr als Worte. Zeichen. Symbole. Sinnbilder“ (2015) das Zeichenhafte in der Kultur zu diskutieren. Die Auswahl der Themen wurde dabei durch die im Museumsdepot befindlichen Objekte geleitet, die jedoch neu betrachtet und in überregionale Fragestellungen eingebettet wurden. Dies ist etwa auch bei der Ausstellung „Alles fremd - alles Tirol“ (2016) geschehen, in welcher stereotype Vorstellungen ebenso angesprochen wurden wie Aspekte von Kulturkontakt, Kulturtransfer und Hybridisierung. Die Ausstellung war gleichzeitig Start für eine bis heute andauernde thematische Beschäftigung mit der historischen und gegenwärtigen Migration in Tirol. Die darauf folgende Ausstellung nannte sich „Hier zuhause“ (2017) und wurde gemeinsam mit dem „Zentrum für MigrantInnen in Tirol“ (ZeMiT) organisiert. Erstmals wurde in einem Tiroler Museum die Arbeitsmigration der 1960er und 1970er Jahre behandelt - obwohl sich bis dato kein einziges Objekt zu diesem Themenkomplex in der Sammlung befand. Es musste deshalb ein "Sammelaufruf" organisiert werden, dessen Ergebnisse in das vom ZeMiT neu gegründete "Dokumentationsarchiv Migration Tirol“ (DAM) einflossen. Die Ausstellung „Hier zuhause“ stellte in vielerlei Hinsicht ein Novum für das Volkskunstmuseum dar, vor allem aber, weil neben Deutsch auch die Sprachen Türkisch und Bosnisch-Serbisch-Kroatisch als Schriftsprache verwendet wurden und bei Vermittlungsprogrammen auch Farsi oder Arabisch berücksichtigt wurden.

In den Jahren seit der Wiedereröffnung des Museums wurde ein immer größerer Wert auf ein umfangreiches Rahmenprogramm gelegt. Neben „klassischen“ Formaten, wie Vorträgen, Lesungen oder Konzerten, wurden mehrsprachige „Tandemführungen“, interkulturelle und interreligiöse Gespräche oder Erzählcafés, aber auch Modeschauen, Poetry Slams oder Tanzveranstaltungen organisiert. Wesentliche Treibkraft hierfür war und ist die Abteilung Besucherkommunikation der Tiroler Landesmuseen, deren Experimentierfreudigkeit sowie fachliche und kreative Expertise seit 2009 zu einem wichtigen Teil des Museums und Knotenpunkt zahlreiche Kooperationen geworden ist. Eine ihrer Aufgaben ist auch 
das von der Stadt Innsbruck veranstaltete „Fest der Vielfalt“, welches seit 2016 im Kreuzgang des Museums stattfindet. Ziel all dieser Veranstaltungen ist es, das Museum als einen „mehrheimischen“ (Erol Yildiz) Ort der kulturellen Begegnung zu etablieren.

Bereits wenige Jahre nach der Neueröffnung wurde begonnen, die Dauerausstellung in Teilen zu verändern oder zu ergänzen. Mittels „Fake-News-App“ wurden beispielsweise Objekte zum antisemitischen Kult des Andreas von Rinn markiert. Die in Tirol kaum beachtete 500-jährige Wiederkehr des Thesenanschlags Luthers bot Anlass, im Depot nach „protestantischen“ Objekten zu suchen und diese in die Dauerausstellung zu integrieren - so zum Beispiel Ofenkacheln, die die Porträts der Reformatoren Luther und Hus zeigen. Eine Andachtsgrafik aus dem 16. Jahrhundert, an prominenter Stelle im „Prekären Leben“ positioniert, weist auf den Umgang mit Menschen mit Behinderung hin. Auch dieses Thema beschäftigt das Volkskunstmuseum schon seit Jahren, indem - in Kooperation mit der Servicestelle für Gleichbehandlung und Antidiskriminierung des Landes Tirol - beispielsweise Schwerpunkttage oder eigene Führungen für Menschen mit unterschiedlichen Behinderungen organisiert werden, etwa für Sehbehinderte, Gehörlose oder für geistig beeinträchtigte Menschen. So wurde - im Hinblick auf die baulichen Veränderungen für die Neuaufstellung leider zu spät - Barrierefreiheit mittlerweile ein Leitsatz. Während des Umbaus wurde dieser Komplex lediglich mit Rollstuhltauglichkeit übersetzt. Ein umfassenderes Verständnis und Sensibilisierung für Aspekte der Barrierefreiheit führte zur fast vollständigen Erneuerung der Beleuchtung und auch die neu entwickelte App, die 2017 den 2009 eingeführten Museumsguide ablöste, wurde entsprechend programmiert. Schließlich wurde auch die Beschriftung der Vitrinen und Objekte vollständig ausgetauscht und in Kooperation mit dem Blinden- und Sehbehindertenverband barrierefrei gestaltet - ein keineswegs einfacher Prozess, der noch nicht abgeschlossen ist. Gleichzeitig wurden bei dieser Erneuerung der Beschriftung kleine Nuancen verändert. Nunmehr ist beispielsweise bei einer Krippe zu lesen, dass sie von „Josef Benedikt Probst und Töchter" gemacht wurde, während bei einer anderen Krippe steht, dass der/die „Künstler*in unbekannt“ sei.

Mit dem Bau des Sammlungs- und Forschungszentrums der Tiroler Landesmuseen in Hall durch das Land Tirol, der damit verbundenen Übersiedelung von etwa 35.000 Objekten und der Digitalisierung des Sammlungsbestandes ist seit 2018 ein wichtiger Fokus wiederum auf die Betreuung und Bearbeitung der Objekte gelegt worden - zumal seit 2017 auch die landeseigene „Sammlung Jäger" in Oetz vom Volkskunstmuseum betreut werden muss. Jedoch stehen diese Objekte den Ötztaler Museen zur Verfügung. Diese Zusammenarbeit findet seine Fortsetzung im Bemühen, andere Museen in Tirol als Partner zu gewinnen um dadurch auch in den einzelnen Bezirken aktiv zu werden. In den letzten Jahren 
wurden kleinere Ausstellungsprojekte mit dem Museum in der Widumspfiste in Fügen (2020), mit dem Zunftmuseum Bichlbach (2019), dem Stadtmuseum Kitzbühel (2018), mit dem Landwirtschaftlichen Museum Imst (2016) oder mit dem Augustinermuseum Rattenberg (2015) umgesetzt.

Die hier vorgestellten Projekte und Veranstaltungen wurden in guter Zusammenarbeit mit verschiedenen externen Partnern, einigen Sammlungsbereichen des Ferdinandeums, mit den Abteilungen für Öffentlichkeitsarbeit und Restaurierung sowie dem Sammlungsmanagement realisiert. Zentrale Aufgaben kamen der Tischlerwerkstätte der Landesmuseen (Hannes Würzl) sowie der Abteilung Besucherkommunikation (Katharina Walter) zu. Das Kernteam des Volkskunstmuseums besteht derzeit aus Karl C. Berger, der 2015 die Museumsleitung von Herlinde Menardi übernommen hat, der wissenschaftlichen Mitarbeiterin Anna Engl (geb. Horner) bzw. ihrer Karenzvertretung Antonia Pidner, der Sekretärin Heidi Kapferer sowie dem Bibliothekar Richard Beer. Dazu kamen bis vor kurzem Depotverwalter Bernhard Frotschnig sowie Restaurator Peter Haag, die jedoch durch die Neustrukturierung innerhalb der Landesmuseen 2016/17 der Abteilung Sammlungsmanagement bzw. der Abteilung Restaurierung zugeordnet wurden. Intensive Unterstützung bekam das Team außerdem durch Katharina Niedermüller, die u.a. die Ausstellung „Geschenke und Präsente“ (2015) kuratierte und sich um die Digitalisierung bemühte, sowie durch die Textilrestauratorin Ursula Lingscheid. Schließlich arbeitete von 2014 bis 2020 Reinhard Bodner im Museum. Er führte das vom Land Tirol finanzierte und mit der Universität Innsbruck umgesetzte Forschungsprojekt „Tiroler Trachtenpraxis“ durch und war Kurator der Ausstellung „Tracht. Eine Neuerkundung“ (2020). Zwar gab es auch in anderen Bereichen eine Zusammenarbeit mit der Innsbrucker Universität etwa beim Universitätskurs „Restaurieren historischer Kachelöfen“ (seit 2016), doch war dieses Projekt - von kleineren Publikationen abgesehen - die einzige umfangreichere Forschungsleistung, die mit dem Volkskunstmuseum in den letzten zehn Jahren verbunden war. Es ist zu erwarten, dass dies so bleiben wird, schließlich soll 2023 ein Großteil der Sammlung durch eine Datenbank online recherchierbar sein. Bis dahin soll außerdem für die dem Museum angeschlossene Hofkirche ein neues Marketing- und Vermittlungskonzept entwickelt und umgesetzt werden. So dauert das Neuaufstellen des Tiroler Volkskunstmuseums schon über ein Jahrzehnt an und wird - das ist zumindest zu hoffen - niemals vollständig abgeschlossen sein. 
Dieses Buch behandelt die wechselvolle Geschichte des Tiroler Volkskunstmuseums. Nach einer langen Gründungsphase, die bis in die 1880er Jahre zurückreicht, Diskussionen um seine inhaltliche Ausrichtung sowie Überlegungen zum Standort wurde das Museum 1929 im ehemaligen Franziskanerkloster im Zentrum Innsbrucks eröffnet. Seine umfangreiche volkskundlichkulturwissenschaftliche Sammlung stammt räumlich aus der Europaregion Tirol-Südtirol-Trentino. Sie steht im Spannungsfeld von Kunst, Alltagskultur, Handwerk und Massenproduktion. Während in der Vergangenheit kunsthandwerklich-ästhetische, historische und Gesichtspunkte der Außergewöhnlichkeit im Sammlungsfokus standen, wird die Sammlung seit der Neugestaltung 2008 verstärkt zur Gegenwart ausgebaut und berücksichtigt mehr das Alltägliche.

Der Band enthält eine editorische Notiz der Herausgeber (Reinhard Bodner und Timo Heimerdinger), einleitende Bemerkungen des Verfassers zur jüngeren Forschungsgeschichte, ein Geleitwort der Obfrau des Freundeskreises des Tiroler Volkskunstmuseums, Herlinde Keuschnigg, sowie ein Nachwort des jetzigen Leiters des Museums, Mag. Dr. Karl C. Berger.

Wolfgang Meixner, Diplomstudium der Europäischen Ethnologie/gewählte Fächer in Innsbruck, 2001 zum Dr. phil. promoviert. Seit 1991 Universitätsassistent, seit 2007 Assistenzprofessor. Forschungsschwerpunkte in der Sozial- und Wirtschaftsgeschichte. Von 2007 bis 2020 Vizerektor für Personal der Universität Innsbruck.
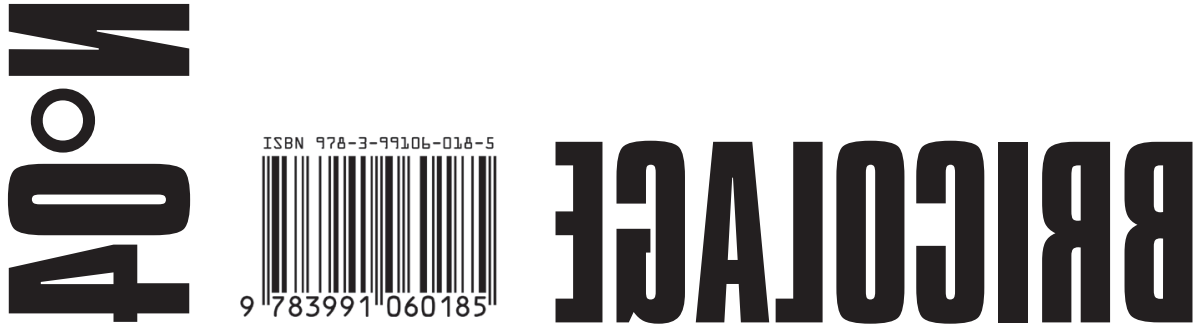